\title{
Architecturalising Aged Care Delivery for Urban Dwelling Elderly
}

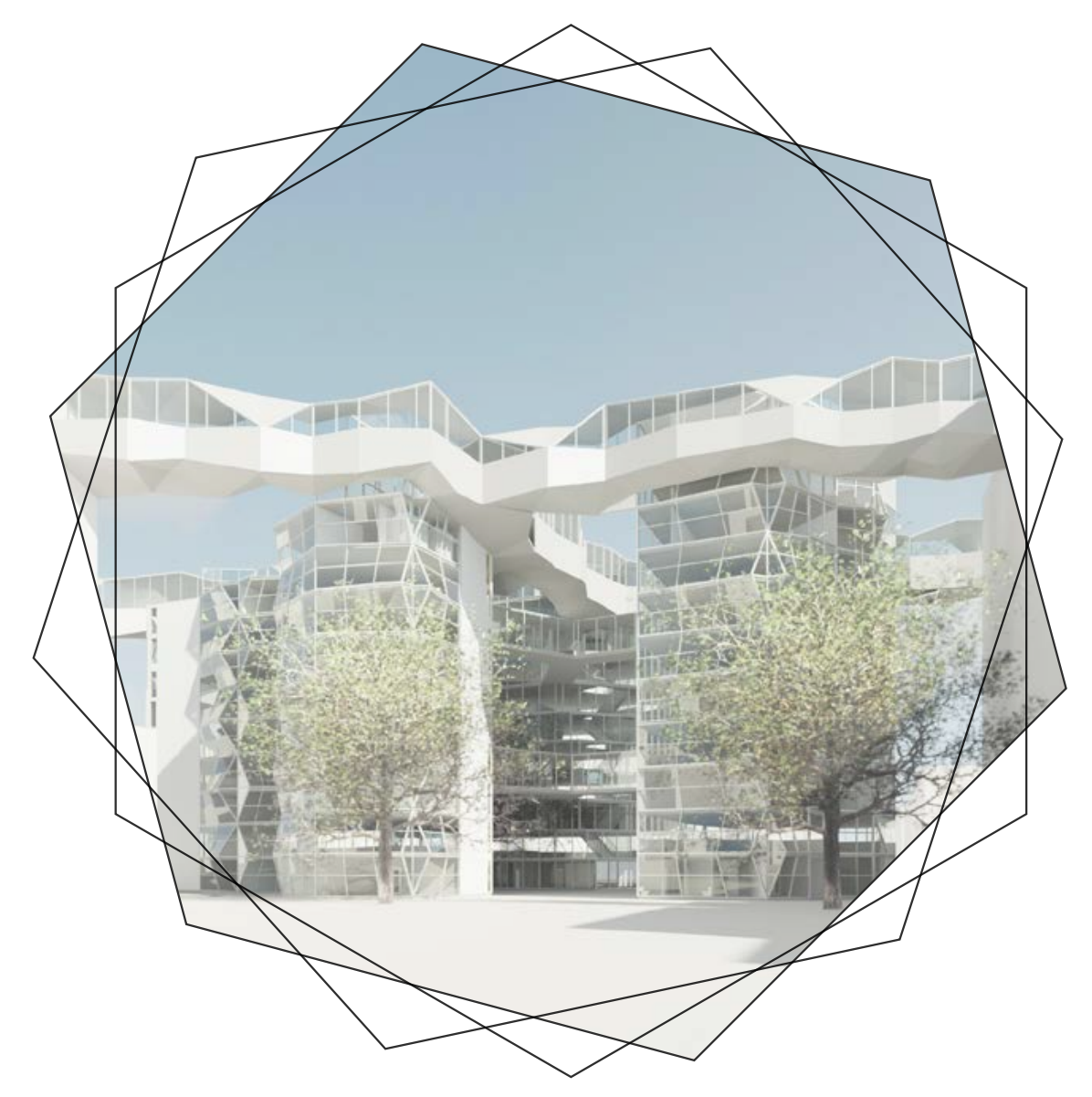

Masters Thesis ARCl 591 MArch(Prof)

Emma Leech 
内

8
8
0
0
0
0
0
0
0 


\section{Acknowledgements}

My sincere gratitude goes to my supervisor Michael Dudding for his continued support, direction and guidance throughout this year, his invaluable insight into the issues surrounding aged care have pushed me to consider what is possible.

I would also like to thank my parents, sister, friends and partner Elliott. Without your enduring patience, support and encouragement during all my years of study this would not have been possible.

This work is dedicated to my late grandmother Melva, who lost her battle with dementia in 2018 upon entry to an aged care facility. Rest in Peace. 
内

8
8
0
0
0
0
0
0
0 


\section{Ackowledgements \\ Abstract}

Chapter 1: Introduction

Aims and Objectives

Methodology

Chapter 2: Literature

Literature Review

Current Facility Analysis

Conclusion

Chapter 3: Initial Design

Design Exploration

Design Criteria

Site Analysis

Continued Design Exploration

Chapter 4: Developed Design

Form, Facade and Detail

Development

Structural Design

Programme

Interior Details

Walkway Bridge Development

Chapter 5: Final Design Outcome

Final Design Drawings

Visualisation Renders

\section{Chapter 6: Conclusions}

Critical Reflection

Conclusions

Recomendations and Further Research

\section{Works Cited}

\section{Appendix}





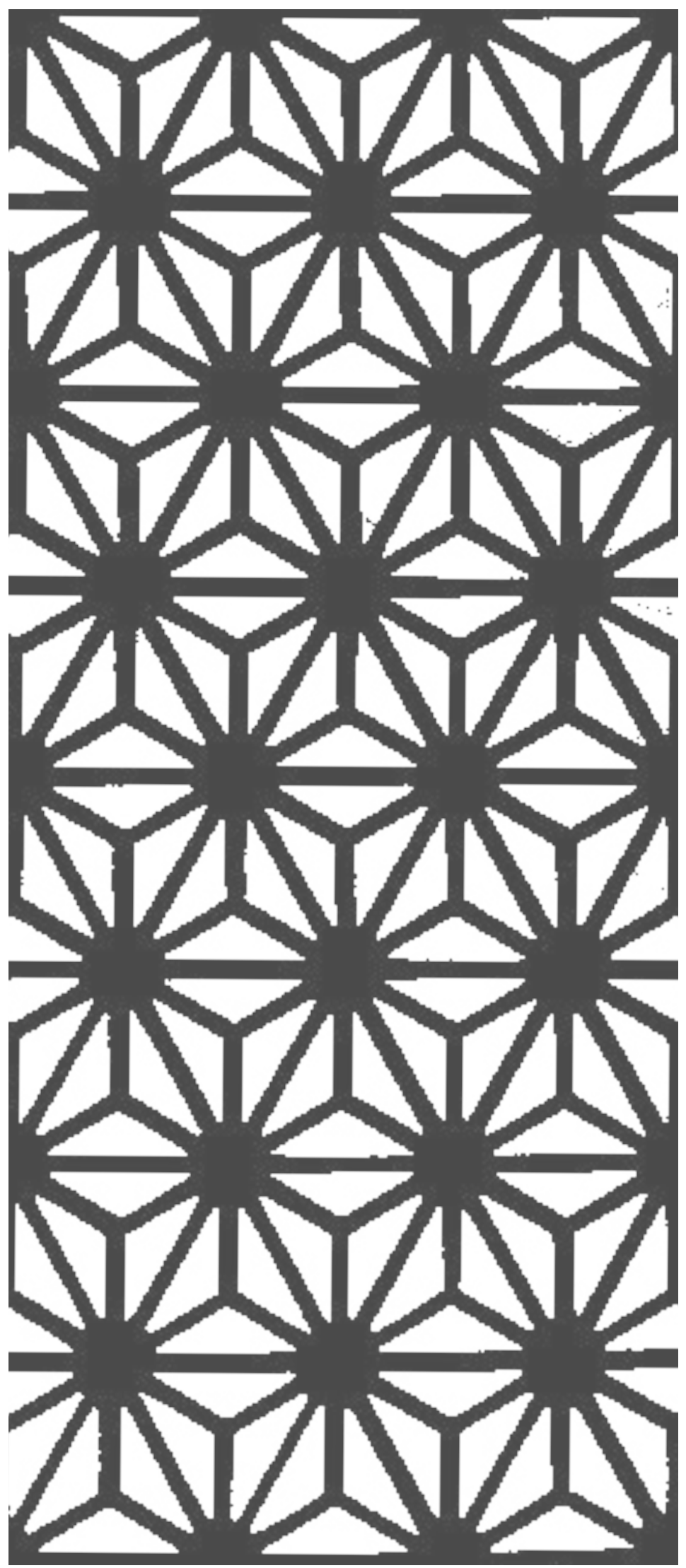

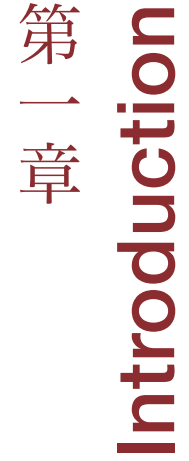



"As the human lifespan lengthens, the old age period of life lengthens" (Lynch, 2012).

The world's demographics are drastically changing, with people living longer and are healthier as they age (WHO, 2018). By 2050 the world's population over 65 years old will be $17 \%$ almost double $8.5 \%$ in 2015 (Cire, 2016). With this come struggles both physically and mentally as health declines but also socially as friends and family die and a lack of mobility isolates. The way in which the world is designed to support elderly health needs to drastically change when one in five people are in this elderly age bracket. Considerations of how to best provide increasing heath care for a larger amount of elderly than we have ever seen, has caused a building boom of various styles of residential aged care across the world over the last 20 years. Architects are generating new ideas about how these buildings should function and look, catering to a vast majority of elderly who still have active social lives and independence. For many years, since their creation, aged care facilities (AGF) such as rest homes, nursing homes and hospices have been design to deal with heath needs on a large scale. Starting as hospital wings the idea of inpatient elderly nursing care started through the need to separate sick and poor elderly from the rest of society (Ritch, 2015). Throughout the 1960's in an age of heath care revolution the institutionalized hospital was created with wings dedicated to elderly for those needing more specialized care than could be provided by relatives (Jones, 2007).
As the typology has evolved, a more homelike approach has been adopted as research suggests that better health outcomes and better quality of life can be observed through the familiar vernacular of home (de Veer and Kerkstra, 2001). In many western cultures the retirement village is the epitome of this home-like approach as the existence of the largescale building has been removed in favor of individual unit houses surrounded by perfectly manicured lawns and winding streets. Home-like is not home. The familiarity of home is not observed except in the most superficial typological sense. No matter the context, design or level of landscaping achieved by Aged Care Facilities the lack of integration between this typology and the surrounding neighborhoods both suburban and urban create social and physical separation between elderly and their communities. Studies have shown that a rest home positioned on the outskirts of a neighbourhood compared with one the positive benefits of ageing in place and the stimulating and diverse environment of the urban street are the tools needed to create a more positive ageing experience.

Several researchers conclude that the city is the best environment to age in place. Being in an individual apartment in an urban environment means that the elderly person has control of their everyday decisions and actions with the ability to live independently as their daily needs are on their doorstep. This is not the case in the traditional suburban neighbourhood, which is separated from amenity. 
An urban environment creates opportunities for social interaction and allows the shrinking capabilities through the progress of age to not seem as large or restrictive on ones lifestyle. However, while the connectedness and proximity to amenity in an urban setting is favorable there are issues to still mitigate in order to ensure the longevity of this residential option. The largest of which is the density that makes home care delivery difficult. Excessive traffic and limited car parking can influence time spent with residents and delay carers in emergencies. The ability to deliver efficient care in an urban environment is the main focuses of this design investigation.

Despite knowledge of the benefits of urban environments, it has been noted that alternative models of housing the elderly (solutions other than new build aged care facilities) remain relatively underexplored by design professionals, the focus remains on improvements to current models even though this has been proven to have very little affect overall (Lansley et al 2007). What is marketed as a more socially integrated retirement than the ageing in place model (living in individuals own home for as long as possible) actually becomes more isolating as individuals lose their ability to physically maintain social connection and mobility. "There is surprisingly little published information about the adaptation of the home to meet the needs of older and disabled people" and Taylor and Buys argue that there are "still relatively few innovative approaches to housing for older people" (2014).

This research explores how architecture can deliver aged care services to make ageing in the urban environment possible. Crucial to innovation, future proofing the final solution depends heavily on both an international approach, and positioning the design response in a context that not only supports a large amount of elderly already living in urban environments but also represents a larger scale density overall than most world cities. This is to acknowledge the continued growth of world cities and propose a design solution for future density. For this reason Tokyo Japan was chosen as with a far larger and faster growing elderly population than any other country they face the challenges involved with urban care.

Allowing people to live and die within the comfort of their own home and giving individuals choice around care and support as they age, unique to their circumstances. It looks to uncover what architectures role is in modern healthcare systems. Determining from research the extent to which built form can help or hinder well being outcomes and support independence and ultimately design an overarching model that supports community based aged care within an urban setting. Overall the aim of this design is to question what is possible. What does elderly care look like with the individual in control and continuing to make decisions around their health and wellness? Does preventative care make a difference to elderly lives and justify a large-scale architectural response? Can a truly independent, yet supported elderly life change the experience of ageing and can architecture contribute to this change in a meaningful way?

\section{RESEARCH OBJECTIVES}

The overall aim of this thesis is to present a design solution accommodating of the choices of individual elderly. Using existing urban landscapes and adapting the underutilized space above streets to service elderly care to the home, through the hub and sky tunnel (not sure on this name) $\}$ approach, care can be brought to individuals- full circle to the days of mobile nursing and care in the immediate community. This type of care approach brings the 
Sense of efficiency experienced in nursing homes and hospitals where care is centralized. Instead of feeding into individual rooms or apartments within a facility. This model will feed care into existing apartment buildings and homes within a 10minute walking radius. With this overall aim in mind the objectives for this work focus on blending traditional health services with architecture to deliver these in a different way.

\section{METHODOLOGY}

The methodology of this research is used to guide the different stages while allowing for flexibility and adaption as new ideas and literature are involved in the design process. It uses a research 'for' design and research 'through' design process in order to initially gather a background of solid literature to then base design ideas and criteria but then through the process of design enable further research into other avenues and through critical reflection and review against objectives and criteria determine the effectiveness of the design and use this information to further develop ideas, create new literature research avenues and ask further questions.

The research 'for' design stage creates a framework from which the research 'through' design will be initially informed. However the research through design at the prototype stage and even through to the form finding and development stage will inform new areas of research to contribute to the overall research findings. This is why for the structure of this thesis the two research actions are split into 3 subcategory stages, which will help to navigate this cross research approach

Stage 1: literature review and Typological study

Stage 2: Design Prototypes

Stage 3: Form Finding and Testing
Stage 2-design prototyping allows for reflection early on in the creation of the design criteria by the integration of both research 'for' design and research 'through' design at this stage the criteria and initial design forms are created along side each other both informing and reshaping each other while in action.

\section{SPECULATIVE DESIGN}

Speculative design has been used in this project to test ideas that stretch the possibilities of today's reality. Not only does it challenge todays structural technology but also built policy, through the use of the intersection space, crossing streets and building onto existing fabrics. The design proposal works without policy restriction in order to test the relevance of design ideas that challenge the future of this sector. The positives for using speculative design for research is the ability to reach beyond what is existing in search of innovation. Unlike design fiction, work that takes a speculative approach does not place itself in complete impossibility and is grounded by real world principles and background research. "A design speculation requires a bridge to exist between the audience's perception of their world and the fictional element of the concept" (Auger, 2013). Why this design method was chosen was to allow analysis, critique and a rethinking of todays aged care options as well as presenting an alternative solution. The speculative approach only heightens the differences between the final design outcome and the reality of todays approach, paving the way for future change and an understanding of today's problems. 


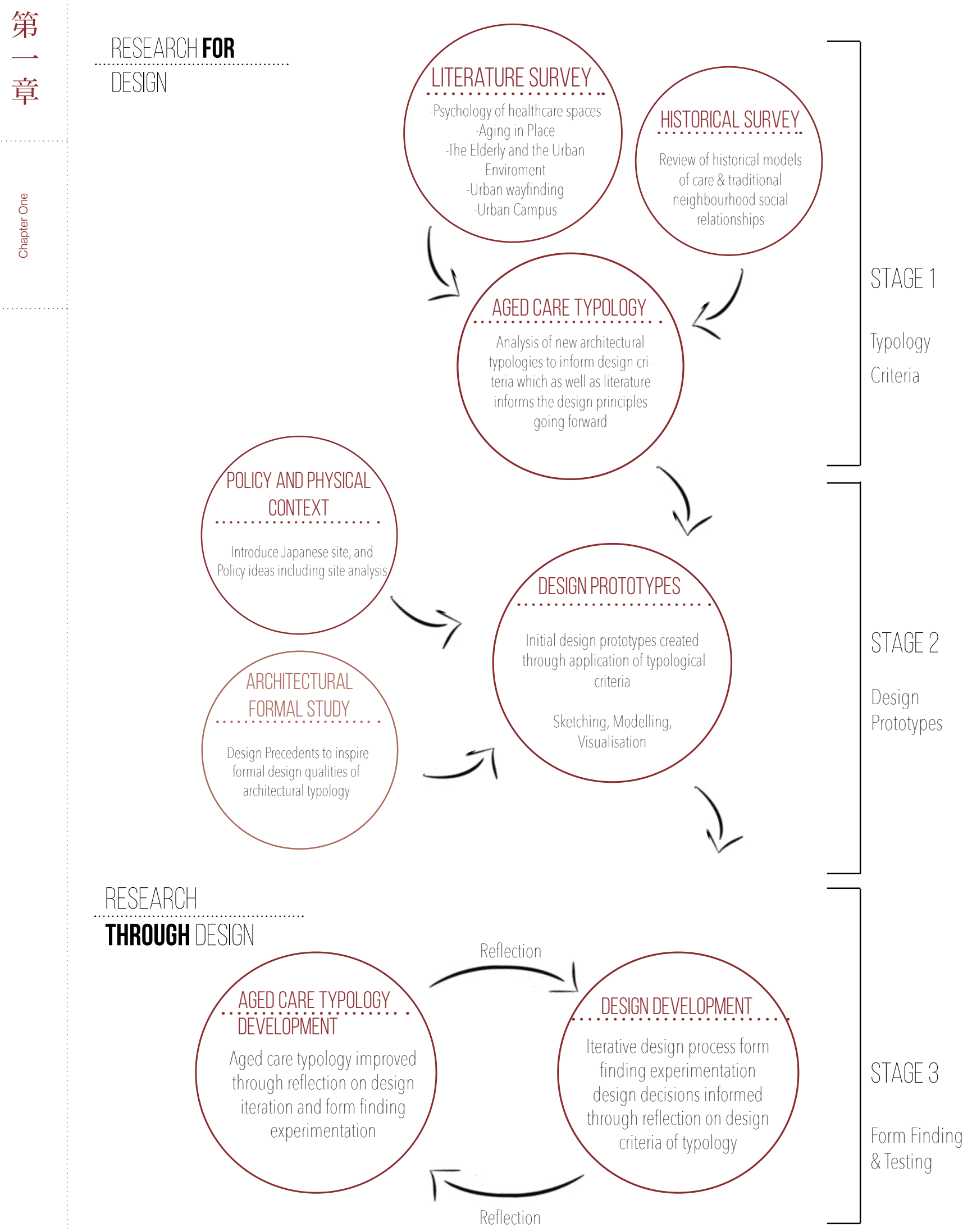




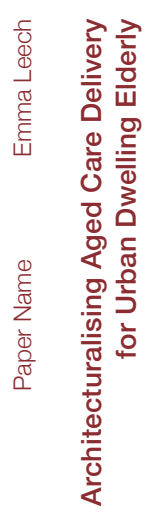





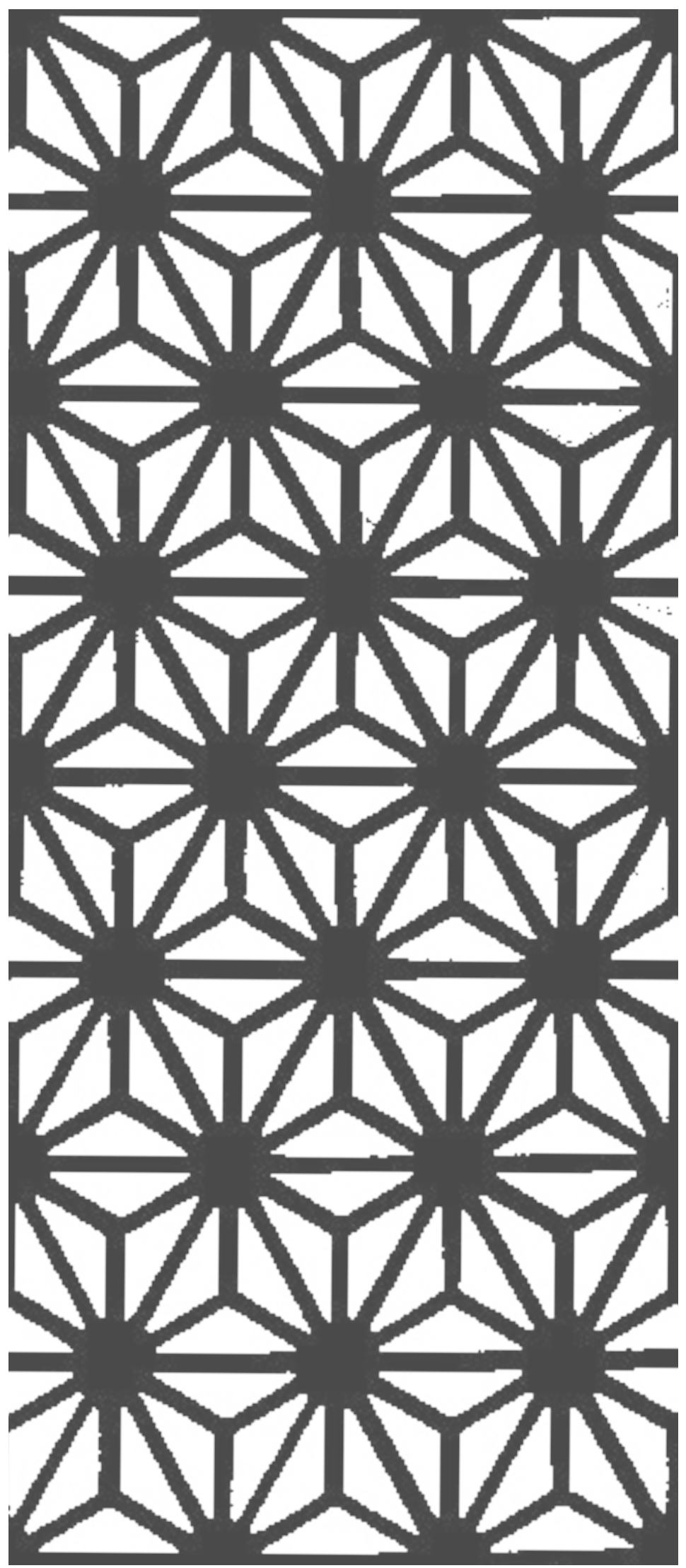

第 $\frac{0}{ \pm}$ 


\section{PURPOSE OF LITERATURE}

REVIEW

The Literature Review Identifies the position of this work amongst pervious studies and seeks to link previously separate ares of study to support the design proposition. the five focus areas of this review area Aged Care Facilities, Ageing in place, Urban Ageing, Palliative care, and Aged care in Japan the creation of design criteria is a direct response to the ideas unpacked in this review and it is the guiding forice behind design decisions and development throughout the research. 
There is a large body of literature on aged care facilities that focuses on the physical and psychological impact of life as a resident within full time care. The aim of this research is to understand which factors of facility care work successfully and what are their shortcomings. Understanding the extent of which individual lives are impacted by this type of care and separation in order to improve care. In preparation for the largest elderly cohort reaching retirement age, higher-quality research into the relationship between place of residence and health in later life has been strongly recommended (WHO, 2006). Significant changes to the areas of importance for delivering aged care in facilites have revolutionalised the sector in the past 20 years, acknowldging the shift of importance from a medical to social person lead care is neccasery to increase health and well being outcomes (Brownie and Nancarrow, 2013). The shift in this thinking has changed the way facilities are designed. Recent literature focuses on whether this change goes far enough to improve physical and psychological experience.

In recent years architects designing residential aged care have attempted to create the idea of community living to make residents feel more comfortable as if they are in the 'familiar' environment of home (Veronica Cerina Et al, 2016). This comes as research suggests that sterile hospital settings are contributing to reduced well being and low quality of life amongst seniors (Kane, 2001). What was designed during early modernism to be an objective and functional approach to care is what we now know as the medical model emphasising "the provision of skilled nursing staff for residents with physical illness rather than cognitive imparenment" (Barnes, 2002). A dominant institutional context impedes resident individuality with all aespects of living in an institutional care environment contributing to the preservation of self (Davis et al. 2009). Person-Centred care is a new holistic approach which emphasises "individual needs, wishes and choices... strengthening his or her autonomy and self determination" (Nord, 2018). With an association between at-homeness and autonomy contempoary facilities are aiming to meet social care visions through the architectural enviornments they provide (Nord, 2018).

\section{TRANSITIONAL TRAUMA}

The issues with elderly living in long term residential care facilities is initially separation from their community through the transitional phase and later on declining health outcomes associated with minimal physical activity motivation and meaningful social relationships. There is increased anxiety about moving into residential care before it even happens. As "US aged care residents fear losing their independence and being atmitted to a nursing home, more than they fear death" (Ellis, 2010).

The transition between the home and a residental facility is the most physically 
and mentally traumantic stage in the institutional care process, the effects of which are now recognised as an official cause of clinical anxiety known as relocation stress syndrome (Richards, 2011).

"For over sixty years there has been concern reflected in the research literature over the adverse impact on older adults of moving into a LTCF in terms of increased mortality and increased physical and psychosocial morbidities" (Richards, 2011). Explored by Brownie, Horstmanshof, and Garbutt, A key aspect of the trauma is a loss of autonomy and independence associated with the move into care and a separation from the home. They concluded that for the majority of elderly the home is significantly linked to "daily routines as well as personal and bodily comfort" (2014). "Increased dependance on the home environment" in old age was also linked to a "heightened importance (of the home) as an expression of identity and as a vehical for memory" (Brownie, Horstmanshof, and Garbutt, 2014). As well as this, the home is associated with accessibility to friends, family and other social connections but also the power to exclude others. "In a residentail aged care facility, which is a blend of workplace and home-place, this power to exclude (and include) is radically dimished, as is power over who provides care and when"(Brownie, Horstmanshof and Garbutt, 2014). This can be an isolating experience and lead to a loss of autonomy and connection to loved ones. Similarly, Walker highlights in her research that "participants trade their independence and sometimes their dignigty and autonomy for the safety and assistance they required" (Walker, 2012). These sacrifices don't always lead to a physical improvement in health or assistance. self assessed satisfaction and quality of life was evaluated by veronica cerina who found that "older people who spent their later lives at home evaluated their quality of lives higher than those who were faced with relocation" due to health issues or cognitive decline (Cerina,
2017).

"Each person entering an aged care facility faces their own unique struggle as they move from the known world of their home to an alien world of the aged care facility, trying to retain a sense of their own personhood and create a sense of place meaningful to them as they are pressured to conform to the will of the institution. The uniqueness of the struggle is reflected in the emotional responses, which vary considerably in nature, intensity and timing. The entry into a LTCF is not a one-time event but a continuing process that for some is never resolved." (Richards, 2011)

This quote, by Stephen Richards summaries the traumatic experience of transitioning into long term residential care environments. The research also noting the significant increase in struggle and risk factors for those who do not make their own decision to enter facility care. He makes the conclusive link between the stress of the transition on physical and mental health outcomes, previous work has not linked elderly stress to the event itself but other health issues causing the admission of residents. (Richards, 2011)

Architectural features can have a significant effect on the stress levels and settling time for an individual transitioning into long term care as they contribute to "fear, anxiety and worry, by interfering with independent way-finding, promoting deconditioning that limits recovery" from the stressful event (Parke and Chappell, 2010). The inclusion of home-like architectural features that culturally connect individuals to a sense of home sets to limit the visual disconnection between environments to limit this stress (Brownie, Horstmanshof and Garbutt, 2014). While this significantly improves well being associated with these stresses it doesn't eliminate them entirely. Spatial research on aged care institutions studies the features, designs and floor plans and analyze whether the design of the 
care environments impacts the physical and mental well being of residents. Frequently it was found that "the average resident has difficulty maintaining spatial orientation within the typical institution" due to complicated layouts, similar design features and a lack of the emotional trigger of home allowing for a recognition of space (Parke and Chappell, 2010). Spatial issues within institutions have an impact on an individual's mobility as the recognition of space and the ability to orient prevent getting lost and increase the scope of the usefulness of different social areas. Rule, Milke and Dobbs suggest that residents "did not use the available space frequently enough to become familiar with the institution, consequently they got lost or that they didn't use the space because they were afraid of getting lost"(1992). This only contributes to feelings of anxiety. Morgan et al also signifies the importance of architecture in aged care highlighting "Design of the physical environment is increasingly recognized as an important therapeutic resource in promoting the well being and functional ability of persons with dementia” (Morgan, Stewart, D’arcy \& Werezak, 2004). Identifying importance on psychosocial environments as impactful on well-being for dementia suffers as well as elderly in general.

The change in environment, particularly from a house to a single room also has a physical impact. "These changes and their consequent functional limitations, lead to an increased risk for disorders of physical mobility"(Clares, Freitas, Borges, 2014). This can have an ongoing effect on the physical mobility of individuals throughout their time in residential care without intervention. Although the knowledge of immobility and its consequences on health and quality of life have been known for many years "elderly residents living in long term care facilities still commonly sit in wheelchairs or lie in bed for prolonged periods of time, in many cases for most of their waking day" not only does mobility have a huge effect on quality of life and independence but "both the time and cost of health care escalate dramatically" (Slaughter, Estabrooks, Jones \& Wagg, 2011). The constrained resources of the industry are typically to blame for the significance of immobility in aged care facilities, as $60 \%$ of cases are treatable or preventable with effective rehabilitation and frequent physical activity (Slaughter Et al., 2011). The absence of independently driven lives in aged care facility environments decrease motivation for exercise. "It has been found that staff institutions for the frail old often overleap and foster spiraling helplessness (Avorn and Lager, 1982). Minimizing the world of elderly people to within the walls of the facility also decreases interest in getting out and about in the community, which has been proven to have significant effect on the health and maintenance of mobility skills (Clarke and Gallagher, 2013).

Brownie and Nancarrow suggest that the transition of care from medial to social person lead care environments, while supportive for well-being and mental health, is also associated with an increased amount of physical accidents and falls. Relating the shift in "hierarchy of need" to prioritizing well being factors to the diminished ability to provide comprehensive physical and medical care with the same amount of care support workers (2013). They suggest further research into this area is needed to understand the implications for this shift in care model and whether a medical or social model of care provides the best quality of life for residents. (Brownie and Nancarrow, 2013)

Sandra Davis et al. argues the social model of care doesn't go far enough and that, "despite efforts to move aged care away from the medical model to a more balanced social model of care we still struggle with the dominance of an 
institutional context which impedes individuality and choice" The institutional nature of residential care means that an improvement to their design and a shift in focus to well being outcomes cannot change their major issues. (Davis, Byers, Nay \& Koch, 2009)

This is echoed by Steenwinkel, Dierckx and Heylighen who conclude that private spaces where an individuals can control guests and people coming and going was more valuable in modern facilities than the larger open communal spaces that were designed to support a more social model of care (2017). Ownership of ones space and the ability to withdraw created a greater sense of freedom among residents than the ability to move through and occupy multiple communal social spaces at leisure (Steenwinkel, Dierckx \& Heylighen, 2017). The perception of homely social spaces through architectural detail did not compare to the freedom experienced by the possession of individual space. Small scale groups with a lack of strict rules and scheduling helped individuals to feel comfortable in residential care space highlighting again the importance of self directed actions and environments. Reynolds and Bleamish supporting this arguing that "perception of loss of control to external factors in the environment can contribute to a sense of limited options and lead to decreased sense of satisfaction and freedom" (2003).

Significance on the importance of privacy and its evaluation in residential aged care environments highlights that privacy is highly linked to autonomy (Tao, Siu Yu Lau, Gou, Fu, Jiang, \& Chen) "A claim to privacy is not a claim to complete withdrawal from the public world; rather is it a claim to among other things a partial and controlled withdrawal" (Hughes 2004). Issues around providing adequate privacy whilst also ensuring physical care both standard and intimate is completed to a high standard to ensure comfort, is a balance that is hard to get right, particularly in facility care where the power is held with the professionals not with the individuals receiving care. "Conflict occurs when circumstances inherent to institutional living make the maintenance of privacy difficult, if not impossible" (Applegate and Morse, 1994) With a high work load and a lack of time "privacy norms defined by the dominant culture are redefined in the professional caregiving relationship" suggesting that "many caring procedures are carried out in areas that are shared with other patients" (Applegate and Morse, 1994) As well as, a lack of privacy perceived during "numerous precarious and intimate situations in which a patients privacy may be violated" studies link lower levels of independence to less positive perceptions of privacy, corresponding to lower sense of self worth, well being and physical health (Stop, Leino-Kilpi, Valimaki, Dassen, Gasull, Lemonidou, Scott, Arndt \& Kaljonen, 2003). Likewise relinquishing control over ones own privacy can result in an interdependent relationship with care givers, not only does this affect an already burdened health system but also contributes significantly to an elderly person's self worth and independence. Caregivers in nursing homes often have a higher level of control of individual privacy than other institutional carers, due to the vulnerability of their ongoing everyday needs. "Paradoxically, for elders to have any privacy, they must depend on care-givers to allow them the means of maintaining privacy control" (Petronio \& Kovach, 1997). The balance of this relationship in an institutional environment is fraught with problems particularly relating to the ambiguity of space ownership.

\section{COMMUNITY IMPACT}

Facility environments don't just affect the elderly people experiencing them. Institutional care has a wider impact on the community and has shaped the 
relationships between generations. While the physical built environment of care shrinks elderly lives to inside the facility, simultaneously family members, friends and community members are kept out due to spatial experiences of exclusion. (Petersen, Wilson, Wright, Ward and Capra, 2014) This results in social issues, not only for the seniors themselves but also the wider relationships between the old and young, that is formally structured through institutional environments. Peterson et al highlights the issue of family involvement in care of elderly living in institutional care environments. They highlight the need for family care as essential in the maintenance of social relationships and that serious consideration should be given to how "families and residents in aged care facilities can continue their relationship on their own terms rather than being constrained by a care focus, an institutional space and concurrent requirements of risk management" (Peterson et al, 2014). This is a concept, in which the ideas and the reality haven't come together as,

"While the importance of involving families in care provision in residential care facilities is recognized, how to achieve an inclusive care space that balances the needs of families, residents, staff and regulatory requirements remain problematic for the aged care sector" (Peterson et al, 2014).

The issue of ageism and stigmatizing of elderly has only increased through the marginalization of families in care giving creating a disconnection emotionally between elderly and younger generations (Hagestad \& Uhlenberg, 2005). Sociology and anthropology have long recognized age as a basis of social organization and social integration. Quoted as "an extreme version of residential age segregation" residential aged care facilities impact the engagement of face-to-face interactions of individuals of different ages (Hagestad \& Uhlenberg, 2005). Limiting cross-age interactions "blocks essential opportunities for individuals to meet, interact and move beyond 'us vs. them' distinctions". Braithwaite points out that characteristics that elicit the stigmatization of elderly are beyond personal control, such as frailty, forgetfulness or nearness to death but that these characteristics distinguish the elderly person as differing from the 'standard norm' and influence their treatment by others (Hagestad \& Uhlenberg, 2005). "Institutional, spatial and cultural arrangements maintain or increase ageism, which in turn maintains separation" (Hagestad \& Uhlenberg, 2005). This cyclic relationship created through the initial segregation of elderly to help with the health related challenges of ageing has far reaching consequences for community, family and individuals. At the Ageing Asia forum in Singapore in 2018, "Bill Thomas passionately questioned the relatively modern phenomenon of segregating older people from the rest of society through placement in residential care, believing this only increases and perpetuates ageist attitudes towards older people and within older people" (Shears, 2018). Strengthening the role of community based care and facilitating on going interaction between different demographics of society is "a key weapon against stereotypes and prejudices, which allows individuals the opportunity to challenge homogenized categories and see beyond stigmatized characteristics to other relevant qualities" (Shears, 2018). 
"For ageing in place to work well, housing and neighbourhood environments need to facilitate older people's independence and wellbeing" (Burton, Mitchell \& Stride, 2011).

Within mainstream media, there is a large emphasis on preparing for retirement, elderly apartment style living, downsizing and how to renovate homes to better suit elderly needs. Most of these articles advocate for the ageing in place model, due to the expense and separation of aged care facilities. Stressing that it is easier and cheaper to adjust the home as and when it is needed instead of moving into an unfamiliar environment. (Nichol, 2016) The consideration of issues and ideas around elderly life and retirement within print media suggests the importance on this topic for the community as well as for the field of research, and hopefully means that new measures and policies will ensure the next generation of elderly, the baby boomers will have better experiences of well being and health than the previous generations. With more choice and freedom around where and how they spend their golden years.

Often thought of as remaining in ones home, ageing in place is defined as "peoples ability to make choices in later life about where to live and receive the support to do so. It implies that older people will remain in the community rather than move into residential care"
(McClintock, 2016). As individual's capability decreases and their needs increase, different countries provide different layers of home help carers, cleaning services and meal preparation to allow individuals to age in place with the support of their community.

HOME CARE SERVICES

Examples of the types of services that elderly may require access to as part of their home care include:

-Personal services: bathing,

showering, toileting and dressing

-Nutrition, hydration, meal

preparation and diet

-Continence management.

-Mobility and dexterity

-Transport and personal assistance

- Management of skin integrity

-Assistive technology

-Aids and equipment

Current literature focuses on whether those ageing in place can maintain quality of life for longer than individuals in residential care facilities. Establishing if where people age in place has an effect on its effectiveness as a care option, and the optimal conditions to age in place. Weissert, Matthews Cready, and Pawelak, promote ageing in place and community based care on the basis that it improves well-being for elderly. They criticise the age care industry for a lack of innovation 
and highlight the lack of expectation on nursing homes to achieve health or well being outcomes for residents. Their analysis for home and community care consisting of a review of literature post 1960, relates home care success directly to an improved experience of receiving care at home. Positive health outcomes cannot be an expectation of the industry because of the natural decline as part of the ageing process but found care was better received at home as it provided some level of comfort and associated mental health benefit compared with institutional models. (2005)

Care of the Aged: Old Problems in Need of New Solutions, is an article written in 1978 about the issues of institutional care models in the United States. Its authors Robert and Rosalie Kane discuss the need for a more, well rounded approach to care with the focus on preventative approaches, and home help solutions to enable individuals to age in place and remain healthier for longer. They similarly critique the existence of the institutional nursing home as a "catchall service" for elderly with a medical focus for social issues. "The nursing home, as an all-purpose solution to the health problems of elderly, has created a set of iatrogenic problems: increased dependency, depression and social isolation among the aged" (Kane and Kane 1978). This article could haveeasily been written any time in the last few years, as there has been not a lot of influential progression in the real world of elder care. (Kane and Kane 1978)

Rosso et al identifies that "Opportunities for social engagement may decline with age, particularly as physical function declines" directly linking mobility to social engagement of elderly ageing in place (Rosso, Taylor, Philip Tabb and Michael, 2013). This relationship can have a large effect on the engagement of elderly in social activities and reduces their overall quality of life as "active engagement with life, which includes social engagement is recognized as an essential component of successful ageing” (Mendes de Leon, 2005).

Architecturally "Well being in later life is closely related to the physical environment, which is an important mediator of ageing experiences and opportunities" (Burton, Mitchell, Stride, 2011) Research suggests that ageing in place and maintaining the familiarity of home throughout elderly years reduces disorientation and has better mental health outcomes overall compared with residential care (Woodbridge, Sullivan, Harding, Crutch, Gilhooly, Gilhooly, McIntyre, \& Wilson, 2018). However the relationship between the architecture of the home and the surrounding area was of the upmost importance and was the difference between a positive and negative experience of ageing in place (Newton, Ormerod, Burton, Mitchell, Ward Thompson, 2010). Accessible design research, on the home and public space has been widely studied, as it directly impacts the day-to-day movements of elderly and disabled individuals. Accessible design for the home seeks to adapt the home to better suit care needs, widening doorways, adapting the floor plan to create more accessible open plan living and using wall and floor covering to create a higher level of contrast for those suffering from dementia or loss of eye sight (Stevens, 2014). This work is frequently seen in relation to elderly disability with high levels of care need, understanding how the home can better work to minimize their daily struggle. It often does not consider those on the lower sale of need who slowly need to make changes to their lifestyle and introduce more care as a preventative measure. Even though introducing more accessible architecture earlier can help with long-term mobility, maintaining good health longer and therefore increasing aged quality of life (Nummela, Sulander, Rahkonen, Karisto, Uutela, 2007).

Outside of the home, in some ways is even more important than the home itself in creating a quality healthy lifestyle for those ageing in place, although this area 
of research has less scope of previous literature. Hennessy in her book on quality of life in old age looks at the affect of loneliness and social separation on the well-being and mental health of elderly living in their own home. The reality for a lot of elderly is that they live in sprawling suburban environments, no longer navigational when driving is not an option, as a lot of our modern world is designed around the car. The sentimental attachment to their familiar surroundings and local community, stop the move to more serviceable housing options like urban apartments in which amenity is much more accessible. This means that elderly are often confined to their homes, stopping social participation the same way they would have previously and making them dependent on others for their everyday needs. Supermarket shopping, doctors, hairdresser and several other services become overwhelming tasks. (Hennessy, 2004)

The links between where elderly is aging in place and their ability to maintain social connection and mobility have been looked at through the research of Fobker and Grotz who say that the suburban model affects the ability to age in place because of the proximity between home and amenity (2006). The inability to walk to retail and public areas reduces the social contact individuals have with their community contributing to loneliness and a decrease in mobilization, quickening the decline of health (Fobker and Grotz, 2006). They discuss the ideal neighbourhood for the positive ageing, highlighting the importance of walk able suburbs with a suggestion that the urban environment provides a better foundation of support for ageing elderly due to the proximity of several daily essentials (Fobker and Grots, 2006). Philippa Clarke and Nancy Gallagher draw similar conclusions as they look at the role of the built environment in optimizing mobility, highlighting that the urban environment can be help and a barrier for the social lives of elderly (How) and their ageing in place experience. The condition of outside space surrounding the immediate location of an elderly persons home can significantly affect their use of public space and overall mobility (Clarke and Gallagher, 2013). New Urbanist social community ideas are explored by Nichole Campbell and Daejin Kim which also highlights this link between proximity of the home to public services, community activities and social life in order to create a positive ageing in place experience. This separates the individual needs of the elderly away from the specific building that they occupy and suggest that an overarching approach to urban design fabric as well as the planning of internal space are important to creating a wellrounded positive ageing lifestyle for elderly (Campbell and Kim, 2016).

"In 2017 WHO published the guidelines on integrated care for older people, to provide guidance on preventing, slowing and reversing the decline of the intrinsic capabilities of older individuals and maximising their function abilities" (Saito, Haseda, Amemiya, Takagi, Kondob \& Kondoa, 2019). In response to these guidelines Saito et al suggest that more can be done than just targeting 'at risk' individuals and suggest a whole community approach to health intervention. (Saito 2019)

Japans productive ageing social policies, support elderly into alternative employment once over retirement age, keeping them engaged in the community and giving purpose to their lives (Casey, 2005). A key component to this social policy is the idea of community-based care, utilising ageing in place and the consideration of the value that can be added by these demographics in different sections of the community as they age. Not only does the engagement in paid or voluntary employment support the self worth, independence and well being of the elderly person but it also ensures the vitality of the Japanese economy, which is experiencing a depletion of workers due to an increase in elderly demographic. (Uesugi, 2010) 
There is a relatively small amount of research on ageing in an urban context. Studies in this area are mostly concerned with the wayfinding and physical abilities of elderly within the density of the city, and studying how the overstimulation of urban areas affects orientation ability and delirium. Studies focus on the independent elderly in these contexts and little research has been conducted on these relationships when independence is lost and the daily challenges of lost independence in this type of environment.

A physical activity study on older adults living in apartment buildings compared with traditional detached housing found that "living in a high-rise apartment environment does not decrease physical activity and may promote overall quality of life" (Cheng et al. 90). This study enhances understanding of elderly's physical relationship to the home and the effect of different living environments on physical activity. The study concludes that household activities were the bulk of physical activity undertaken by older people and "were carried out in personal living areas, not affected by residence type" (Cheng et al. 90). This suggests that while apartment style living does affect the physical activity and health of younger people, within elderly groups there are less negative impacts on physicality (Cheng et al. 90).

Focusing on outside of the home, Frobker and Grtoz examine the affect of the urban environment on elderly mobility identifying its supportive role in physical health. Recognizing,

"Urban areas offer better conditions for a self determined way of life until old age because they possess a high density of supply (Amenity), leisure activities and a well integrated public transport system compared with suburban or rural areas" (Frobker \& Grtoz, 2006).

The research, which focuses on investigating "what type of neighbourhood corresponds best to the needs of elderly", uses the everyday mobility of German elderly in different settings to determine the extent to which different residential areas affect daily activity (Frobker \& Grtoz, 2006). The study stipulates, "An essential aspect for ageing contentedly is an independent and socially integrated life" which is more easily enabled in urban areas (Frobker \& Grtoz, 2006). Increasing age is associated with a withdrawal from public to private space therefore the proximity of amenity and leisure activity determines mobility patterns for those no longer able to drive (Frobker \& Grtoz, 2006). Similarly determined by Bowman who emphasizes

"Central city locations ameliorated fears of dependence and institutionalization and enabled aged persons to maintain independence... The high level of proximate behavior which is typical of old age can easily be maintained in the central city." (Bowman, 2) 
The ability to access services within greater proximity to the home is the main advocate for ageing in urban environments. While this is preferable than in suburban and rural areas overall, there are challenges for elderly living in urban lives. This includes but is not limited to, spatial inequalities, social exclusion, security and the lack of the 'neighbourhood' environment. Physical spatial inequalities have implications for the every day experience of elderly in urban spaces. Lack of provision for appropriately even pavement, the use of stairs in urban social spaces and a general lack of accessibility, contribute to the exclusion of elderly within urban environments and to a high percentage of public falls and accidents (Newton et al. 2010).

"Analysis identified the components of a street that influence their decision to go out such as adequate seating and smooth pavements... if these are absent some older people limit outdoor activity”(Newton et al. 2010).

The perception of safety and security was a significant contributing factor to the physical activity of urban elderly residents. Those who had fears around their security in the area surrounding their home were less likely to go out at night and were less involved in social activities (Pohl1, Sandlund, Ahlgren, Bergvall-Kåreborn, Lundin-Olsson, Melander Wikman, 2015). A study on perceptions of city environments showed that the city was perceived as more dangerous than reality due to a heightened connection between crime and cities compared with other residential areas. As well as this "Older adults in poor health and with reduced mobility are less capable of coping with potential safety risks that may occur in public spaces, which contributes to a sense of insecurity" (Tan et al. 2019)

Similarly the absence of a sense of community also affected the physical and social activity of those living in urban areas

"The significance of the neighbourhood dimension in later life reflects both the reality of long term residence and extended amount of time spent at home in later life and in the immediate neighbourhood following retirement" (Philipson and Ray, 2016)

A lack of social ties is more prevalent in urban than suburban and rural areas due to a more individualistic lifestyle (Van Hoof et al. 2018). The city can seem dehumanized due to the volume of different people it is servicing on a daily basis. "To any one person, strangers are far more common in big cities than acquaintances" (Jacobs, 1961). The shrinking of physical capabilities made the immediate community more influential to the social lives of elderly and a lack of community more likely to contribute to social isolation (Van Hoof et al. 2018). In response to the challenges facing elderly living in urban environments the "Age Friendly City" has been proposed by the world health organization as a means of improving specific aspects of living in cities that are challenging for elderly. "An age friendly city is one that promotes active ageing. Such a city optimizes opportunities for health, participation and security" WHO along with world leaders have created guidelines for cities that will result in healthy ageing through a multi-dimensional approach (Plouffe $\&$ Kalache, 2010). The eight domains of an age friendly city were determined fromcollaborative research on the important aspects of active or healthy ageing as well as specific characteristics of urban environments contributing to this (Van Hoof et al. 2018).

"There are various approaches to creating age friendly environments ranging from an emphasis on physical infrastructure to the quality of social relations that promote social participation" (Buffel and Philipson, 2016). The recommendation of age friendly cities through this research 
and subsequent guidelines highlights the willingness to embrace age diversity in urban areas and acknowledges the contributions that ageing populations can make to the life of cities. 


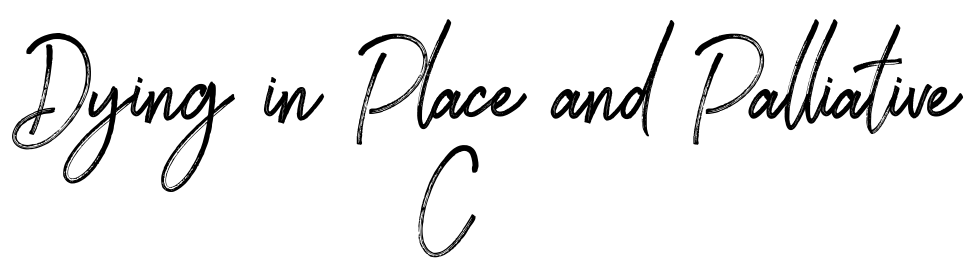

"Our inability to confront death means we lose control of one of the most significant events we will face" (Cossins, 2019)

Choices around death and dying are confronting in a way that people don't like to deal with. "Death is outsourced, the dying itself is medicalised and the aftermath is sanitized and stage managed" this gives us a false sense that the circumstances surrounding our death and the lead up to death as being out of our control, much like the experiences in institutional care. The unpredictability of death only heightens these feelings of helplessness. (Cossins, 2019)

Increasingly, more people are dying in aged care facilities than ever before and yet most are not equipped to manage end of life care in the same way as specialized hospices and palliative care providers. A European study on dying in long-term care suggests that "there is a rise in chronic disease and increasingly complex care needs among residents of long term care facilities" beyond the capabilities of their design (Honinx, van Dop, Smets, Deliens1, Van Den Noortgate, Froggatt, Gambassi, Kylänen, Onwuteaka-

Philipsen, Szczerbińska \& Van den Block, 2019). But if aged care facilities are not designed to deliver palliative and end of life care then where should people die?

Where people want to die and where they actually die are significantly different says Andrew Macpherson and Ravi Parikh (2017). In their article in the Washington post they identify that the majority of Americans want to die at home but "settle for end of life care that is inconsistent with their wishes and administered in settings that are unfamiliar" (Macpherson and Parikh, 2017) like Daniel Cossins they believe that lack of knowledge, planning and a perception of a lack of choices surrounding death significantly contribute to the end of life care received and ultimately the location of death. The World Health Organization have identified that improving end of life care was a global public health priority (Broad et al, 2012). Accessibility is a key part of this improvement as well as how palliative and end of life care can be integrated across health and social care systems on a global scale. Understanding where people die and the constructs around these places of death is a key component to investment in policy and infrastructure to support place of death management. A review of the place of death in 45 populations confirmed that institutional death was the prominent outcome. Whether this institutional setting was within hospital or within aged care facilities, depended on the policies for long-term care planning within individual countries. Significantly, for those over 65, Korea had the lowest deaths in aged care facilities but the second highest hospital deaths, Japan had the highest hospital deaths, New Zealand and Iceland had the highest aged care facilities deaths and Cyprus 
had the highest other locations for death which included private homes. The study concluded that over $54 \%$ of deaths within the populations analyzed died in some kind of institutional setting in spite of widespread preference to die at home. The key reasons to not die at home were a desire to not burden family members or a family members lack of knowledge about place of death and end of life care preferences of chronically ill individuals. (Broad et al, 2012)

The study suggests greater investment in end of life care within aged care facilities as "in many populations residential aged care was an important site of death for older people, indicating the need to optimize models of end of life care in this setting" and while this conclusion is relevant to support current place of death data, the current predominant place of death is unrepresentative of population preference therefore providing the means to carry out these preference needs should be prioritized to ensure wishes are upheld. (Broad, Gott, Kim, Boyd, Chen \& Connolly, 2013) 


\section{A}

Japans ageing population is much more advanced than any other nation in the world (Annear, Otanin \& Sun, 2016). Recent government guidelines promoting the care of aged people in the community are aiming to reduce the amount of hospital stays and institutionalizations, which is both damaging for individual's lives and relationships as well as an economic disaster as the percentage of elderly people is due to rise even further and the workforce is continually shrinking (Kavedzija, 2018). Japan is at the forefront of aged care investment with a high level of interest in products and services that can keep individuals in the workforce and in their own homes for longer (Forbes, 2019). Their interest in technology to help with a lack of aged care workers and as companions for elderly to combat loneliness are just a few examples of the technological investment making the likely hood of architectural and infrastructure innovation in line with these values of interest.

The density of Tokyo and particularly central areas like Chuo City bring the relationship between elderly and amenity closer. It also makes projects like this more viable as there is a higher percentage of elderly that will use this type of intervention. Although data from the 2015 census shows that Tokyo's elderly population $(22.9 \%)$ has a lower percentage than the national average $(26.8 \%)$, a large jump in population in 2015 compared with 2010 brings Tokyo's elderly population to over 3 million. When specifically looking at Chuo City district, there are over 30,000 individuals over 60 within just over $8 \mathrm{~km} 2$ of land area and another 22,000 over 50 that will be retirement age in the next 10-15 years if the population where to stay the same, but it will continue to steadily increase until the approximated peak in 2030. (Statistics Bureau of Japan, 2015)

When comparing this data to household numbers, elderly people are more likely to live on their own than any other age group. 21.71 million households across japan had elderly members aged 65 years old and over and in total 5.93 million of these were elderly living alone. The National Institute of Population and Social Security Research predicted that this would only increase with a projection based from the 2015 census suggesting that over 9 million elderly would be living alone in 2040 . (Yamamoto, 2019).

Experts have called for urgent measures to deal with the growing need for elderly care and other services as those senior citizens increasingly become unable to care for themselves. "There will be even greater need for elderly care services and neighbourhood watch programs to check on such senior citizens," said Shiro Koike, director of the institute's Department of Population Structure Research (Yamamoto, 2019). 
"There is a need to think about support measures in order to prevent seniors from becoming isolated in society" (Yamamoto, 2019).

While these statistics show the extremity of japans super aged society this growth is reflected across the world on a smaller scale. Using Japan, as the testing ground for innovation will create the example for providing aged care solutions within highly dense environments and will begin a conversation on how best to support elderly, as their population grows compared with workforce numbers.

Current aged care support and services centre on Japans "Mandatory Long Term Care Insurance” (Campbell, 1984). This involves everyone aged forty and older with income to contribute to the scheme with all care financed from the age of 65 for those eligible. "They are required to join the citizens health insurance plan, a decentralised system providing various care levels of home care and also institutional care" (Mitchell, Piggott and Shimizutani, 2004). Care systems specifically for the care of elderly were first established in 1961 with reforms in the 1980's and 90's due to the increase of "Social Hospitalizations" as free hospital care was provided, even if individuals did not require intensive medical care (Mitchell et al., 2004).

The current system, introduced in 2000 , is structured around four key objectives for elderly care

-Reduce the family burden of home care, shifting responsibility from

family to state

- Create a more transparent relationship between premiums and care benefits

-Integrate systems of health, medical and welfare services to create consistent comprehensive support across all institutions

-Separate long term care from health insurance cover to reduce hospitalizations due to a lack of

\section{alternatives}

Through financial support Japan has significantly decreased the burden of supporting elderly relatives and their ever-increasing health needs (Mitchell et al., 2004). This insurance scheme aims to destigmatize aged care services and accessing appropriate care for those in need. In 2000, the percentage of elderly people in japan was $16.9 \%$ compared with $28 \%$ in 2019 and future predictions of $38 \%$ by 2050 (Kavedzija, 2018). Tighter restrictions of the eligibility criteria and the type of care provided have already begun as the government struggles to support higher health bills each year. Along with this a lot of the supported programmes are run by volunteers and the majority of these individuals are over 60 years old themselves, meaning an unsustainable workforce in this area (Tsutsui, 2014).

In line with the objectives of the aged care health system, japan has been increasing its levels of institutional residential care environments since 1994. This is in a bid to not only reduce long hospital stays but also to reduce the number of elderly dying in hospital as well as a way to relive family stress around caring for elderly members. Even though the majority of japans population wishes to die at home the hospital was perceived as a safer environment for those with terminal illness even if this didn't line up the hospital palliative care options or end of life care protocol (Fukui, Yoshiuchi, Fujita, Sawai \& Watanabe, 2011). The perception of safety in hospital care is a reflection of the decreased mortality rate through medical advancement, not through actually increased health of those receiving care in hospital compared with at home (Lim and Kyung-Hoon, 2017). The residential care facilities available for elderly does not have the same medical resources as the hospital system with residents unlikely to see a doctor or nurse more than once a week, making a hospital 
death and multiple hospital transfers more likely upon entry to residential care. Particularly those needing palliative care are affected as "Existing (ACF) facilities were not designed to provide residential end of life care and the proportion of aged care facility deaths in 2016 was still less than 10\%" (Sugimoto, Ogata and Kashiwagi, 2016). $76.3 \%$ of deaths in japan in 2012 were in hospital contributing to significant elderly healthcare expenditure (Sugimoto et al., 2016). Sugimoto et al. discusses the factors that contribute to the governments approach to promote aged care facility deaths and living as a key strategy moving forward to deal with the rise in elderly population (2016). Residential care is significantly less expensive than caring for elderly in hospital. The main factor reducing the rate of death in these environments is the lack of provision for end of life palliative care and staff education as the majority of institutions, particularly those who outsource their health professionals lack the expertise or resources to provide this type of speciality care (Sugimoto et al., 2016).

As a continued development of Japans social care system the Japanese government now also advocates for community-based care at the core of their aged care plan. Especially for those with minor disability and care needs, treatment and care at a community level at home with the support of neighbours and friends along with local service providers, is recommended with a particular focus on preventive treatment (Saito et al., 2019). "In 2006, the government implemented measures aimed to identify frail or semi frail older adults and provide early preventive careprogrammes for functional decline, to delay dependence on long term care" (Saito et al., 2019). Although this screening process was thought to help with reducing long term health issues, the low participation, put down to physical and environmental barriers of attending screening tests including transportation costs and the socially disadvantage low participation in health check ups meant that only a small amount of individuals received this preventive care. Since then social determinants of health have been included in other preventive care option strategies as recognition that "social isolation has been identified as a strong risk factor for long term care and premature mortality.... Public long term prevention plans now focus on promoting social participation and preventing isolation of older people" (Saito et al., 2019).

What this reflects is the development of the aged care plan in japan to both minimise cost as well as provide socially considered health reforms as well as a consideration of physical health. The move towards treating people at home and a new focus on preventative care follows research that ageing at home is better for mental health. All of these factors signify the compatibility of Tokyo as the testing ground for these ideas. Despite the speculative nature of this design research the goals and guidelines of japans health system for elderly is in line with the ideas I am trying to test making it a more likely development scenario. 


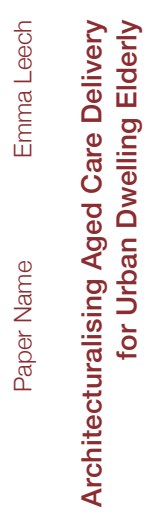



INTERNATIONAL AGED CARE

DESIGN

The analysis of current aged care facility architecture and care delivery will increase understanding of what is missing in the industry and areas of growth. It is hoped that through this process a more defined design direction for the important values and ideas behind this project will be discovered and solidified. Analysis of current aged care delivery and architecture along with Literature will form the basis for future design criteria and will form the foundations for the overall aesthetic for the design. What will be analyzed from these aged care facility examples will be:

-The key components and values of facility care models

-Whether cultural differences are strongly reflected in facility care

-The extent to which the facilities care vision is reflected architecturally and which architectural features are conducive with particular facility care visions and values.

\begin{abstract}
An important element to explore through looking at facility precendents was not only innovations within the sector but also to look at and understand the key elements of a standard model of care across different countries and cultures. Referencing the book 'Design for Ageing' five facilities where identified as a representation of international aged care case studies for both building design and program. These models highlight the differences in facility architecture acrossEurope, America, Australia and Asia as well as differing care visions responding to cultural context. This provides a snapshot of standard practice to further communicate how far innovation steps away from this.
\end{abstract}


Denmark

This content is unavailable.
Please consult caption for citation details

Salem Nursing home in Denmark supports very dependent older people and is surrounded on three sides by apartment buildings within a mixed residential and commercial area. residents live within 4 separate but linked 'household' of between 8 and 13 people. "Deliberately domestic in sale each household has its own identity, culture and purpose, although all households are visually linked to one another and use the central common areas. the goal of the facility is to provide realistic independence and choice to older people. what this building lacks aesthetically and the scheme lacks fundimentally is a connection to the surrounding areas. The dependancy of the residents on their carers is largely due to this but there is no visual or physical connection to the surrounding fabric. (Anderzhon et al., 2012)

United States of America

This content is unavailable.

Please consult caption for citation details

Leonard Florence Centre for Living is a multistory household in an urban context. Modeled after the green house movement in American aged care the scheme aims to create a series of smaller buildings on a larger plot of land to replicate the ranch style dwellings popular in the area. The use of integrated community spaces on the campus aim to bring the community into the design and the use of nature and landscaping throughout gives the campus a 'village-feel'. The intention of this large campus grounds and their actual psychological affect are very different because it creates a larger amount of distance between the nursing home and the surrounding community. This makes it difficult for people with limited mobility to transport them around and maintain independent. Drastically removing the urban quality from the design identifies this space as different from the rest of the urban spaces unwillingly creating a stigma for the surrounding community (Anderzhon et al., 2012) 
This content is unavailable. Please consult caption for citation details
Moses Montefiore Home

Ranwick is situated in the eastern suburbs of Sydney. spread over five stories, and inspired by hotel design the design team have attempted to deinstitutionalize its aesthetic. the majority of the garden areas are inwardly focused with the idea that this "provides a quiet setting for the community" but this design, common in facilities of this age acts as a tool of segregation and not of privacy. the patchwork facade and interior fernishings dont deminish the scale of the building which is within a residental area is out of place and institutional (Anderzhon et al., 2012)
United Kingdom

This content is unavailable.

Please consult caption for citation details
Belong Atherton is located in an urban neighbourhood, town center and is an integration of long term care and independent living in the same development. the intension behind the design is to "prevent isolation and to protect, promote, and maintain a persons autonomy and independence" while this scheme offers a balance between personal privacy and public space, giving individuals a sense of ownership, the lack of diversity within a still large scale project unintentionally segregate this community from the rest of the urban area. from the plans it is clear the scale of this project provides its own community in amongst the larger urban area reducing elderly peoples ability to form natural relationships with others outside of the facility. (Anderzhon et al., 2012) 
This content is unavailable.

Please consult caption for citation details

NPO Group Fuji is a private not for profit organization that maintains a unique connection to the surrounding area. It provides suburban assisted living to 21 elderly residents in Tokyo with day care services for another 25 . As well as this it is a group home for young people experiencing physical and mental disabilities and contains a day care center and a restaurant both of which are open to the surrounding community. Separating the different user groups across the different floors of the building means the opportunity for cross generational interaction with the ability to withdraw to ones own space. Started by 5 local community mothers, this facility began as a support system for local community residents who needed help with caring for elderly parents as well as children. Designed for the need of community life is less controlled by carers than traditional aged care environments. The built environment is designed to provide opportunities for privacy and socialization as each elderly resident may choose. What is fundamentally important about how this scheme operates is it's focused on keeping elderly individuals in the community, providing care in a group home situation somewhere in between home and facility.

(Anderzhon et al., 2012)

\section{ISSUES AND LIMITATIONS}

The challenge the facility faces on a daily basis is balancing the different needs of the groups the facility cares for. As well as this while the care vision is set up to work in line with intergenerational research, and social models of care the relationship between the building and the street as well as the floor plan do not reflect this care vision physically within the architecture, more concerned with fitting into the surrounding vernacular. The assisted living apartments, which are pictured in the third floor plan, are actually designed similarly to a traditional nursing home as individual rooms with ensuites and shared communal living spaces. It is also likely that individuals are encouraged to stay within the facility with their meals prepared within the in-house restaurant and daily activities organized. This type of set up brings the community inside the facility but because of the suburban neighbourhood the proximity of amenity and leisure isn't close enough for residents to undertake daily independent tasks. 
Through a brief analysis of aged care in different countries and cultures, understanding their similarities and differences, it became clear that the aged care industry is slow to accept innovations and changes. Where changes are made, they are small ones, in attitude and care delivery and not always in architecture, interior or the design of programmatic layouts. The introduction of singular rooms with individual bathrooms for elderly as a transition from the hospital ward set up that become popular in Europe in the 1960's is the largest innovation within the industry in the last 40 years. This isn't always reflected in all cultures either. An industry wide acceptance of a more residential scale approach to aged care is slowly being introduced across the sector, although the demand for aged care facilities means that companies have no choice but to design large scale buildings or complexes to accommodate the numbers.

Another significant outcome of analysis is that the architecture is often not expressive of the facilities care vision, Sometimes due to lack of funds to adapt older spaces and also a need to facilitate staff efficiency over residential legibility. A long corridor connecting into residents rooms may not be conducive to resident's wayfinding ability but makes the delivery of medication, meals and daily care more efficient
The next stage of analysis includes understanding innovations in the industry in more depth. An analysis of the strengths and weakness of these innovations that step away from the traditional model of aged care in some way or form formed a solidified way forward for the design direction of this project. This analysis provided an understanding of what is needed in the industry and what is yet to be explored both in terms of care delivery approaches and architecture. These precedent projects provide a clear picture for the future of aged care through the holes in their delivery strategy. 
This content is unavailable.

Please consult caption for citation details

Azalee Nursing home is situated in Edogawa Ward of Tokyo. It houses both full time residents as well as short term respite care and day services for independent elderly who want to use the recreation, physical therapy, and bathingsupport the facility can offer.

Their goal is to act as a community hub so that their residents will have a sense of security and can continue to live in, and be part of, the community they love. Residents are involved with daily exercise routines and maintain in control of their daily activities and social activity with other residents. The Care provided here is designed around creating a restful space for peaceful ageing, with a focus not on preventative care, mobility or keeping individuals busy and active but elders are recognized for the value they have given over their lifetime and allowed to structure their day around their own energy even if this means staying in bed. As the facility operates more like a medical model of care, different therapies, care and daily tasks are done either in the open public spaces or within the corridors to accommodate the easy maneuver of large machines for therapies that diminish individuals pain and help improve their daily life including circulation therapy for example. Activities such as hairdressing, dentures cleaning, vaccinations and daily medical checks are facilitated in one of the many social break away spaces from the main corridor. (Koujukai, 2017)

This allows multiple individuals to be seen and cared for at the same time, reducing the time of these activities. These daily checks are important to monitor individual's health and determine if they are getting the care that they need.
Setting themselves apart from traditional aged care facilities Azalee integrates a children's day care center into the programme of the residential care. With priority given to staff's children to encourage women in the workforce the children frequently interact with the elder residents as well as watch them play and sing together. This brightens the day of the elderly people who wouldn't often have contact with younger generations if it weren't for the relationships fostered at Azalee. (Koujukai, 2017)

This content is unavailable. Please consult caption for citation details

This content is unavailable. Please consult caption for citation details

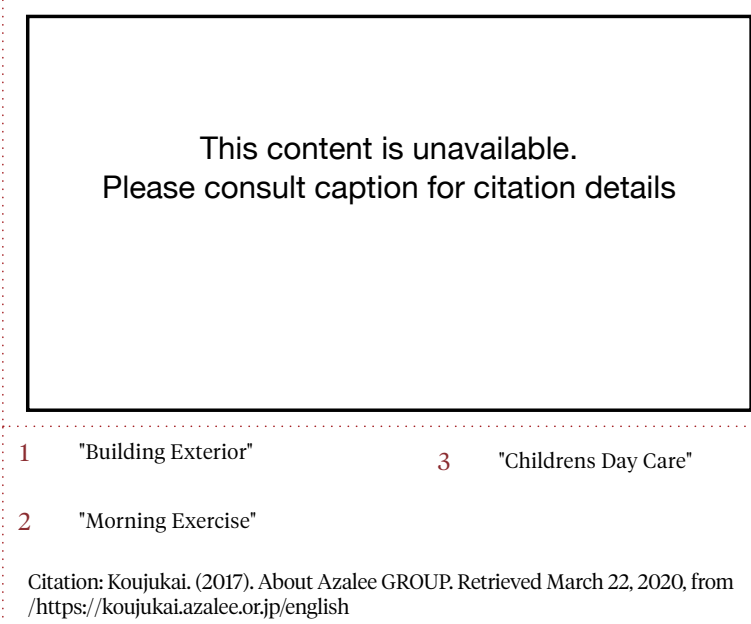




\section{KEY ATTRIBUTES}

-There are two different ward types, those who are more independent have their own rooms with ensuites and those with higher needs or are bedridden are on wards of 4-6 beds per room and living in more medical surroundings.

-Everyone who can feed themselves eats together in a large dining hall where food is prepared separately in the industrial kitchen, which prepares meals based on the resident's ability to chew and swallow their food with a choice of two options daily. -There are many spaces within the less dependent section of the home for social activity which includes daily exercise and interaction with the children's day care downstairs.

-Staff working at the home have the first opportunity to have their children in the day care downstairs in the nursing home, not only does this mean they can spend time with their children during the day but also means they are looked after while they do their job.

-The manager of the nursing home prides the system as a mini hospital and that his staff provides the best care possible for the residents. (Koujukai, 2017)
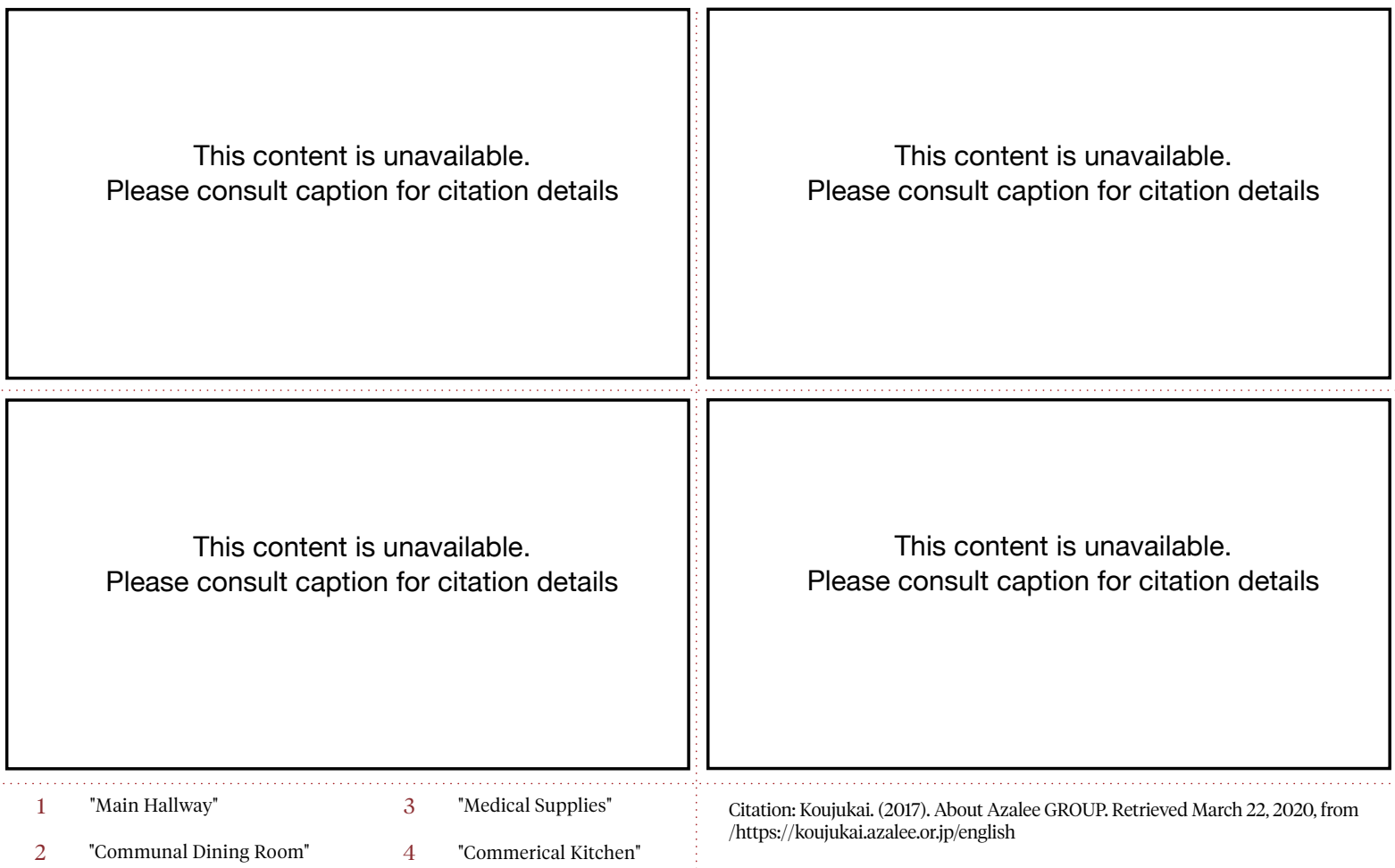

\section{ISSUES AND LIMITATIONS}

The main issue with this model is that it upholds the traditional medical approach to aged care. The architecture communicates more of a hospital ward environment and the layout demands the scheduling of daily activities such as exercise and meal times. Although non bed ridden residents have the freedom to move between their own rooms and the social areas for tea, activities or to get their hair done the relationship between individual needs and the functional requirements of care are skewed because of the architectural form. The dignity of elderly is compromised as they receive medical care in public spaces to save time and money and independence is relatively low due to the strict daily schedule of the residents, decisions are not made by the individual but are dictated by the convenience of staff and their ability to support residents with activities and daily tasks. Through innovation in technology they are able to bath individuals while seated which allows even frail elderly to maintain cleanliness without significant pain or discomfort. The architecture of this building is significantly impacting the care that staff is able to provide their residents and the dignity residents feel receiving care. 
This content is unavailable.

Please consult caption for citation details

Privately run, Maihama Club is the nursing home environment for those able to afford the best of care in Japan, The Architecture of the building and grounds has been designed to maximize residents connection with nature and gives them the exclusivity of more private space and high quality care and services. In Japan standard nursing home care is provided free of charge for elderly over 65 through needs assessment as part of the long term care insurance scheme however places like Maihama fall outside of the care provided through this scheme and is only available to those who can pay the monthly fees. Reflecting a more westernized exterior the fundamental difference architecturally between Maihama and standard aged care environments is the quality materials used, the interior detailing and the use of soft furnishing, contributing towards an expensive and luxury atmosphere. The building is designed to feel like a hotel and create a home away from home. Here, Sweden born Gustav Strandell has integrated the progressive values of long terms and palliative care from his home country into the Japanese cultural context.

With a strong focus on delaying the progress of dementia, Strandell has spent the past decade trying to spread his ideas about nursing care for the elderly throughout Japan, China and Singapore. He believes that "regardless of country and culture, we need to start seeing the individual" in elderly care. (Strandell, 2018)
Strandell suggests that the medical model, which employs doctors and nurses and uses significantly more medication and resources, caring for higher care need is more than the costs of his nursing home Maihama Club, even with the luxury that they provide. The myth that hospital care is less expensive only perpetuates this type of care model in Japanese culture. Preventative care is the answer to lower health care bills for elderly people.

Care staff are glad they are able to put residents' needs first. "Some other nursing homes tend to prioritize their own daily plans and work which they then make residents follow or even obey...Here, it is up to the residents to decide what to do" (Strandell, 2018) As well as the visually opulent European mansion aesthetic, expansive floor to ceiling windows, ensuites toilets and heated floors within all rooms, residents receive meals from Michelin starred chefs, Music Therapy, which helps with memory retention, physical therapy, spa services and traditional Japanese bathing within a Hinoki bath. With an almost 1:1 staff to resident ratio there is always time for individual care here. Making the resident's individual needs a priority has meant that even elderly with minimal care need choose to make Maihama Club their home, in order to ensure that their needs are met if and when they need higher levels of care later in life (Seah, Tan \& Lien Foundation, 2017). 
-Every window reaches the ground so that even those in wheelchairs can see outside

-Individuals bring their own furniture making each residents room individual and personalized

-Flexible daily routine prioritize

individual preferences

-Meals are the number one pleasure of the day and are personalized and prepared by Michelin starred chefs

-Each resident has their own bathroom

\section{ISSUES AND LIMITATIONS}

Nursing homes like Maihama are changing the way that care is being delivered in Japan; they provide individuals with choices and positive experiences. Ultimately though individuals would prefer to live in their own homes but choose Maihama because they know that they will receive the care they need and be looked after well when they have health difficulties in the future. "There must be something very special for them to want to die here [Maihama Club] he managed to create an environment that is a home away from home.... his version doesn't look like a nursing home but I still prefer my own home" The main issue with this type of care is the relationship between the outside community and the residents here. With minimal physical relationship to the outside world, and the position of the facility outside the central area of Tokyo in a more suburban context means access to amenity outside of the home is almost nonexistent. Despite the high quality environment that has been created here the transition from home to care can still be challenging due to the separation from the surrounding community. The key values of "personfirst' are reflected in the systems of care, staff ratios and activities they provide, however physically individual rooms off long corridors presents a not so different image of care to other residential care environments in japan. An individual has no means of preparing food for themselves or doing any daily tasks as everything is still looked after by staff. The daily individual routines of every day life work as a preventive care process and are passively maintaining individual health. Without this, the therapy provided here is designed to ensure that the maintenance of health is not compromised by the lack of daily constructs embedded within an independent day. This is no longer a passive process and individuals have to actively engage in physical activity with a shower to enable them to bath themselves for as long as possible and reduce the need for adult dippers -Emphasis is placed on visits from family and friends with the doors always open to visitors

-Hotel aesthetic away from an

institutionalized model of care creates and home away from home

Issues and Limitations

(Seah et al., 2017).

This content is unavailable.

Please consult caption for citation details

This content is unavailable.

Please consult caption for citation details

This content is unavailable.

Please consult caption for citation details

within the nursing home environment to Receive the same physical benefits of living at home. This task based physical activity is more draining on mental capacity and well-being.

Overall Strandell is to be praised for the way he has changed the qualities of aged care in Japan and created an environment closer to individualized personal care. It is clear that he cares about the resident's mental and physical health and wishes to provide the best possible environment for them to receive care. What makes this environment better is the quality of materials and finishes and not the physical space or layout. This work is definitely a step towards the right direction but still stuffers from a lack of connection to community surroundings and lack of innovative architectural planning. 
This content is unavailable.

Please consult caption for citation details

This aged care facility serves as a formal architecture study and less as a critique on the model of care provided here. This work by Japanese architecture studio INTERMEDIA architecturally responds to site and materiality that reflects both a modern form and exterior vision while taking inspiration from traditional Japanese woodworking for the interior details and atmosphere. The major idea behind the physical form and presence from the street was an invite inward through the expression of the enveloping front canopy. The use of timber on the canopy's underside whilst seamlessly connecting to the buildings exterior externally, creates a transition from exterior to interior before even entering the building itself. This evokes a sense of welcome and visually connects interior and exterior environments. Similarly, through contrast between the wood and metal materials used internally and externally the warmth and welcome of the building's interior space is highlighted even further.

The modern nursing home visually expands its interior connecting out to the urban surroundings through a large reaching canopy.

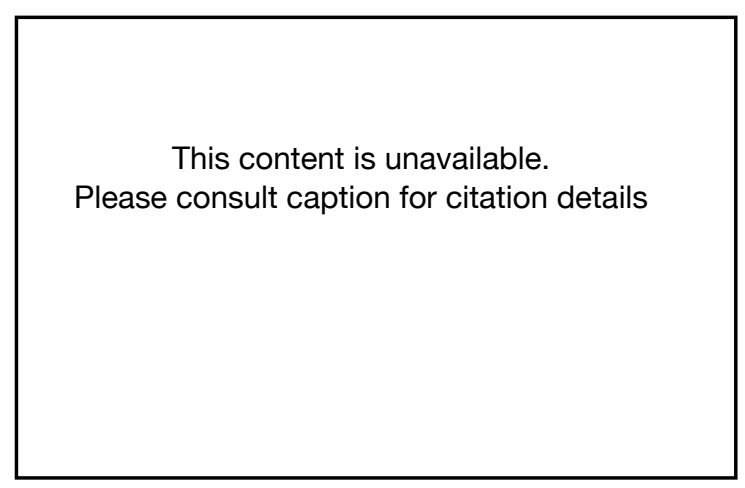

$1 \quad$ Front Facade

2 Timber Canopy
The project is built on a simple grid of wooden structure sourcing its timber from the local forestry industry. The square grid of the building enables smoother circulation between spaces and the resident's easier understanding of the space around them. A 3m-x3m-grid structure uses the relationship between the front of the building and the street to visually connect to surroundings whole necessary parts of the facility care closed off for resident's privacy. Visually communicating openness and connection the triangular canopy has been created on the largest possible scale, dramatically expanding the inner space visually. The architects explain that "because of its purpose as a facility for the disabled, we wanted to create a space where we could close the necessary parts carefully but still feel the connection with the town without being closed" (Angelopoulou, 2019). The dramatically expanded interior space using the eaves in this way as well as the warmth of the timber used creates the feeling of freedom and welcome for both residents and visitors. (Angelopoulou, 2019)

This content is unavailable. Please consult caption for citation details 
This content is unavailable.

Please consult caption for citation details

This content is unavailable. Please consult caption for citation details
This content is unavailable.

Please consult caption for citation details

This content is unavailable.

Please consult caption for citation details

Angelopoulou, S. L. (2019). Intermedia completes Japanese nursing home with Triangular wooden canopy. Retrieved March 22, 2020, from https://www.designboom.com/architecture/intermedia-nursing-homeshimabara-japan-02-07-2019

\section{KEY ATTRIBUTES}

-Sleek modern exterior that blends into the sky and surrounding streets, feels like an extension of the street through how colour and material have been used -The interior space connects outwards into the urban context through the large canopy expanding the interior space -Built on a traditional $3 \mathrm{~m} \times 3 \mathrm{~m}$ grid makes the circulation of space easy to manage

-Interior wooden structural detailing and joinery reflective of traditional Japanese design

-The building is constructed from $80 \%$ wood locally sourced and contributes to the warmth of the interior.

-The balance and contrasting visual relationship between public and private space ensure clear boundaries whilst encouraging connection with the exterior environment.

Critique

-The overall space is too uniform and similar where individuals with memory loss or dementia can get confused about where they are and how to get around. (Angelopoulou, 2019)

\section{ISSUES AND LIMITATIONS}

Using the same material for the ceiling, floor and doors can increase confusion when experiencing delirium, which can reduce the understanding of edges, transitions and orientations. Contrast between materials and colours help to eliminate these confusions. The visual aesthetic of these spaces although connects to traditional Japanese architecture whilst projecting a minimalistic modern pallet impacts the daily life of the users in this space -The visual communication of the purpose of each space is limited by the use of the monochromatic visual cues and limited furniture and detailing. -The limitations of the dimensions of the timber used means that long corridors connect spaces together like within a traditional nursing home. This limits the scope of innovation in floor plan from traditional nursing home design reducing the impact of the overall scheme and diminishing the impact the open canopy has on the relationship between elderly and their environment. 
This content is unavailable.

Please consult caption for citation details

"What we need is a

radical reinterpretation of longevity that makes elders (and their needs) central to our collective pursuit of happiness and well-being."

-Dr Bill Thomas

This content is unavailable. Please consult caption for citation details
Minka Building System-

Mindfully Designed Small Houses.

Spanning a distinguished 30-year career as a geriatrician, professor and advocate for elders, Dr. Bill Thomas has designed a way of life for elderly in which they can continue to live life on their own terms. The System known as the Minka Building System creates small homes for elderly that can be positioned anywhere, including small blocks in urban environments that are too small to be built on. Thomas' vision for the future of elderly care is the creation of sub communities of micro-homes enabling accessibility and close proximity of urban amenity and lesiure

As part of his model Thomas passionately questions the phenomenon of segregating older people from the rest of society through placement in residental aged care and further separation based on care needs. He belives that segregation supports and perpetuates ageist attitudes both towards older people and within older people. (Shears, 2018).
The notion that the focuses is on ageing as how time deminishes us instead of a focus on growth and development within the third stage of our, lives he belives is a missed opportunity. The goal with the Minka Project is to support and maximize social connections across generations and give the ability to frequently access community activities. Small scale housing provides two opportunities, firstly ensures that getting around the home is manageable even when the world of the elderly person gets smaller, they are still able to make a cup of tea and go to the toilet easily and secondly it allows clusters of houses to take up smaller sites across a city or suburb and not have to be all grouped together on a singular large site cut off from the community. With previous projects across America and the world, reinventing nursing home and long term care through the "Eden Alternative" and the "Green House" model Thomas has continually asked what people want within elderly care. He explains "what people of all ages and situations want most is to live life on their own terms. To live where and how they want." Which is what his small homes set out to achieve. (Shears, 2018) 
This content is unavailable.

Please consult caption for citation details

This content is unavailable.

Please consult caption for citation details

1 Minka Building System- Living Room

3 Minka Building System- Internal Bathroom

2 Minka Building System- Colour Schemes

\section{KEY ATTRIBUTES}

-The consumer begins with the floor plan pictured below which has been designed with accessibility and adaptability in mind and they can make adjustments to the layout and positioning of the different activities within the square footage of the home

-The home is highly customizable with different colours; finishes, cladding and decor that make it feel individual to the owner of each property.

Each component is fabricated through cnc technology simultaneous to site preparation, making overall cost and time saving.

\section{ISSUES AND LIMITATIONS}

The major issue with this model is the overall size of the project wont visually work within an urban context because single storey homes without mixed use or without multiple layers to create apartments do not create enough density to justify their position within an urban context. While the idea is to position into sites too small for development, this model is more suited as an additional out-building to the family home, which doesn't foster independence. This model focuses more on the design of the actual home, which is similar to the majority of small-prefabricated homes on the market. They don't utilize an aspect of a care environment to set this model apart from other small houses. The actual use of these homes in situ would be key to its success. The design, style and finish of this design suggest a suburban context, which doesn't reflect Thomas' care vision to connect with community and amenity.

The scale of this home doesn't cater for entertaining, with the bathroom door connecting into the bedroom and the singular open living space doesn't provide opportunities to withdraw for those living as a couple within this type of house.
This content is unavailable. Please consult caption for citation details 
This content is unavailable.

Please consult caption for citation details

Similar to Bill Thomas, Natasha

Chadwick has created a model of care centered on a community person-focused approach. Bellmere, is what Natasha calls a Micro-town which offers individuals with high care needs a suburban-like environment which could be mistaken for a residential court in any new housing development in Australia. Designed for high care needs specializing in Dementia care the development is set up like a suburban street, in which residents live across 17 small group houses each with 7 ensuites rooms, communal kitchen, living spaces and outdoor entertaining. With everything at residential scale it's just like living in their own home. Daily activities like shopping, going to the hair salon and coffee shop are all part of daily life through the design of the 'town center' and activities integrated into the complex. People are placed within each house according to their lifestyle not their diagnosis, which focuses on their daily needs not solely on their medical needs. Each of the 17 houses responds to different lifestyle approaches from a more urban lifestyle, closer to the shops

This content is unavailable. Please consult caption for citation details to the traditional conservative farm or suburban lifestyle which has a different aesthetic, functionality and relationship between social spaces within the architecture of the home.

Natasha has worked in aged care for over 25 years. She structured the values and lifestyle achieved at Bellmere around what she would want her own mother to experience in an aged care environment. Winner of "The Most Outstanding Care Innovator in the World in 2018" Bellmere is an "Innovative model that provides a dementia-friendly community where 120 residents can live the way they have always lived" (NewDirection, 2018). One of the key parts of the model is the innovative role the staff plays in the lives of the residents. They are highly skilled individuals, trained in dementia care, medication management they are involved with nutrition and menu planning as well as all the cooking in the house, as a social support to allow the residents to live their life as well as to provide all the care support services a resident might need. (NewDirection, 2018)

This content is unavailable. Please consult caption for citation details 
KEY ATTRIBUTES

-Suburban feel of the complex both separates individuals into more manageable groups proven to have positive outcomes for residential care living but also creates a sense of home for the residents making them feel more comfortable in their environment -Several service onsite including, hair salon, cafe, gym and wellness center, groceries movie theatre and day spa this creates amenity close at hand and gives choice and independence to undertake daily tasks within the facility. -Detailed design and finishing by Australian interior designer Shayna Blaze adds layers of home into the spaces, gives them life and makes the space not feel like an institutional facility environment.

-Landscaping, outdoor living and gardens are given high priority with frequently visiting family's enjoying the picnic and bbq spaces together with the residents.

(NewDirection, 2018)
This content is unavailable.

Please consult caption for citation details

This content is unavailable. Please consult caption for citation details

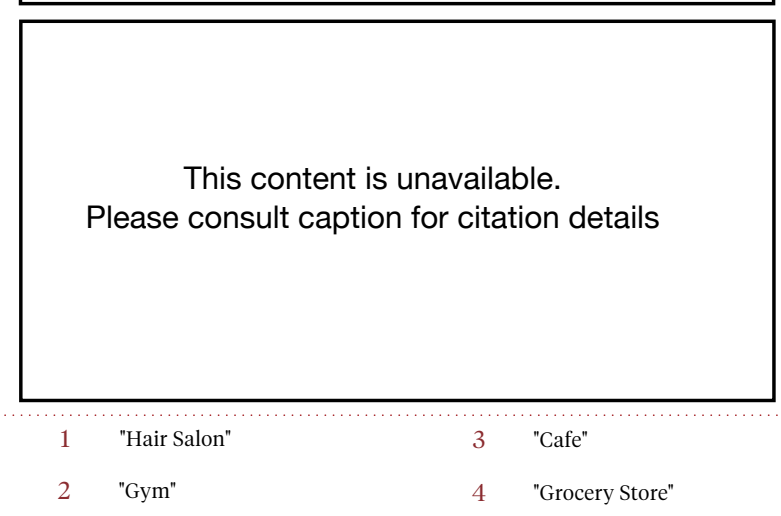

\section{ISSUES AND LIMITATIONS}

The problem is that everything is considered and included within the development meaning that residents don't have to venture outside of the facility to support their daily needs. While having access to amenity is positive and Bellmere does this in a way that still fosters independence through the inclusion of shops and allowing residents to choose the food they eat, the activities they participate in and the people they socialize with, the interaction with others is consolidated to family members, staff, other residents and their family. This is a small pool of the community integrated into the daily lives of these individuals. This is segregation of elderly due to health issues whether it is apparent from the well-designed space or not. This has implications for the community and for the elderly themselves who are consistently surrounded by elderly people. Environments like this, while more focused on social care, individual lives and providing a positive ageing experience, contain some of the same segregation issues as traditional facility care. The transition from the traditional model of care to a model like Bellmere is definitely a step in the right direction but the fundamental implication of segregating elderly into their own communities will still have long term impacts on intergenerational relationships and creates an undertone of ageism towards elderly members of the community. Because of this the suitability of this care model as an overarching approach is not entirely suitable. Dementia as a high care need is difficult to care for so environments like this, cut off from the world are more necessary to control stimulation and ensure the safety of those in care. 
The key findings from facility analysis are as follows,

The types of models that already exist within the industry providing care innovation outside of the medical model of care include group home environments, integrating into the local community. Micro housing, luxury nursing home approaches and facilities with a focus on outdoors living and connection to the landscape. These environments vastly improve on the medical model by focusing on the individual resident and creating personalized care that is not solely centered around diagnosis but a focus on social connection, mental health and happiness. The focus for modern aged care facilities seems to be in suburban environments. Which means that all services provided for residents are in house and therefore controlled by staff. A greater inclusion of amenity and services that would be experienced in a community environment has been included to increase the familiar feel of the nursing home. This could include but is not limited to cafes, grocery stores, beauty salons, movie theatres etc. Instead of connecting to existing amenity within the community, everything is provided in house, discouraging residents from stepping outside of the facility and engaging with the community. "We don't want for nothing, we don't have to go outside to find it"
(New Direction Care, 2018).

The discovery from this analysis is that current models are moving towards making the institutional model more like home and what hasn't been explored in so much detail is how to better facilitate effective and efficient home care to allow individuals to live and die in place. Death within facility care has increased. Decreasing the need for hospital admittance through facilitating an improvement in palliative care and providing clinical treatment close at hand for those in need. What if this could be delivered to elderly within their own home, mitigating the risk of transitional anxiety experienced from moving into facility care and the segregation experienced once in these environments? 


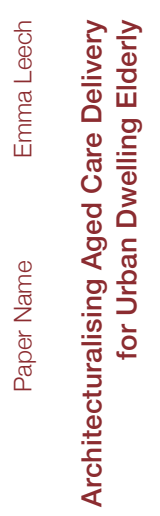





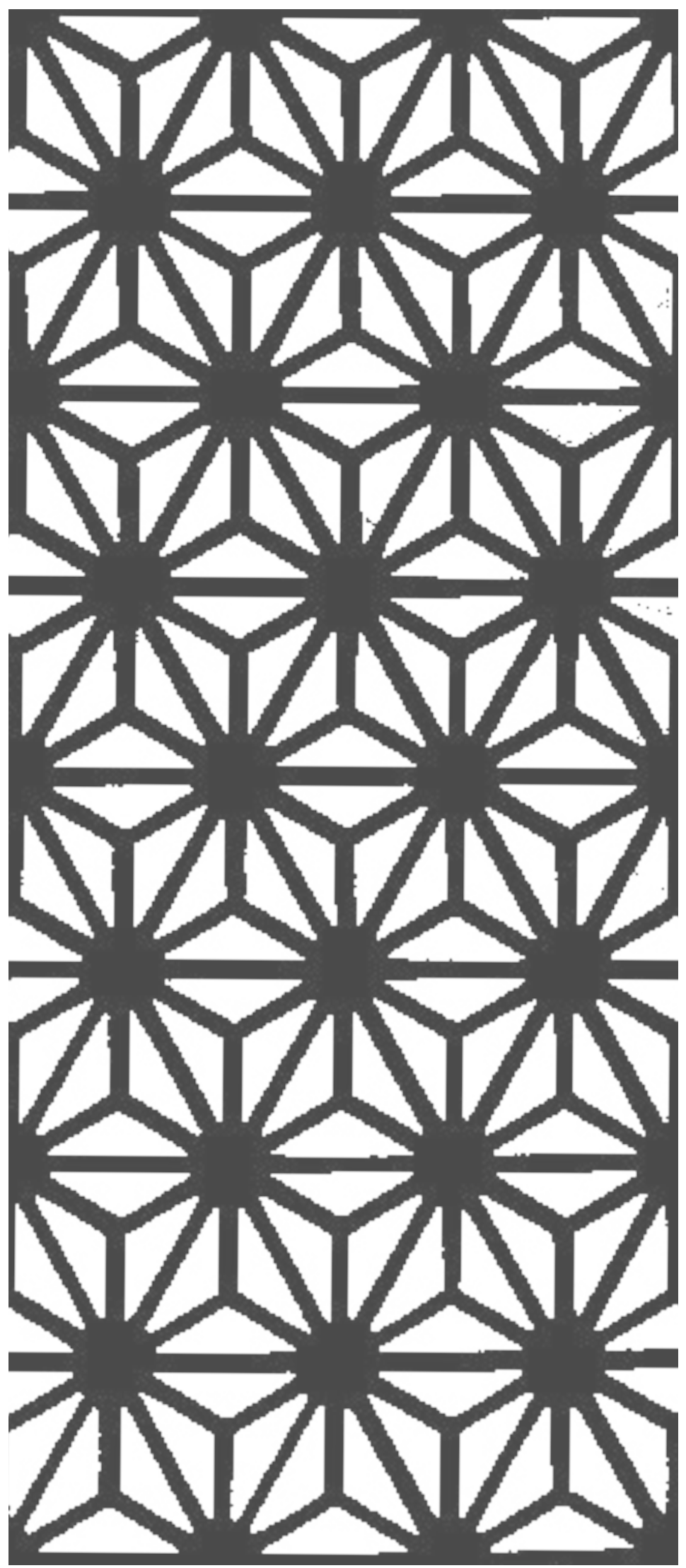

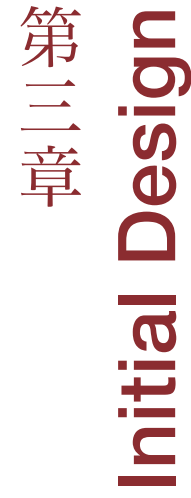



This section highlights lessons from literature to inform the design process. The early stages of the design were informed by the literature review and critique of current aged care architecture in Tokyo. The key understanding from the literature is that the design would need to be further reaching than a building on a single site but also incorporate urban design characteristics and communicate further afield than either a commercial space or the individual home.

I generated a list of problems and possible scales of design to work within considering the wide scope of the possible intervention and determined from this, a design direction to begin initial sketch designs.

Analyzing sites around Chuo City in Japan I was looking for empty sites and spaces that I could consider to build onto. The relationship between the highrise apartments and the old traditional building interested me and through this analysis I was thinking about how home care would be delivered to enable ageing in place to such a diverse sense of scales, particularly those higher rise apartment style buildings which are consistently being built to accommodate more people wanting to live in central Tokyo.
Considering these factors and also the ideas of the street highlighted by Jane Jacobs I began to look at the intersection as a means of connection. Connecting people and delivering care were initially the key ideas that drove my design research. Starting out with multiple sites and testing possible connections between the street and high rises, across large eight lane motorways, and between the low rise and high rise buildings the form developed to incorporate pedestrians and every day users of the street and also to connect buildings together from above through a series of tunnels. These three conceptual means of connection began to form the design criteria to inform more formal design moves. 

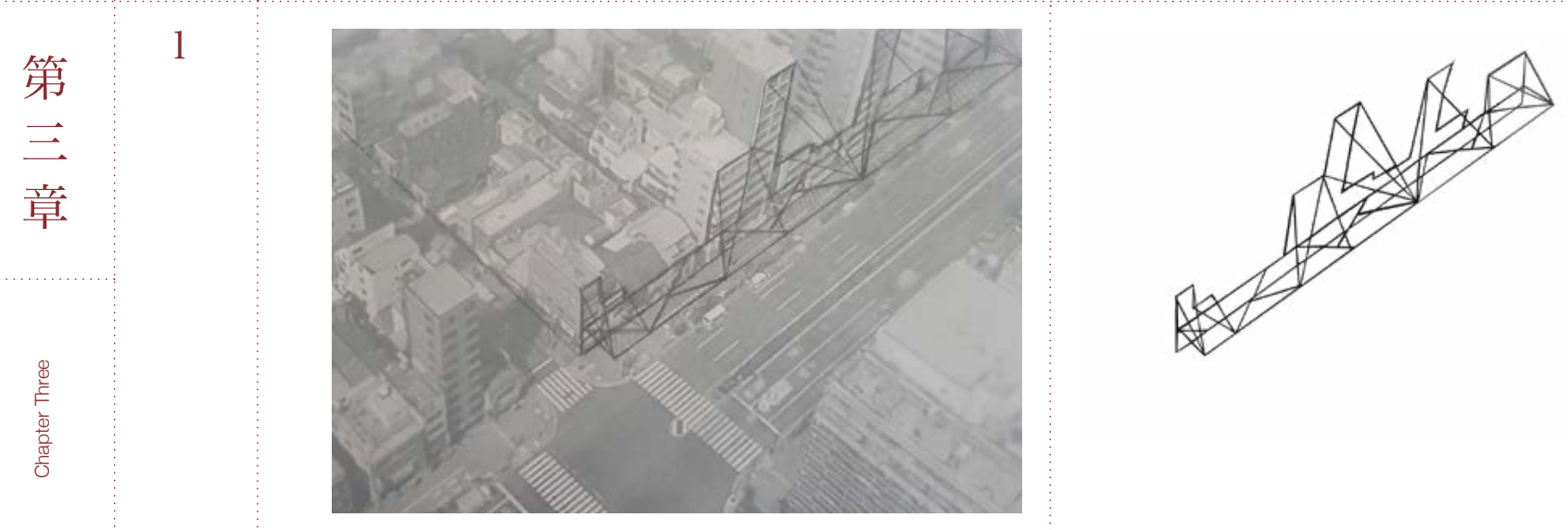

2
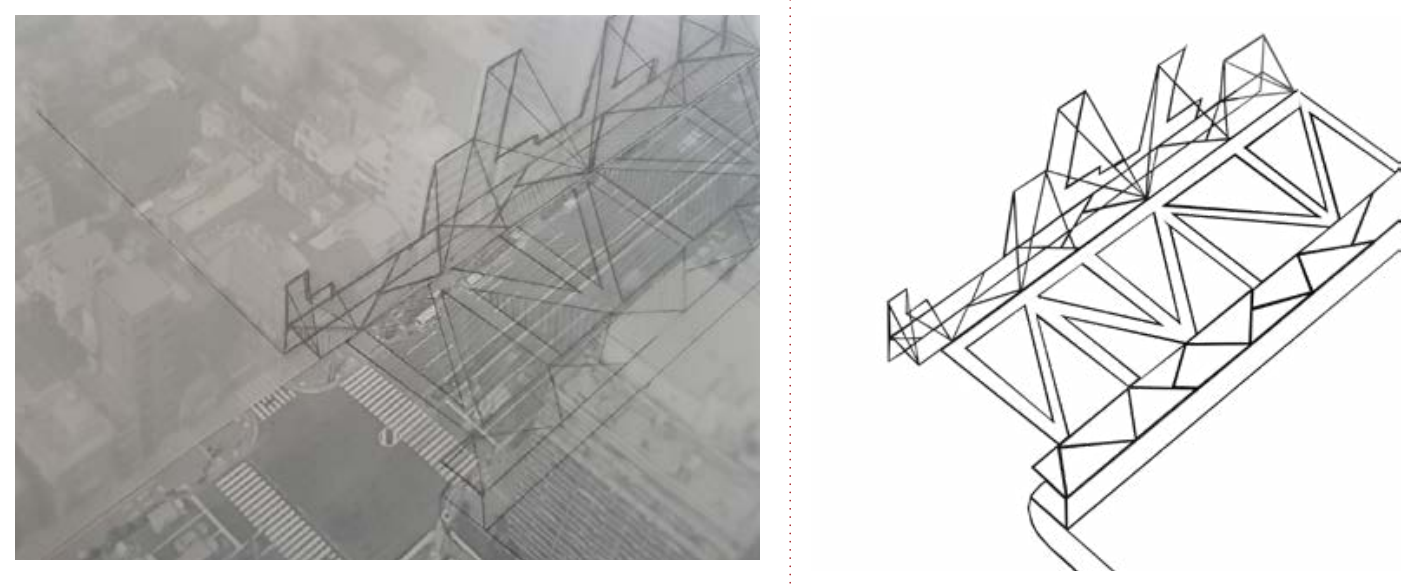

3
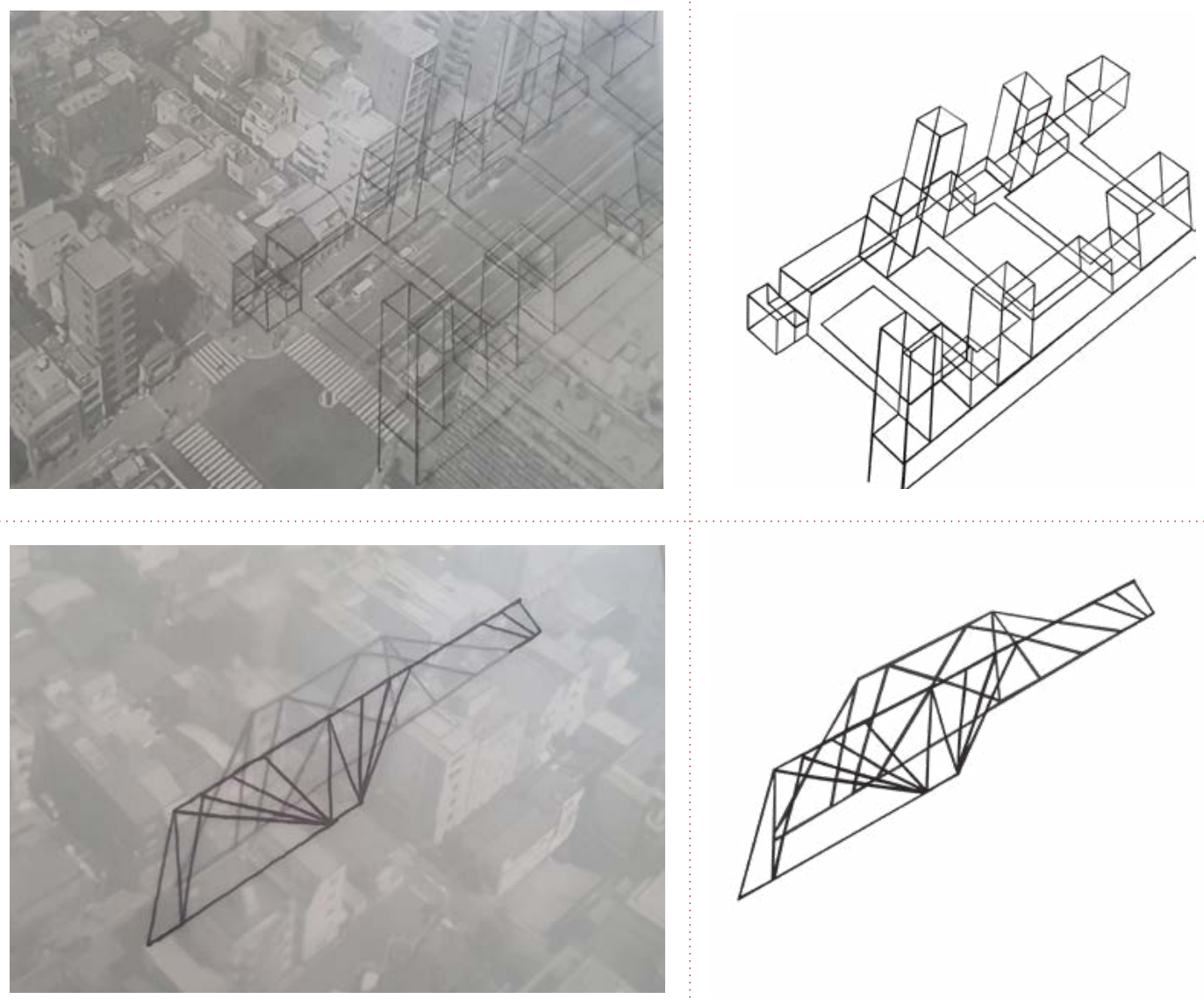


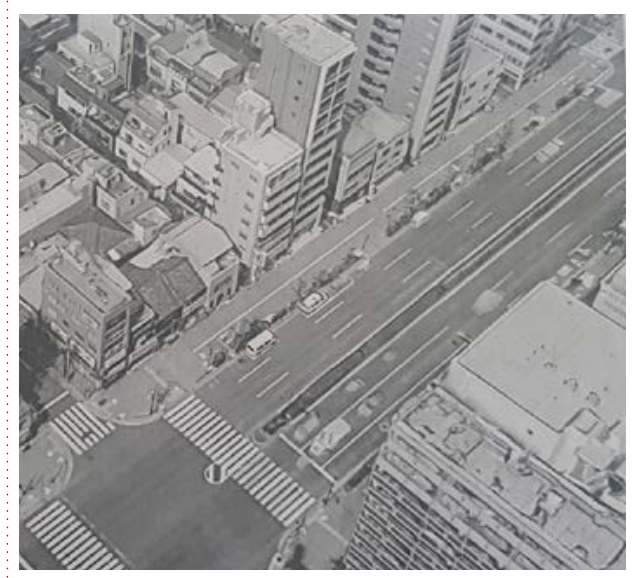

Starting to connect buildings

together above the street

but following the line of the

buildings and jumping up and

down between the low and

high rise
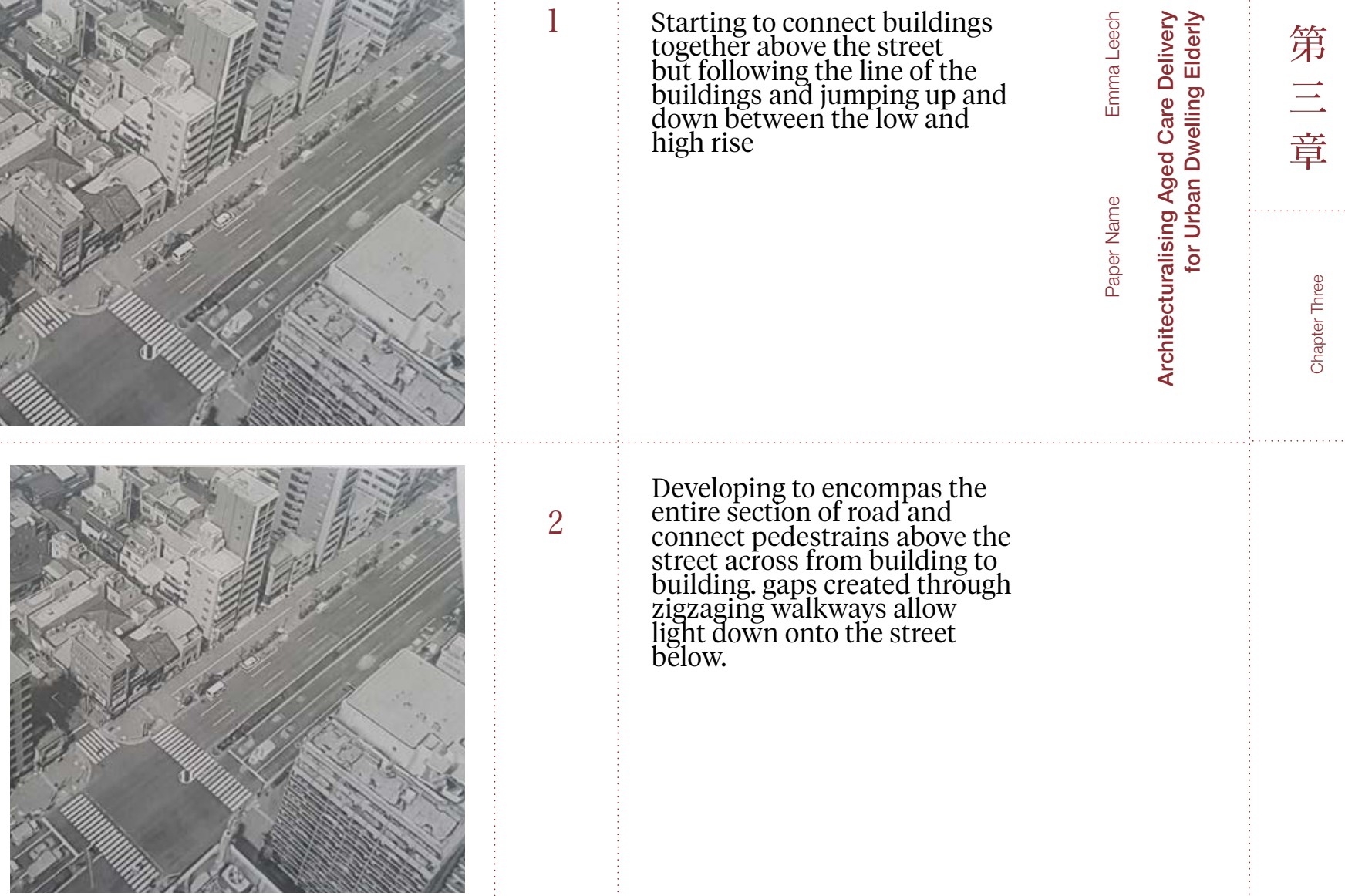

Developing to encompas the

entire section of road and

connect pedestrains above the street across from building to building. gaps created through zigzaging walkways allow light down onto the street below.

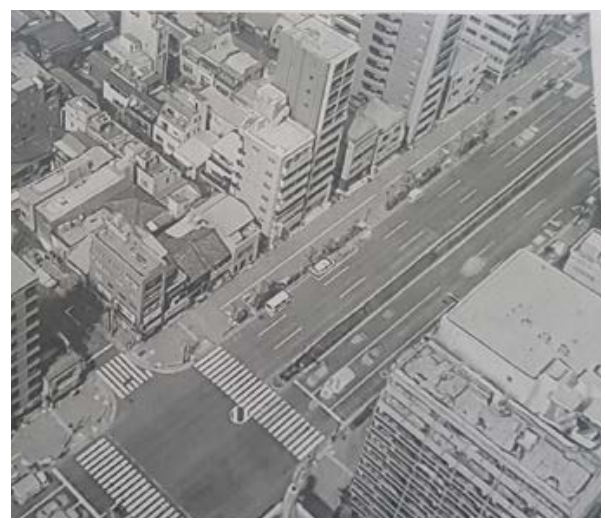

Attach circulation to the side of exisiting buildings that allow for public pedestrain movement up and down as well as across. creating effectively a predestrain plaza above the street.

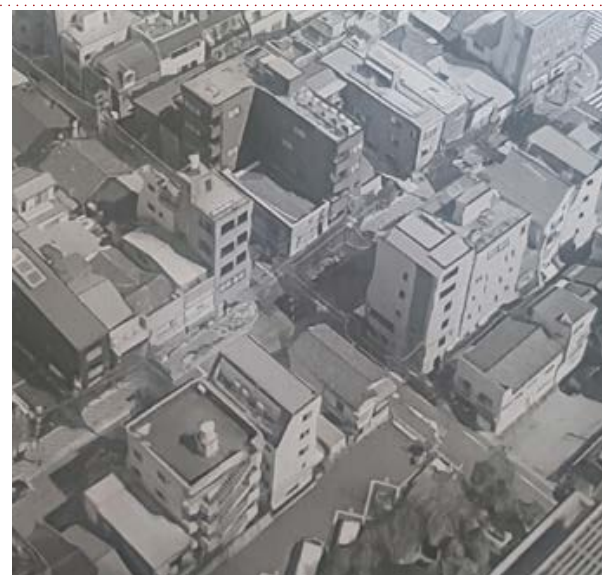

Bbridge like gesture through joining buildings together with lines, this drawing suggests a cross bridge but also vertical circulation. Less focused on how people are connected but the visual form development of the idea.

\footnotetext{
1 Authors own image

2 Authors own image

3 Authors own image
} 

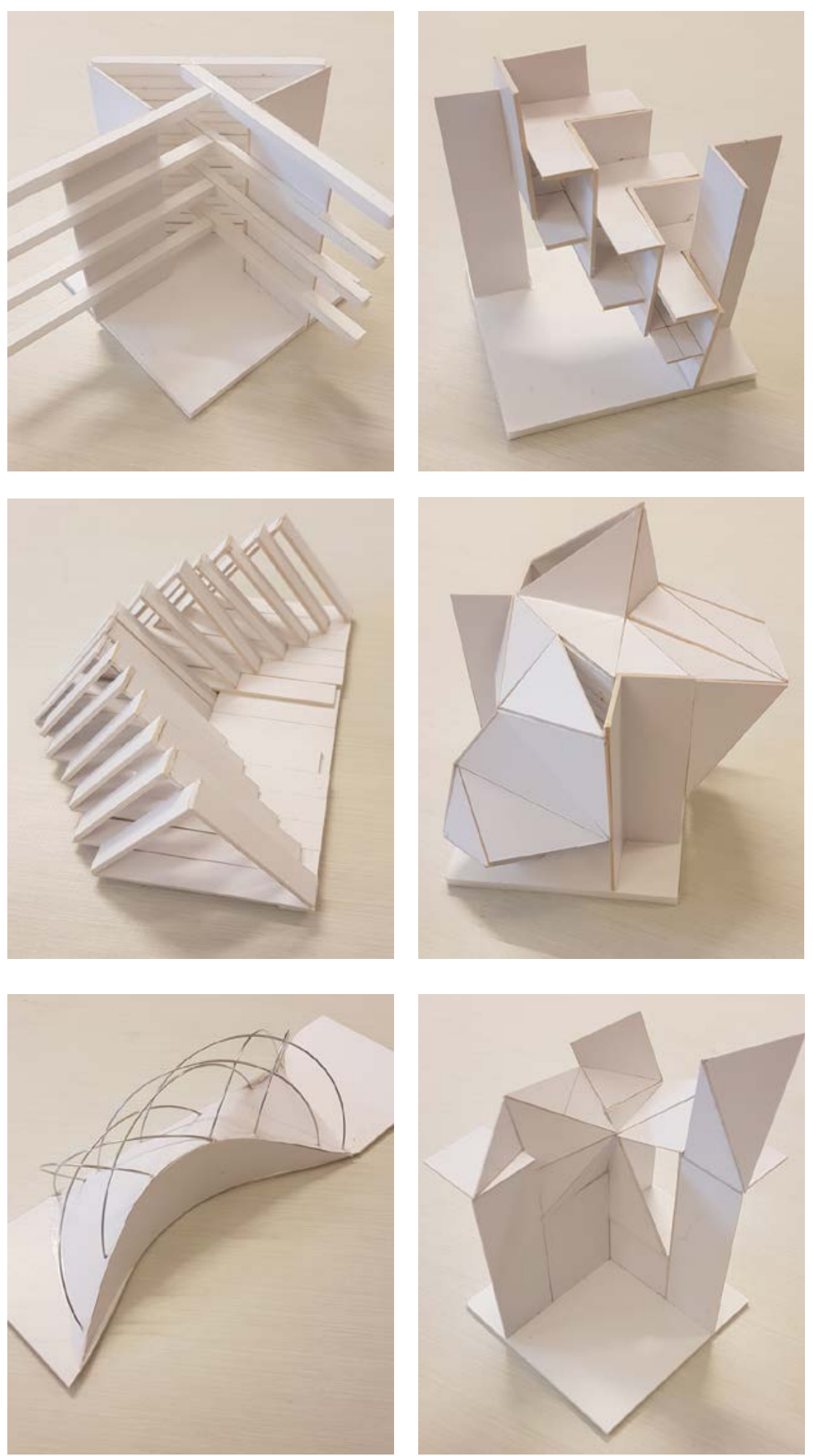

Initial model making consisted of testing design forms, shapes and ideas of connection in order to discover and create a strategy for a more formal expression of connecting across intersections architecturally. I was focused on the journey of a person within the model considering their path from one building to the next and how this design language would direct them through the space. experimenting with a range of forms and design gestures explored both how to cross the intersection and what it would look like to do so. 

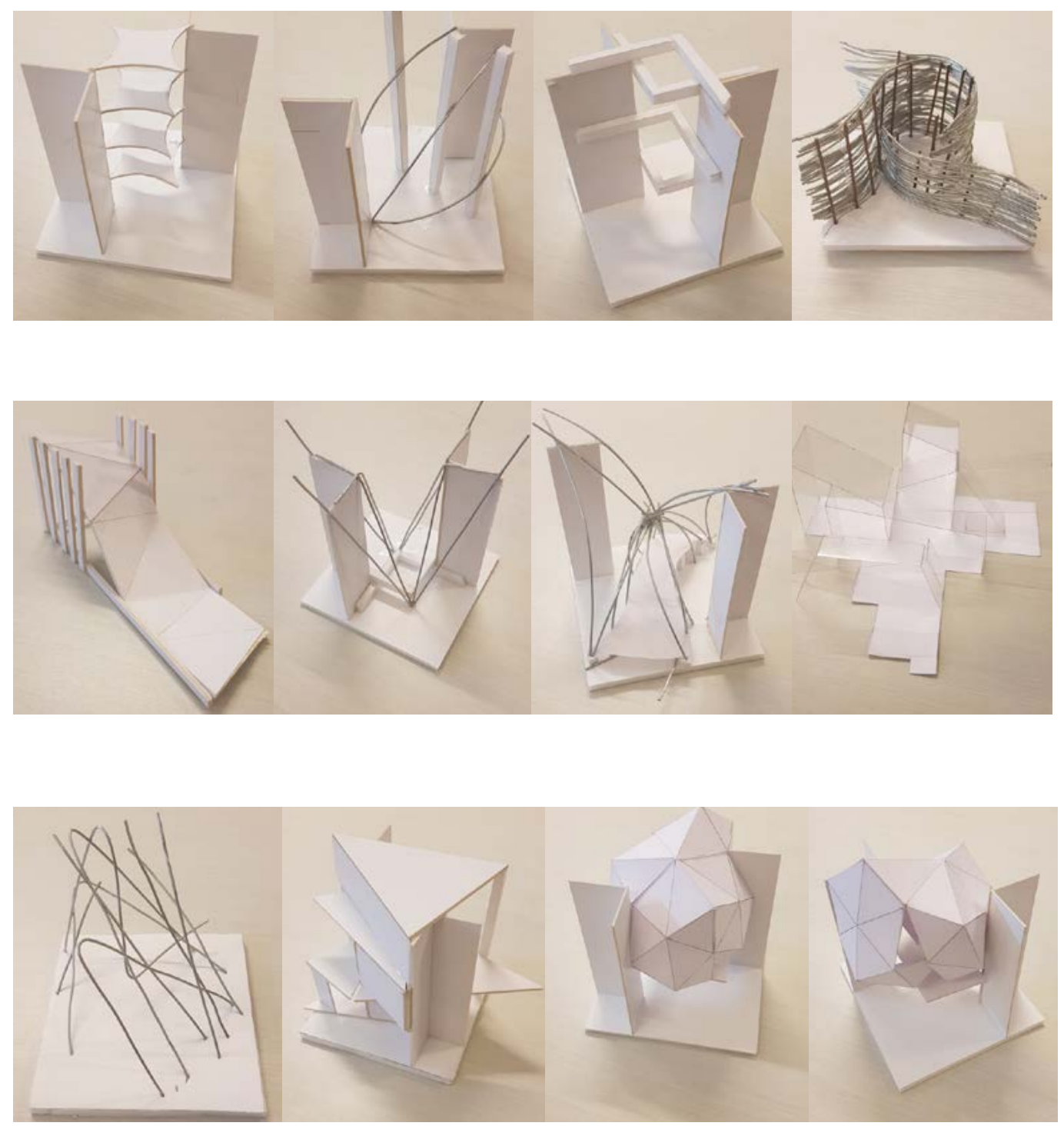

Through this exploration I determined three different ways to explore connection and ideas to further develop. Connecting exisiting buildings to a central hub created a building that i could design as well as the connection from exisiting space into the new design. Connecting pedestrains through bridge design connected other demographics and the street while helping elderly navigate their urban environment more easily. Building over the top of exisiting fabric creates alternative connection points separate of the street, creating a new network reduces the issues of getting care into urban environments and stops carers navigating the streets, two key issues within the literature. 

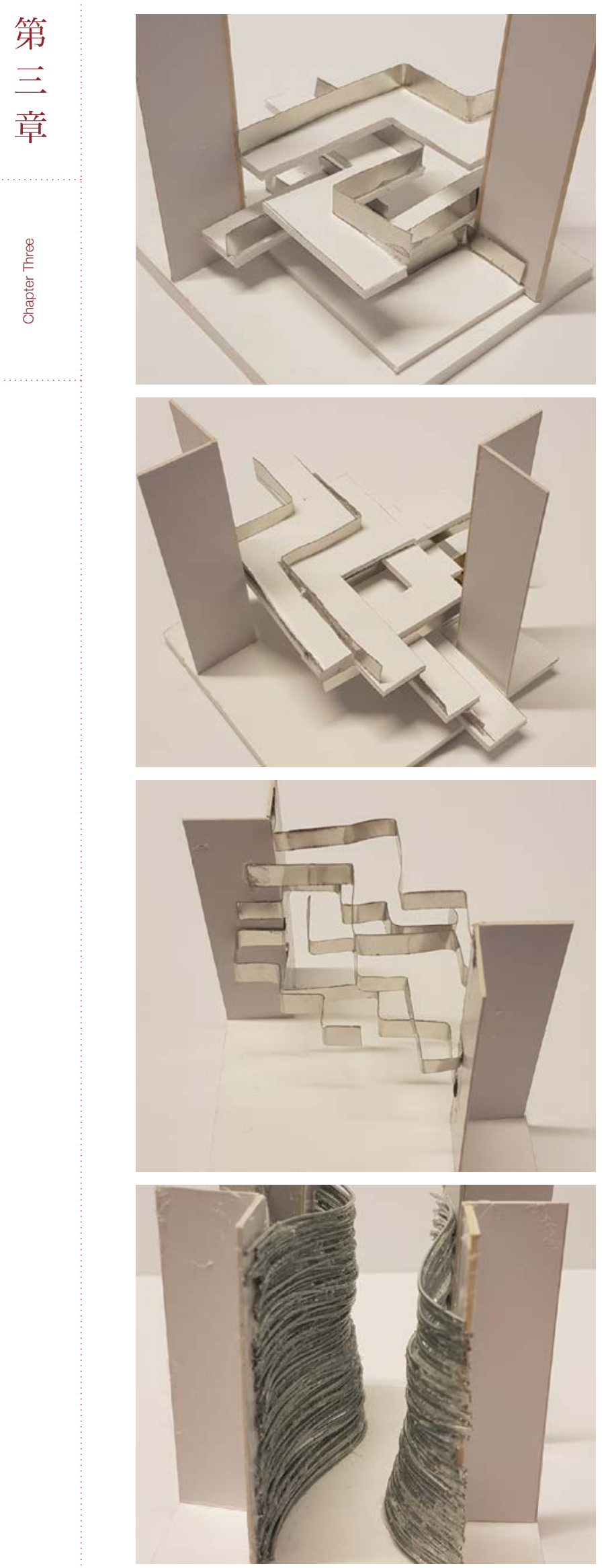

Highlighted further in these

model developments was

the physical connections

I could make between

buildings across an

intersection space, initially

using formal walkway

design langauage in the images above and slowly developing this language into something more

geometric and visually interesting. the triangle and diamond were key motifs created and explored here that I indended to take through into the final design. 


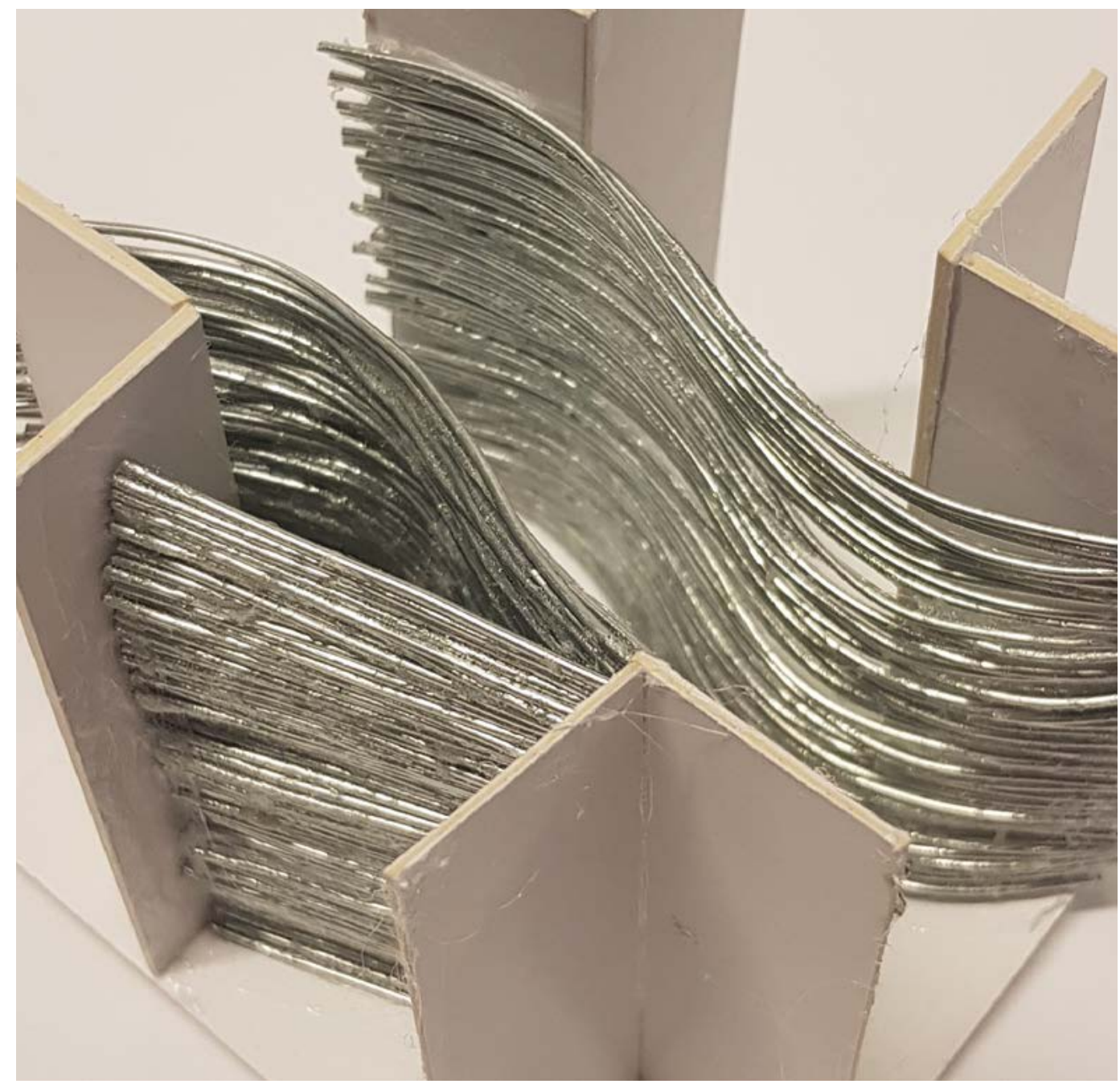

The characteristics explored in the model are key design drivers that $i$ want to take into the building design. Layering to this intensity creates drama and movement within the stillness of architecture and directs the eve through the journey of the space. simultaneous vertical and horizontal direction bring the viewer to a stop and make them look up within the model but are pulled to move forward during this same action. the engagement of the vertical and horizontal language at odds but harmoneous is another design element i want to create with the final design, as a powerful directional tool. 

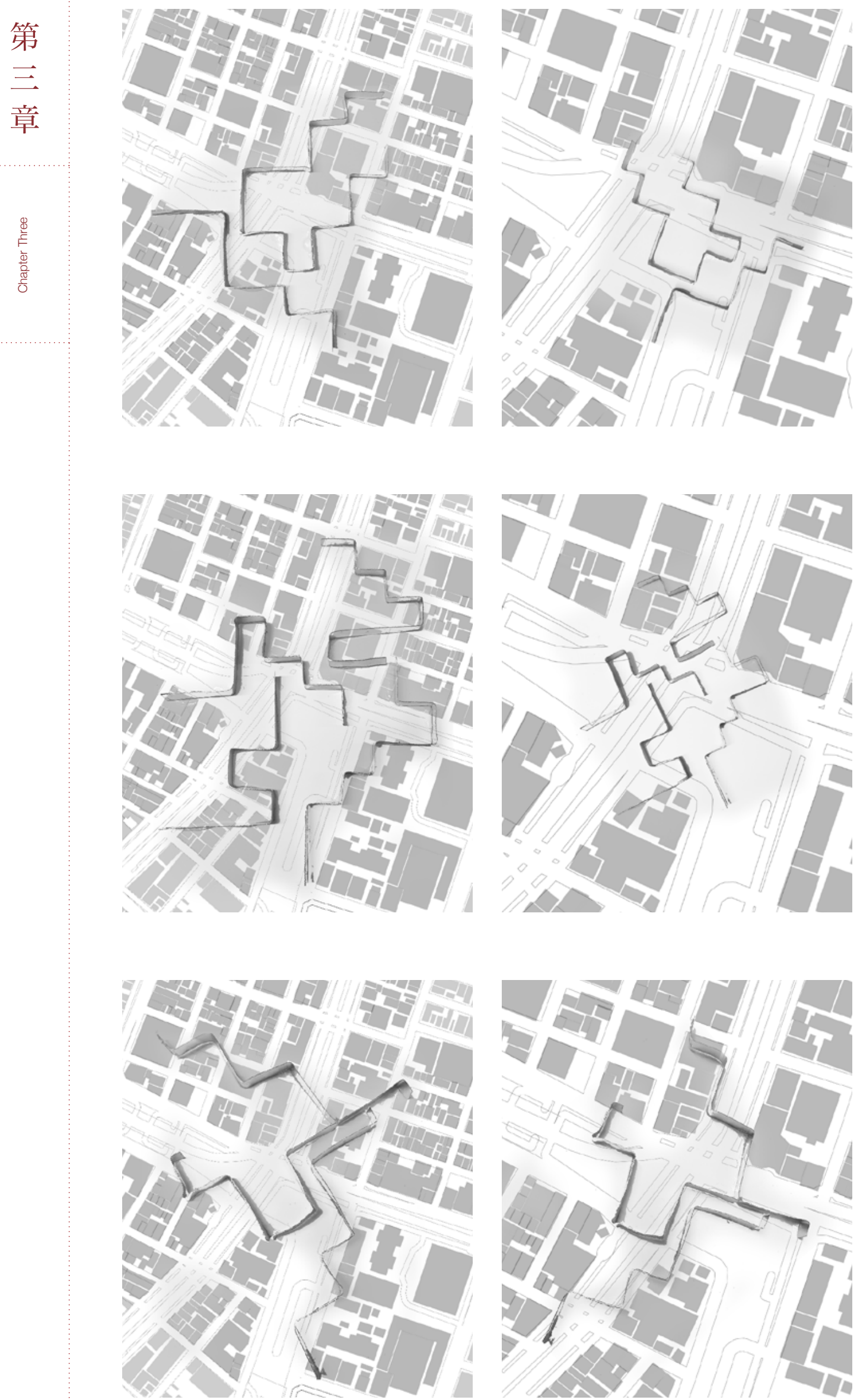

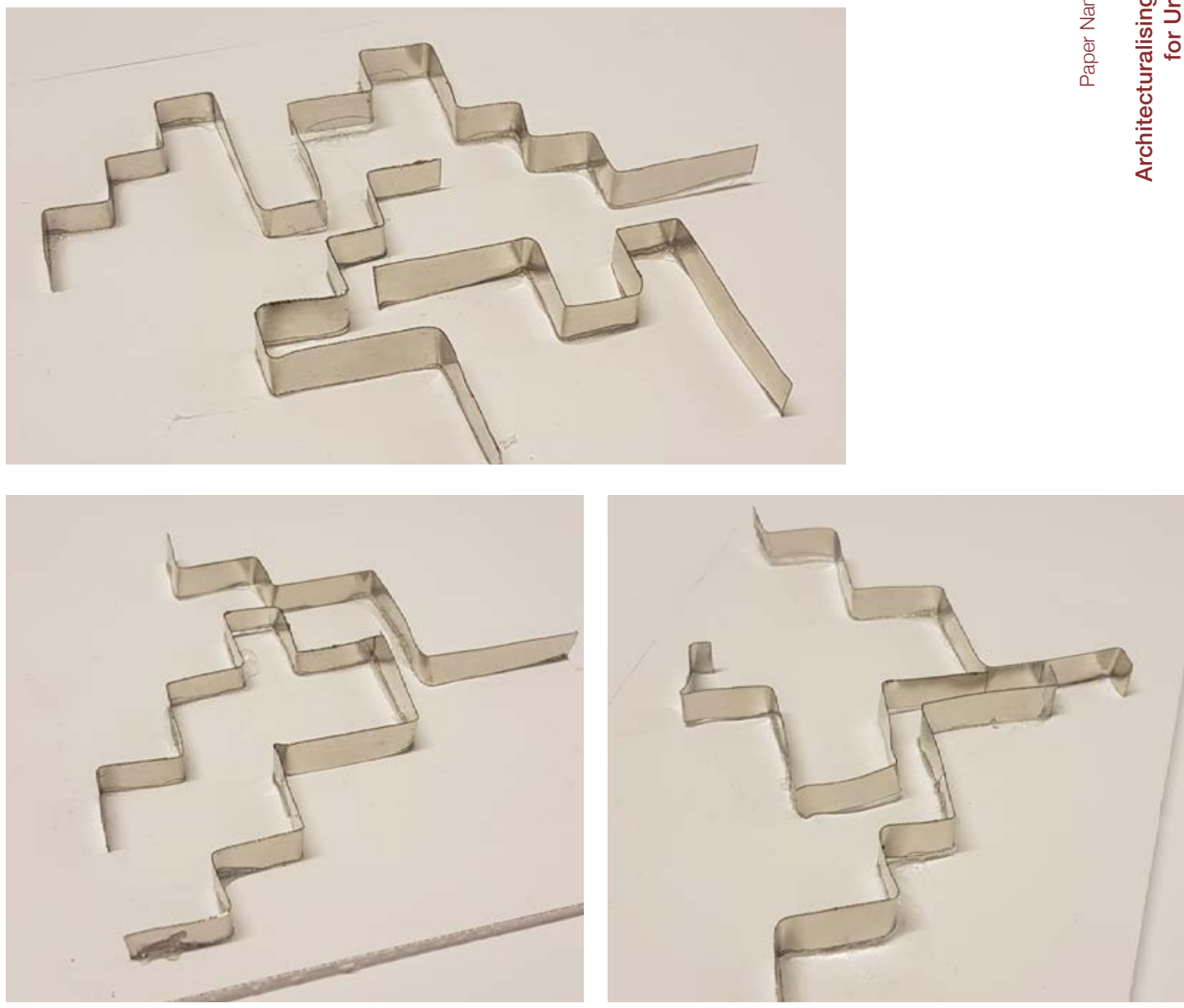

These models look at connecting the

surrounding area with amenities, I played with straight lines connecting amenity to residential and then modeled possible pathways with metal. This was then superimposed over the map of the city to both connect in a practical way and also express visually the connection I was trying to make. 

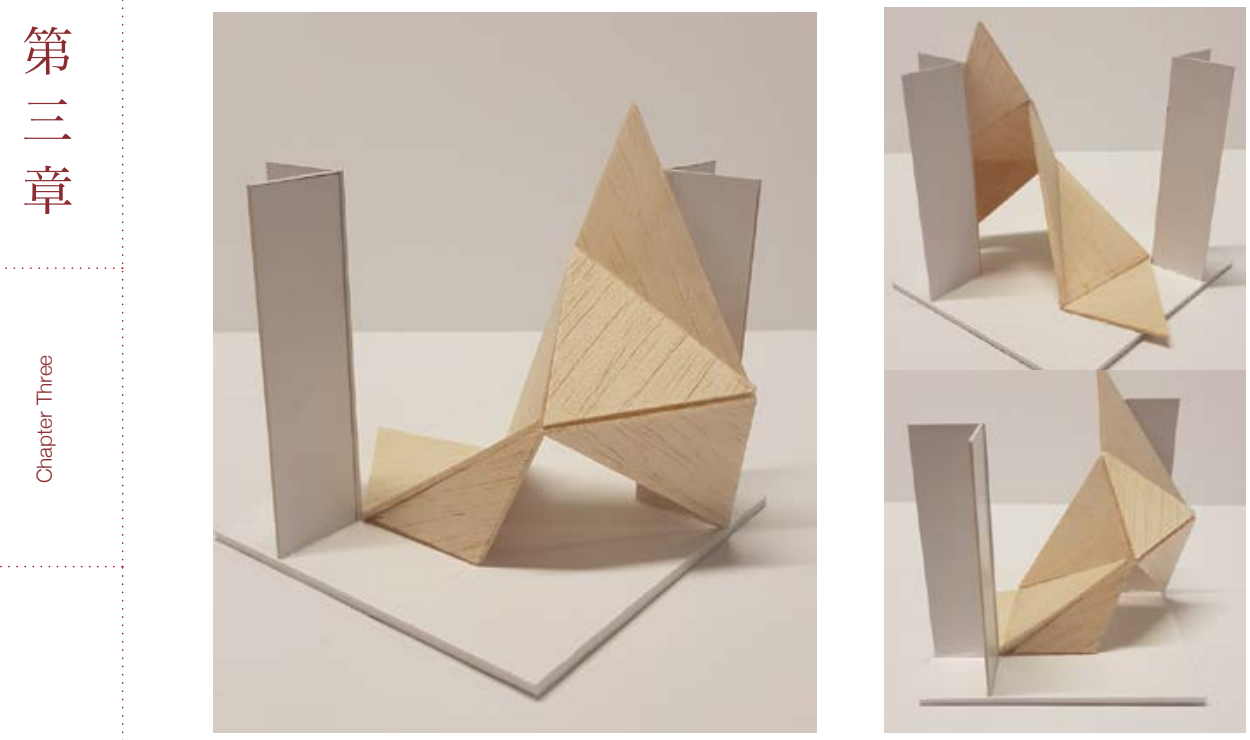

Geometric Exploration of bridge form: Exploring levels and connection from one side of an intersection to another directly across the middle
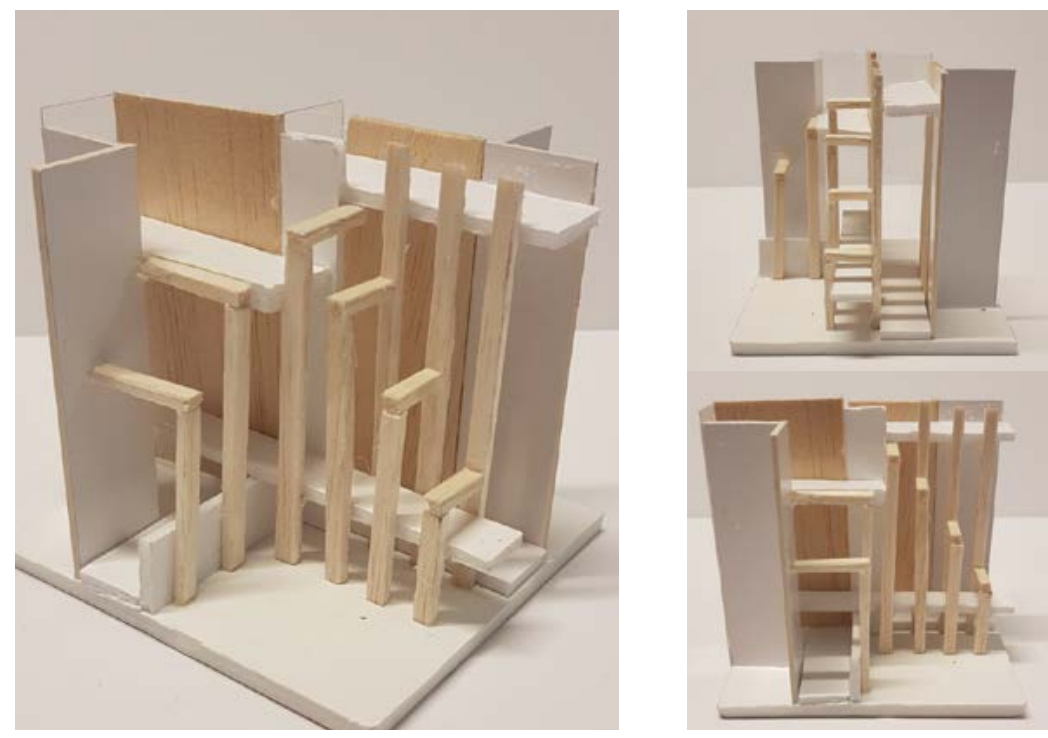

Still focusing on levels and connection but expressing these ideas in a linear way using straigh lines and $\mathrm{L}$ shaped forms
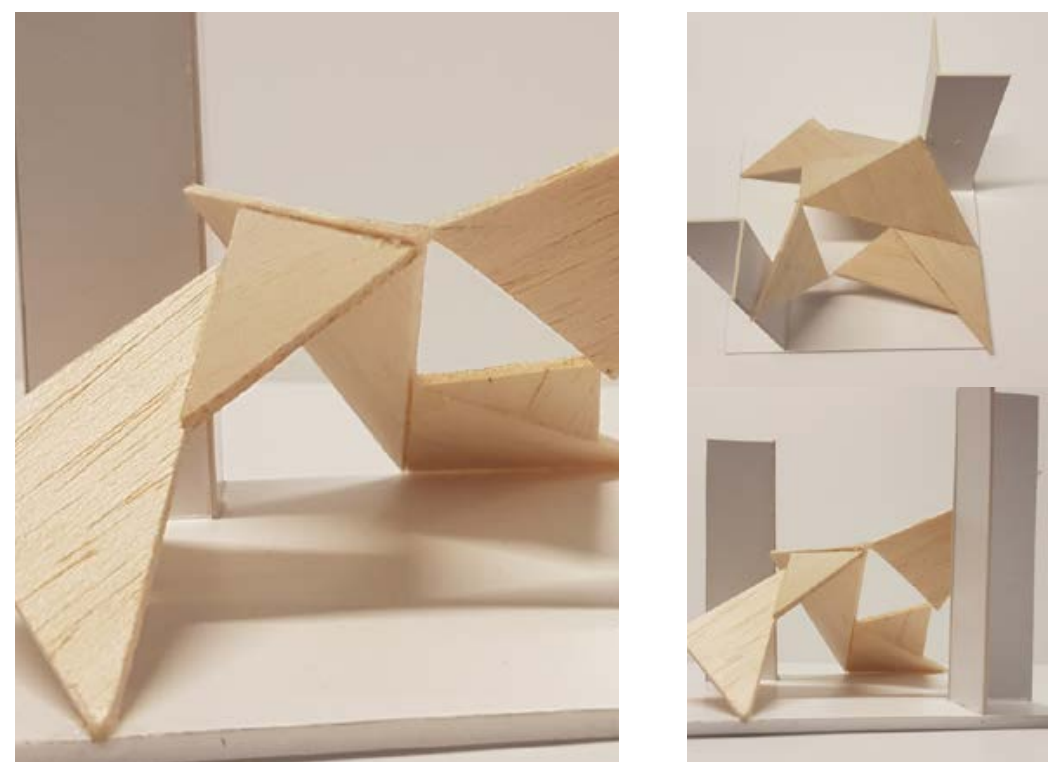

More explicit bridge shapes and starting from the street, connecting to the upper levels and then back to the street once again. introducing multiple pathways of movement. 


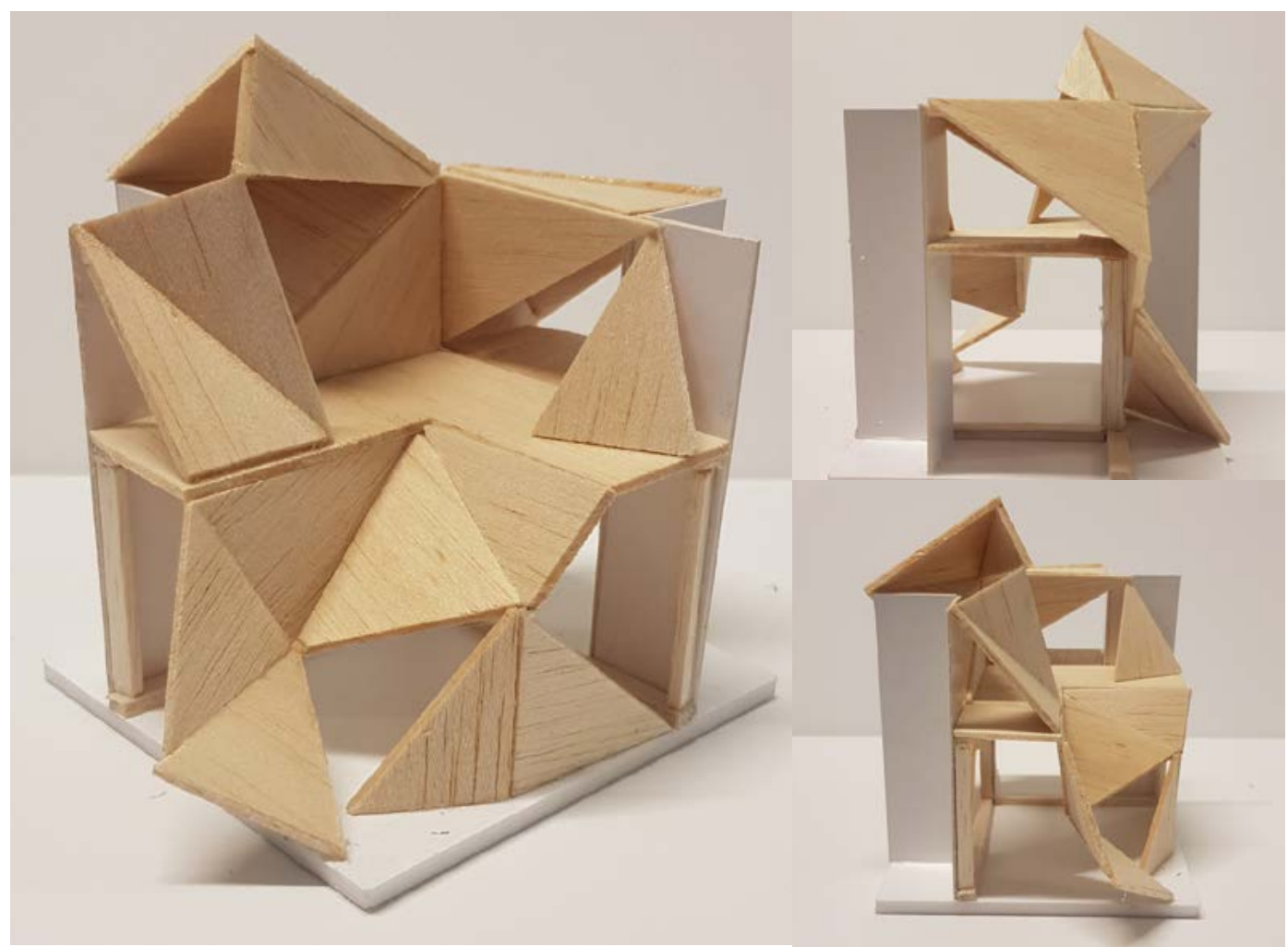

Beginning to explore building on top of existing built form whilst also still working with levels and connection between the street and upper levels of buildings. this model slowly steps itself up and is a more dimensional approach than previous models. creating facits of form able to break up programme.

Citation: All Authors own Image 


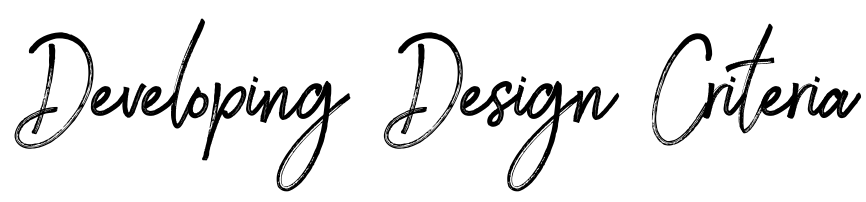

Throughout the physical models I was considering how to connect into elderly's homes and provide them with the care that they needed but I was also reflective on the research that emphasizes autonomy and ownership of ones space as key attributes to maintaining quality of life in older age and so that was always going to be a key driver for me that the design would be created with elderly in the driving seat, able to make their own decisions about their life and care. A connection to the community was also key, as the design would use urban space as well as be a means of connecting elderly to the outside world and making the streets easier for them to use. Including other demographics

\section{Does not encroach on the individuals space and is separate from the home.}

Adapable programme al-

2. lowing unique adaptions to missing ammenity

3. Include other demographics in the design, whether that is through pedestrian walkways, retail, or essential medical services for anyone to access. Making a space that from the outside did not segregate itself, as only a space for the elderly would mean a more seamless and meaningful connection into the surroundings.

From consideration of literature, currently problems with aged care and through initial drawing and models the six design criteria reflect the ideas that I want to communicate through this design outcome, they drive the project to consider the thresholds between spaces and act to connect people.

\section{Easy access for aged care workers who will be the main users}

Non intrusive on the urban

5. street aligning with Janes Jacobs theories on good urban design 6. Providing all healthcare
needs in one place. 



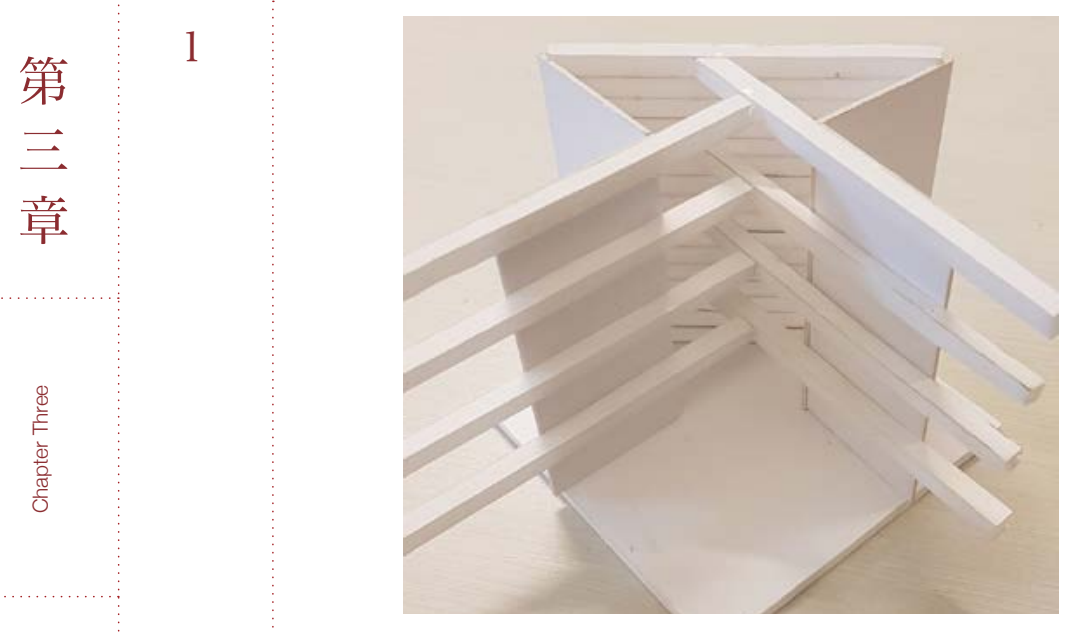

This model focuses

on connecting bridge

walkways between

exisiting buildings and

a new building through

interconnecting pathways

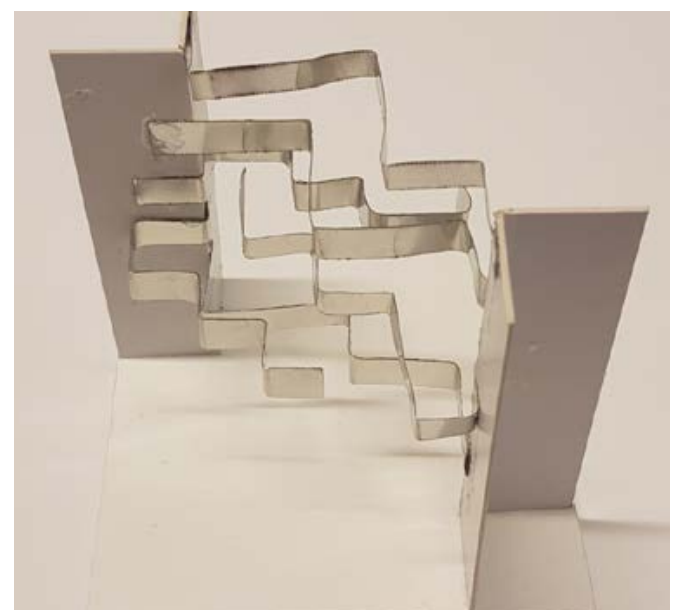

This model connects

multiple levels of exisiting buildings together

focusing on how to cross an intersection at multiple heights

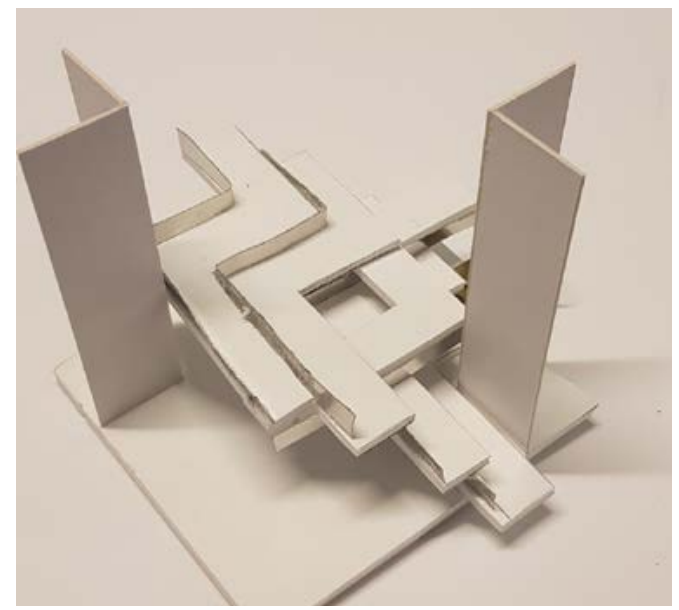

This model creates

stepping height across an intersection exploring how to connect the street to exisiting apartments above street level

DOES NOT ENCROACH ON THE INDIVIDUALS SPACE AND IS SEPARATE FROM THE HOME.

Determining model form finding that best relates to different criteria, understanding what contributes to this to take key attributes and ideas into developed design.

1 Authors own image

2 Authors own image

3 Authors own image 


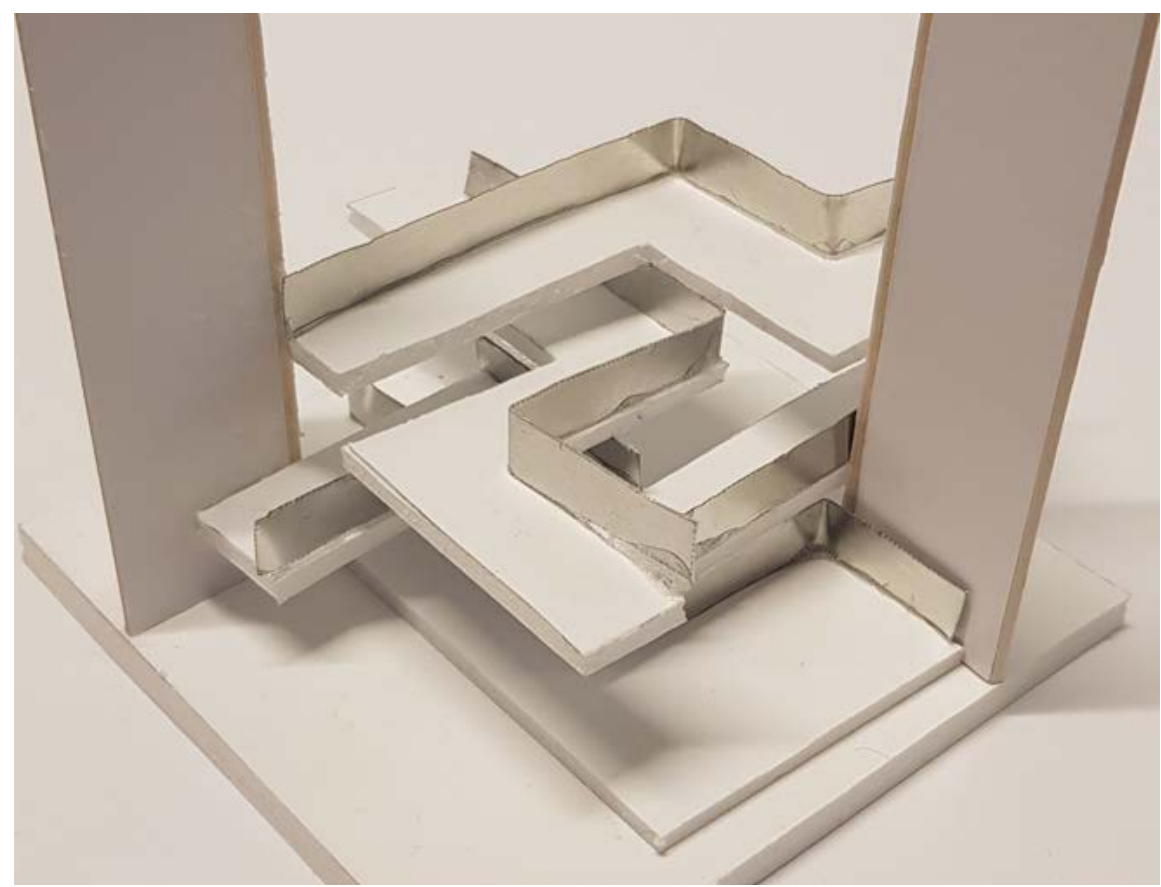

These models discover different ways to connect buildings together to integrate the social spaces of the street with the buildings above. They also think about the space between and beside the walkway. Integrating the criteria of other demo graphics, through consideration of pedestrains and their interaction with the spaces below, inbetween and above the abstracted walkway forms. This allows the community to be connected to the space and therefore less recognisable as an intervention for elderly. 


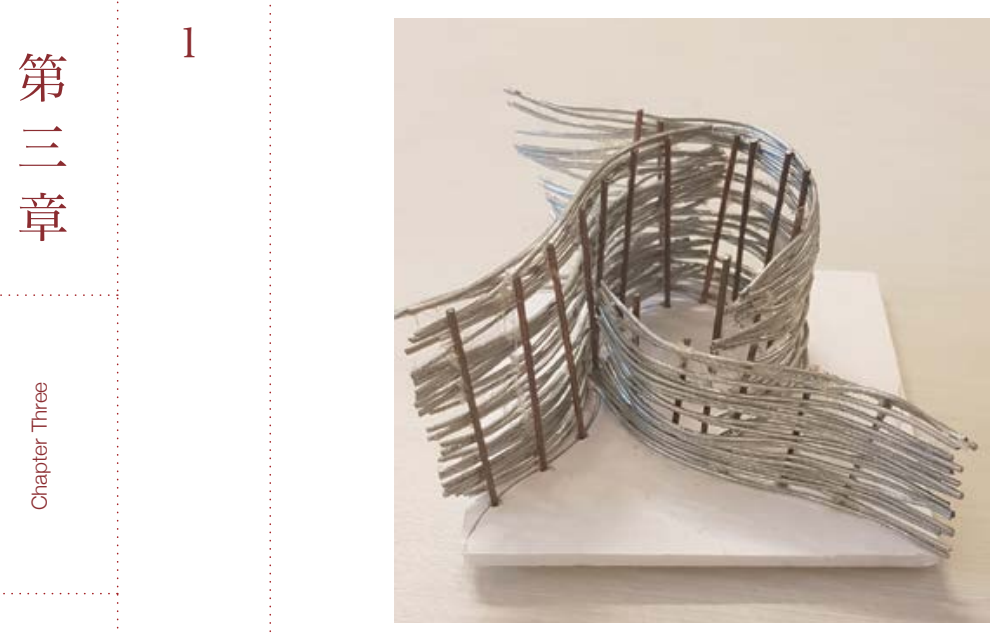

Multiple points of entry and exit as well as the circular and contstant cirucling state makes it easy for mutliple programme to be utilised.

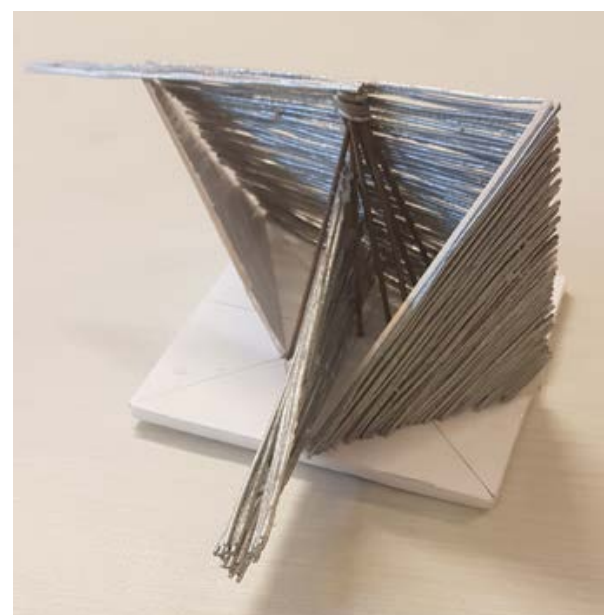

The function of the form is not obvious and the intention is the creation of more experimental form to begin to create a design lanugage

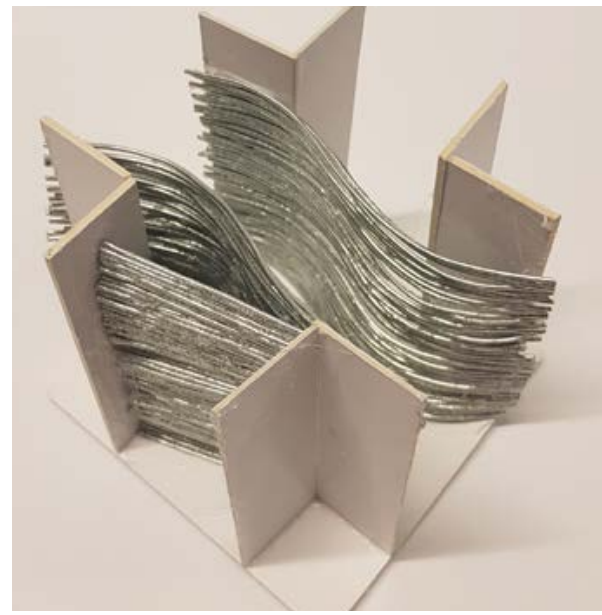

The thougherfair created through this model makes it adaptable to traffic in surrounding area

ADAPTABLE PROGRAMME TO AMENITY GAPS IN SURROUNDING AREA

Determining model form finding that best relates to different criteria, understanding what contributes to this to take key attributes and ideas into developed design.

1 Authors own image

2 Authors own image

3 Authors own image 


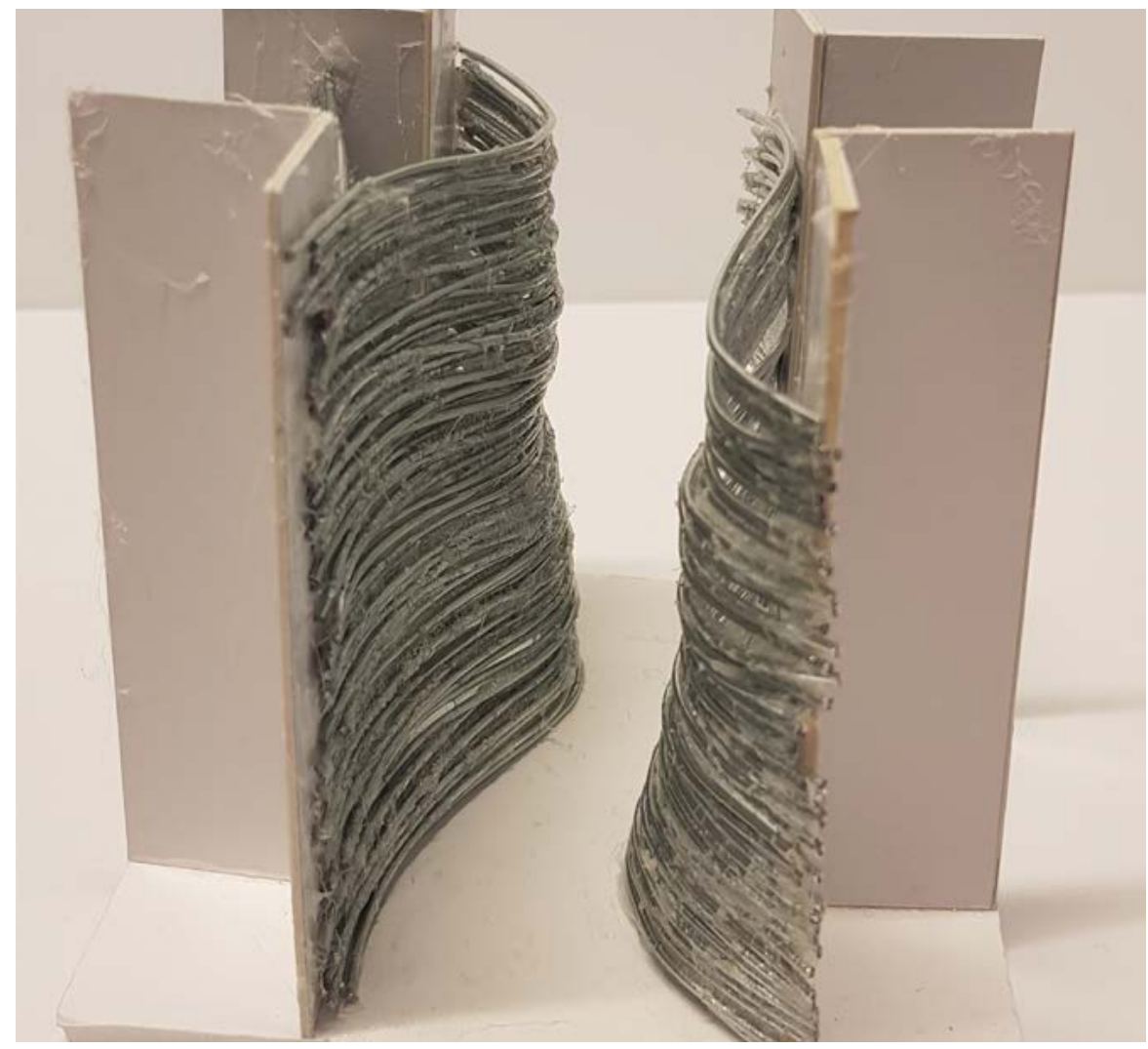

Ambigious programme these models focus on form finding and material, they can be adapted into any site with a range of programmes Integration between user adaptive programme and inclusive of other demographics looking at integrating walkway/ pedestrain traffic through pedestrain hub, using materiality to exagurate this integration. 


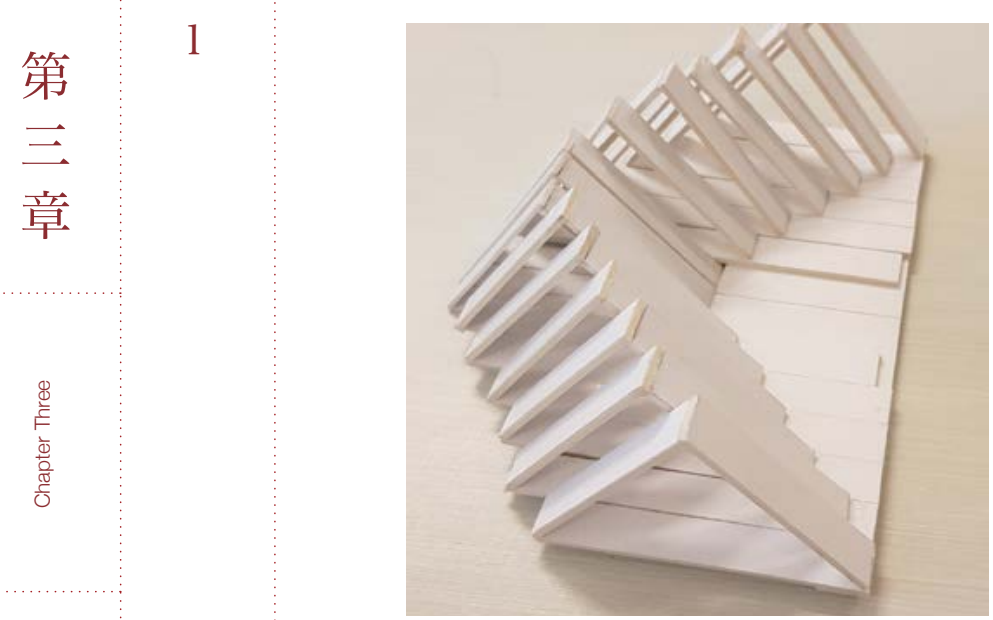

Other demographics are easy to include in these designs because they are situated across the intersection and therefore have pedestrain interaction and have layers of building to incorporate different programmes

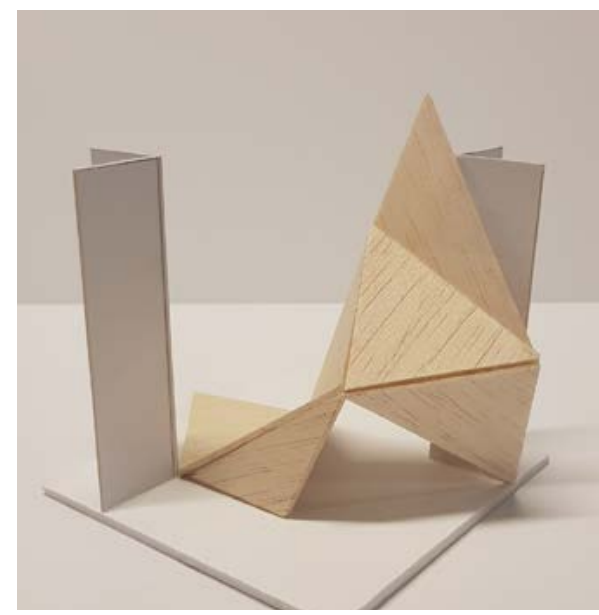

this model focuses on the pedestrain as the main group to integrate into the scheme as this encompases a large range of demographics in particular different ages completeing the same movement. This model provides pathways for the pedestrain through the built form of the hub to have create the idea of an indirect social space.

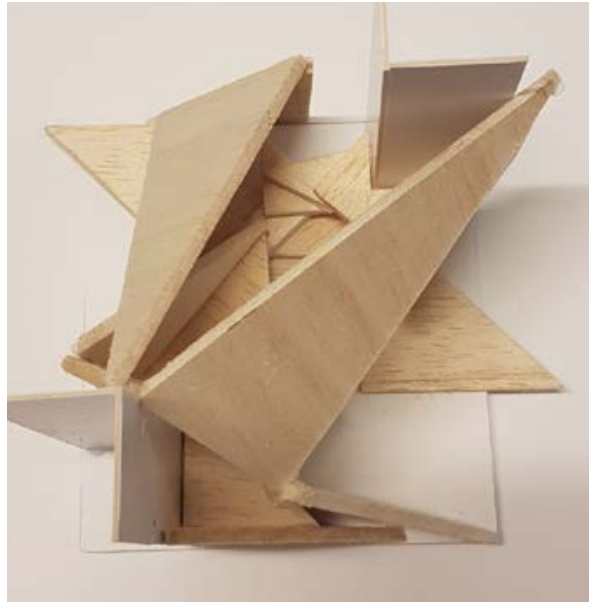

This model focuses on a pedestrian bridge creating the posiblity for multiple pathways both across and layering above the intersection space. integrating the inclusion of other demographics and non intrusive to the lives of elderly with a primary pathway with and secondary choices.

INCLUDES OTHER DEMOGRAPHICS

Determining model form finding that best relates to different criteria, understanding what contributes to this to take key attributes and ideas into developed design. 


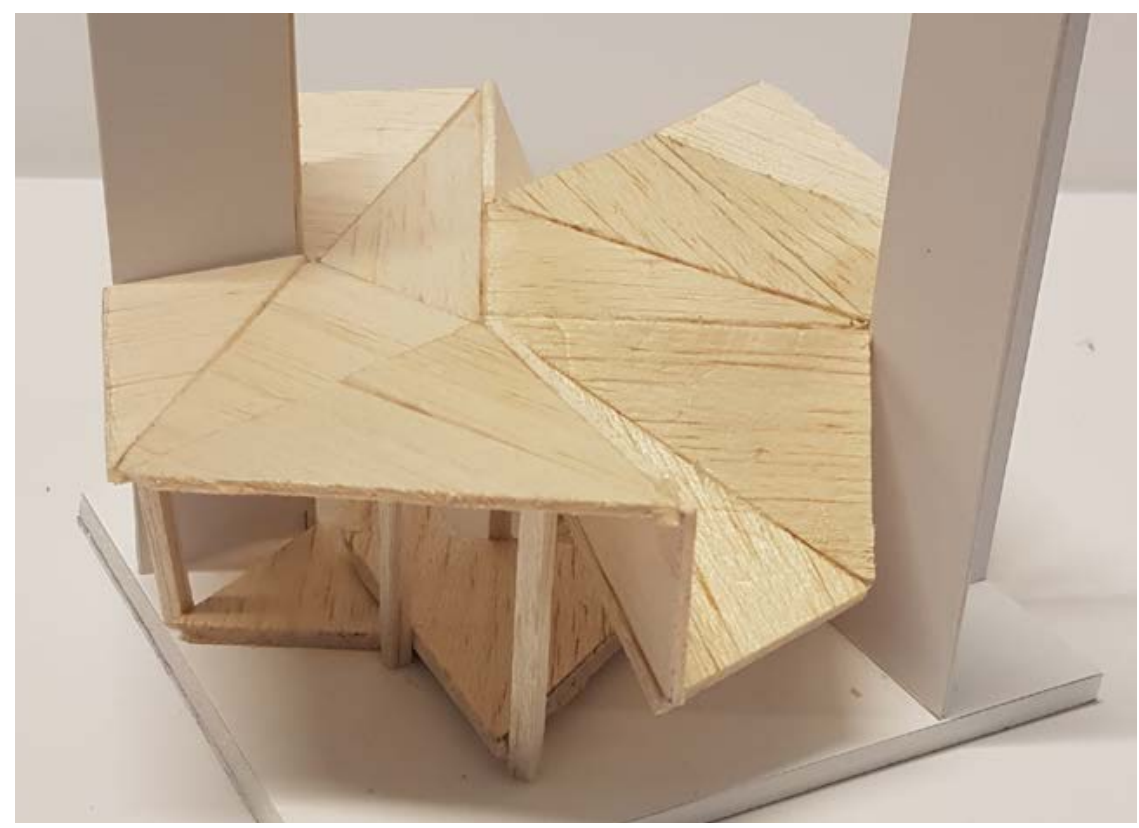

This model gives the user two choices either walk over or under the canopy, which becomes a place to sit, a place to meet people and becomes a space of urban commans these ideas integrate with the ability for a flexible programme combining 3 different criteria points 


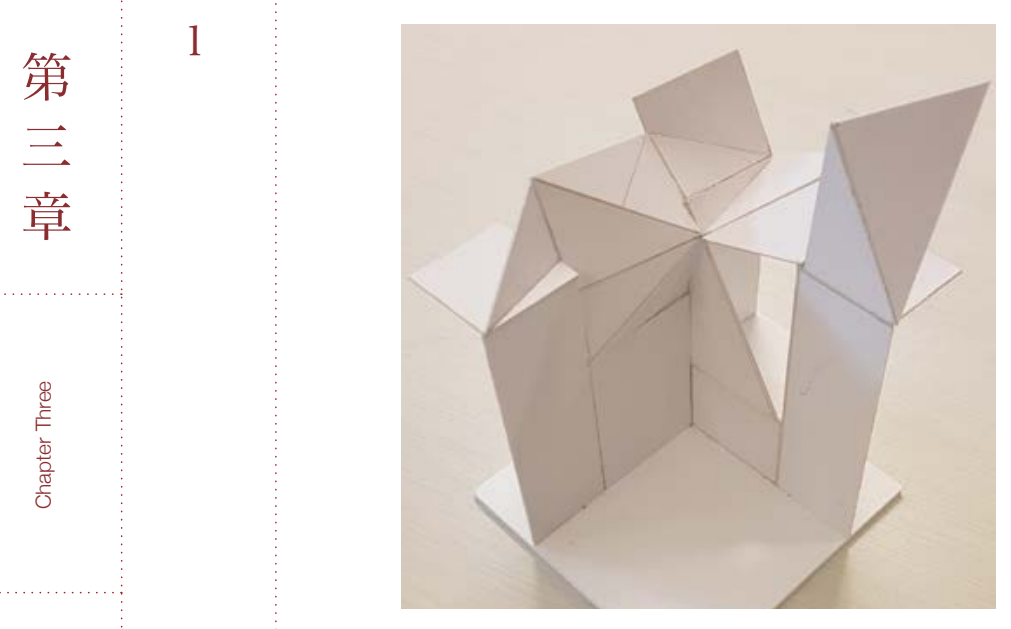

Building over the top of existing building fabric to directly link in with the homes of the elderly as well as providing larger spaces for social space or more detailed care.

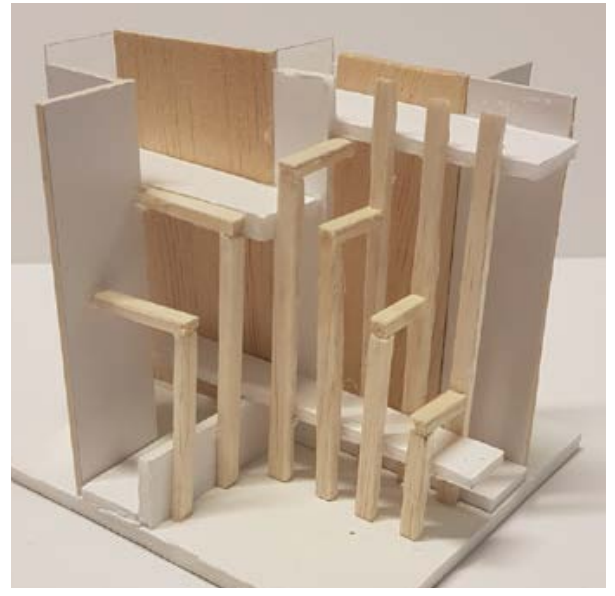

Working with a different design aestheitc using more linear structure for building on top of exisiting fabric which is more true to the aesthetic of the city. Still differentiating itself from the buildings below through material but integrating exisiting shapes. This model also looks at how to integrate other programmes by using both pathways and larger spaces and exploring a layering approach

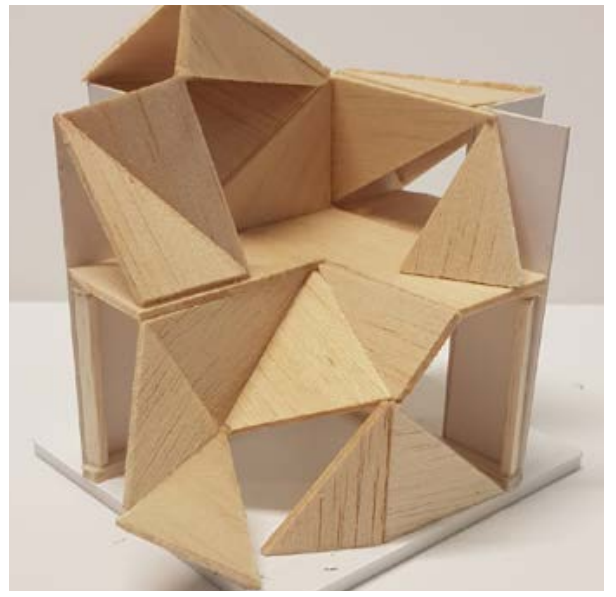

Works on the idea of building on top of exisiting building fabric but with consideration of the site this model attempts to connect also to the street cascading down to street level. this integrates greater access for aged care workers but also provides access for general pedestrains and provides the ability for other programmes to be considered as well as pathways through different buildings

EASY ACCESS FOR AGE CARE WORKERS

Determining model form finding that best relates to different criteria, understanding what contributes to this to take key attributes and ideas into developed design.
1 Authors own image

2 Authors own image

3 Authors own image 


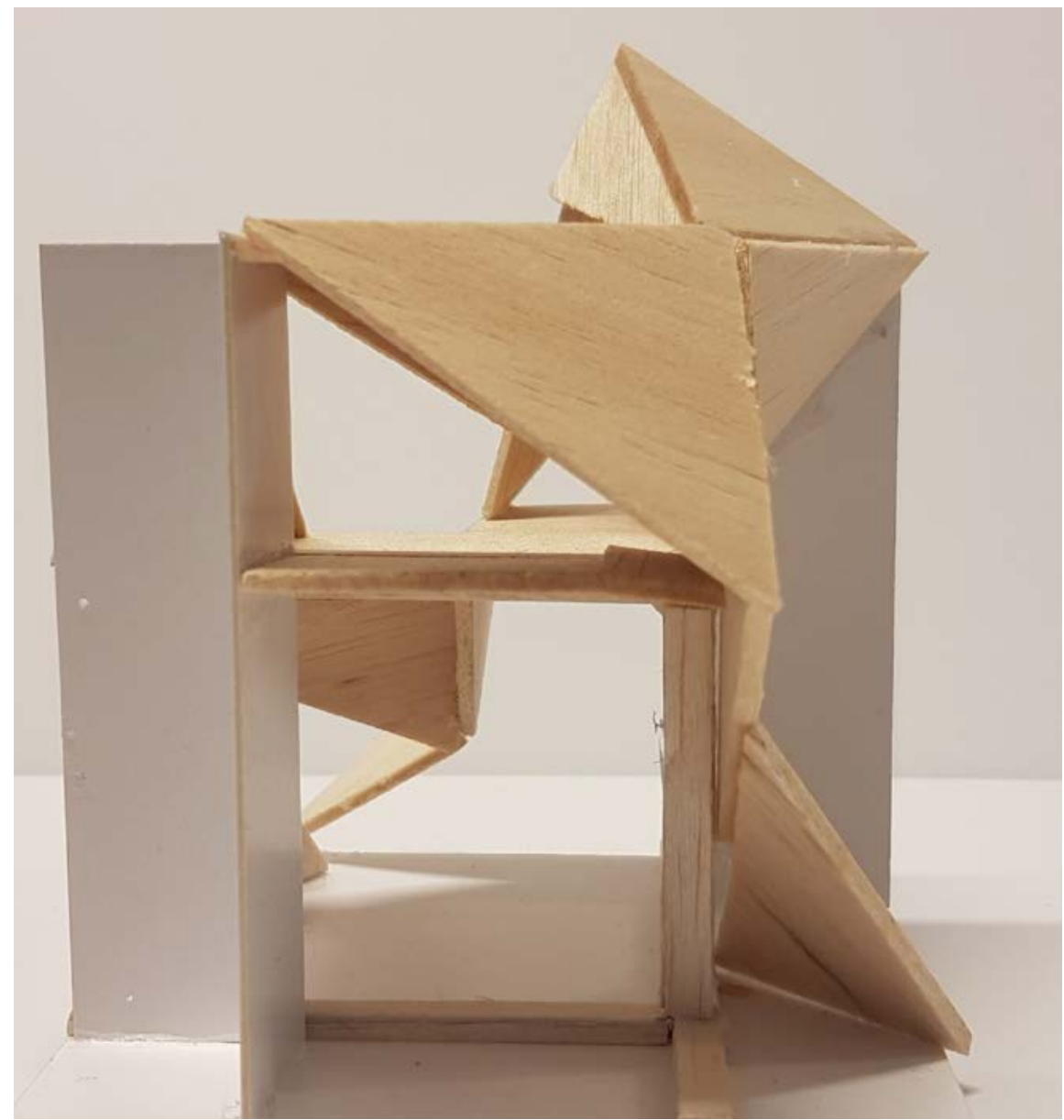

This model gives the user two choices

either walk over or under the canopy, which becomes a place to sit, a place to meet people and becomes a space of urban commans these ideas integrate with the ability for a flexible programme combining 3 different criteria points 


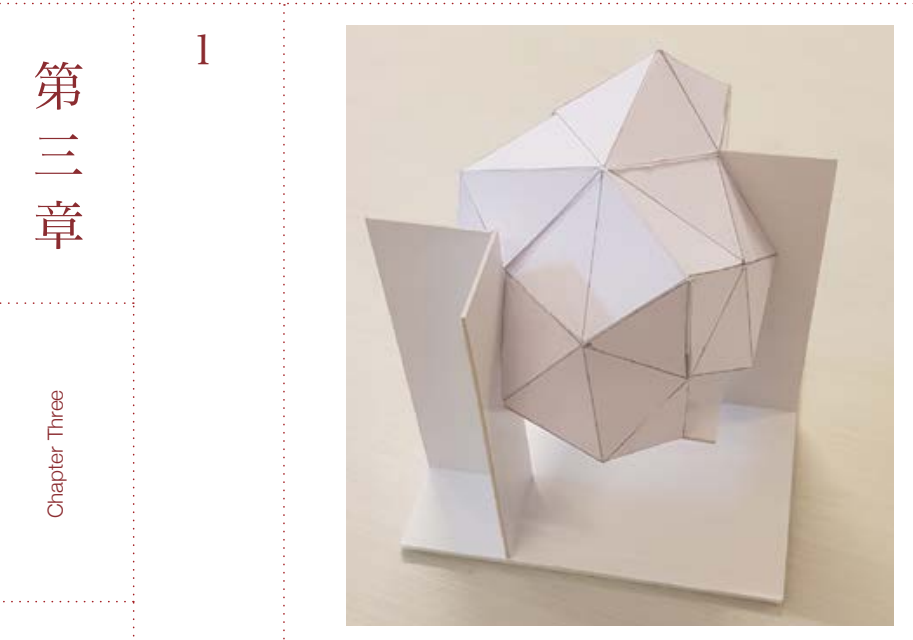

Inspiration for the intersection was to connect healthcare services into the 4 corners of the block with enough floor space to accomidate multiple programmes

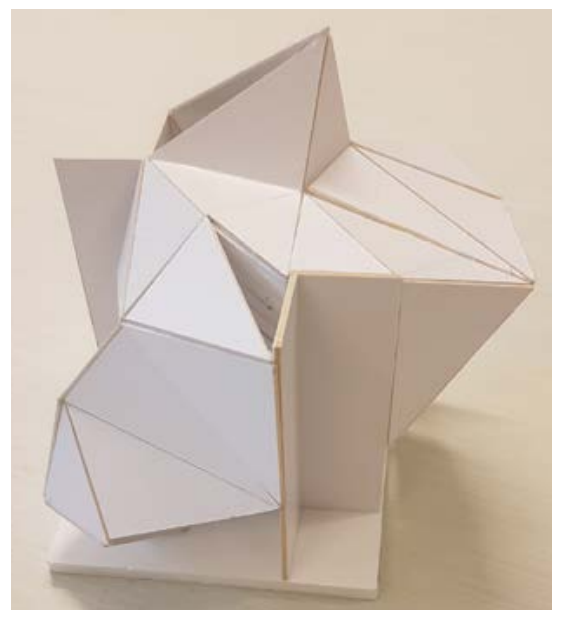

The abstract nature of this model means that it can be understoof as either pathways or as the outline of a possible hub building form which could containe all health care needs in one place.

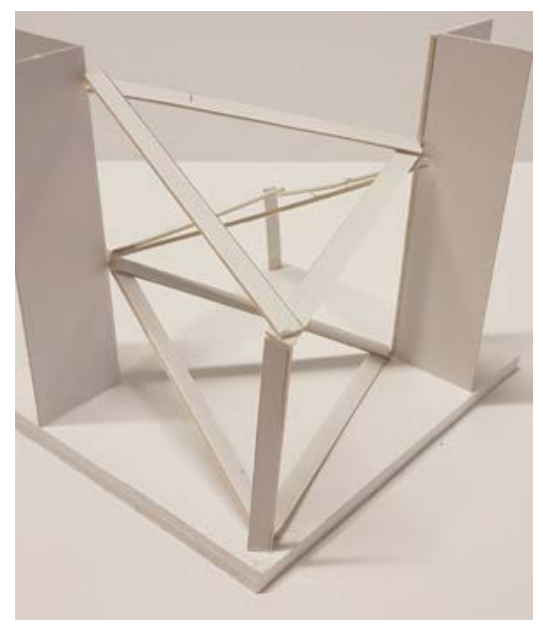

This roof form can be used for multiple programmes including as the roof for containing all healthcare needs in one place below. This considers multiple criteria including multiple demographics programmes and non intrusive. It also has the ability to provide the 3 key elements medication, meals and human contact as well as working with the exisiting urban fabric to increase uder experience.

\section{ACCESS TO ALL heALTHCARE NEEDS IN ONE PLACE}

Determining model form finding that best relates to different criteria, understanding what contributes to this to take key attributes and ideas into developed design. 


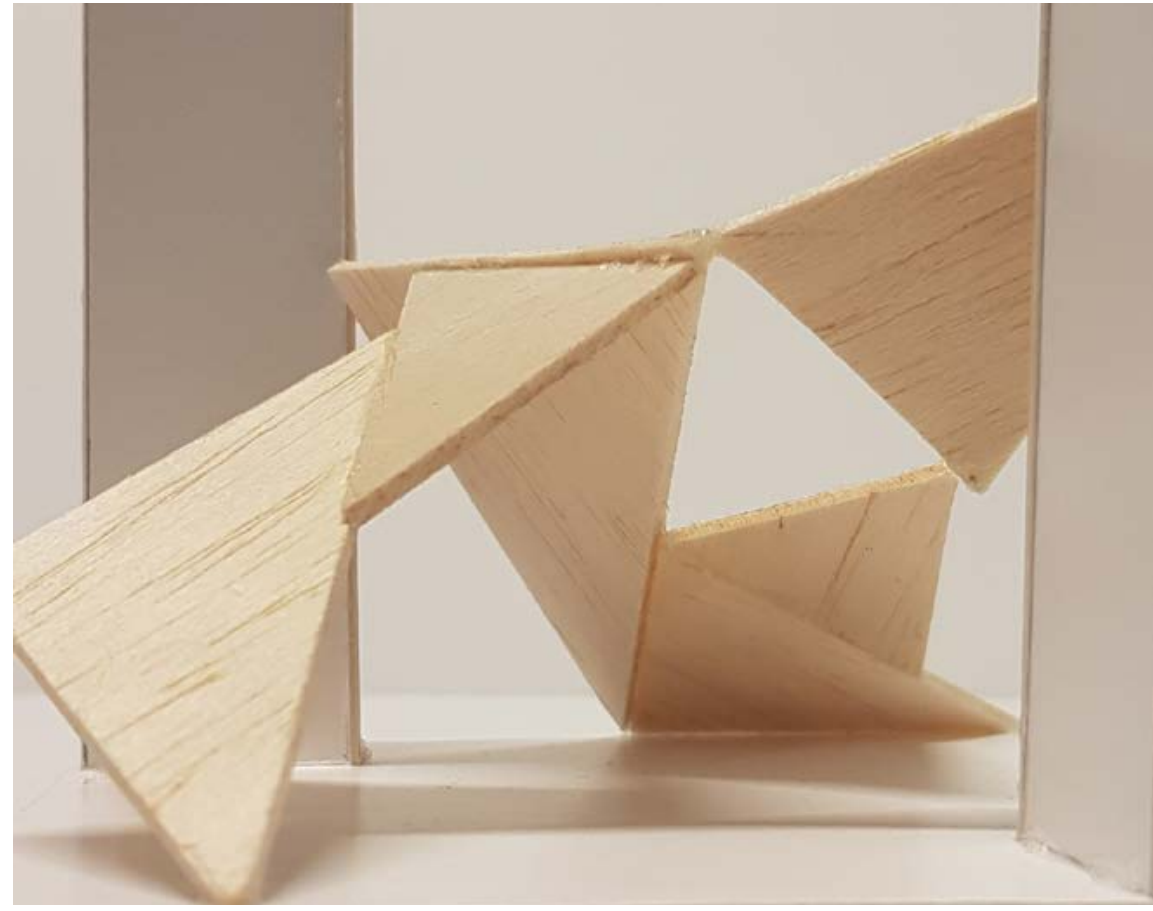

The layers of this model enable both pedestrain movement and the potential to contain all healthcare needs in one place, instead of one ambigious space this separates movement and larger open space allowing for a more flexible programme as well as including other demographics. 


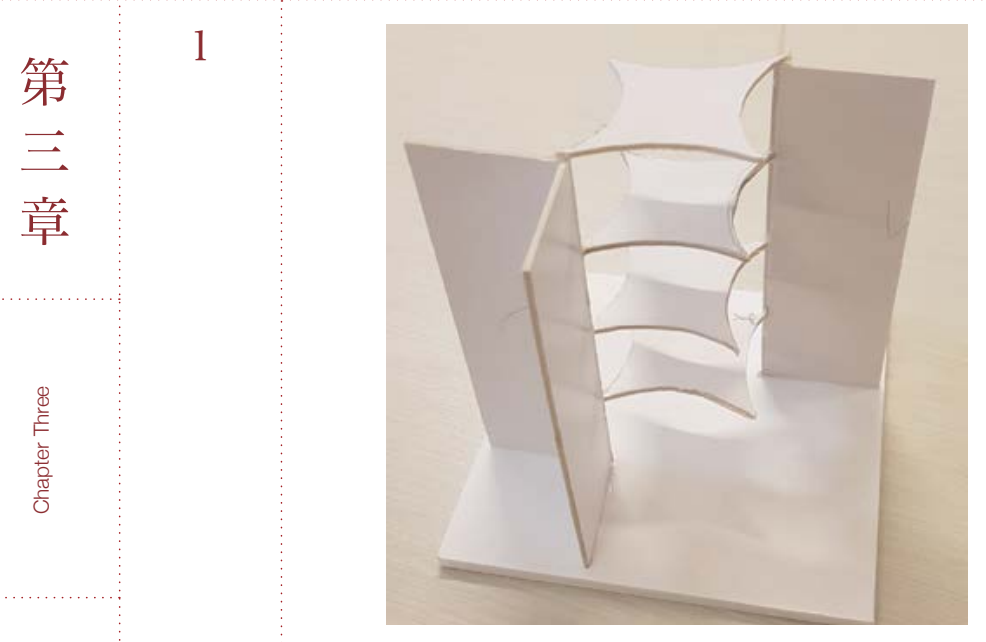

Focused on a different kind of pedestrain user than the street with a focus on access for carers and improvement/ maintance of mobility for individuals. Particularly who wouldnt be able to use/ interact with the street.

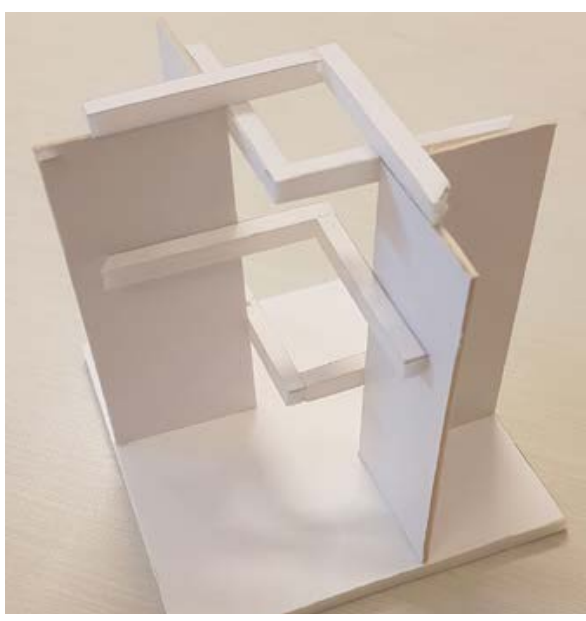

Delicate design language can reduce the intrusive nature of an intervention on the urban environment whilst also improving access to the city for elderly people. this model considers the urban envrionment criteria as well as intrusiveness in elderly lives and including other demographics

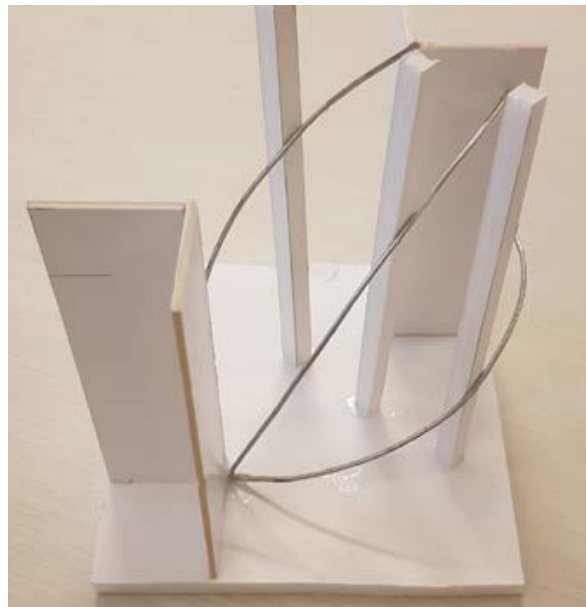

Enhancing exisiting pedestrain movement and use of the space will only add to the urban space already established, therefore large design gestures can be used to highlight and take advantage of this whilst also improving access to the space and activity for elderly. these models integrate this idea of gestures

NON-INTRUSIVE ON THE URBAN ENVIRONMENT

Determining model form finding that best relates to different criteria, understanding what contributes to this to take key attributes and ideas into developed design. 


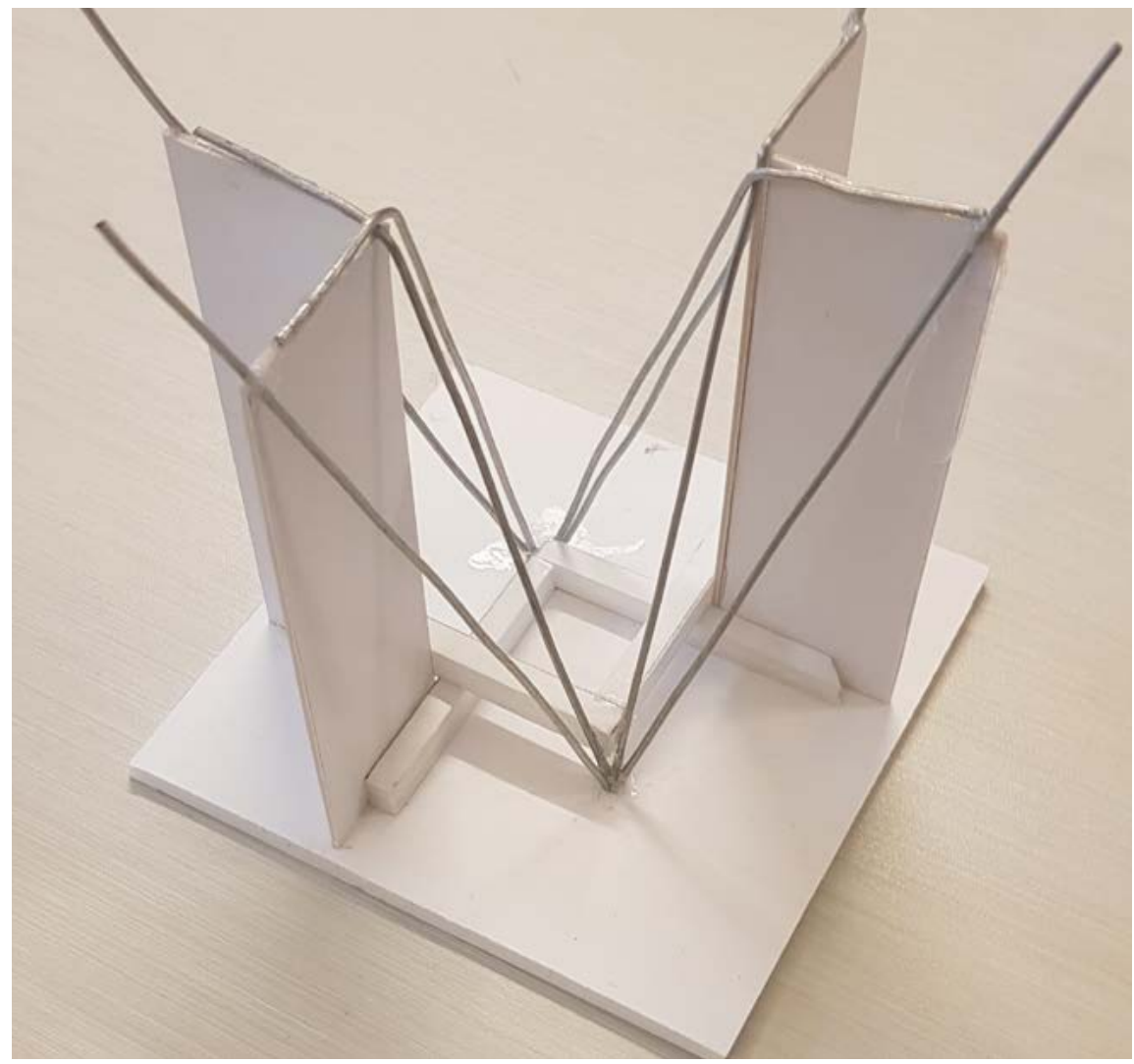

Using different visual aesthetics than the previous model it also enhances exisiting pedestrain movement and use of the space will only add to the urban space already established, therefore large design gestures can be used to highlight and take advantage of this whilst also improving access to the space and activity for elderly. these models integrate this idea of gestures 
The design experiementation with models, development of crtieria and backward testing of this criteria provide not only crtieria to test the final design but also develop a scope and brief to begin further development and define the project. This also develops the research question to explore through this design research and creates objectives for how to answer this question.

\section{RESEARCH QUESTION}

Can architecturalizing aged care delivery and facilitating an urban environment where people can live and die in their own homes, responding to the physical and social separation of elderly, improve psychological well being compared with current models and allow elderly to age positively?

\section{RESEARCH OBJECTIVES}

-Develop a Scheme that architecutrally connects aged care delivery to elderly ageing in place

-Test the scope of delivering care through architecure, can architecture offer more to the aged care sector than institutional models of care.

-Create a closer connection between ageing elderly and the care that they need

\section{DESIGN BRIEF}

From the literature it is clear that for urban elderly getting access to their daily care is the hardest challenge due to the density of the urban environment, the amount of traffic and pedestrains using the streets reduces the efficiency of delivering care. testing ways to improve this efficiency in the city and connect carers more easily to the residents of urban apartments and terraces. The overall design should express the following design ideas:

-A scheme that transitions care from a central building into the surrounding buildings within a 10 min walking radius, connecting into the internal circulation of apartment buidings from above.

-Transitional qualities that include horizontal spread as well as vertical climb

-Geometric approach to aesthetics creating a contrast with current urban aesthetic, encouraging wayfinding memory the encourage use by elderly -Connection with the public to allow for cross-demographic use and interaction. 



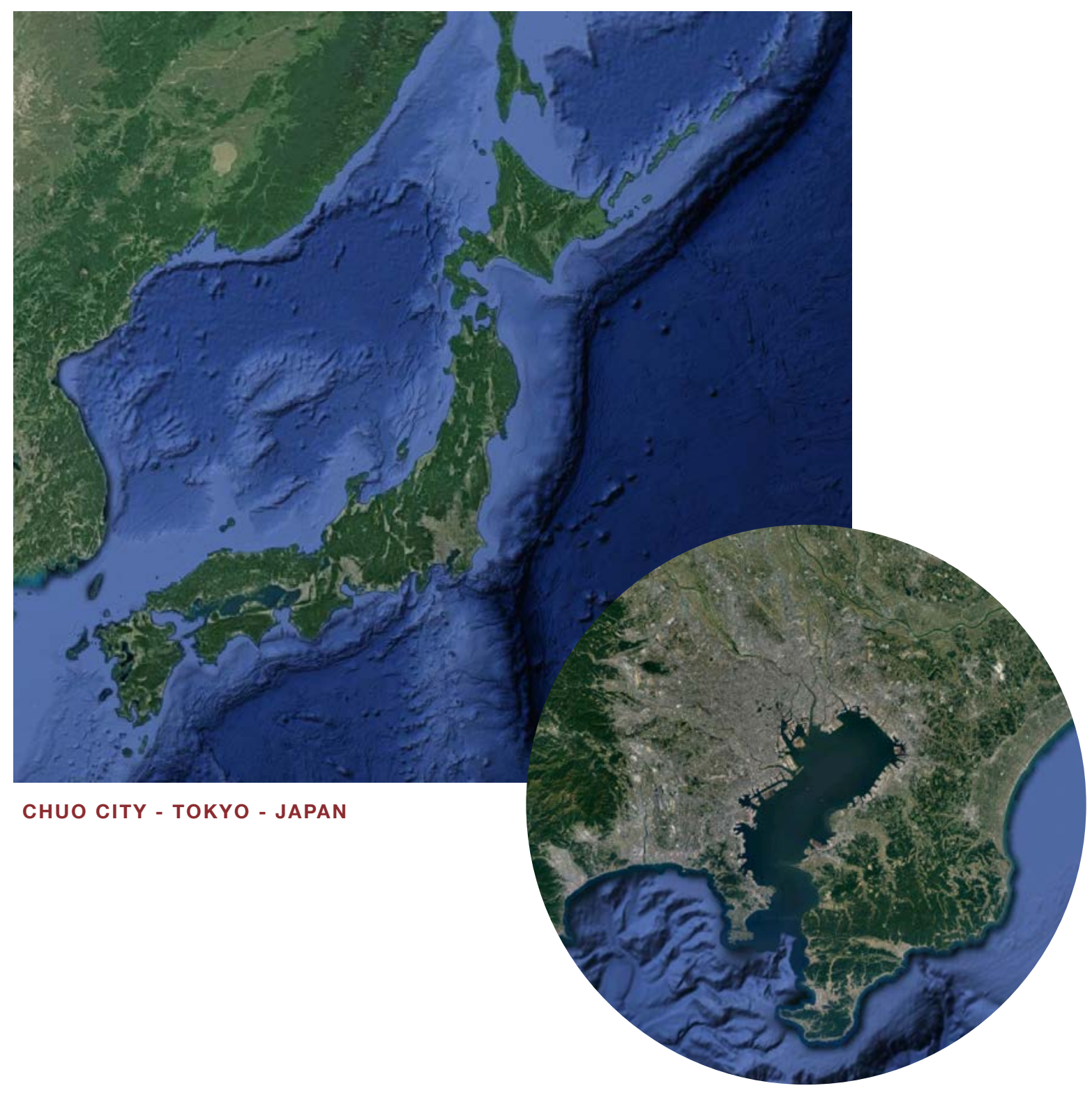




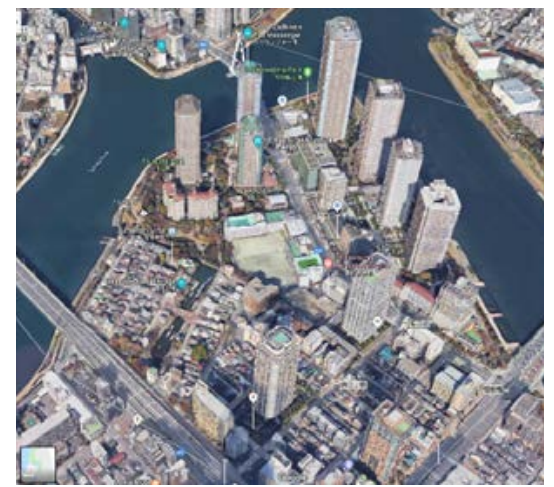

Tsukishima island corner contrast low and high rise

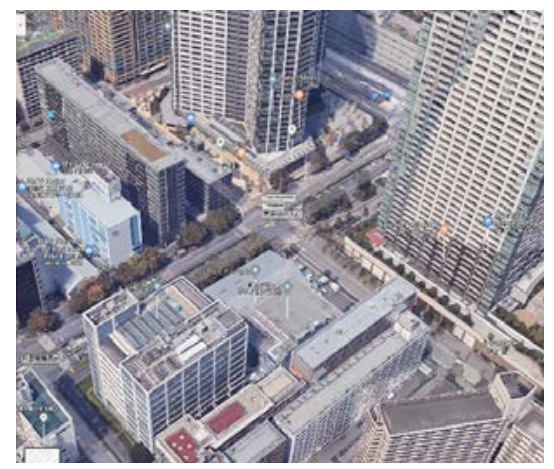

Large scale apartment buildings

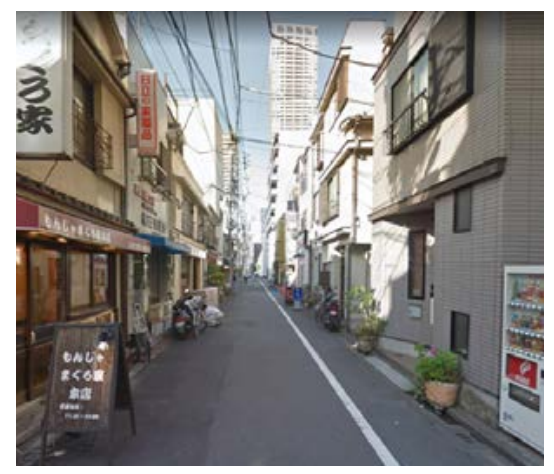

Low rise back street alleyway

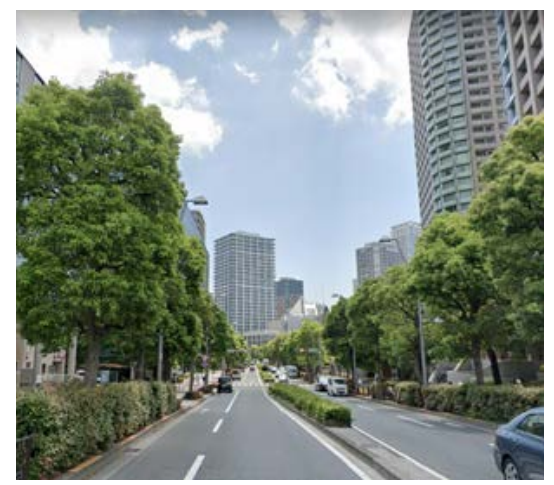

High rise six lane street

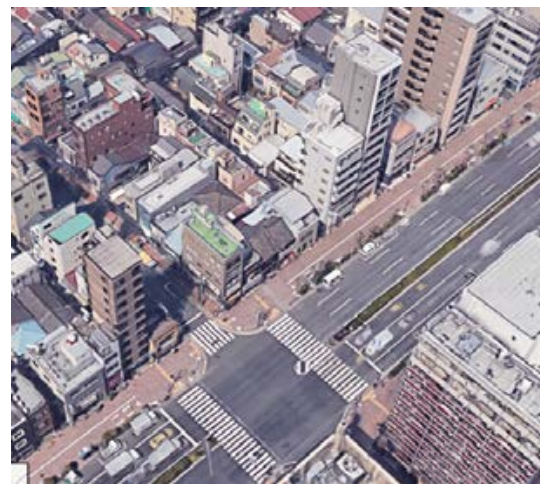

Wide six lane main street with cross walk

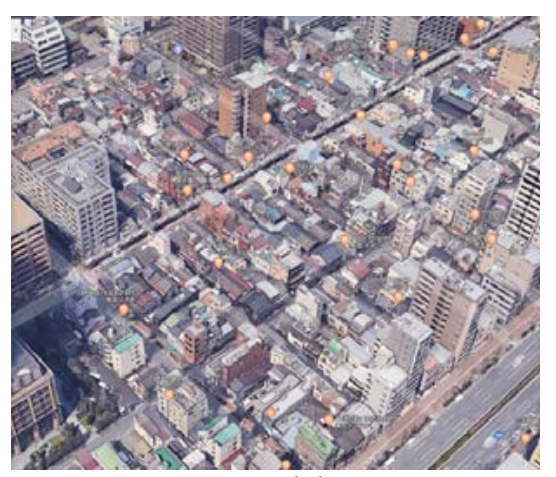

Low rise aouses around the traditional market street

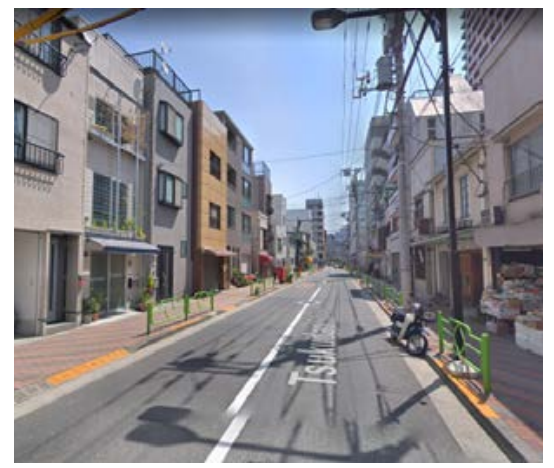

Low rise secondary two way street

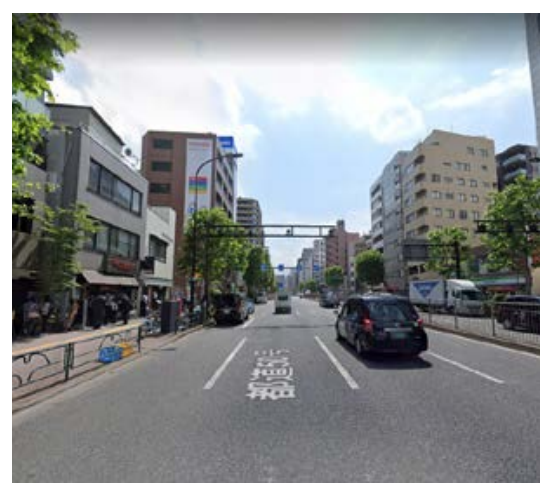

Medium rise six lane street \begin{tabular}{l} 
第 \\
三 \\
章 \\
\\
兽 \\
弯 \\
\hline
\end{tabular}

Different layers of the city show how diverse of a landscape Tokyo and Chuo City is. The overlapping of the old and new low and high rise back street and six lane motor way creates so many scale opportunities to explore connecting elderly with their urban environment. 


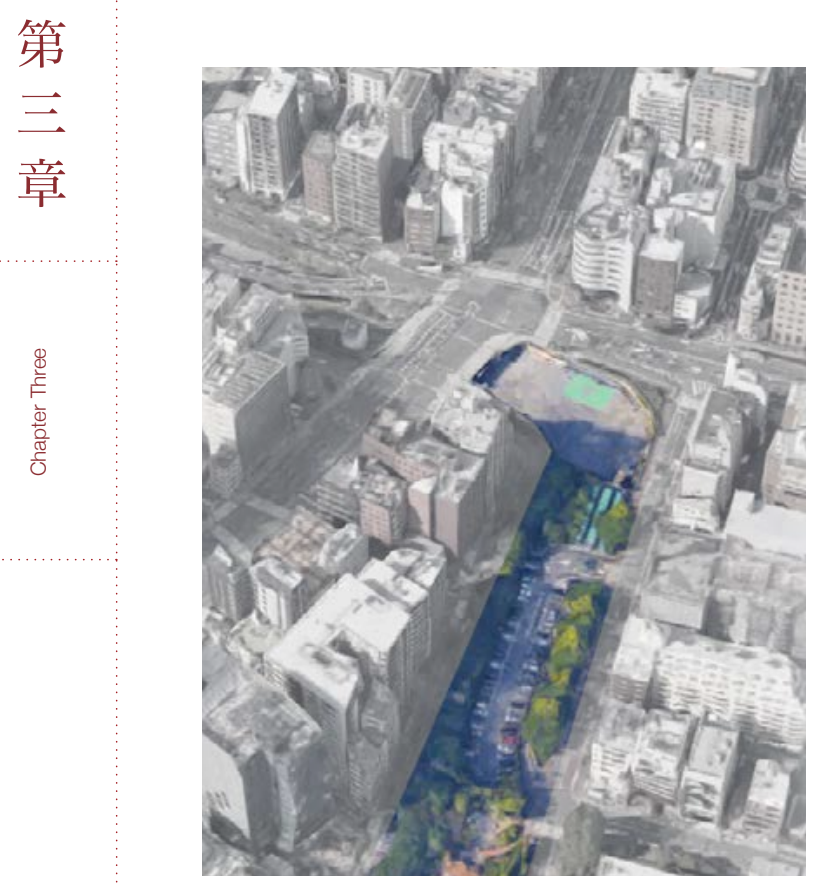

1. 3D site highlighted backing onto car park and urban green park space

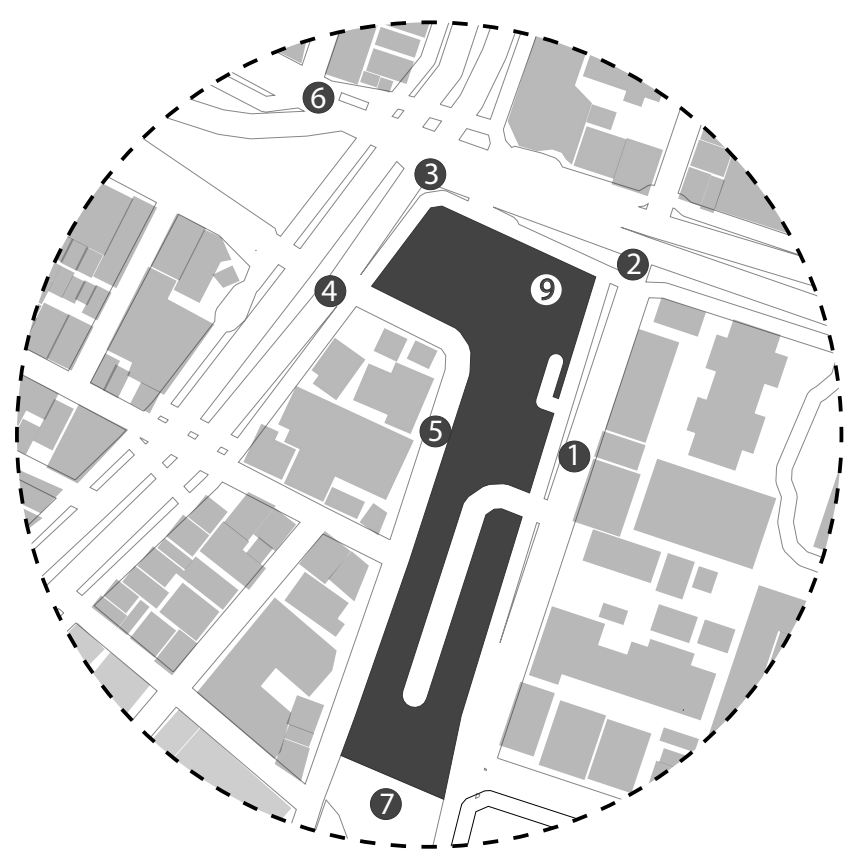

2. Site Plan- Each number corresponds to a view of the site pictured below

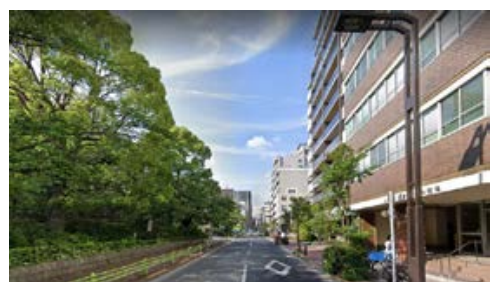

1.

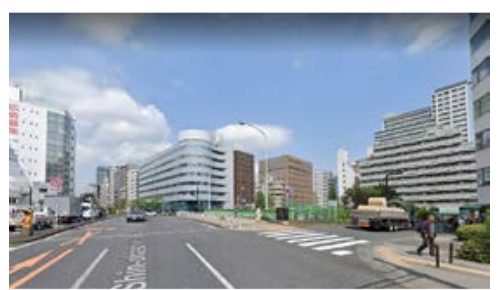

4.

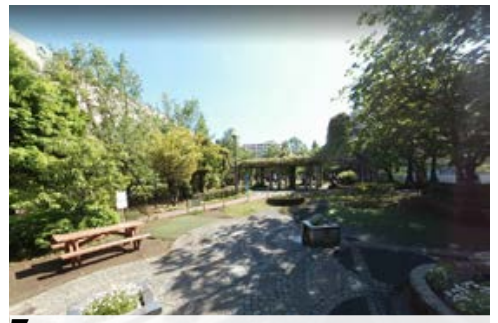

7.

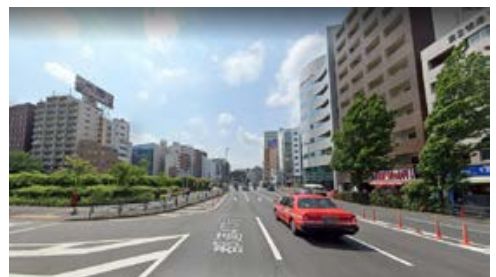

2.

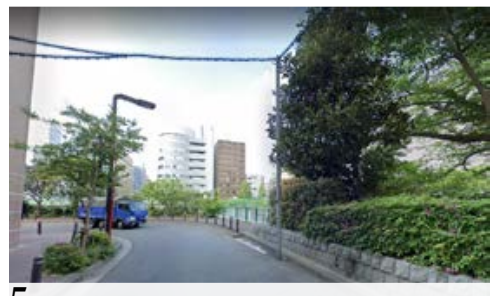

5.

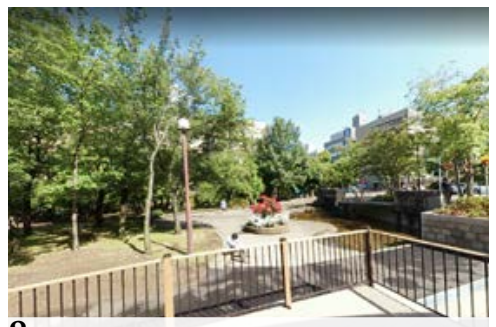

8.

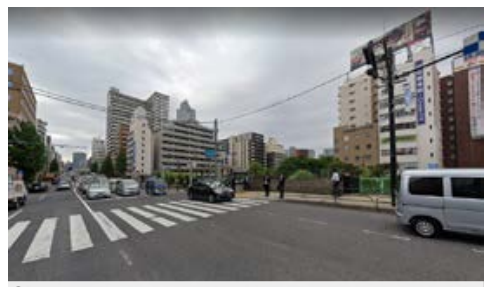

3.

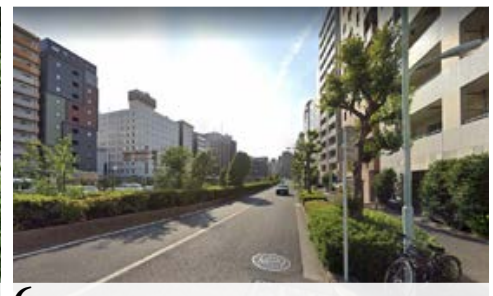

6.

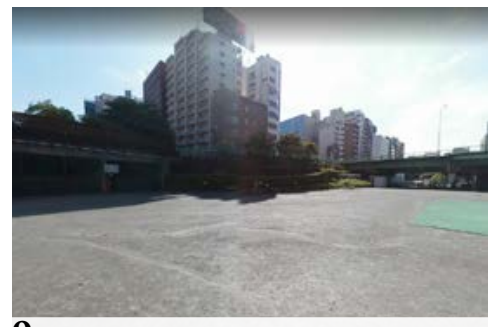

9.

3. Views of the site from different angles showing the diversity of parkland, small side streets, large six lane streets and open concrete yet to be developed site 


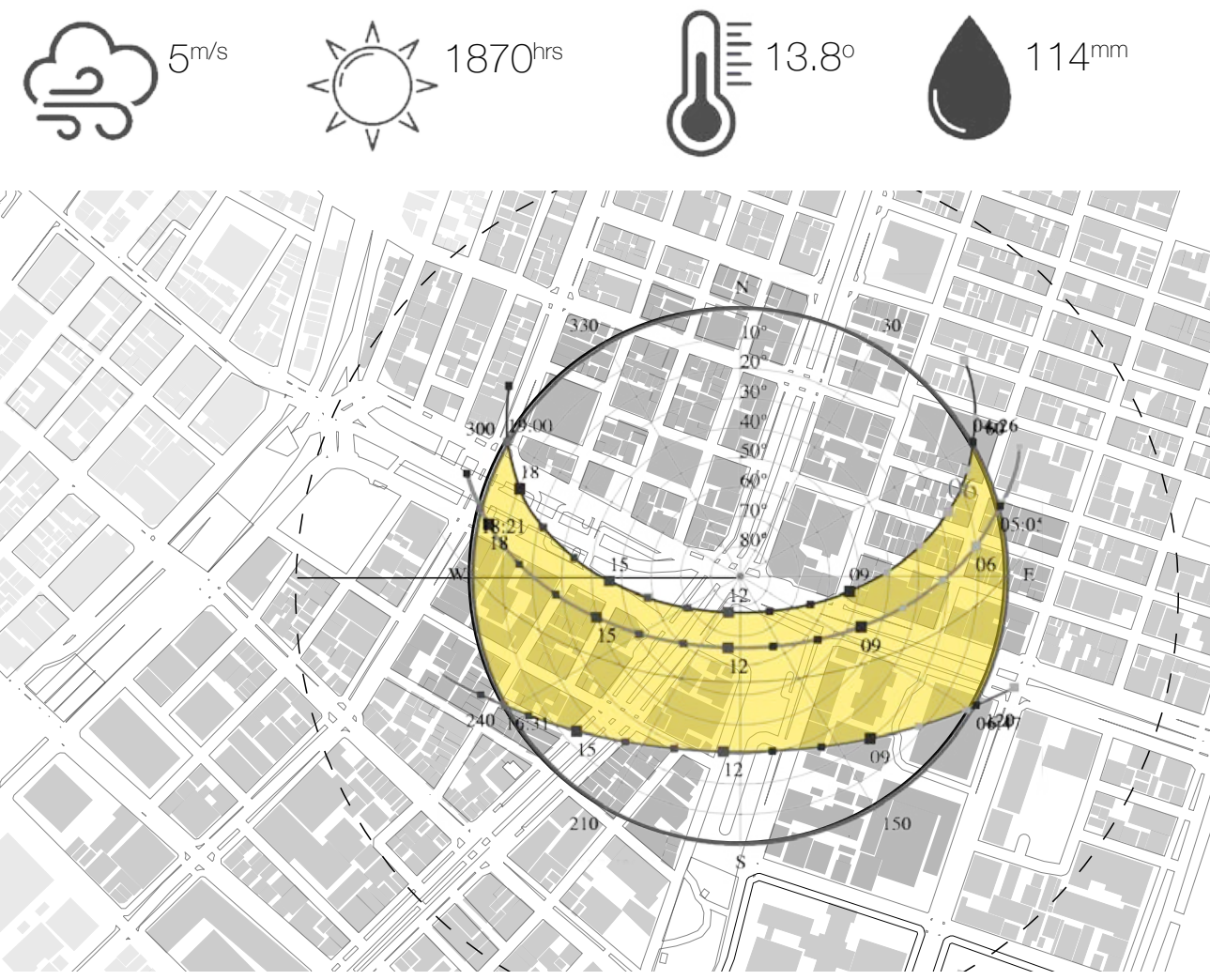

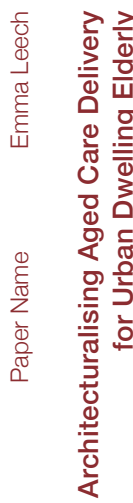

第
三
章

These drawings show light and sun movement

1. around the site and helps to understand

Sun study diagrams show the light and

where on the site will be the best placement

of buildings and where are good places for

2. shadows in the chuo city area across the day

outside landscaping and connections with the street

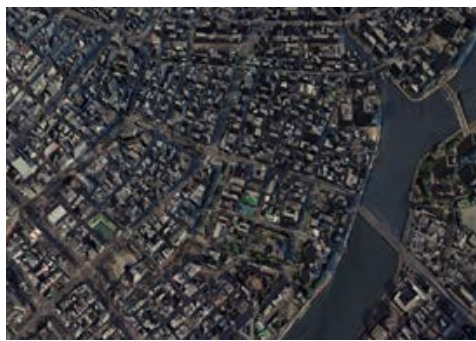

Summer- 8:00am

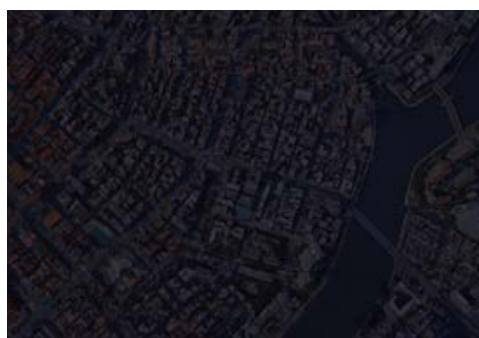

Winter- 8:00am

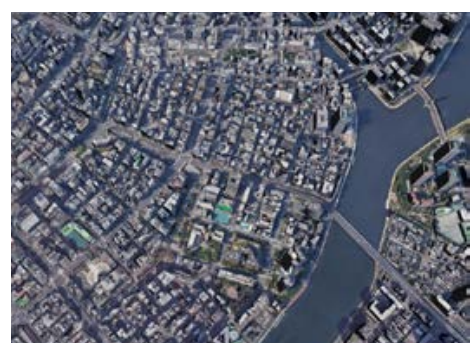

Summer- 12:00pm

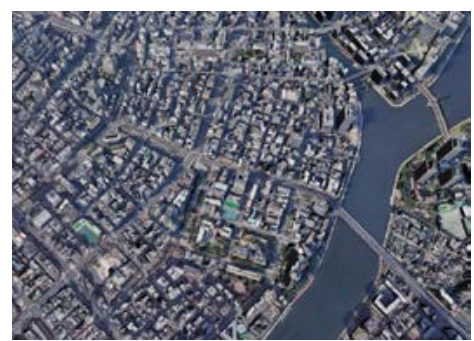

Winter-12:00pm

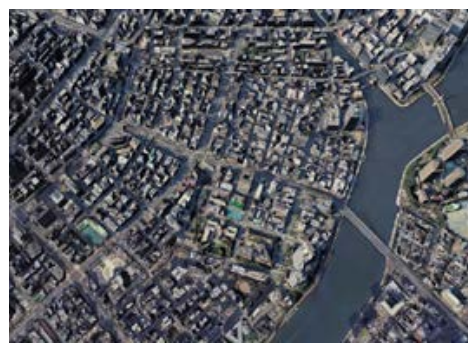

Summer- 6:00pm

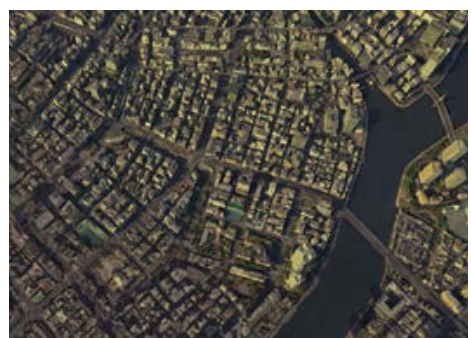

Winter- 6:00pm 


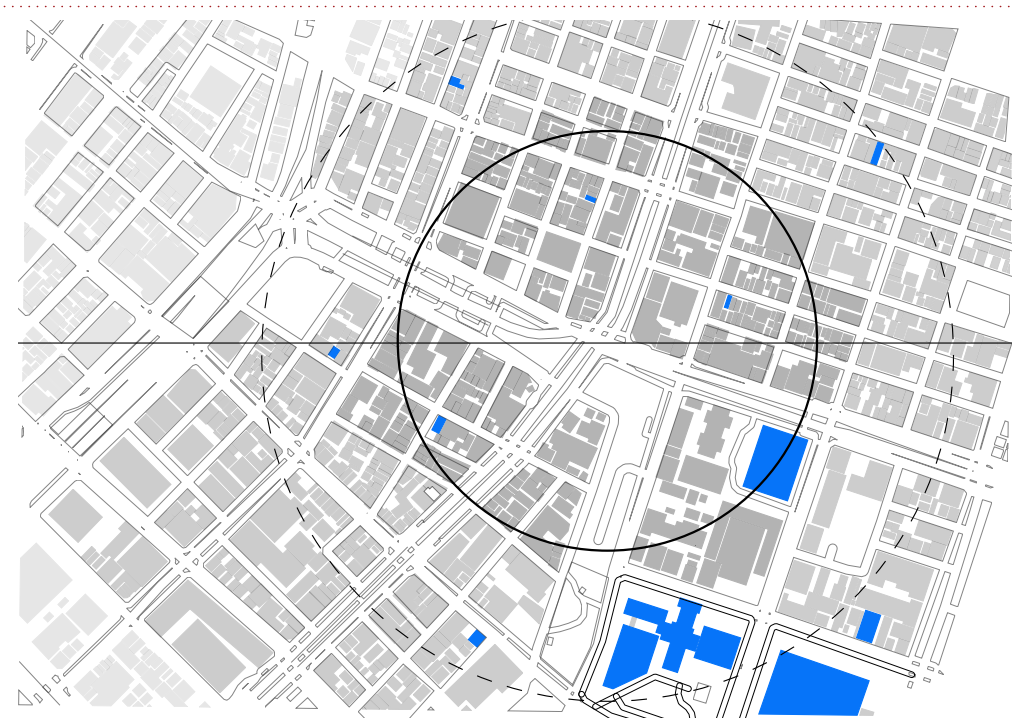

Medical

Centers and

Hospitals

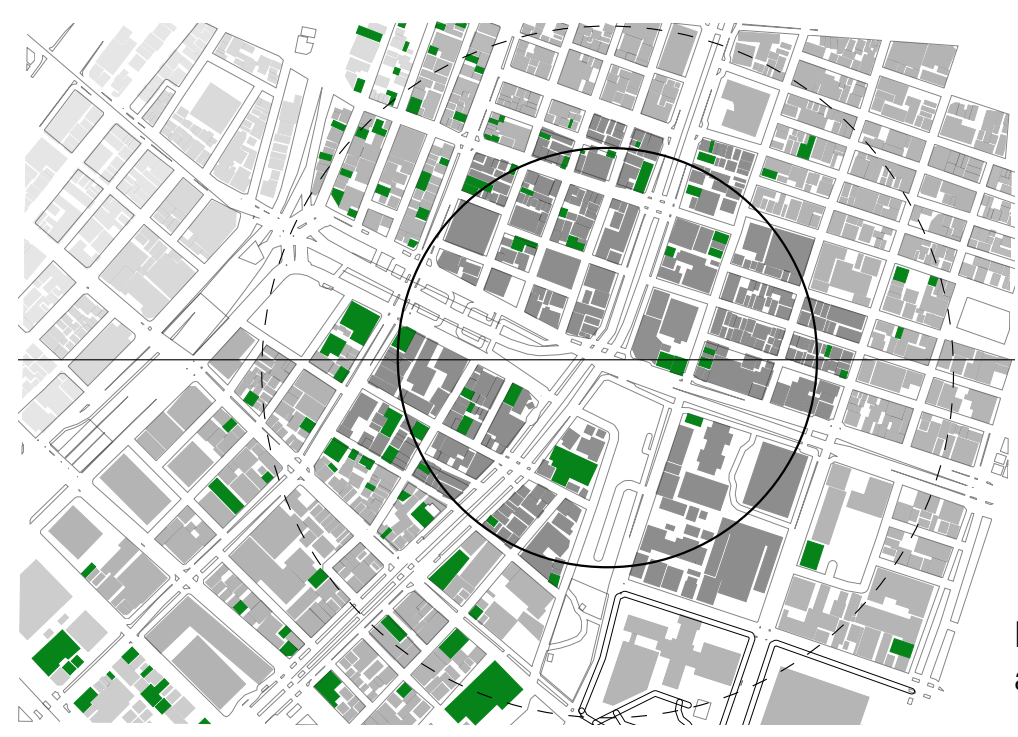

Restaurants and Cafe

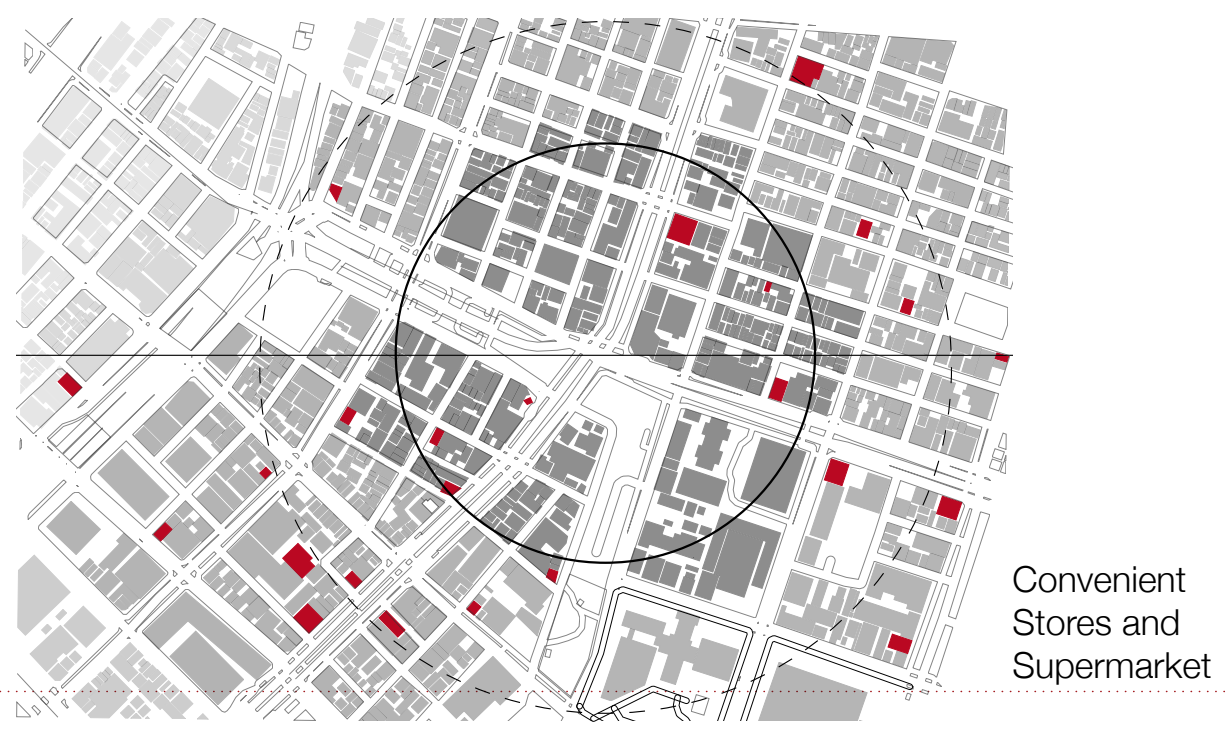



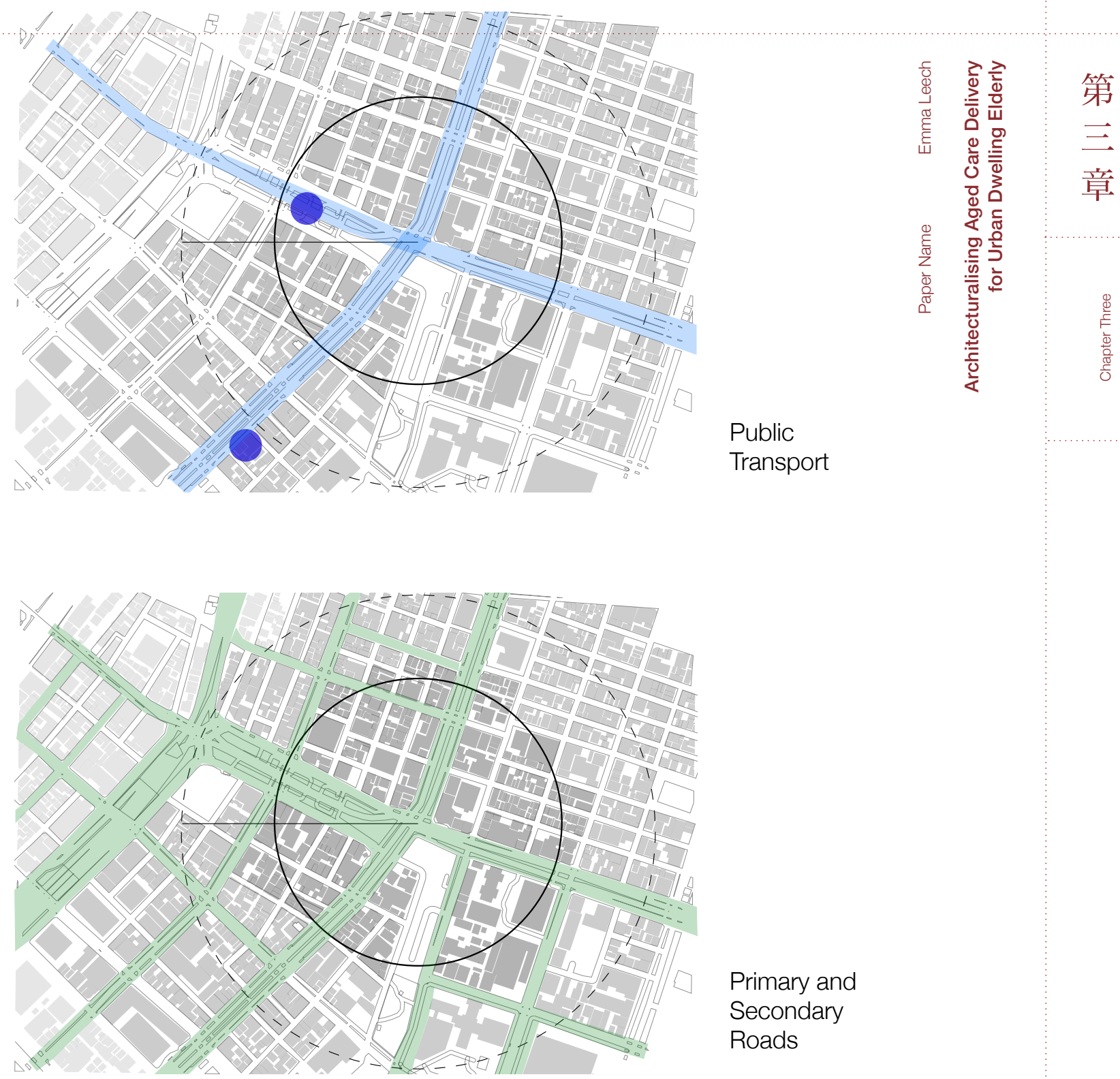

Public

Transport

Primary and

Secondary

Roads

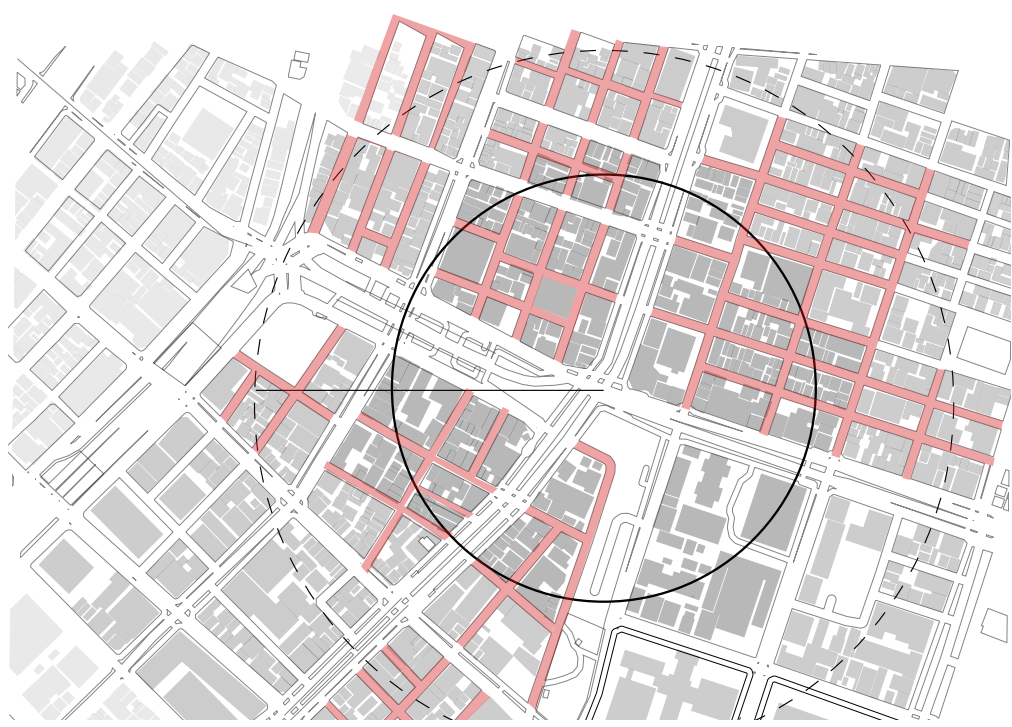

Primary and

Secondary

Roads 
章

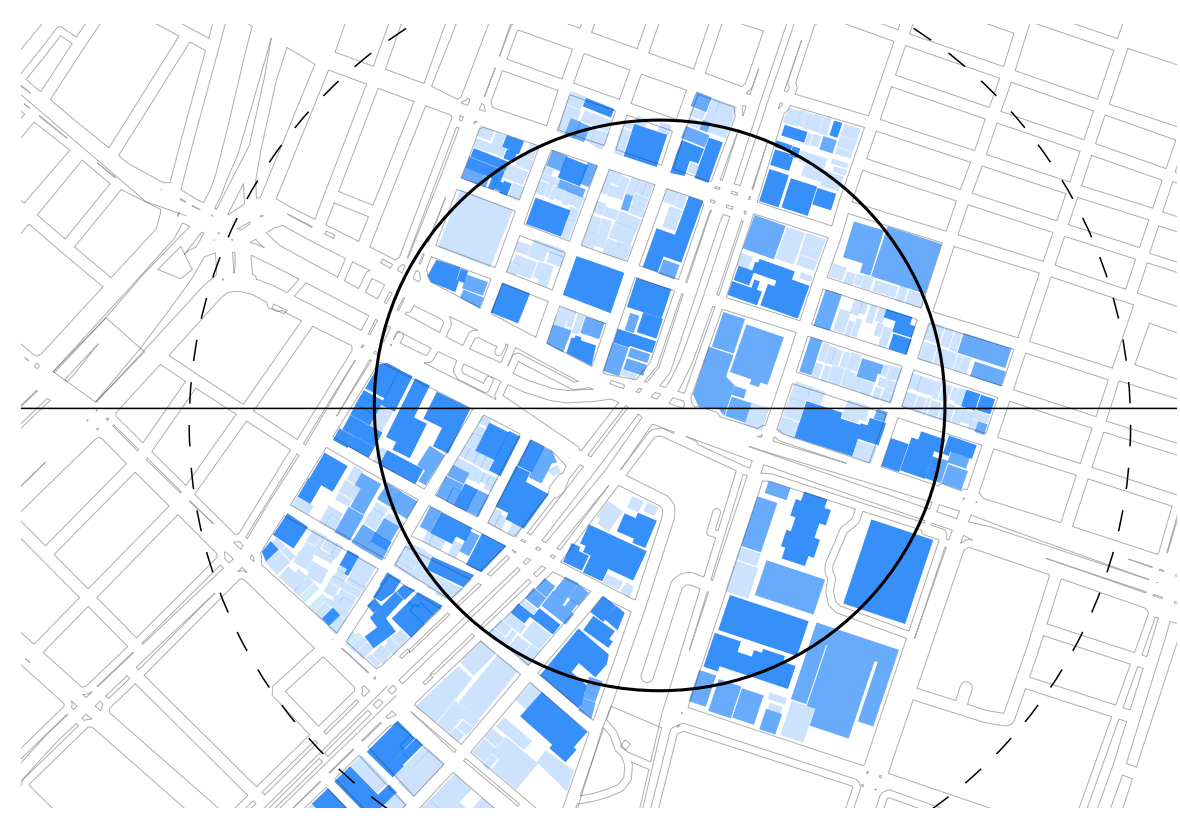

1-5 Floors

5-10 Floors

10-15 Floors

Building Heights

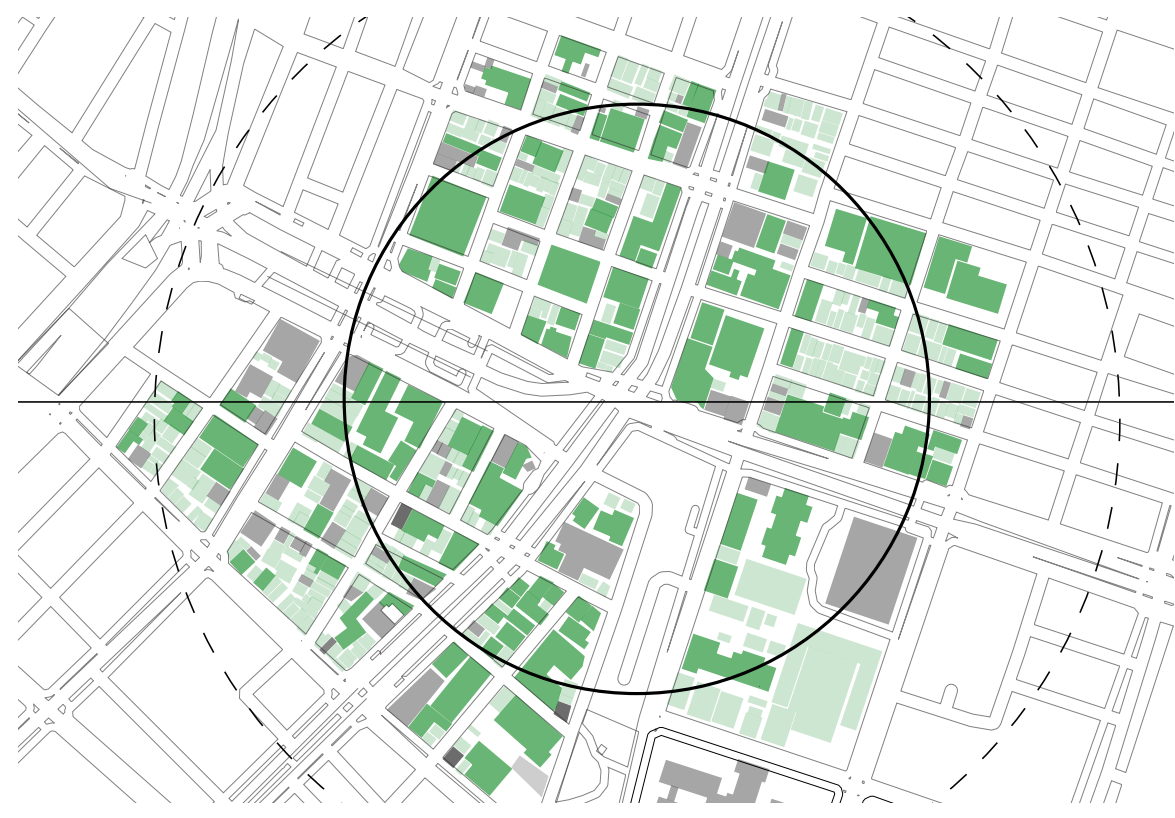

Single Residence

Multiple Residence or Apartments

Residential

Buildings 
Different layers of the city show how diverse of a landscape Tokyo and Chuo City is. The overlapping of the old and new low and high rise back street and six lane

\begin{tabular}{|c|}
\hline 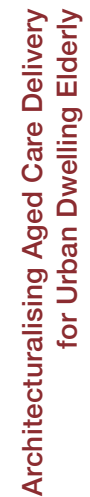 \\
\hline
\end{tabular}
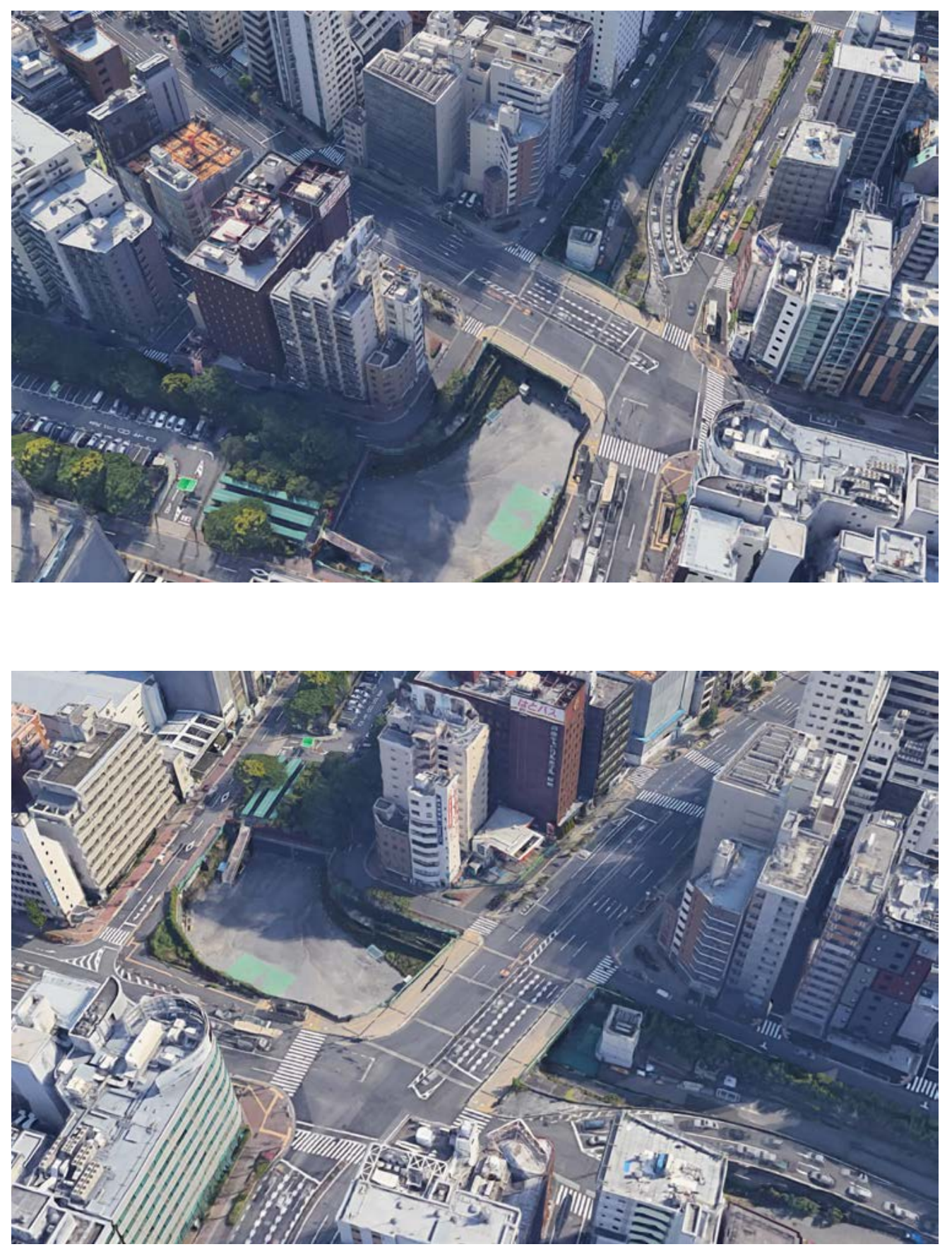
第

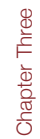




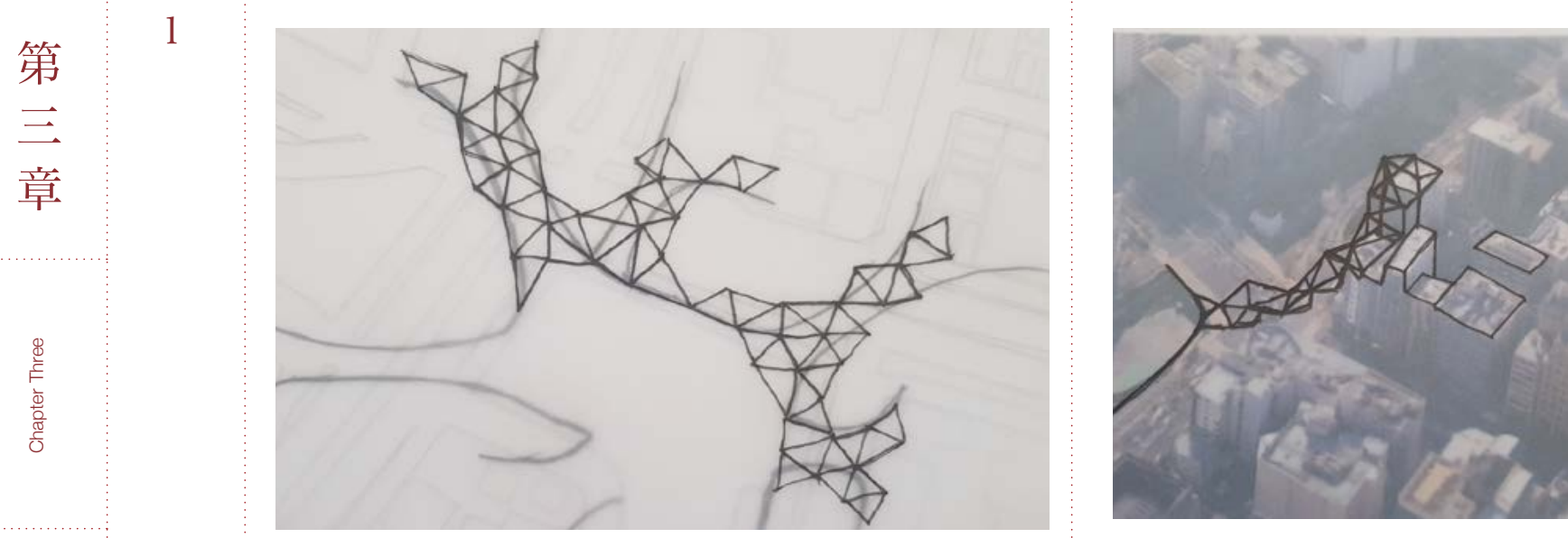

2
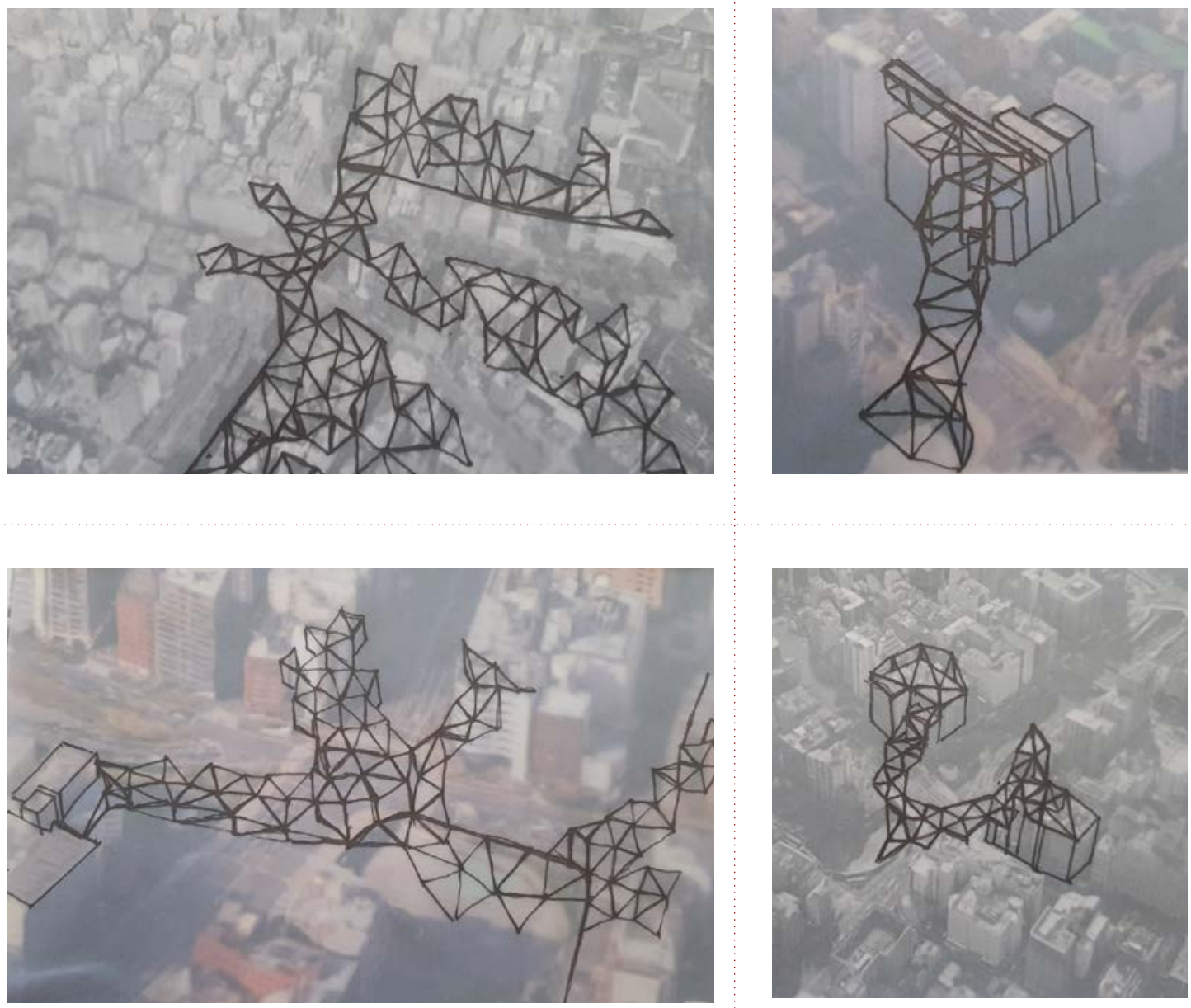

INITIAL DRAWINGS ONTO THE SITE

Beginning to explore ideas from models on top of site images further developing geometric forms. 


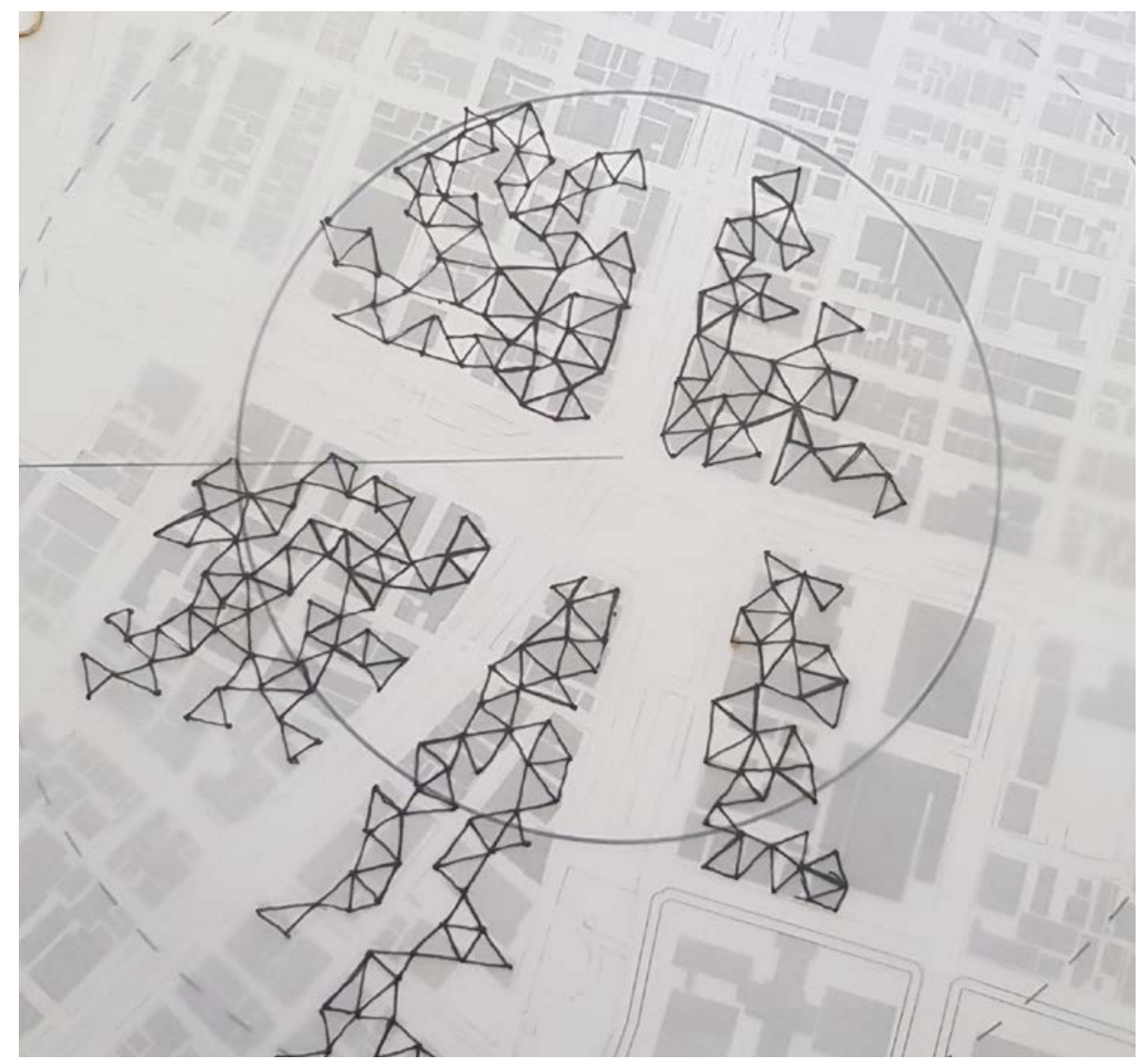

This drawing started the investigation into connecting buildings together it expands the thinking about the scale of this project. How visually and conceptually a scheme could project these ideas, strengthening the geometric communication of ideas. 

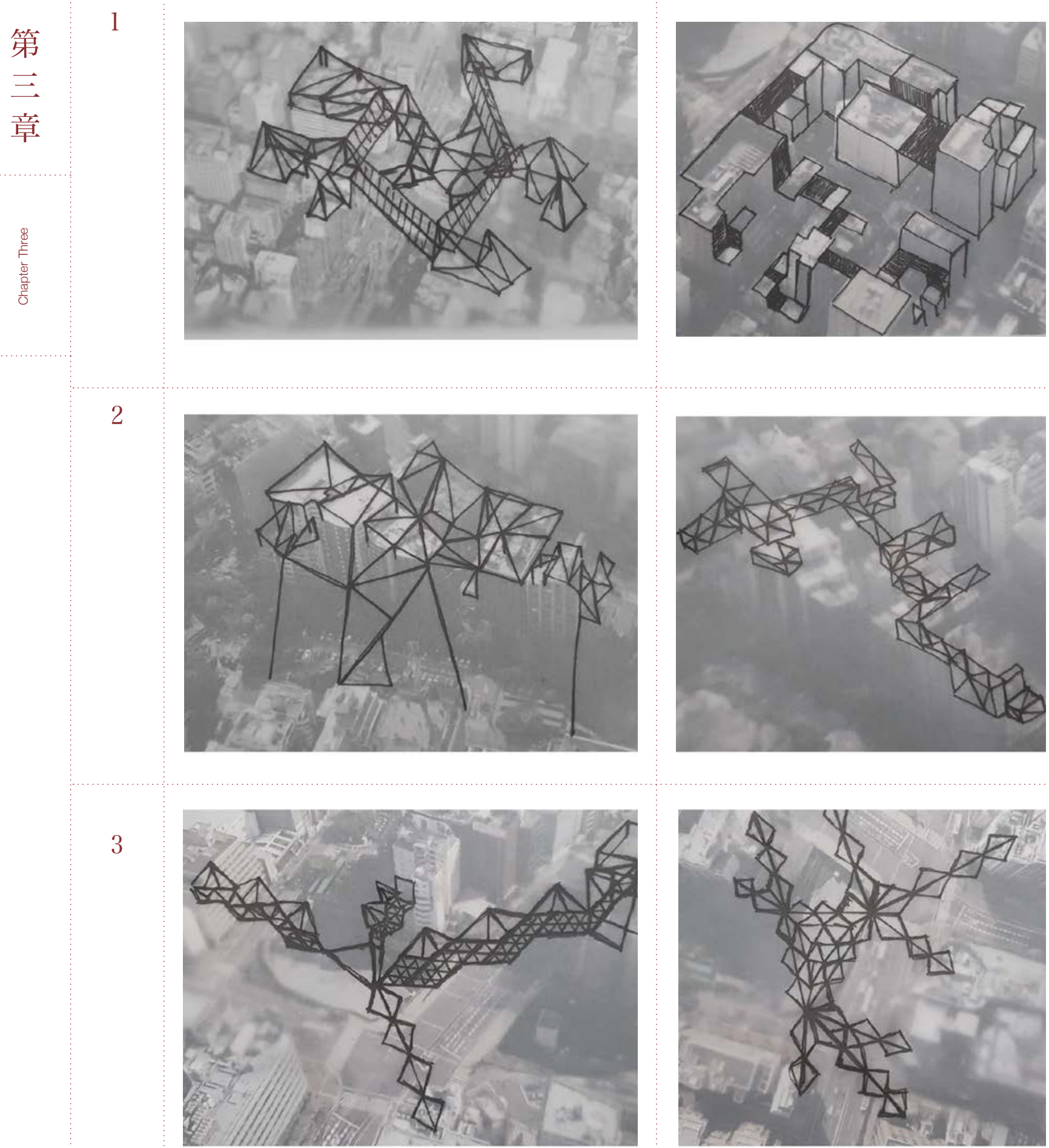

INITIAL DRAWINGS ONTO THE SITE

Beginning to explore ideas from models on top of site images further developing geometric forms. Building above existing buildings on the site as well as connecting up to them from ground level.

1 Authors Own Image

2 Authors Own Image

3 Authors Own Image 


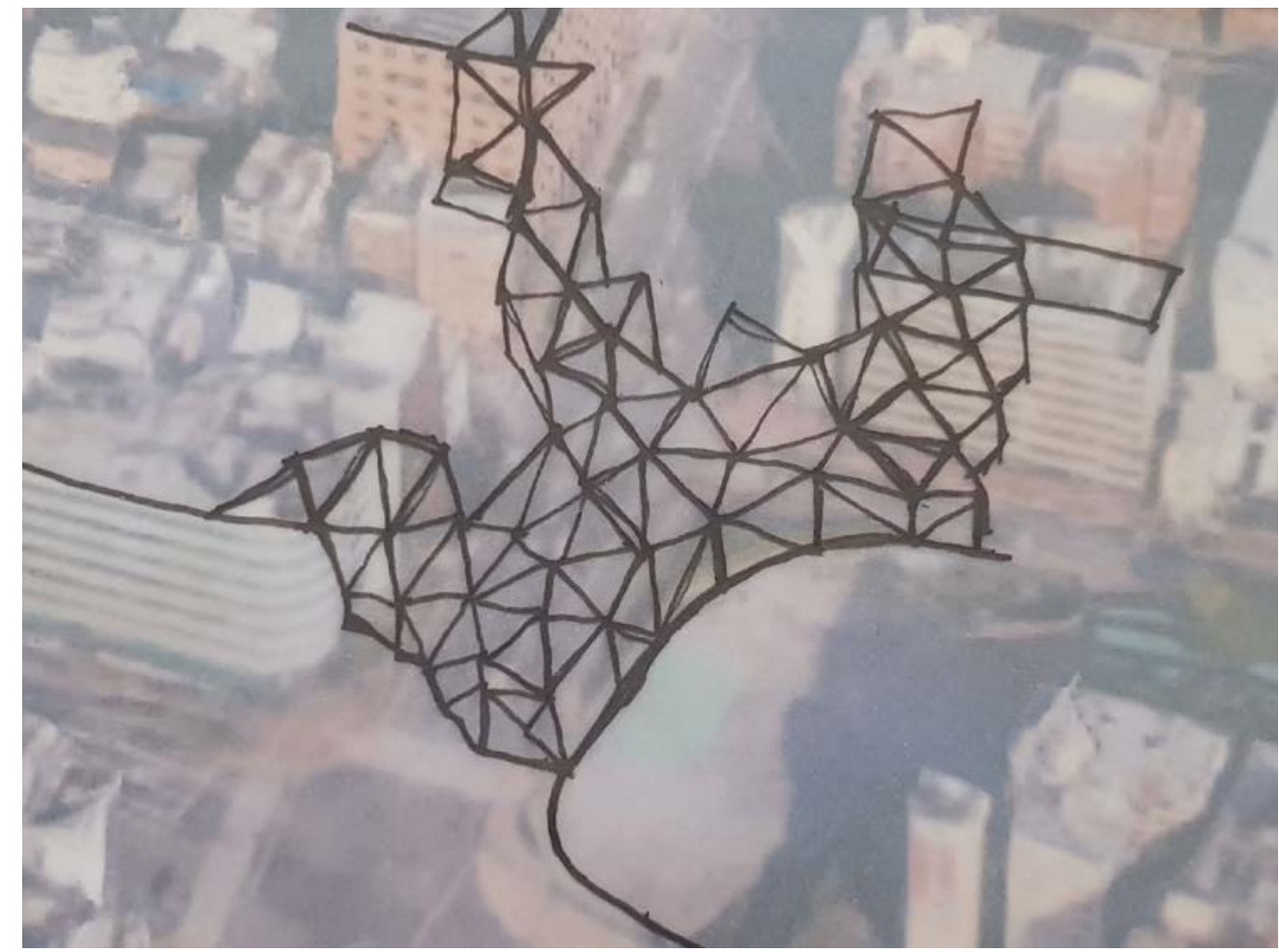

Further exploring this, this drawing uses a geometric web like approach to spread across the street and connect buildings into the site. Still exploring a possible climb from ground to above building height, this opens up the area of the site as open public commons connecting back through to parkland behind the site. 

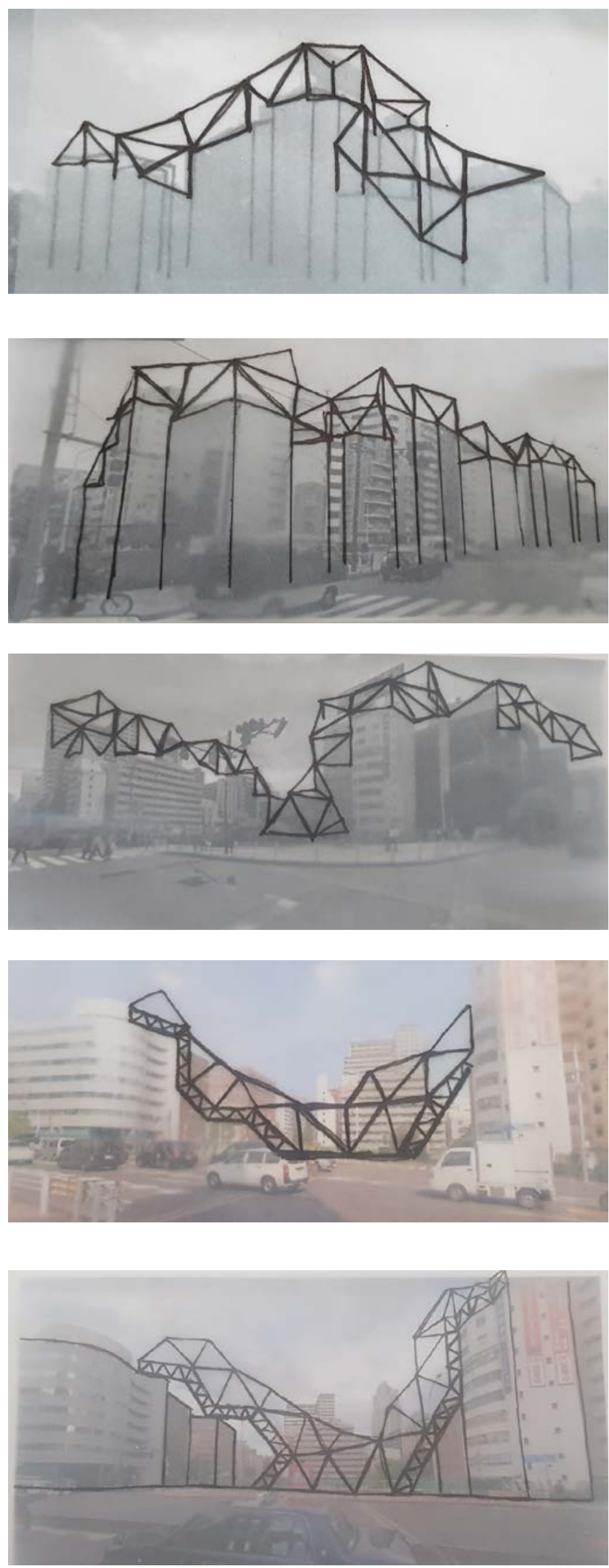

More Explicitly

referencing bridge form and structure these drawings continue to explore ways of connecting across buildings, streets, and intersections within a perspective view. The goal of these drawings was to begin to put together a representation of a three dimensional product to further develop ideas. The Key component to these designs was stepping up from ground level to above building height and figuring out how to balance the relationship between the design, street and existing building form. 

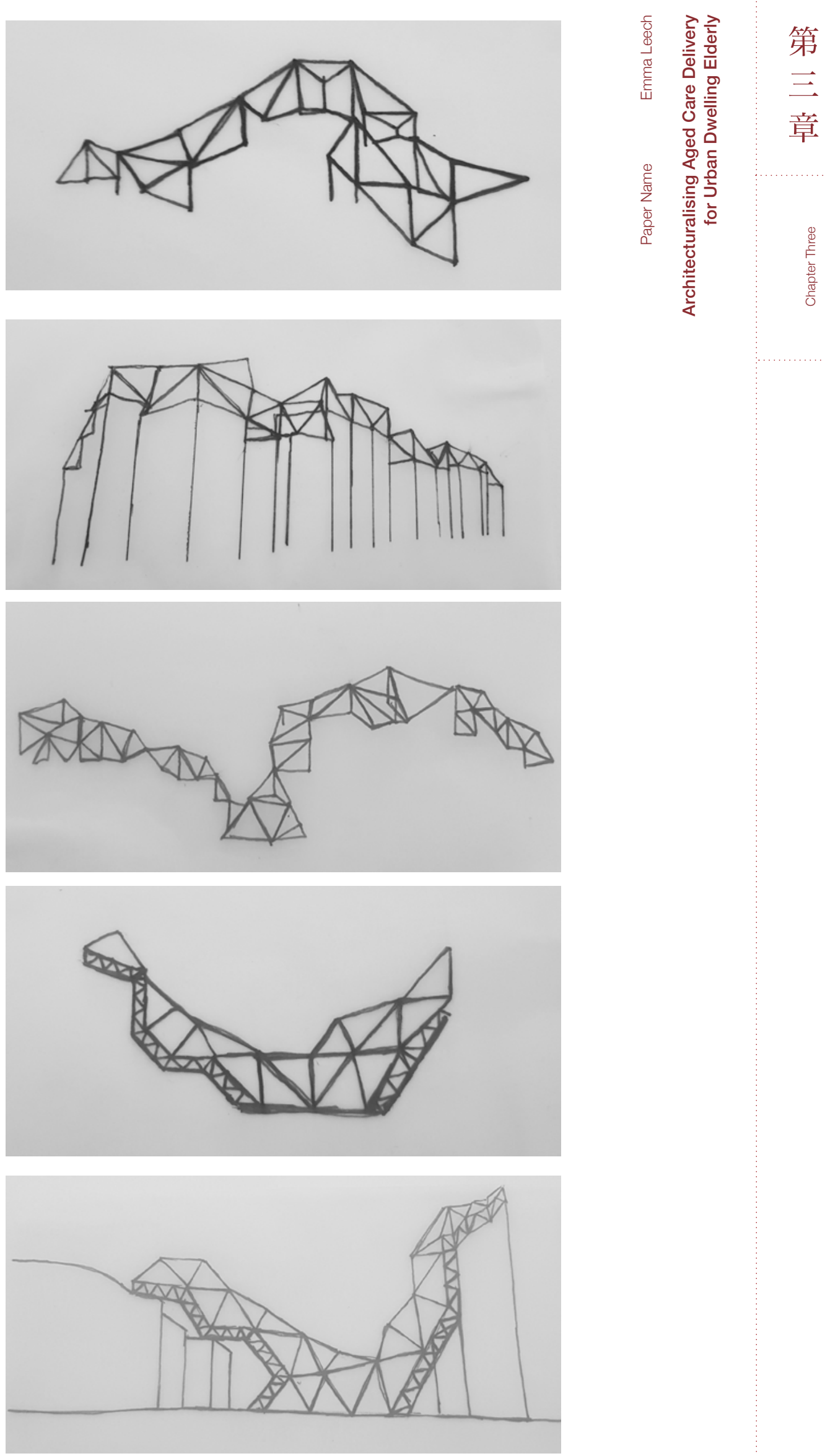

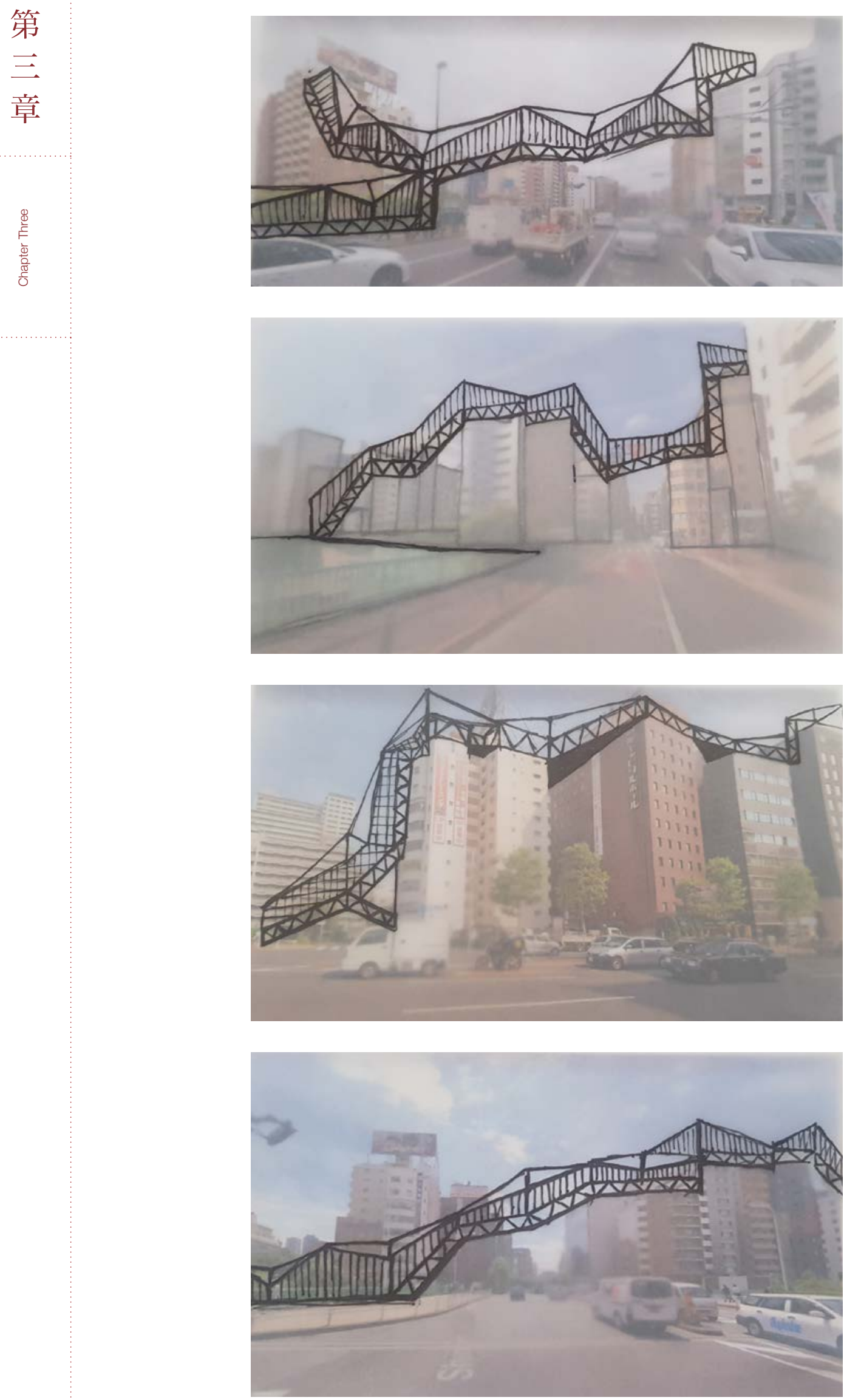


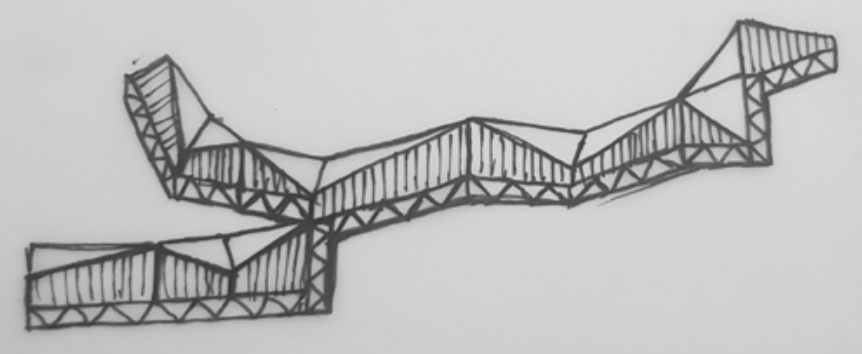

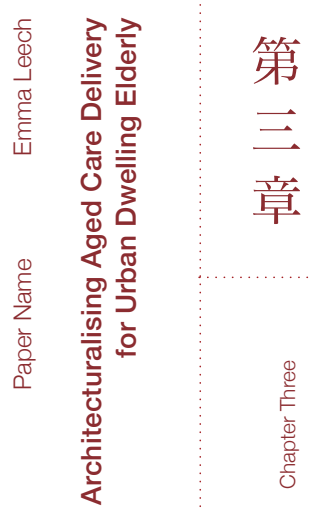
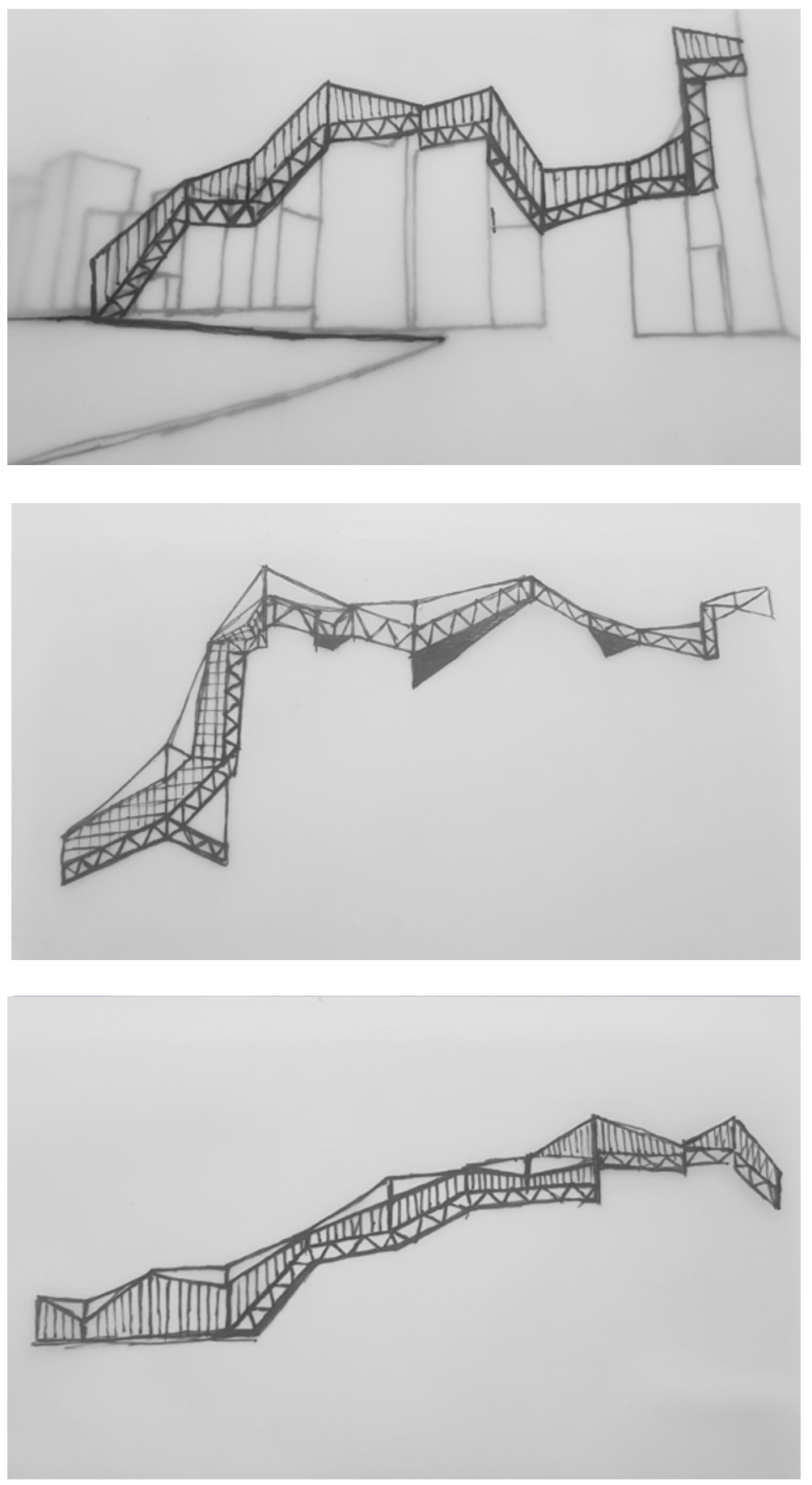



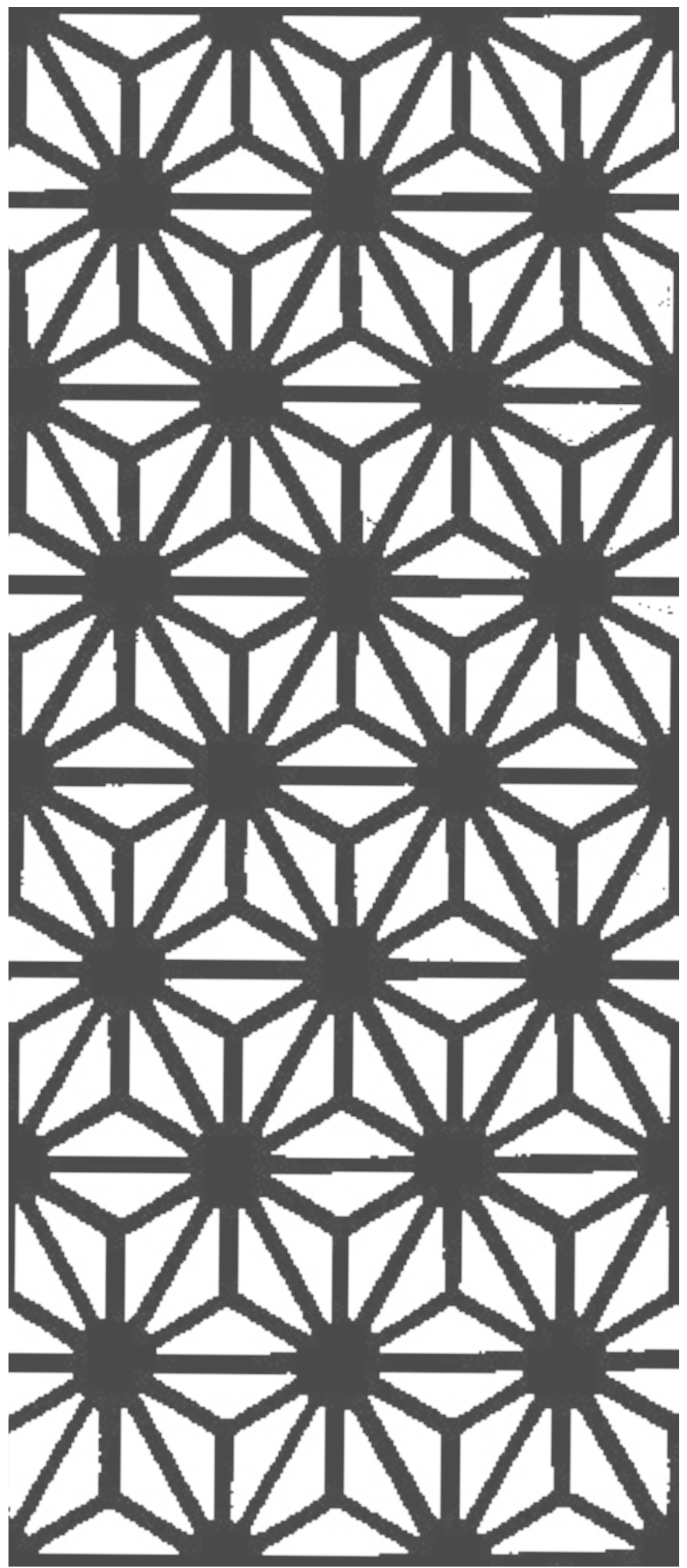

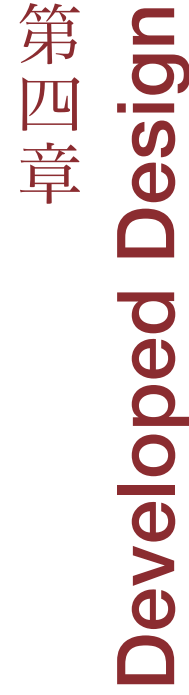

第二章

第三章

第四章

第五章

第六章 


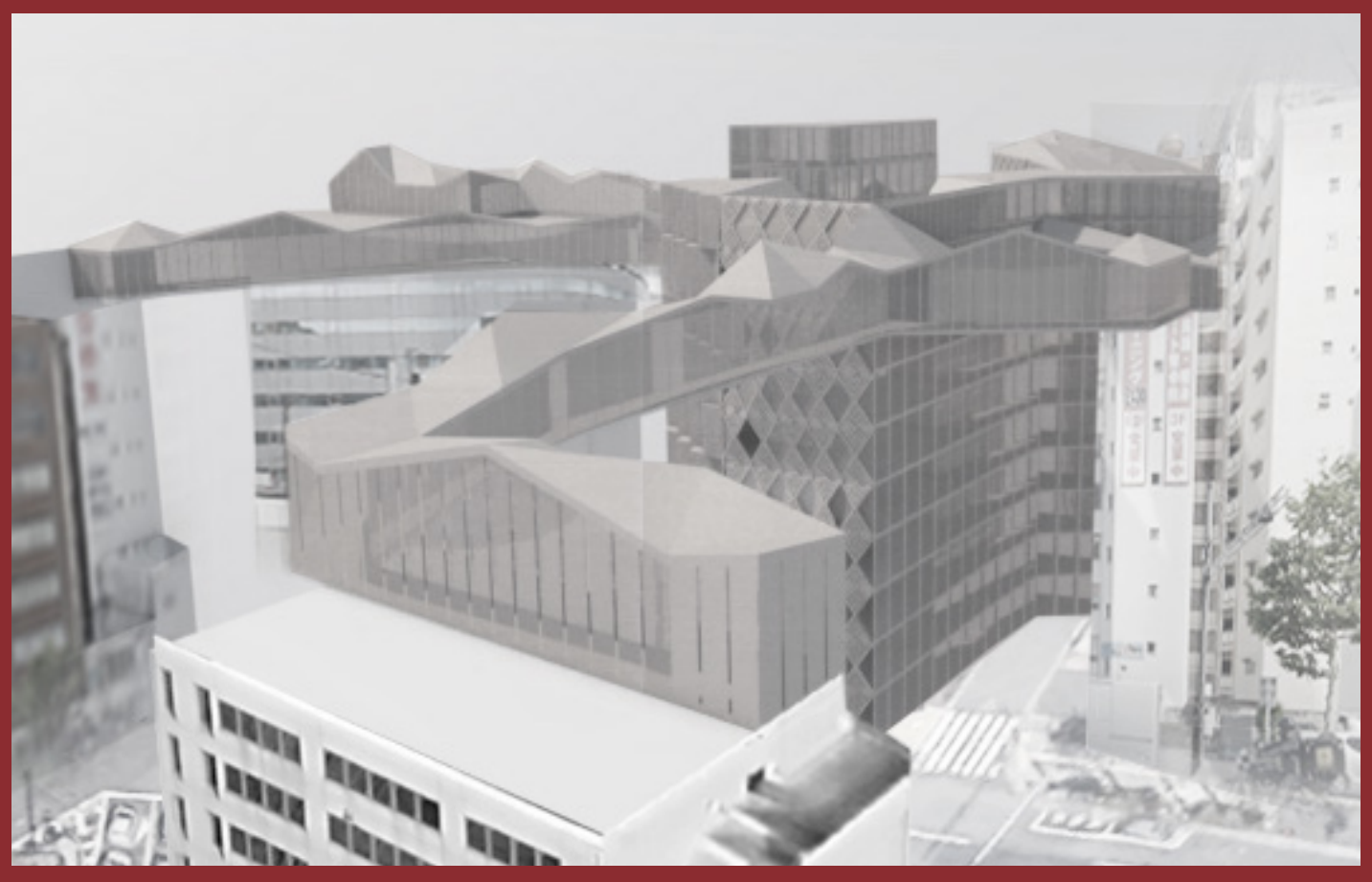


The developed design builds on the initial design process and uses the created design criteria to further inform the design outcome. At this stage, the design becomes less abstract and formal architectural qualities are merged with the initial abstracted ideas and forms to create a starting point for the final design.

Due to this, floor plan considerations, occupation and structural capabilities of the design are considered and further developed ideas for the possible shapes and forms to occupy the site are created, tested and critiqued.

The decision to occupy three buildings on the outer edges of the site was made as both a design lead and structures lead decision. the central courtyard is an idea used throughout traditional asian architecture for hundreds of years in a domestic scale this would humanise a building of significant size and create a connection to the home. Using this idea for this building also reduced the density of the building on the site and also allowed for more through traffic and pedestrian use.

Structurally the connection between the bridge arms, proposed at the initial design phase would struggle to be supported by a single large building and connecting one or two bridge arms to each building reduces the load and allows for more exterior structure needed to support the proposed cantilever. The Bridges went through a lot of development throughout this stage and initially concieved to climb up from ground level this was developed to connect the highest building in each block to the central tower. not only does this make sense in terms of programming to separate the retail lower floors from the care delivery but also structurally keeping the bridges on one level reduces the impact of the load on the buildings structure and makes the design more structurally viable.

The position of the bridge walkways above the street are high enough to not obstruct the sunlight or view of pedestrians on the ground nor people inside their apartments, neither are they designed to blend into the existing building fabric too much. As a large design statement, these walkways are both practical for the nurses and care workers using them as well as a piece of art and interest to commuters and pedestrians. Ultimately these are a significant design statement for my work and separate the design from the current typologies of aged care. therefore the majoirty of design development was focused on the design of these bridges and their connection to the main building both visually and through the floor plan 


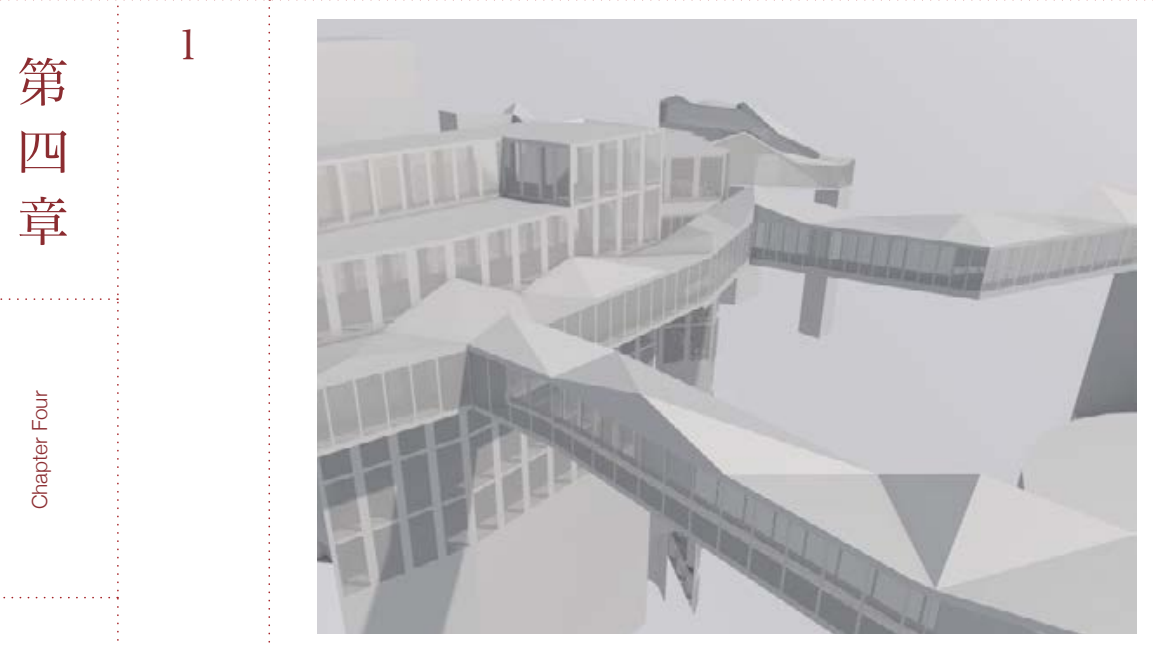

Developing how and where bridges attach to building form separating bridges visually from the main building and canterleivering them off the main structural wall.

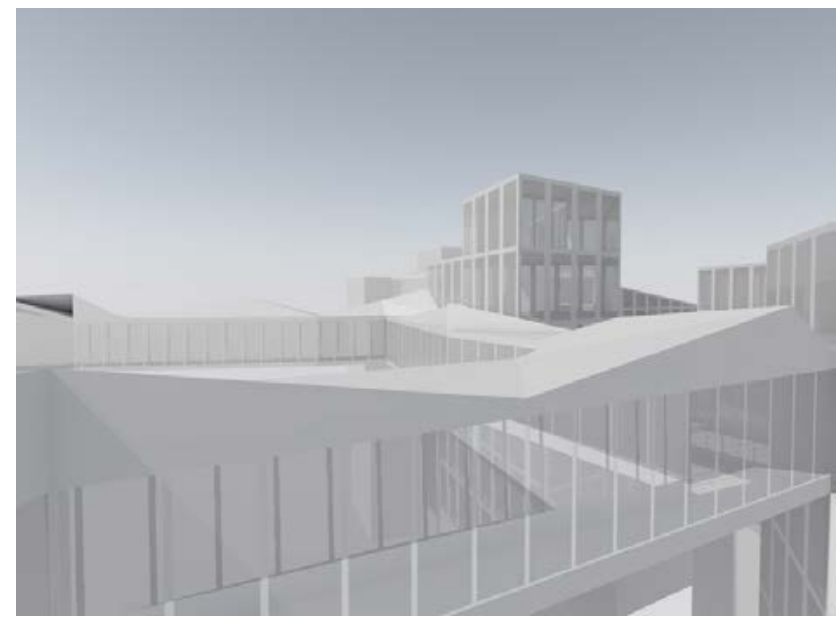

Develop bridge forms- Exterior view of bridges possible view from surrounding buildings

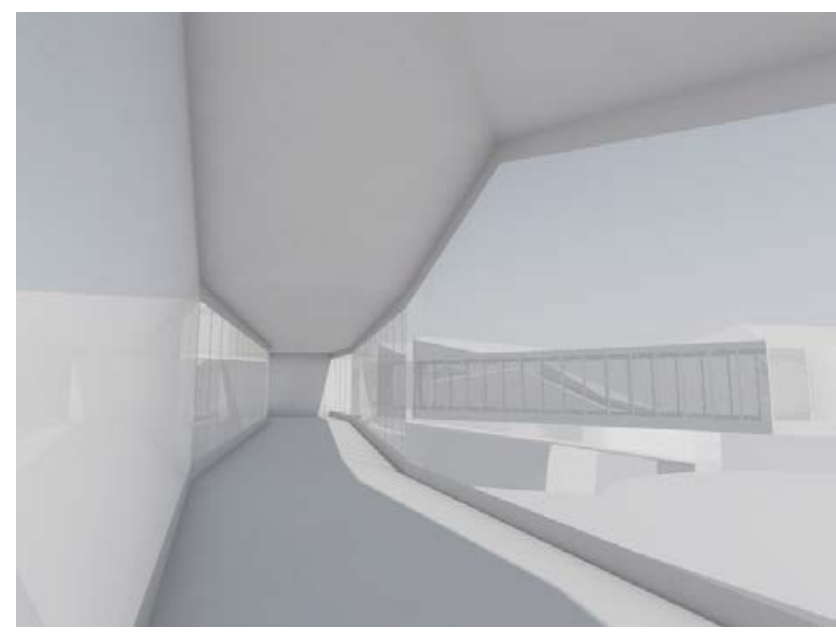

Developing the interior view from inside the bridge formsexperimenting with geometric roof form.

DEVELOPING BRIDGE AND BUILDING FORMS

1 Authors Own Image

Visually exploring connections between main bridges and central buildings. how this connection will look visually and how it will affect the circulation around the buildings. These black and while visualisations focus on form finding and navigate the beginning stages between abstract form and architecture.
2 Authors Own Image

3 Authors Own Image 

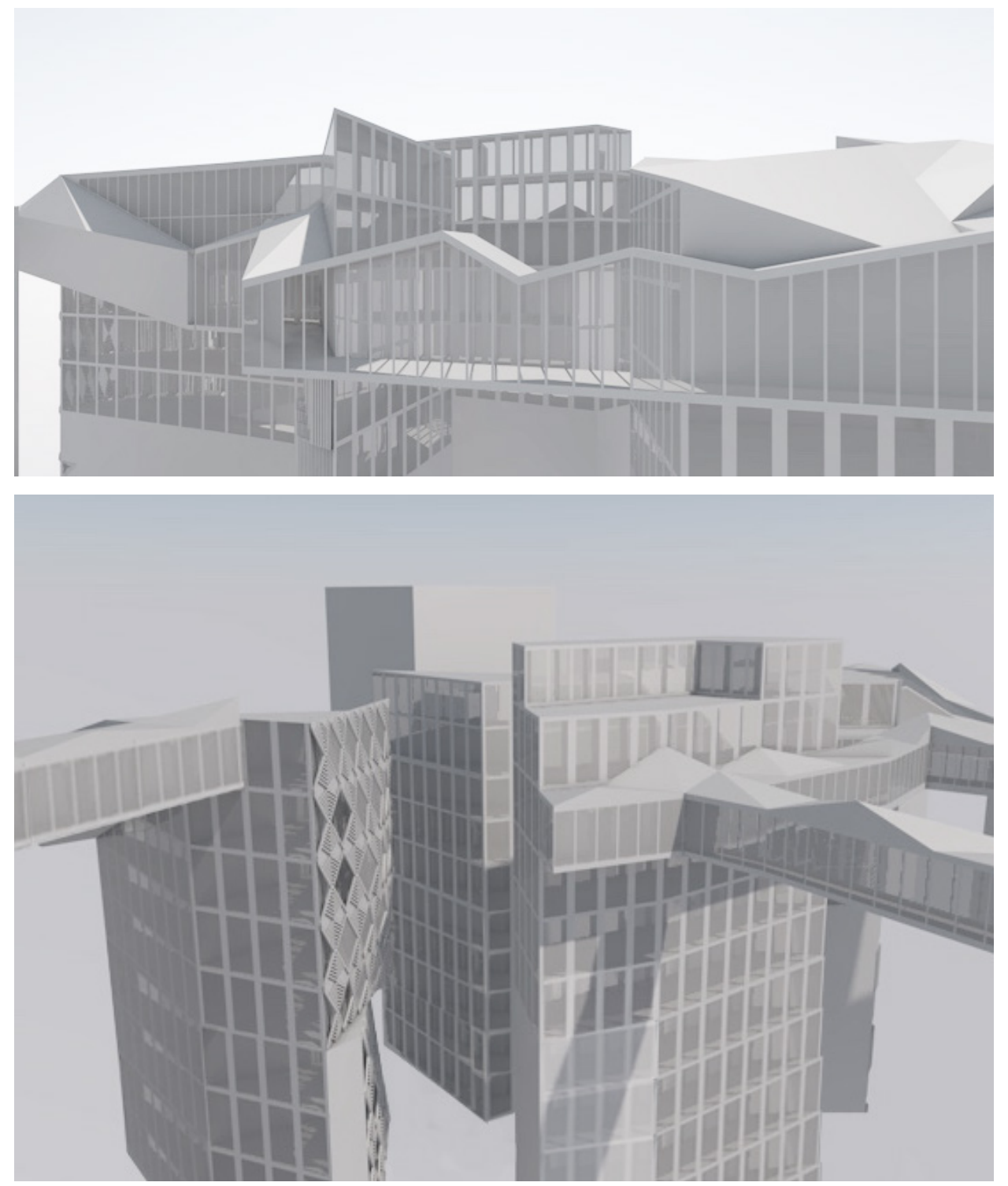

These visualisations focus on the development of the overall scheme in terms of the relationship between the bridge walkways and the building fabric, visually testing the viability of walkways that snake around a geometric exterior and then flipping this so that they wrap around the interior side of the building. this developement was testing both the aesthetic qualities of design options as well as thinking about the efficiency of the floor plan for each design 


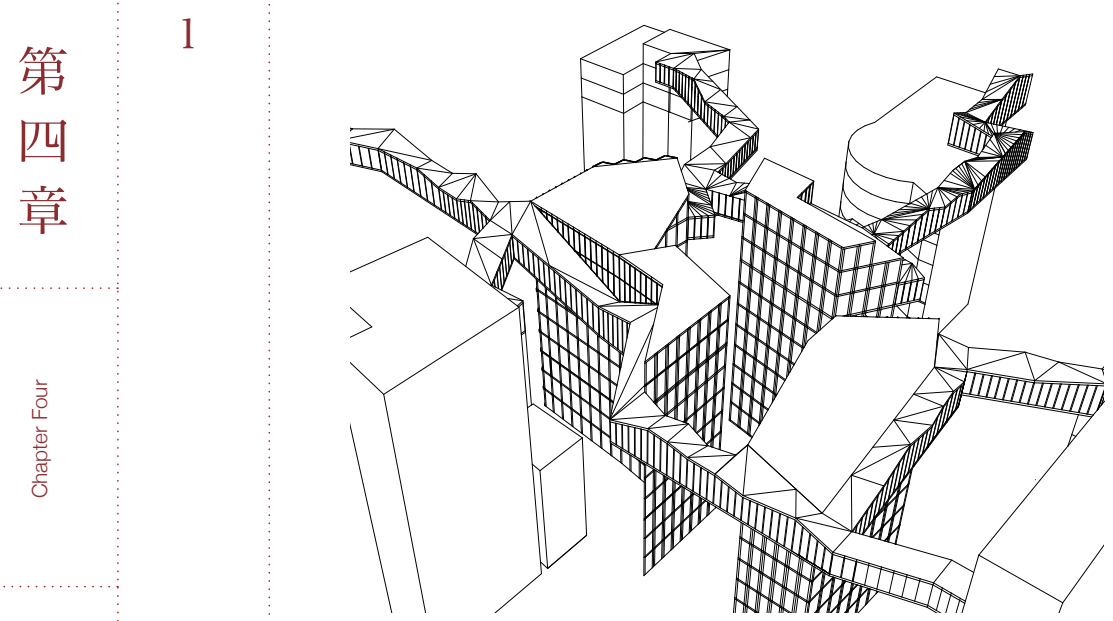

In the first design iteration all buildings are of similar height and the bridges cantilever off the geometric forms of the exterior facade. the positives of this is that the bridges and the buildings are united and visually have a seemless connection. the negatives are that efficiency is compromised as nurses and carers have to walk around the exterior of the buildings to get from one side to the other.

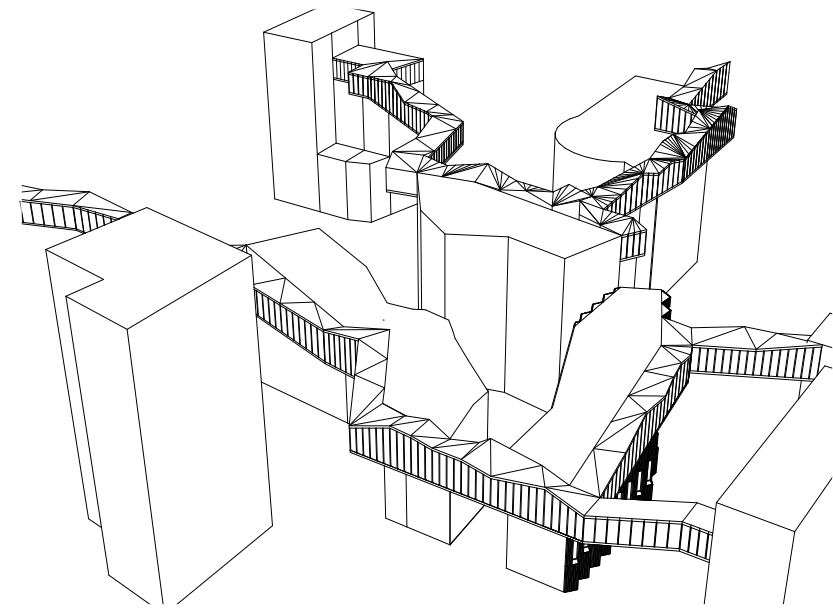

In the second design iteration the bridges are still on the outside of the building but different heights of building are tested as an idea of connecting to lower buildings with the different blocks and allowing more sunlight into the central courtyard. the negatives are similar to the first iteration in terms of efficiency but also different heights of bridges means that connection between bridges is harder and less structurally viable and without through connections across building causes even greater loss in efficiency.

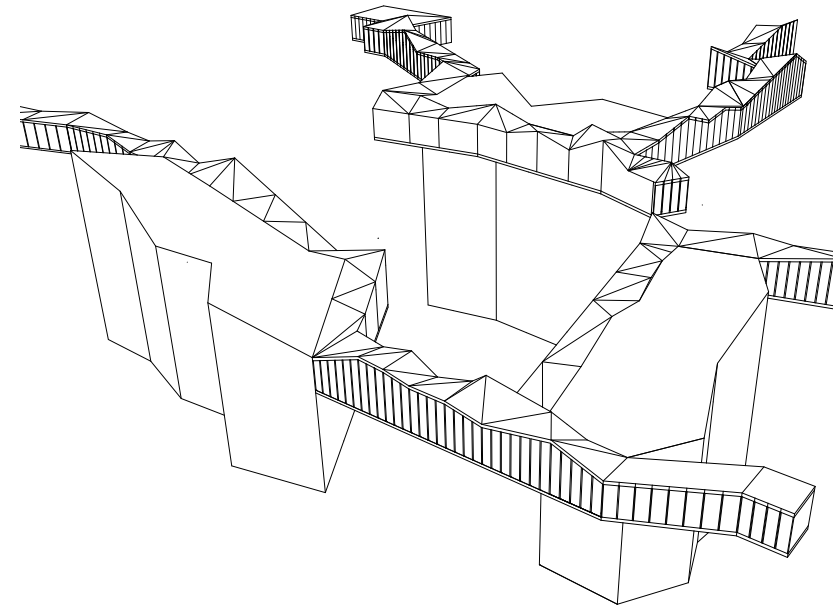

The third design tests bridges on the interior of the building which is definitely more efficient than on the exterior but the connection between buildings is still lacking and each arm is very separated. this is because the arms of the bridge are curving around the geometric shapes of the building causing this lack of connection. this is also no central bridge across the courtyard that can easy connect all three bridges together. visually the arms connect to the building and give it a more dyamic shape and feel of movement.

BRIDGE PLACEMENTS AND CONNECTIONS

Developing the placement of bridges either on the internal walls or external walls of the buildings, working through connections and circulation.
1 Authors Own Image

2 Authors Own Image

3 Authors Own Image 


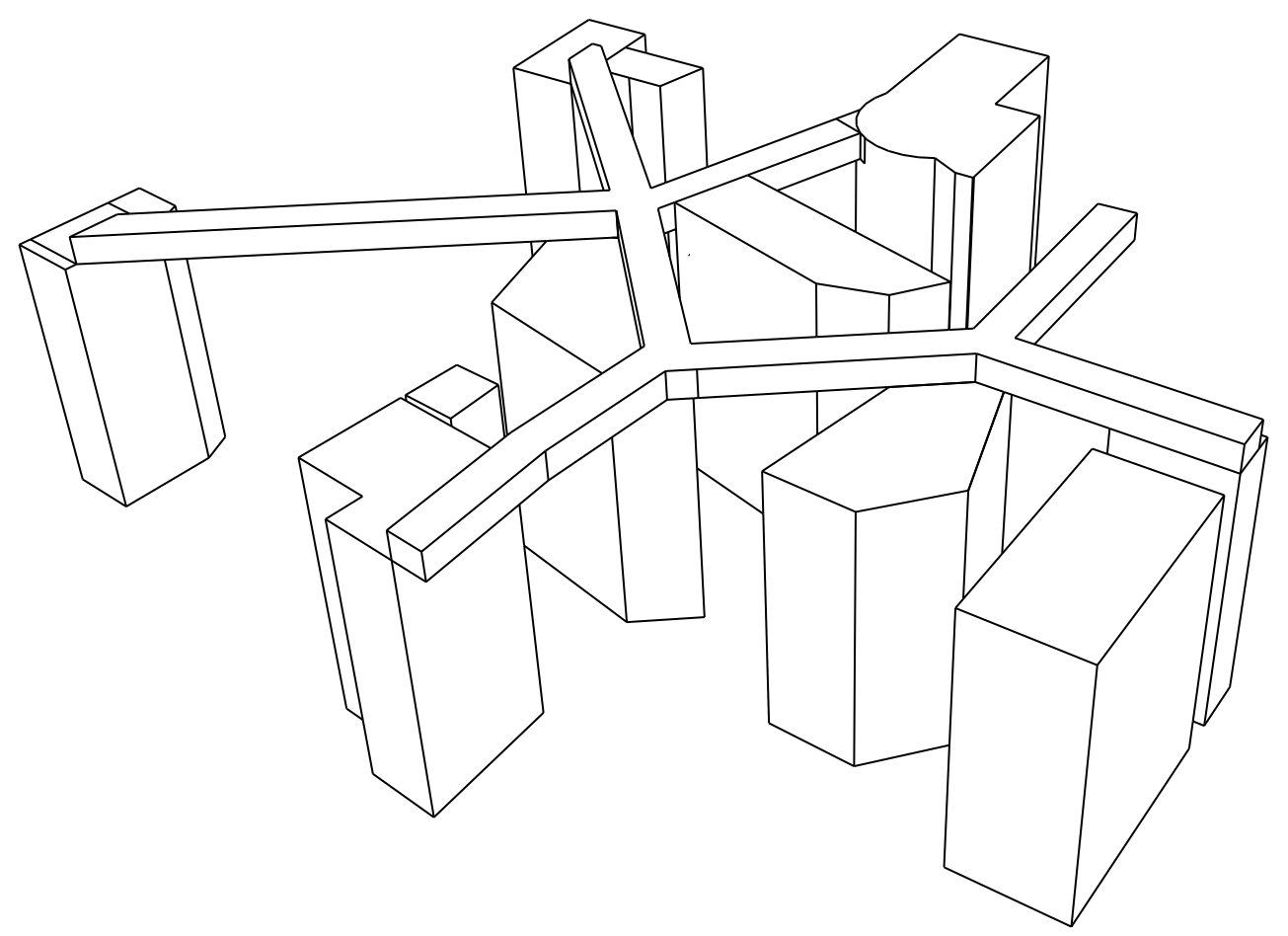

The forth design focuses on blocking out the most effective way to connect these three building together with the intention for merge design three and design four to create the final design. where possible the arms are centalised which means that multiple connections can be made between the buildings and the surrounding apartments and makes travelling between the bridge arms quicker and more efficient. this deisgn now needs to consider the visual connection between the building and the bridge walkways as this is disjointed due to the forms not wrapping around each other. 


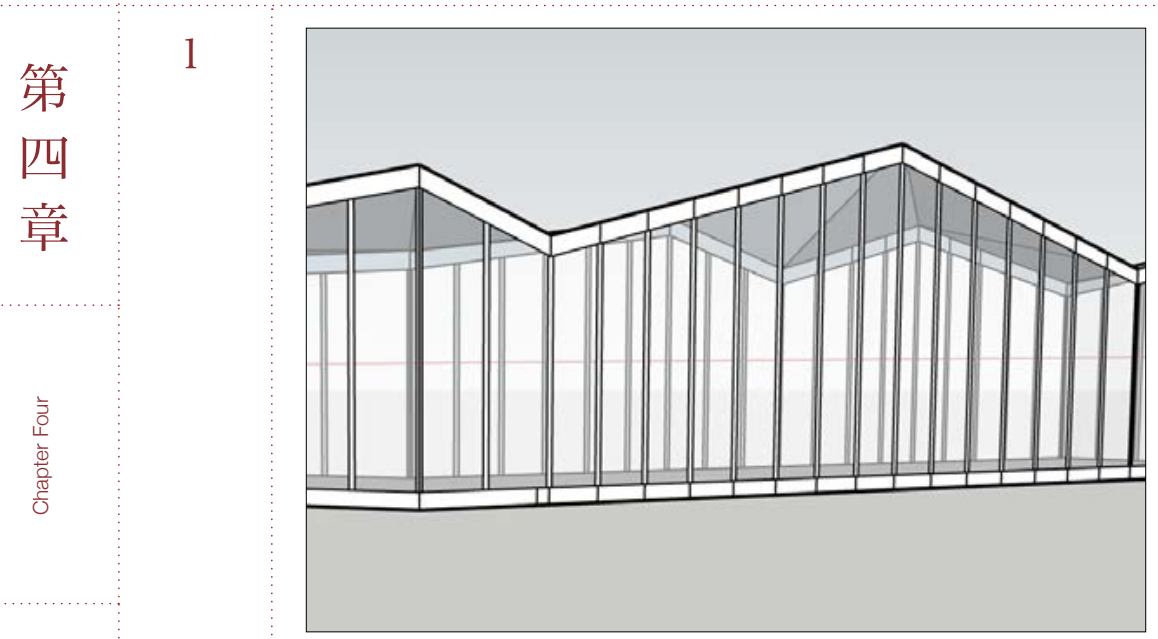

2

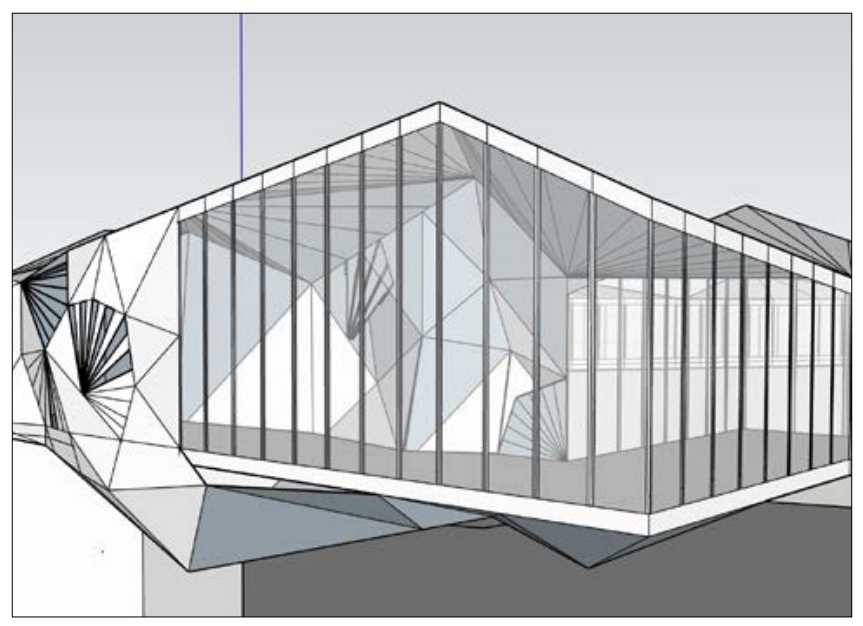

3

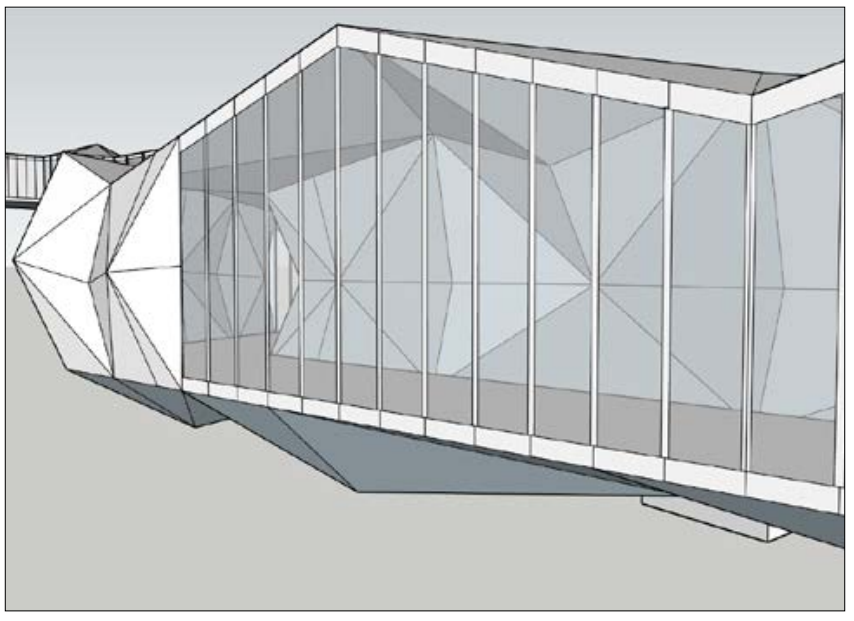

3D BRIDGE FORM DEVELOPMENT

Developing the form and geometry of the bridges themselves giving a dimensional quality to the spaces and so imterest from outside at street level.
Straight sides and underneath side with geometric roof.

Developing the underneath side of the bridges to create visual interest for those below. exploring the idea of wrapping the geometric forms around the bridges in different places

Simplifing the geometric form to something more linear and symetrical whilst still creating interest for the eye. this simplicity creates a more modular approach easier to construct 


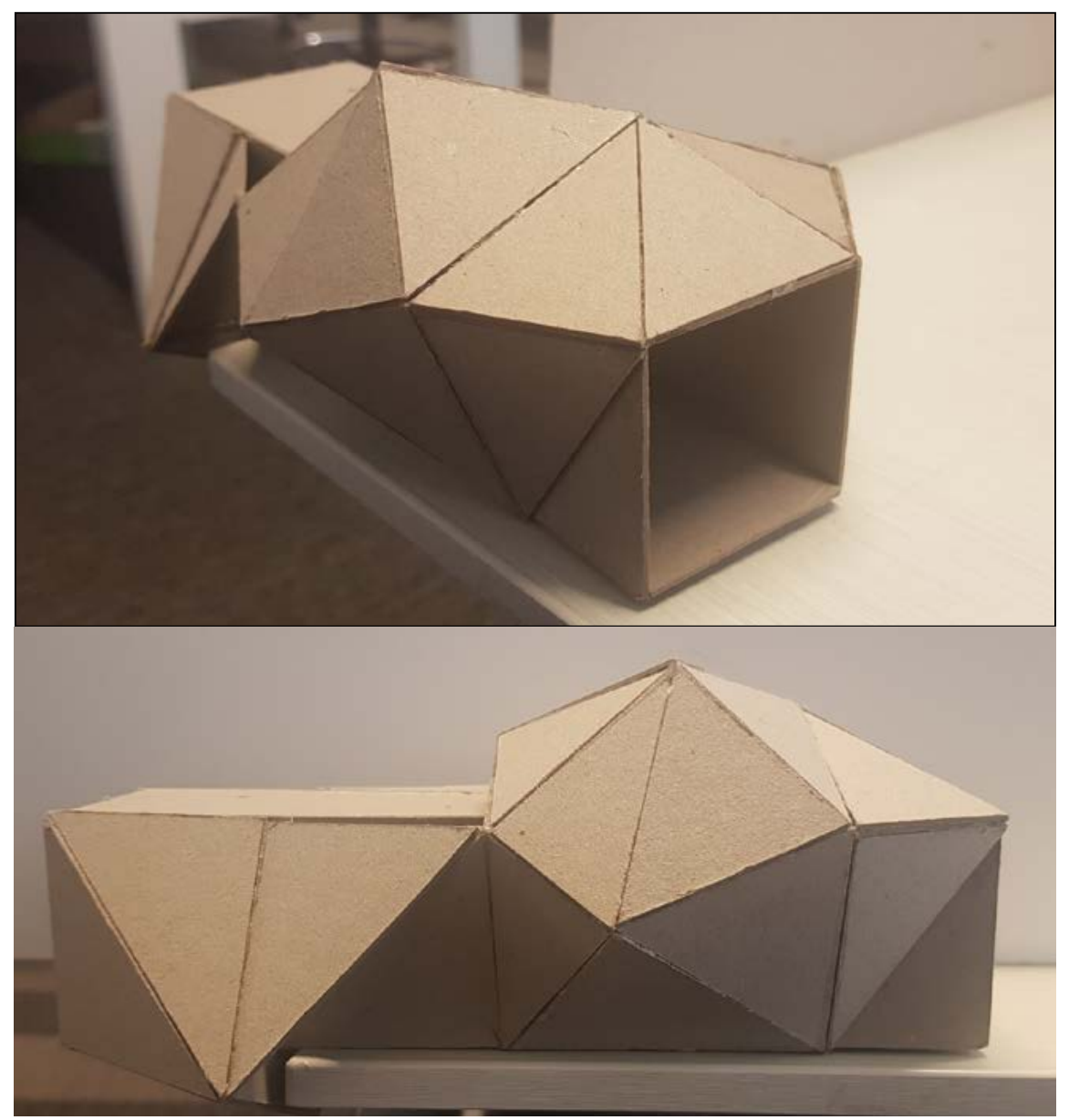

The Dynamics of the bridge from the interior but also externally are equally important as this deaign feature has a bold impact on the surrounding area. Starting with the roof and then developing the geometric fractures to curve around the edges and underneath the bridge form was important as the view of these elements would mostly be seen from underneath. Another consideration was the relationship between the window panels and the panels making up the geometric fractures. both the balance of open and closed throughout different areas of the design as well as the threshold between the two and how this would be finishes was thought through and developed through multiple iterations. once again a merger of all of these ideas to create a design that was fractured by not ordered nor too complex was created with balance between all factors. exploring the extremes and understanding the visual implications of symertry or lack there of was an important process to come to the final design outcome and took, drawing, physical and digital modelling to create the final design. 

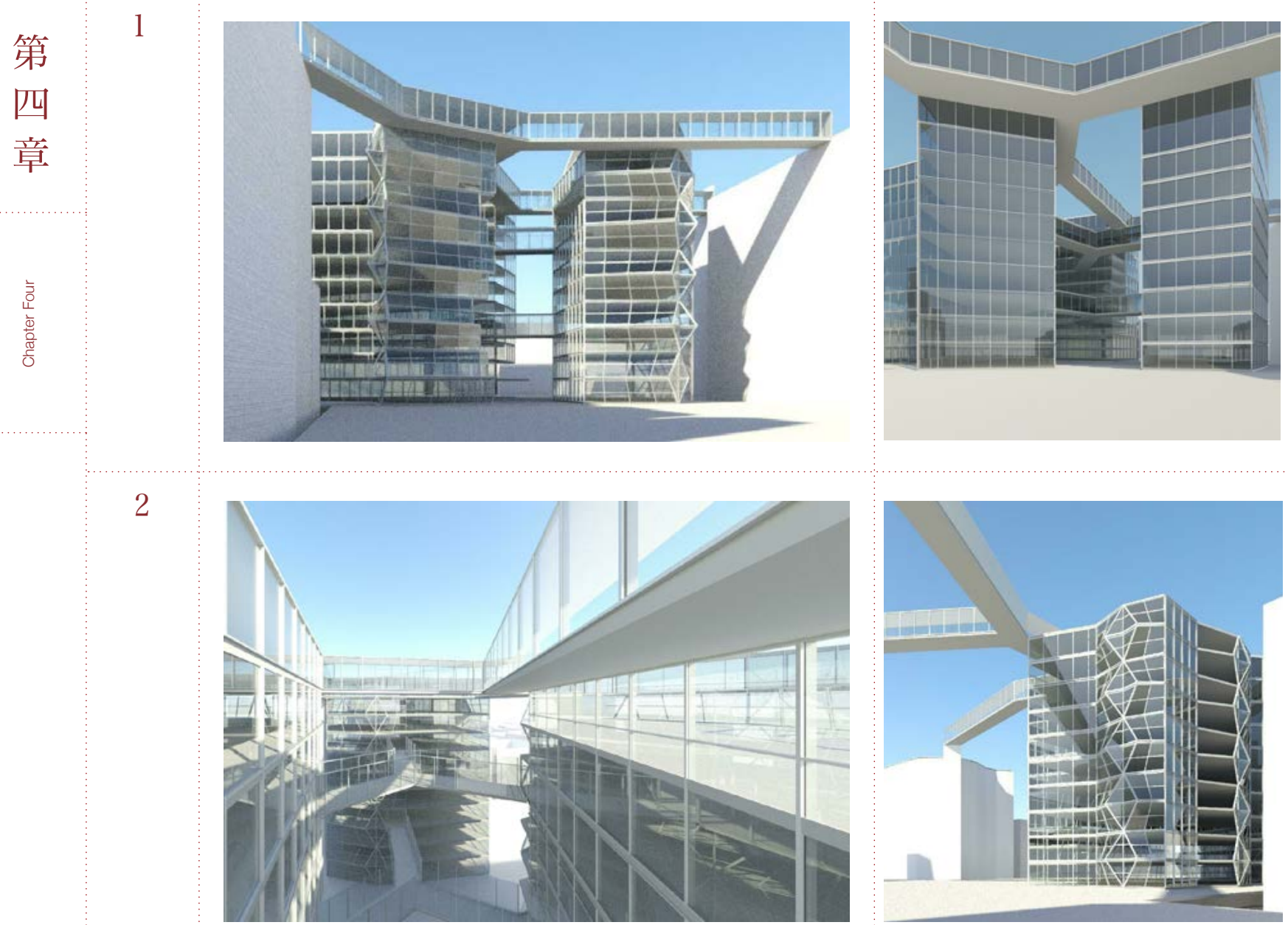

3
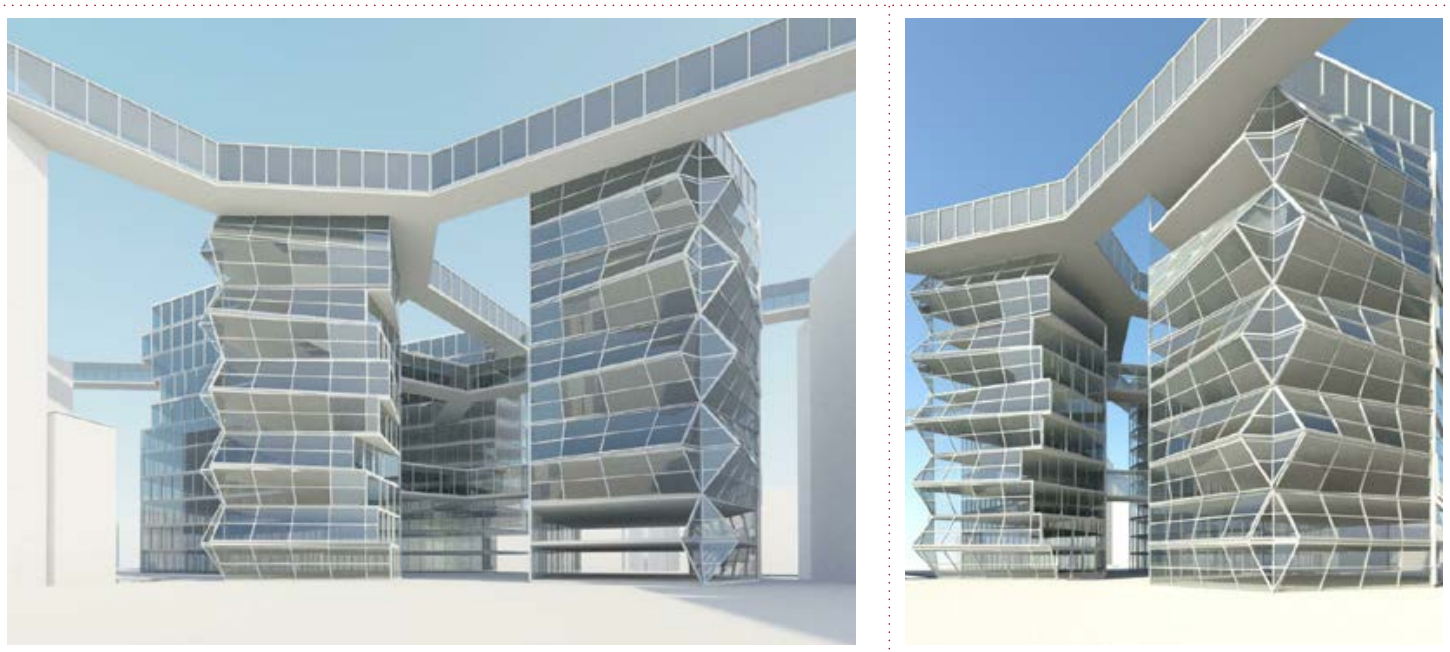

\section{DEVELOPING ABSTRACT FORM TO ARCHITECTURE}

These images begin to explore these ideas in a more recognisable architectural form still developing the geometric aespects from previous imagery and applying them in a way able to be supported through structural design. More focused on ciruclation and occupation of space these developments bring the forms more into the world of realism. 


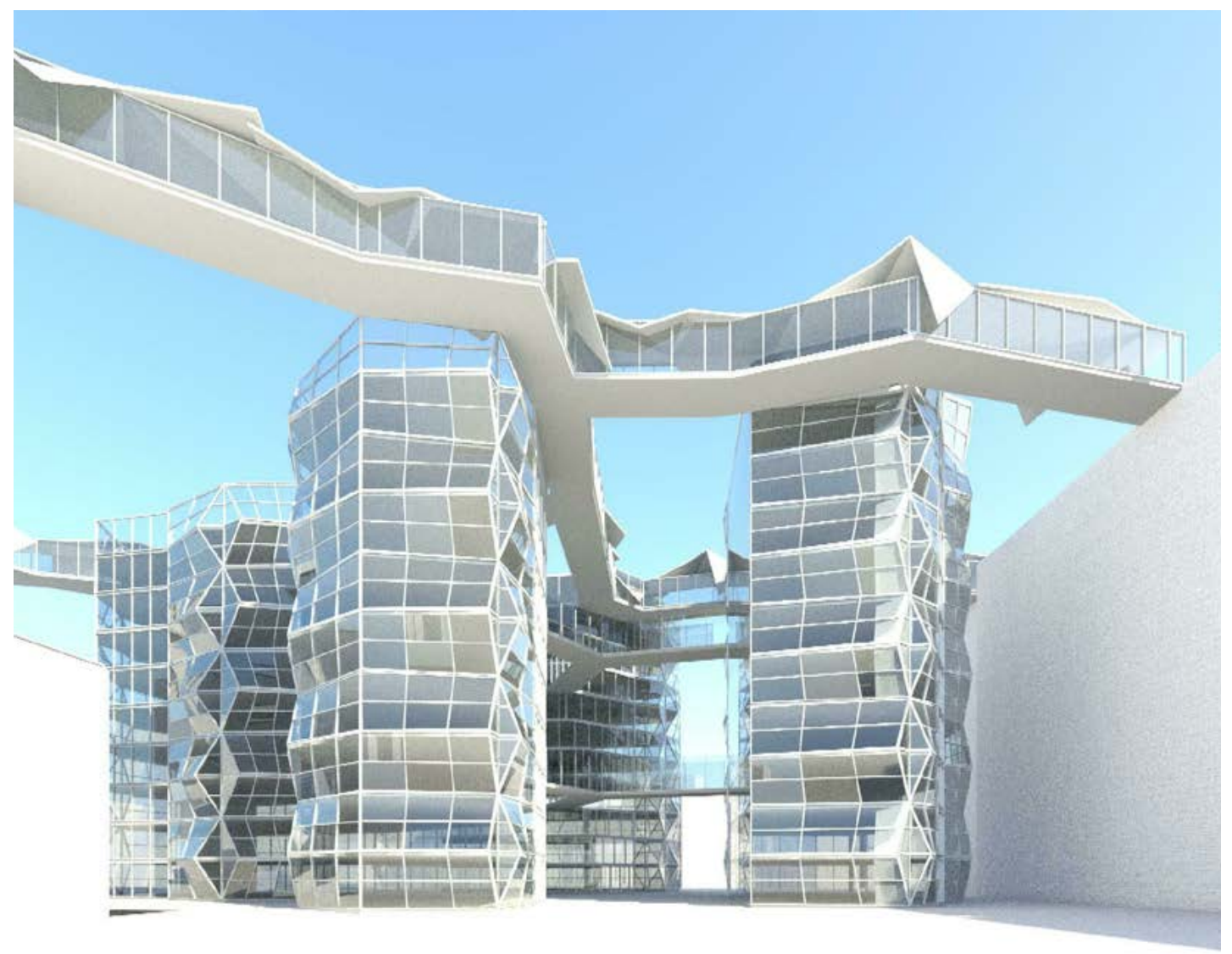

The focus of development in these stages is creating realistic design gestures such as a curtain wall, canopy roof and structural beams and columns and adapt them to display the characteristics and visual ideas previously explored. Although stretching some limitations of gravity and possibility in the way that the bridge arms connect to surrounding buildings the central buildings on the whole could be built with todays technology grounding the project and giving it a sense of realism.

Developing this was really important to the design process and outcome as it provides a stronger position for the ideas rooted in reality. 


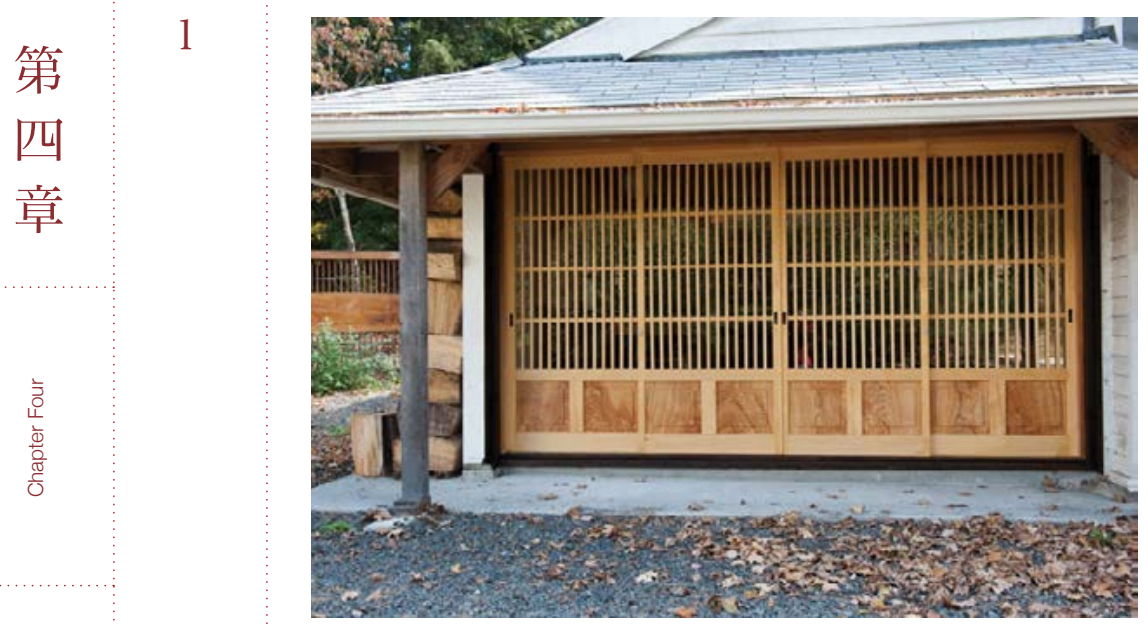

Architecture that explores the traditions and customs of a culture and reflects this back into the building fabric in a way that is meaningful, connects to the sense of place and creates a relationship between the past and the present. traditional japanese architecture is very organic and uses a connection to nature and natural materials in the majority of japanese works both modern and traditional. An incredibly detailed and technical interior detail is the use of Kumiko woodworking to create patterns within wooden panels. This art form dates back to the 8th century and each delicate design is assembled by hand by grooving wodden slits and arranging them in a geometric pattern. Making use of naturally strong shapes such as triangles, pentagons and diamonds these panels are highly durable and long lasting.

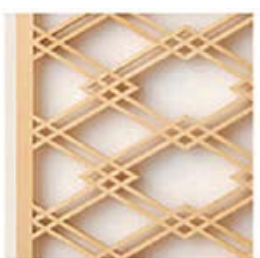

Wari-bishi

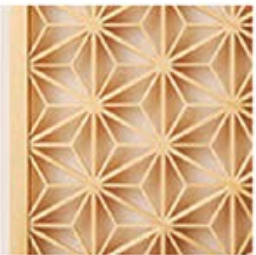

Asanoha

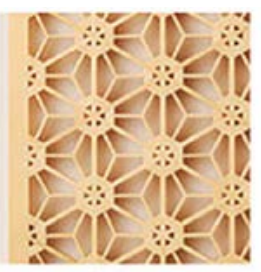

Sakura

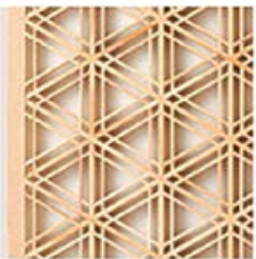

Goma

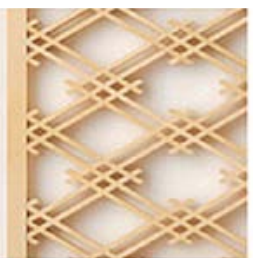

Izutsu-wari-bishi

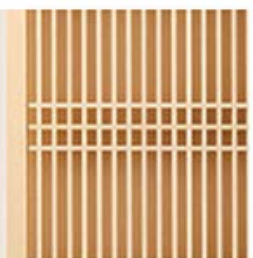

Senbon-koushi

\section{INTERNAL AND EXTERNAL DETAILING}

The fine detailing of the building brings another layer of texture to the overall aesthetics and in this case also brings some colour into an amost entirely glass and steel building. the warmth of the wood gives the building so much life and the traditional way it is being used relates back to the cultural roots of buildings cultural context.

Traditional Japanese screens created by hand with very fine delicate wood, there are some examples of possible patterns used to make these traditional screens.
Popular Woodworking. (2015, May 26). Kōshi-do. Retrieved March 22, 2020, from https://www. popularwoodworking.com/article/koshi-do-2

DiStasio, C. (2016, July 16). Japanese wedding chapel is lined with INTRICATE Hand-carved flowers to

2 connect the past with the future. Retrieved March 22 2020, from https://inhabitat.com/japanese-weddingchapel-is-lined-with-intricate-hand-carved-flowerto-connect-the-past-with-the-future/

Tanihata. (2012). Kumiko design motifs tanihat co,ltd. Retrieved March 22, 2020, from https://www. tanihata.co.jp/english/products/list.htm

Tanihata. (2012). Kumiko design- Asanoha. Retrieved March 22, 2020, from https://www.tanihata.co.jp/ english/monyou/asanoha.htm 


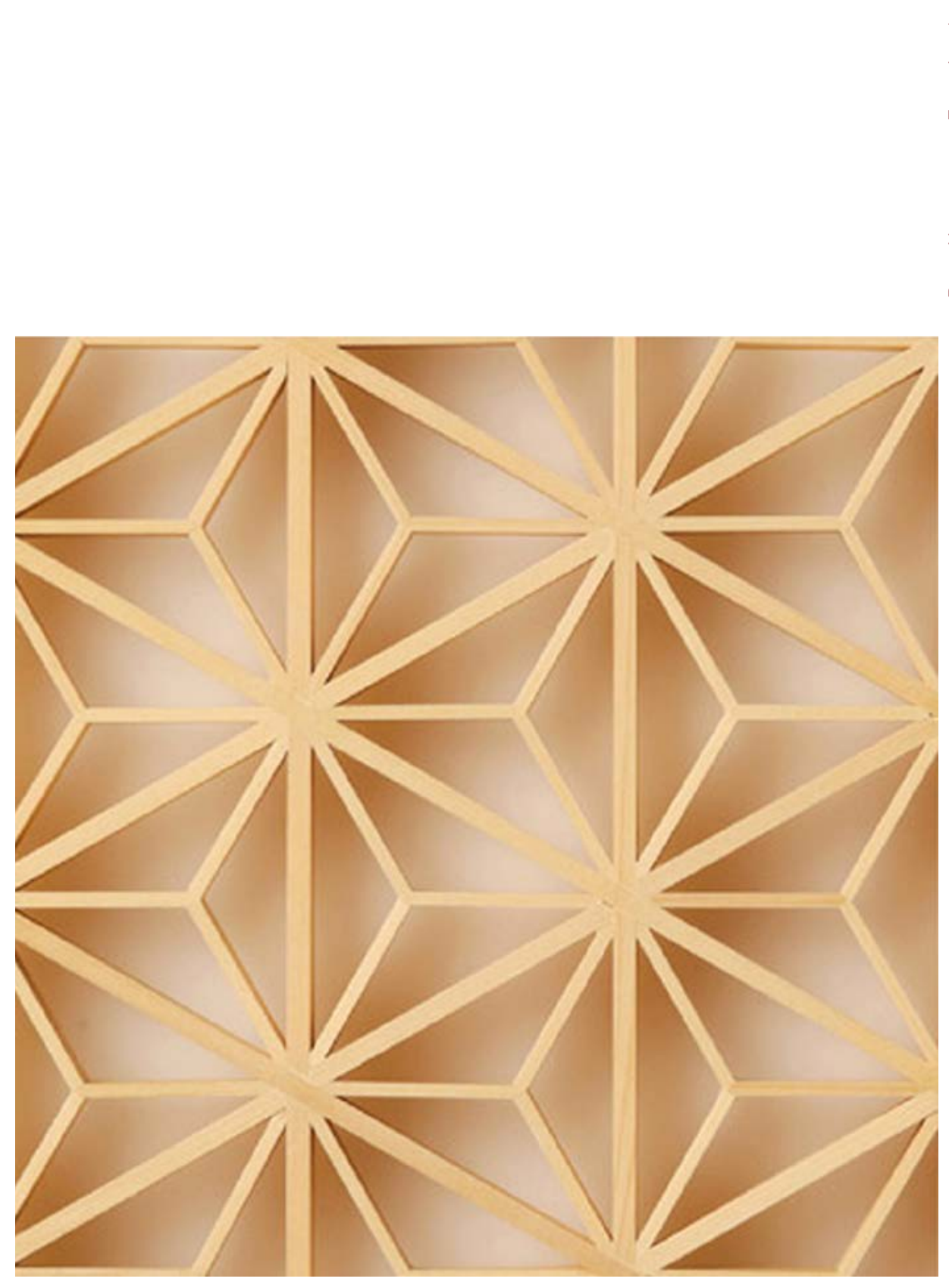

Not only did i want to use this traditional method of woodworking to create the interior detail for the bridge walkway roof and other feature areas in the interior but $\mathrm{i}$ wanted to reflect this art form in a more abstracted way on the exterior building as well in lieu of timber battening throughout the entire building. This not only adds another layer of detail to the buildings facade but also reflects the ideas and art form of traditional japanese architecture in a modern context.

The selected pattern used throughout the building is the Asanoha pattern. This is one of the most popular traditional designs and uses the triangle as a key symbol to protect against evil. An aggregate of triangles the Asanoha conveys a meaning of strength and beauty. connecting this symbolism to the ideas surrounding the building and the Asanoha pattern is a perfect fit for creating a symbol of strength for the elderly community. 


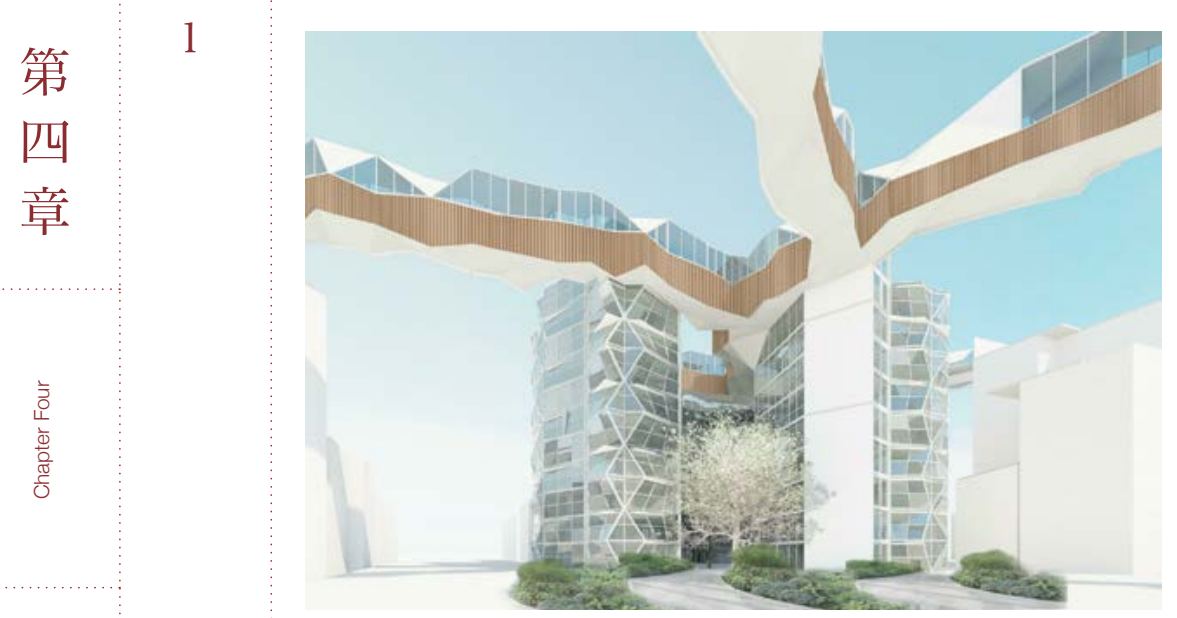

2

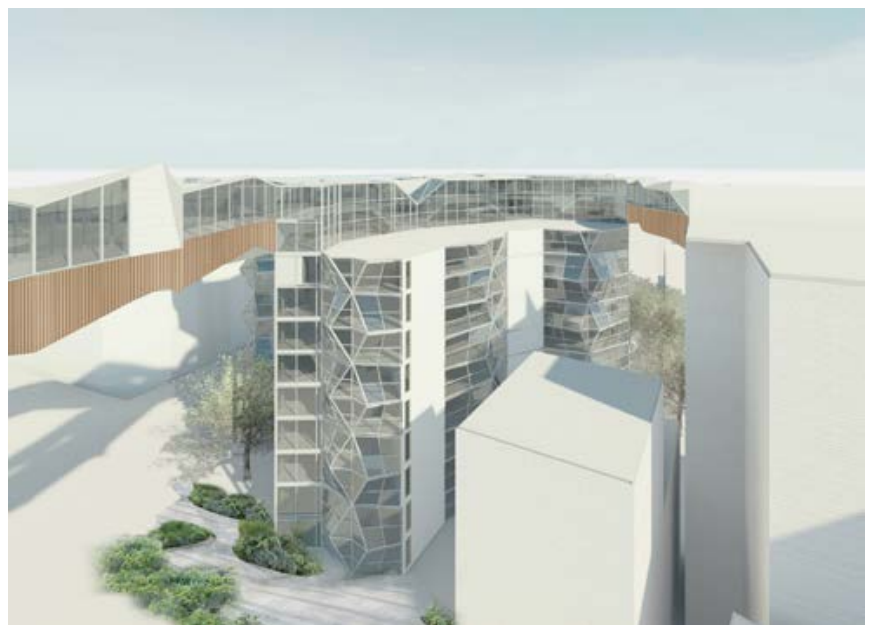

3

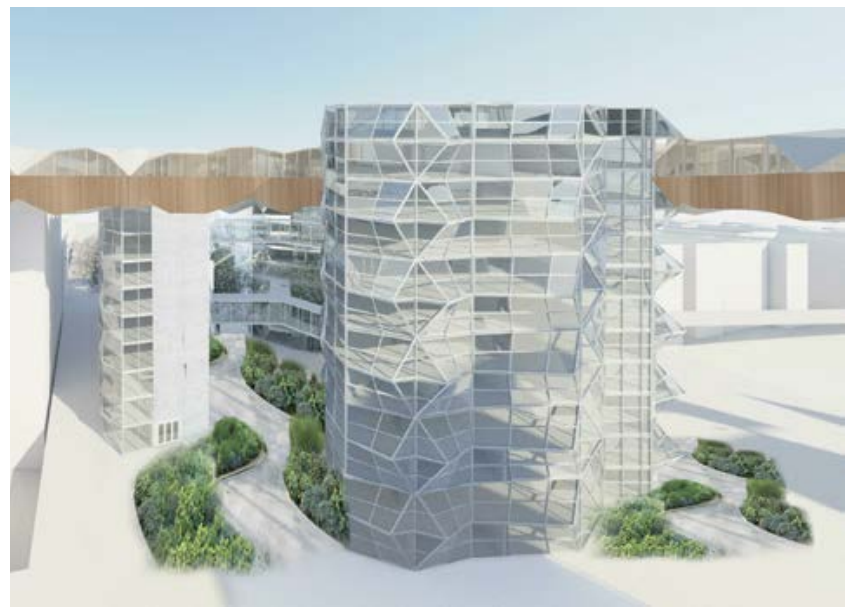

TIMBER DETAILING AND OVERALL ATMOSPHERE

These images start to showcase the timber detailing softening the harsh lines of the glass and mental structure and curtain walls. It breathes life into the building and makes it feel more connected to the natural landscape to the south of the site.
Looking from the large

intersection towards the site, this shows off the addition of wooden detailing to soften and add warmth to the facade.

From the Apartments across the street the integration between the walkways and the main building is clearer as they seamless blend into one.

Buildings on the opposite side experience a much more dynamic diamond facade with the back of the site highlighting the twisted and tilted glass curtain wall 


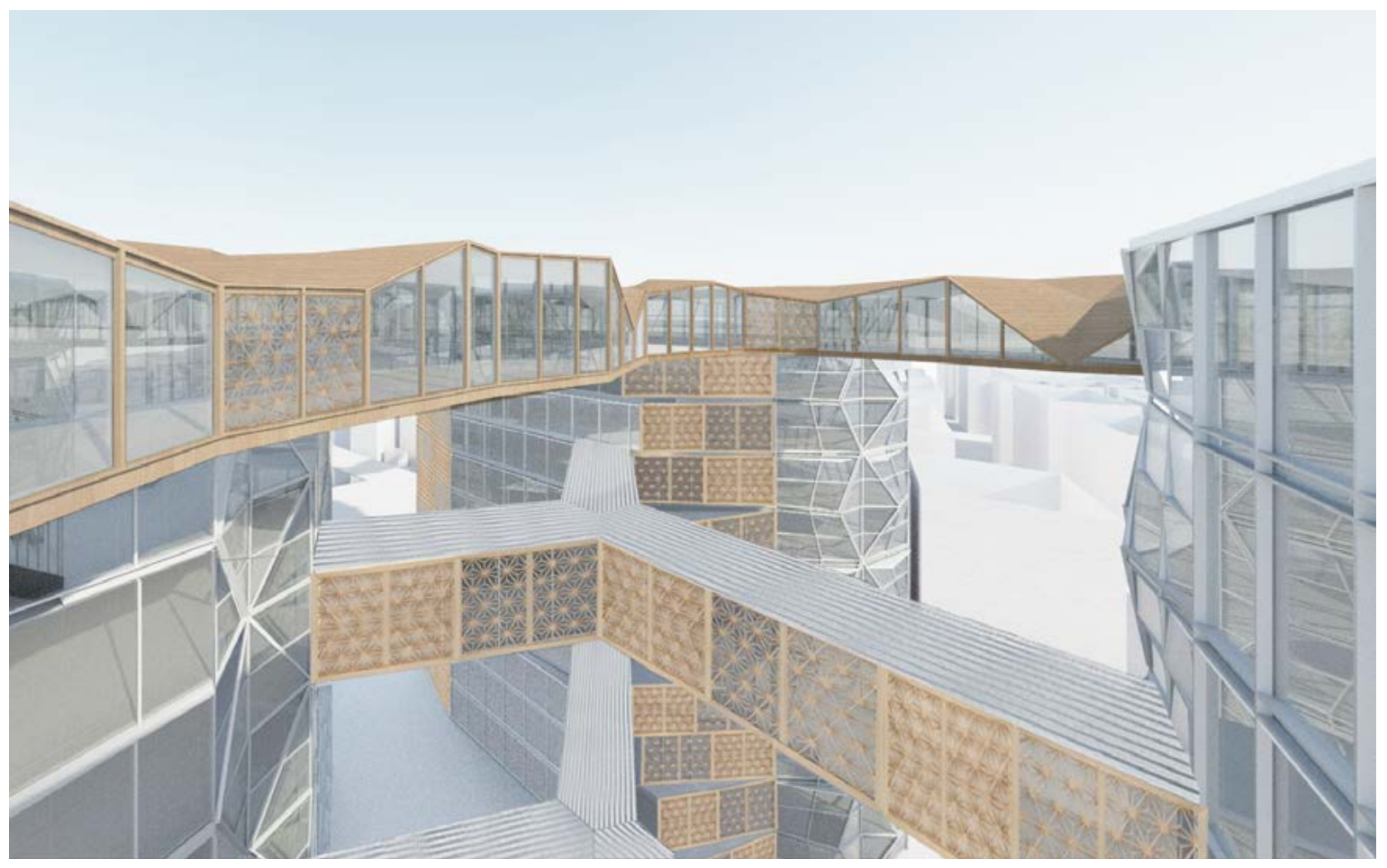

In context the lattice detailing is used to filter light into different parts of the building either opening the corridors to more light or shutting it out. used also as a feature detail on the exterior of the structural sheer walls as a detail over the top of what would be a solid monolithic structural wall. On the interior roof of the walkways the patterning is used in lieu of plain skylights to control the amount of light entering the space from the roof allowing more light to penetrate and create patterning shadows across the walls and floor, changing throughout the day with the movement of the sun. This breaks up the heaviness of the roof structure and creates the imagery of a tree canopy with sunlight penetrating down through the dense leaves of trees. this design detail also brings natural colour to the design complimenting the green landscaped garden courtyard below. 


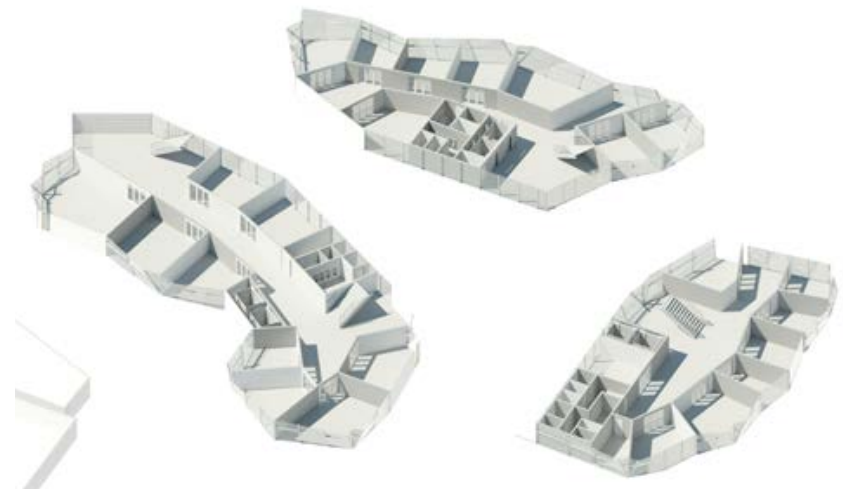

[ [Ground Floor Retail]

- Mixed Size Retail Spaces

- Open Feature Staircase

- Internal and External Access

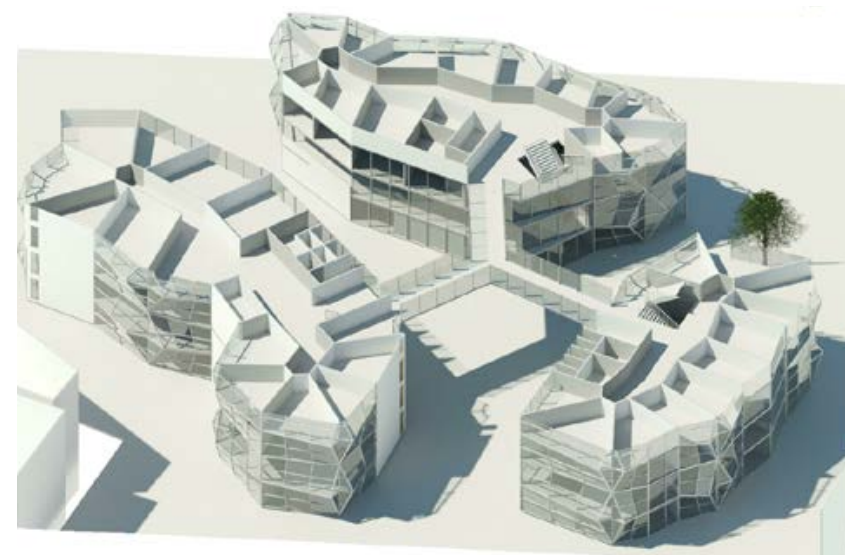

3 [Health Services]

- Doctor Exam Rooms and Offices

- Waiting Space and Reception

- Therapy and Physio Active Mobility Space

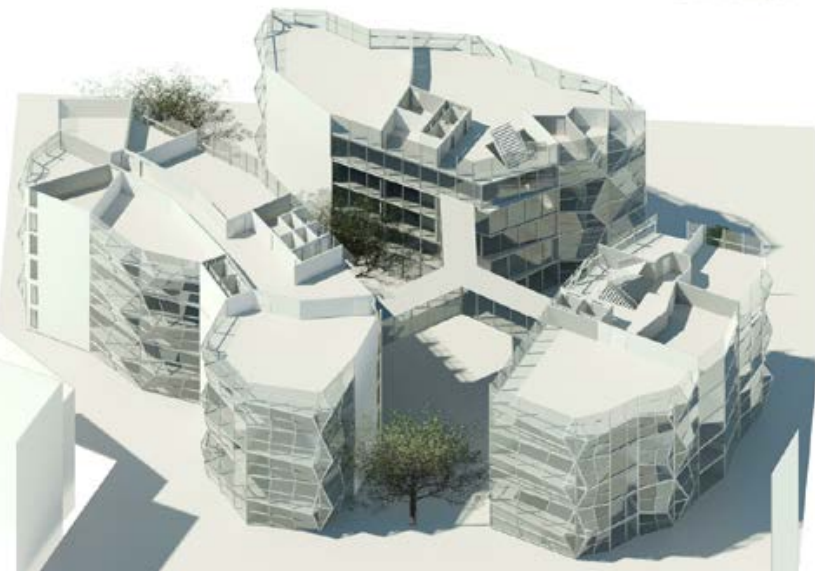

\section{5 [Care Worker Training]}

- Lecture Theatres and Studio Teaching Spaces

- Staff Offices and Internal Staff Space

- Student Dorm Rooms

- Student Open Study Space

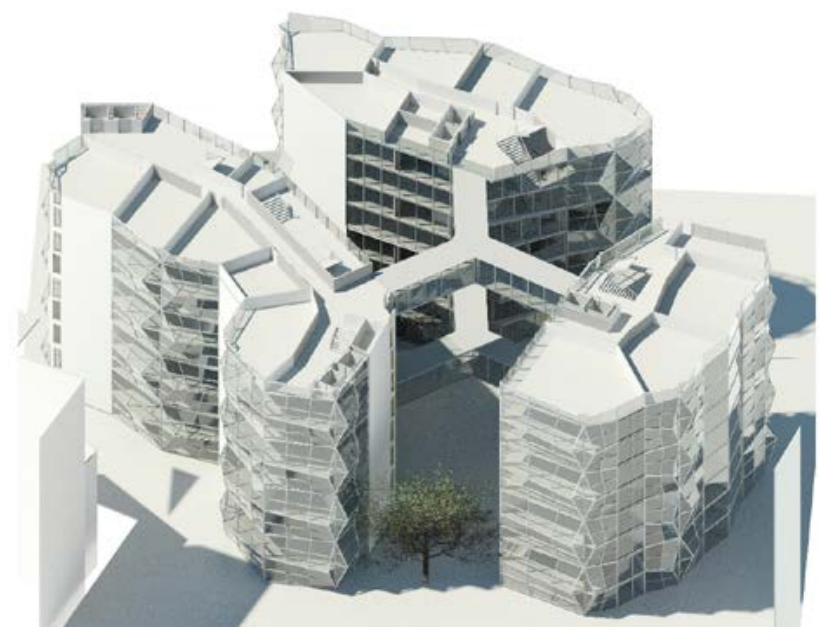

$8 \quad$ [Care Delivery 1]

Medical Supply Storage and Security Protected Drug Room

- Staff Offices and Internal Staff Space

Laundry Storage/ Non Medical Supply Room 


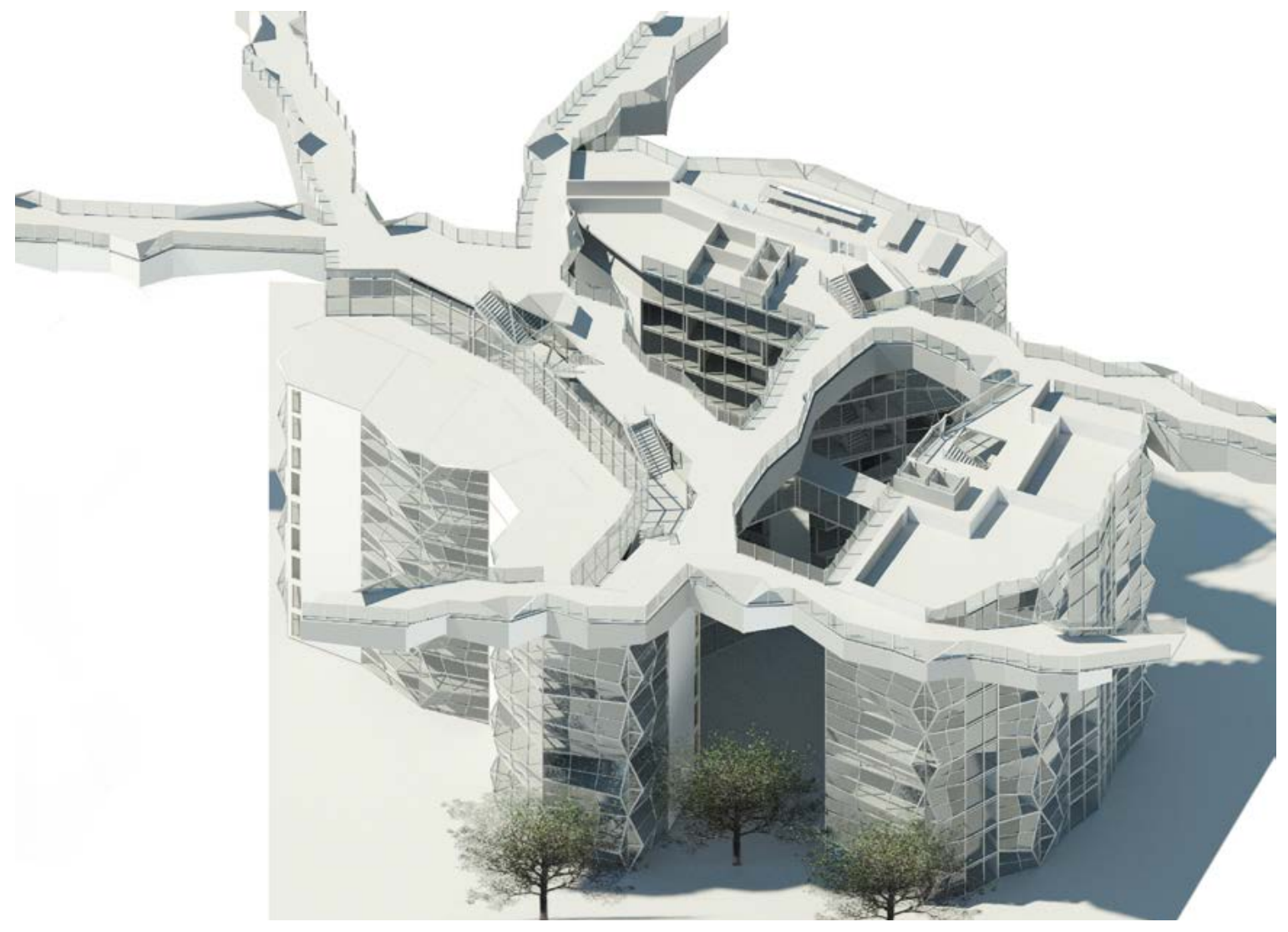

10 [Walkways]

- Walkways connecting to surrounding buildings

- Full Commercial Kitchen and Food Storage

- Medical Supply Storage and Security Protected Drug Room

- Laundry Room Double Height Upper Level -Drying, Ironing and Folding 


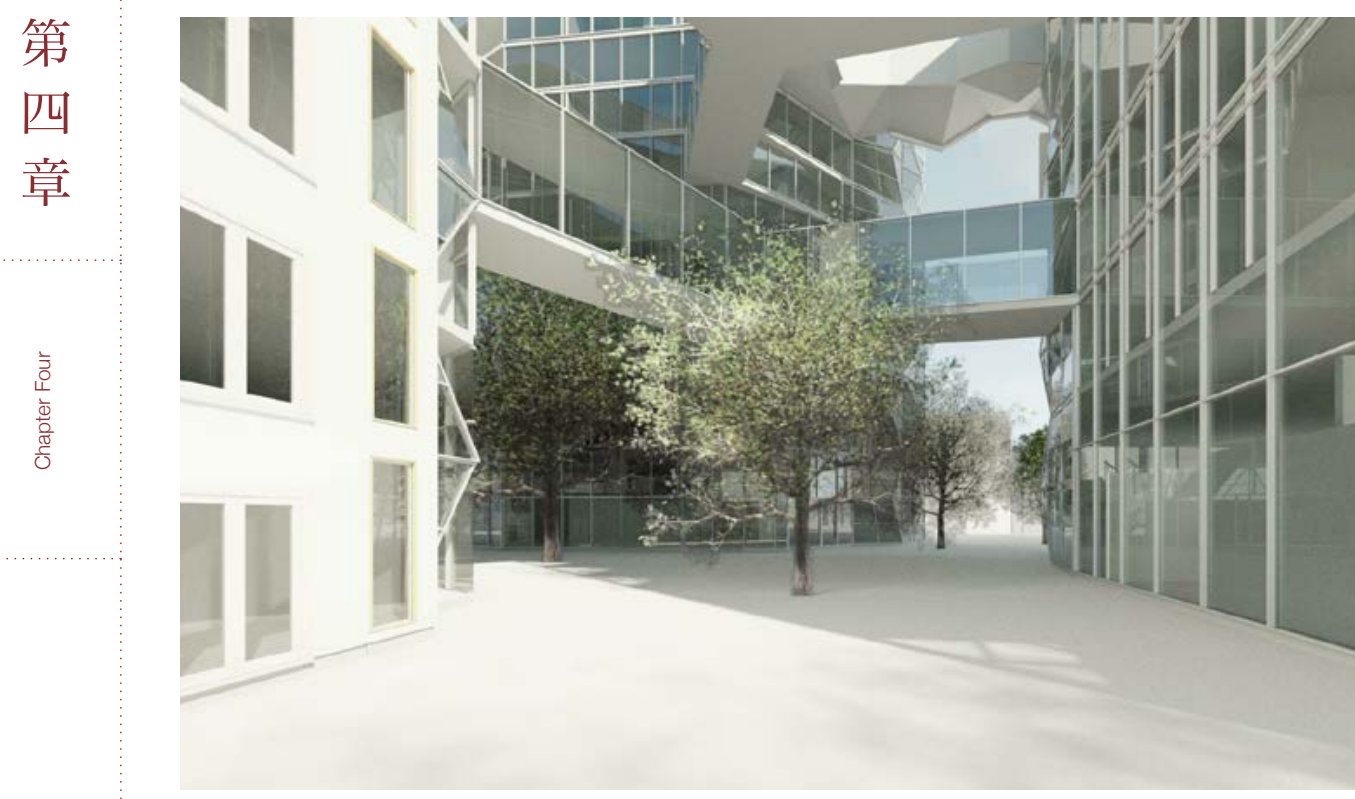

Ground Floor

Retail: Looking into

the ground floor plaza

connection into the

ground floor retail spaces.

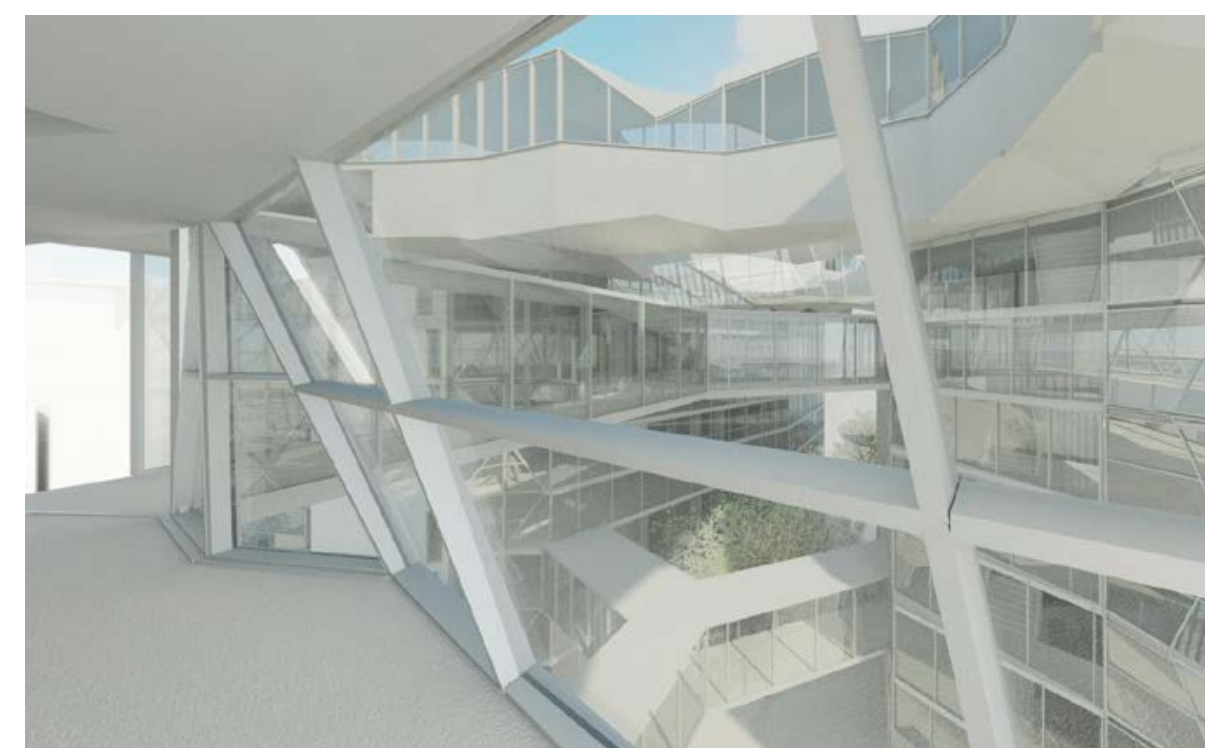

Care

Delivery: level 8

looking out into the central area

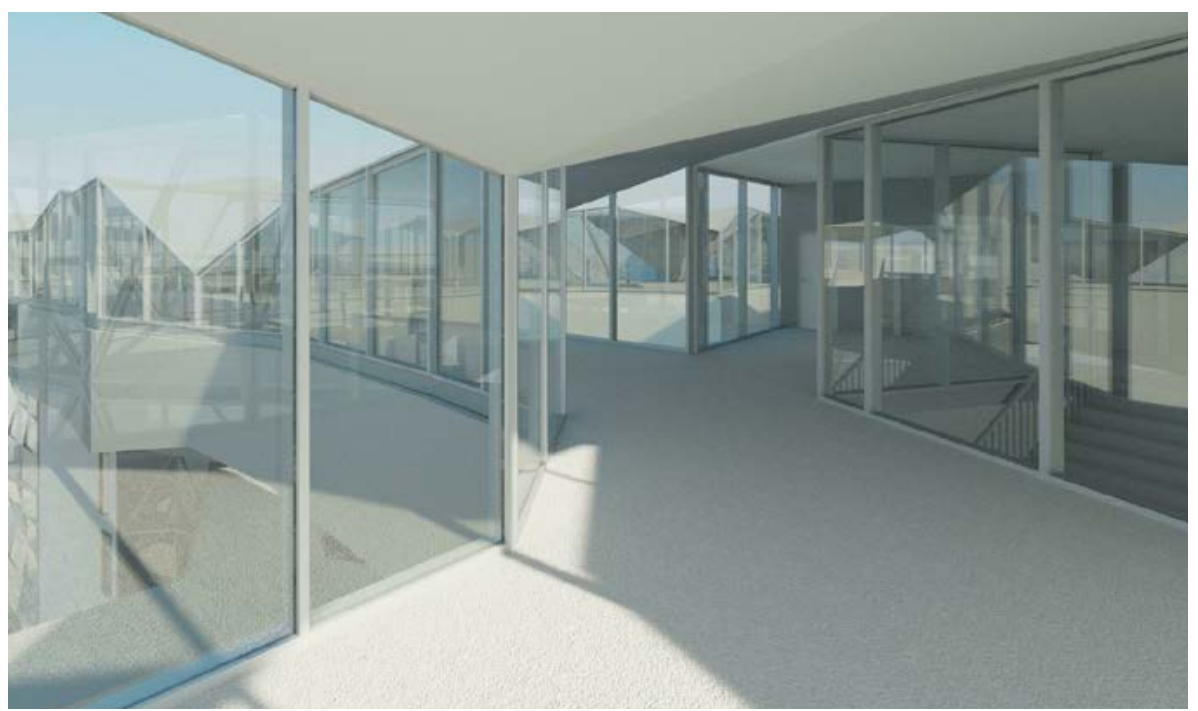

Walkways:

uppermost floor

showing internal bridges intersecting 


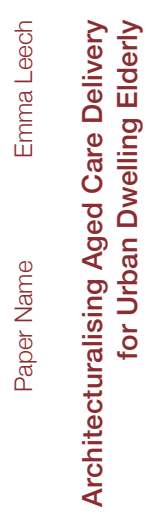




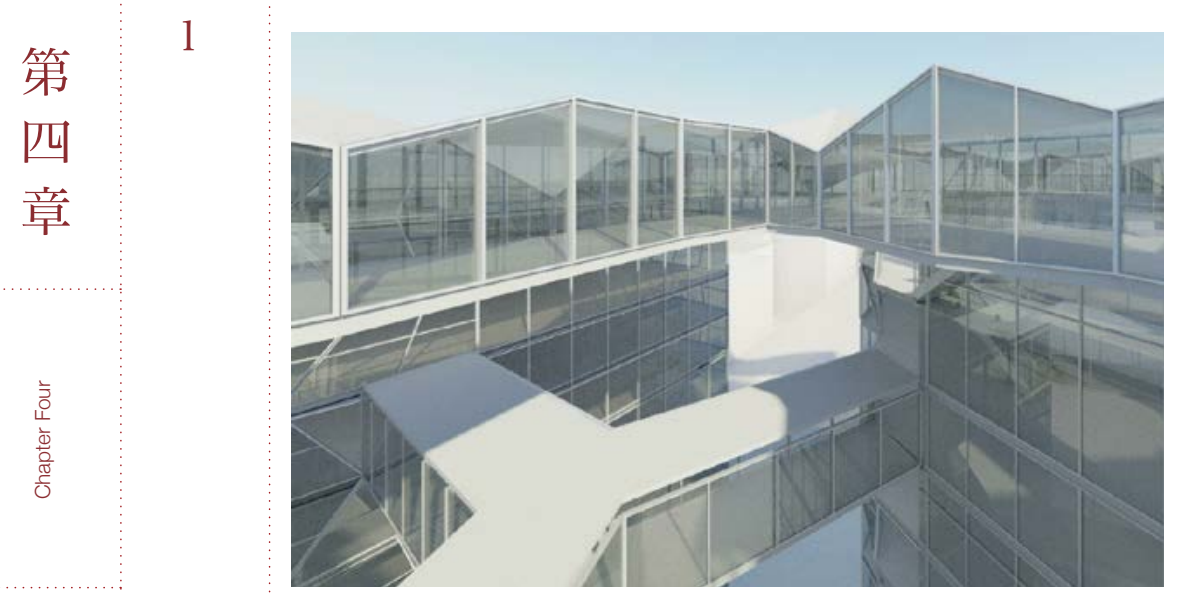

The bridges wrap around the internal facade visually connecting the internal to the external design composition. The development is focused on visual forms and has not yet included the structural support to hold up the walkways.

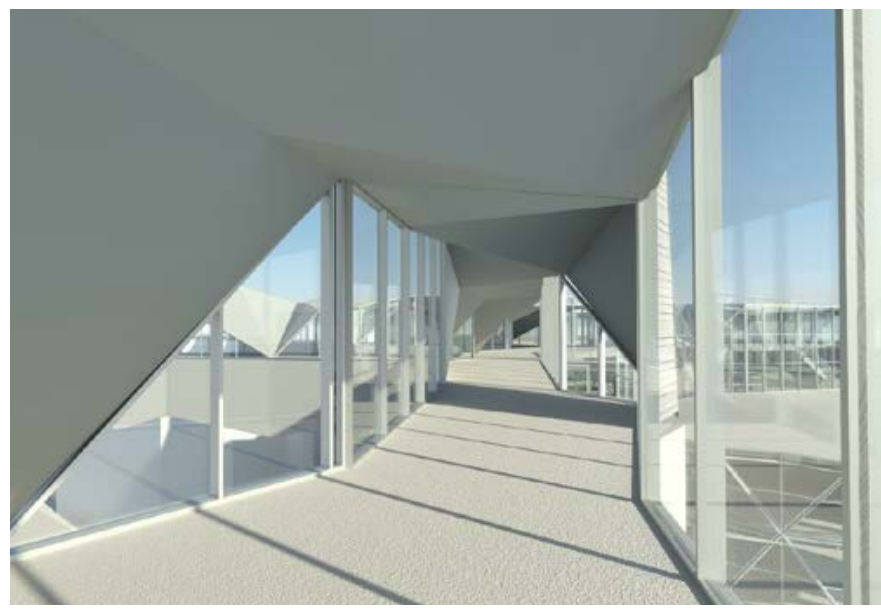

Walking through the bridges the roof panels arch across as a protective canpoy geometrically reflecting the forms of the main building but further abstracted and enhanced.

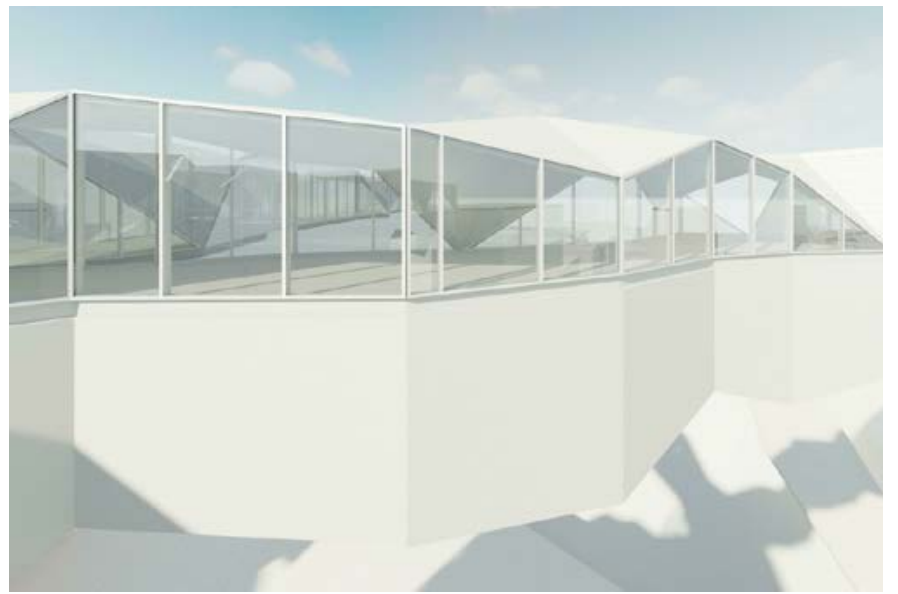

Exterior of bridge showing relationship between underneath structural support and walking space. the structure involved in the design make the full height spread across two floors and is hidden by aesthetic panels that provide a seamless finish.

These visualisations showcase the final stages of the bridge arm development where the structural depths have been considered and the layering of the canopy roof has been added to create a styalistic detail both externally and internally. 


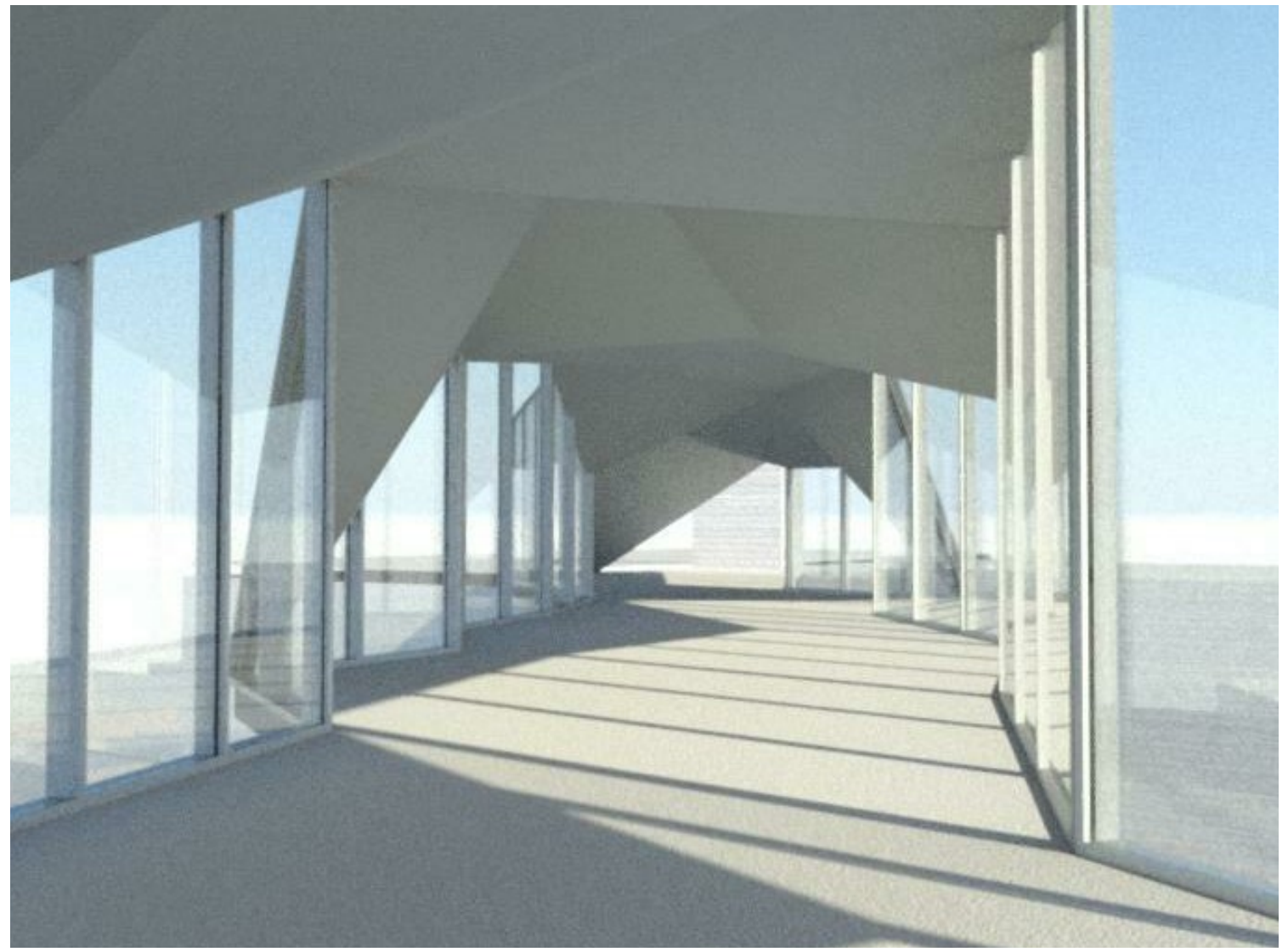

The design of the arms of the bridges was first and formost wrapped around the building form in order to touch as much of the floor plan as possible. This was done to ensure flexibility for the floor plan and allow for multiple points of entry into the bridge system. Each arm of the bridges connects to the highest and most prominent building within each bock surrounding the site closest to the intersection with the assumption that the structure of these larger buildings will be able to cope with the additional sturctural weight. connecting to the closest building also minimises the span of each arm's reach.As the focal point of the design, and most obvious point of difference between my design and the surrounding buildings the decision was made to make the bridges the most prominant design feature. In doing so the primary visual component of the triangle and diamond seen within the shape and fractures of the main buildings is reflected in greater detail here. in the shapes of the winding floor, the canopy roof which connects down to the floor to create triangular angled windows and in the details internally and externally of traditional japanese lattice inspired patterning are all a more detailed reflection of this design intention. 

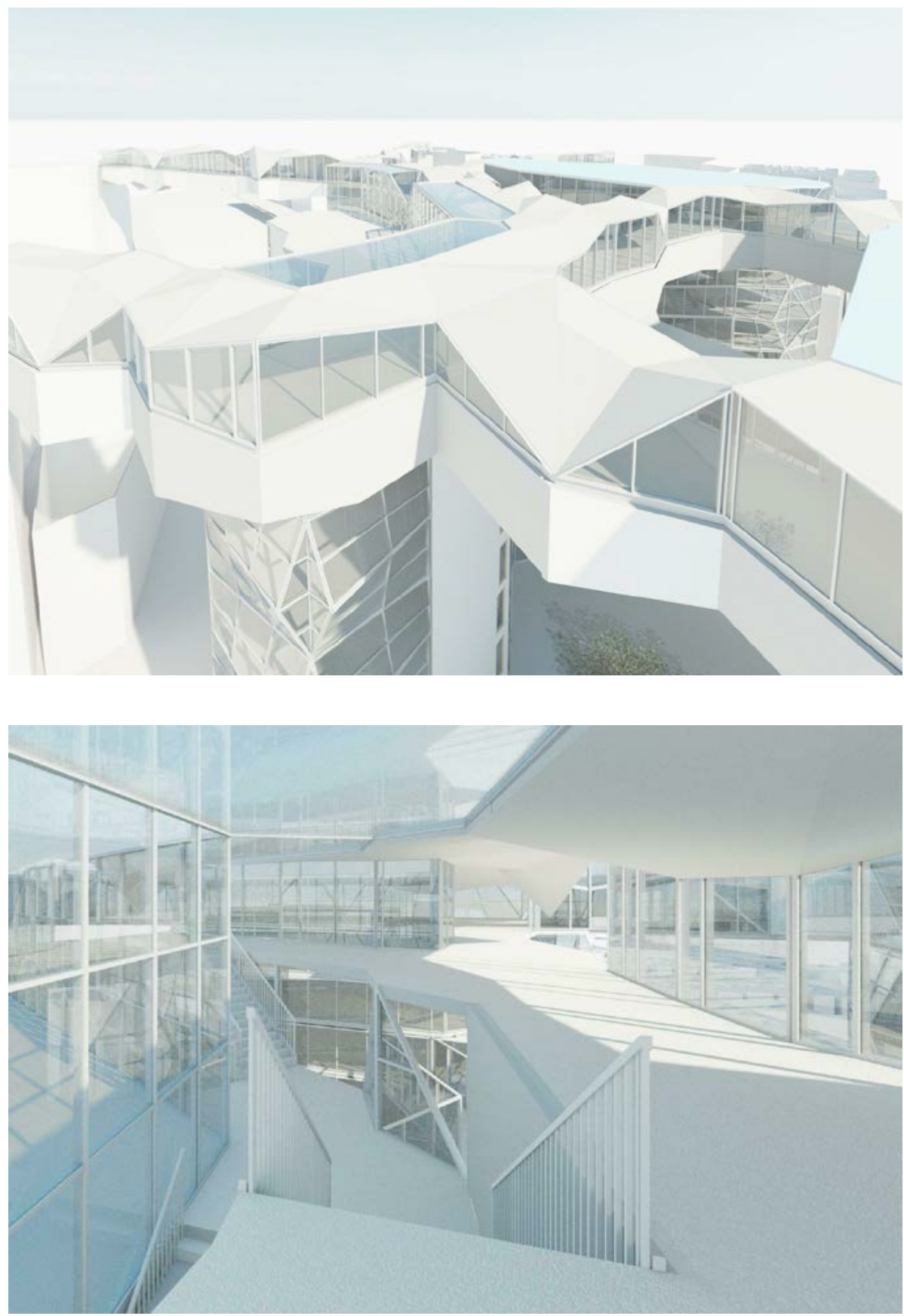

Internal and external view of walkway bridges and their connection to the lower floors. External view is focused on a fork in the road and the connection where two bridges come together to make one and the internal image showcases the internal connection between the bridge walkwavs and the lower floors of the building. It demonstrates the light and bright atmosphere created through the use of a large amount of glass and removing separating walls where possible. 
This image shows all three layers of walkways across the central plaza connecting the three hub buildings together. The bottom two bridges are more simple in style with clean lines and minimal details and the upper walkway has a more unique aesthetic and also is a lot thicker to accomidate more structure to support the larger cantilevers than the other walkways.

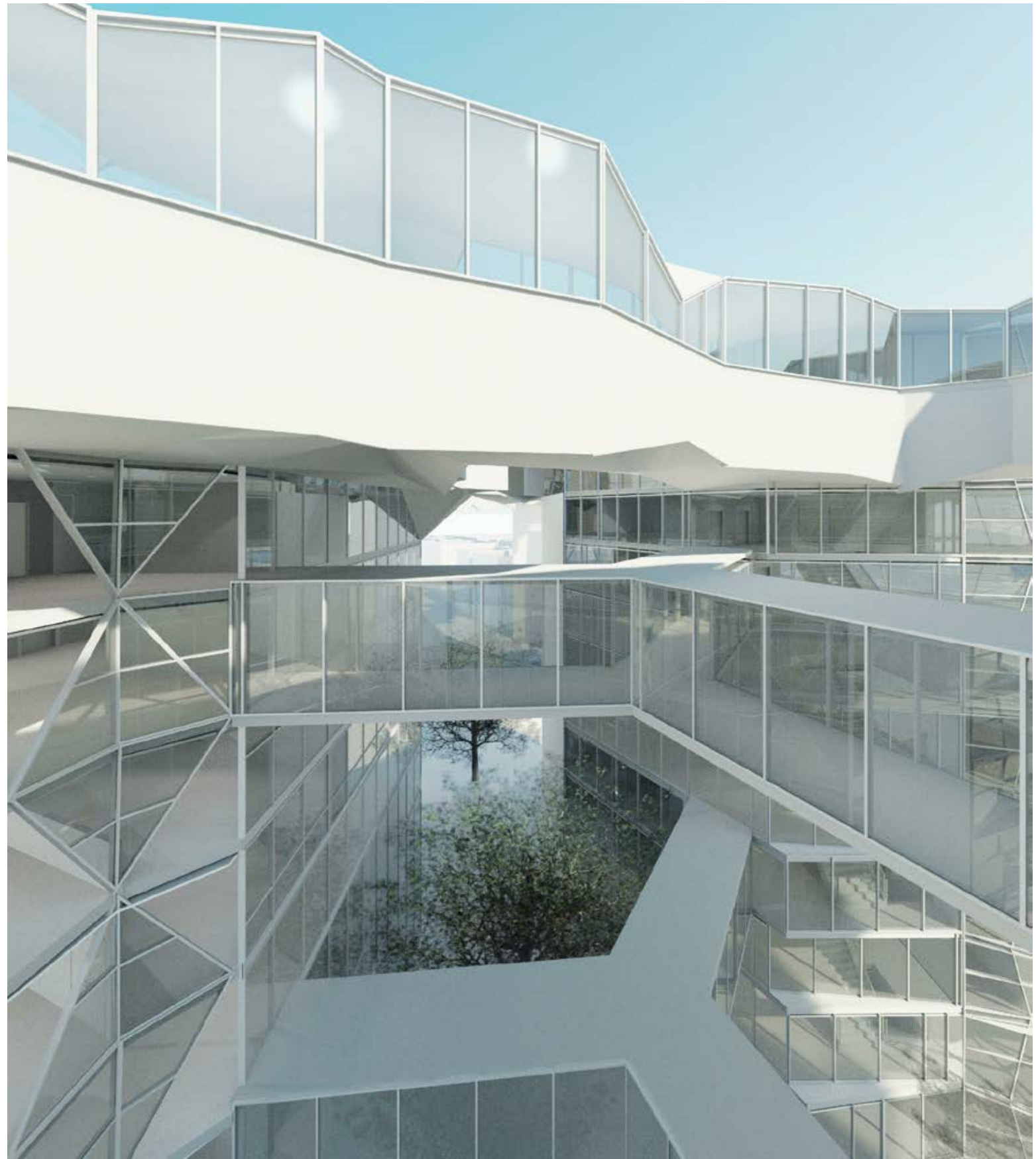


第

四

章

$\frac{1}{0}$
$\frac{1}{1}$
$\frac{0}{0}$
$\frac{0}{0}$
$\frac{0}{0}$

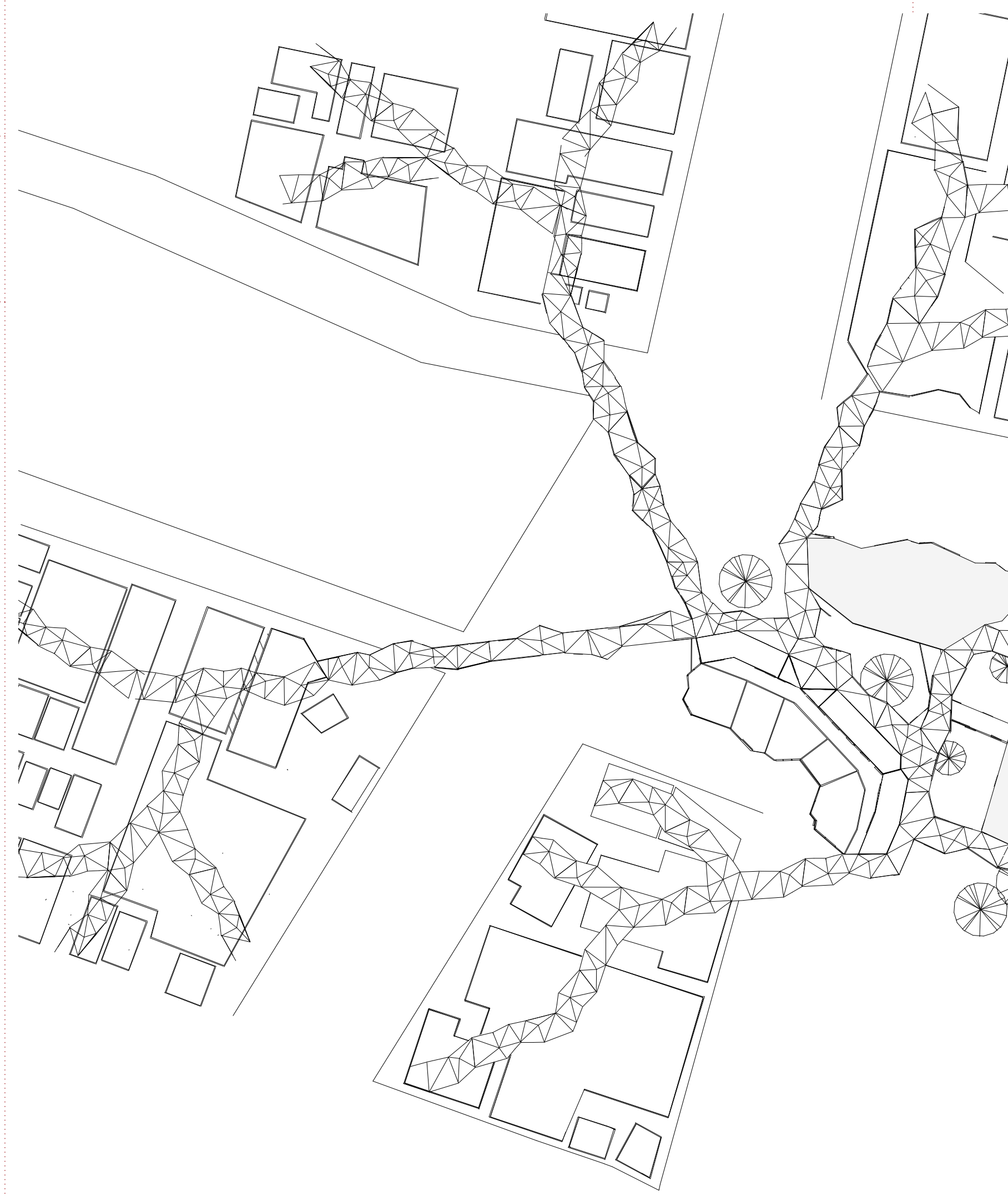


第
几
章

言
善
尊

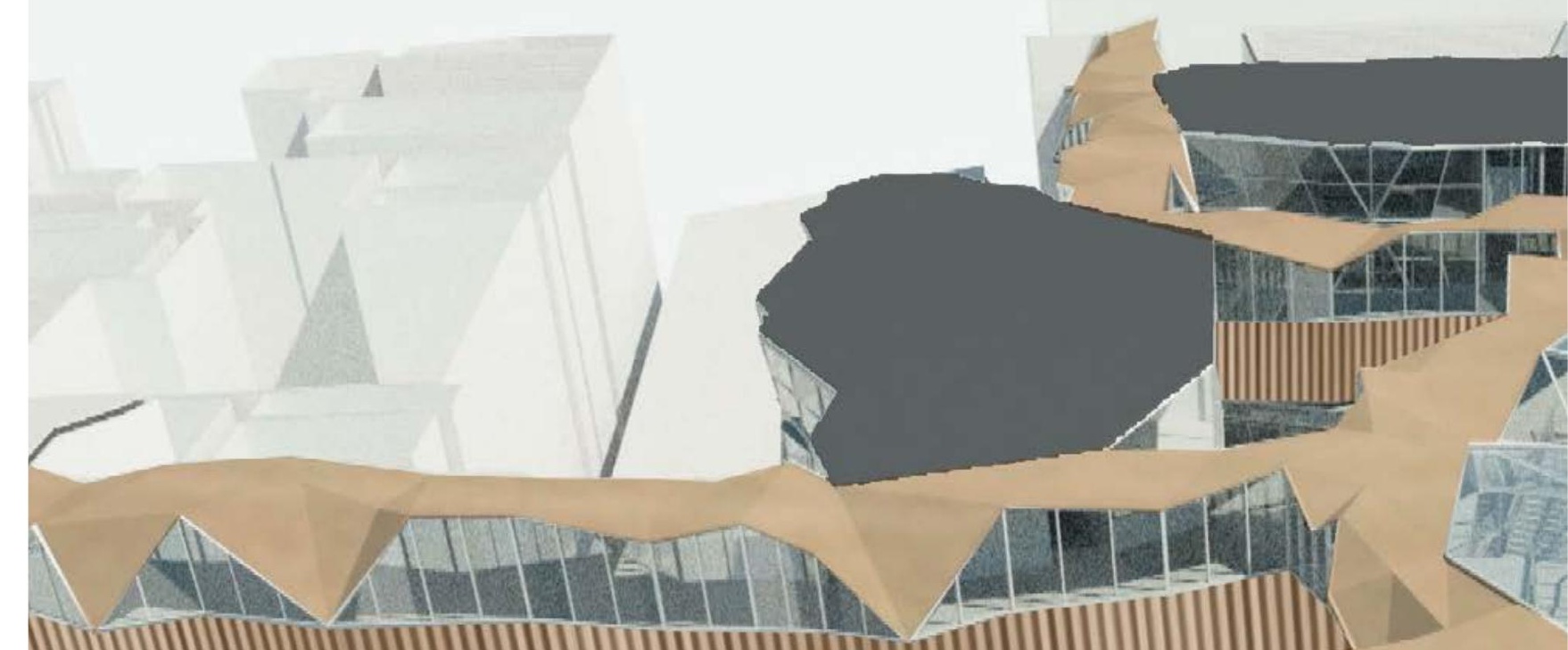
||
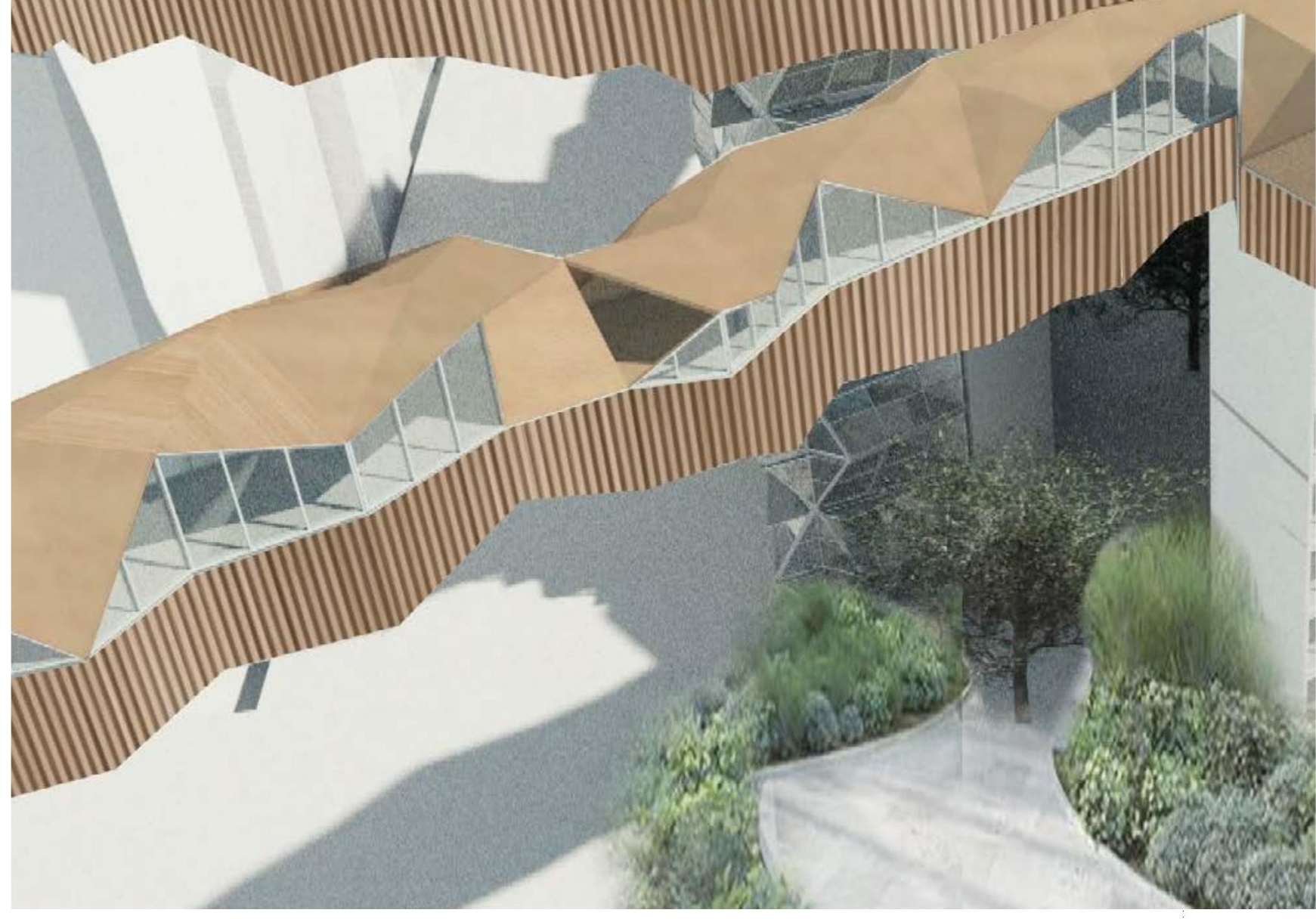


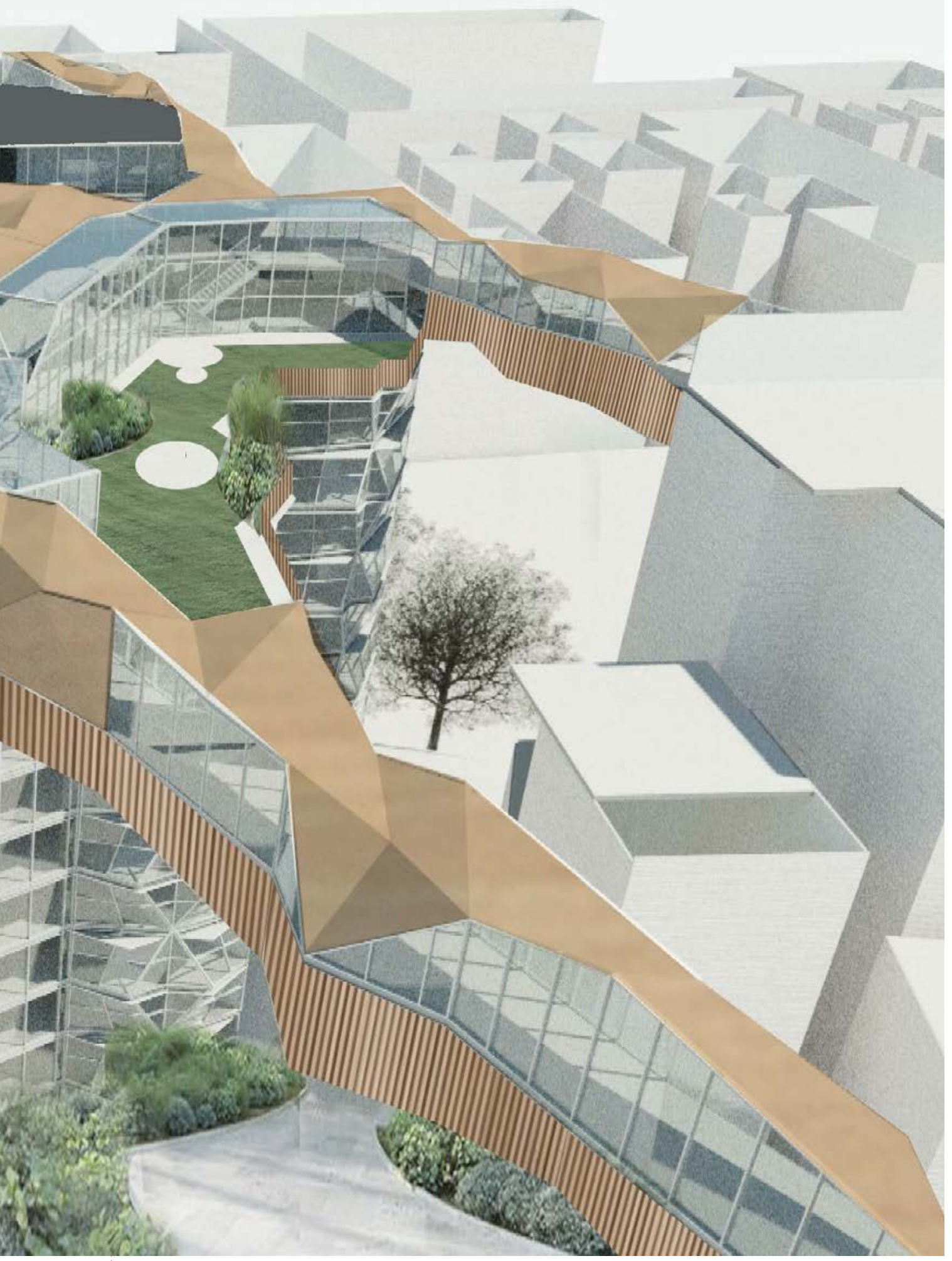

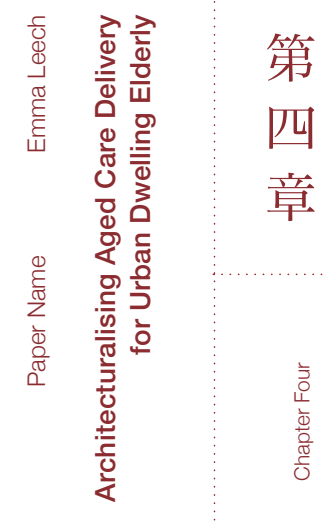





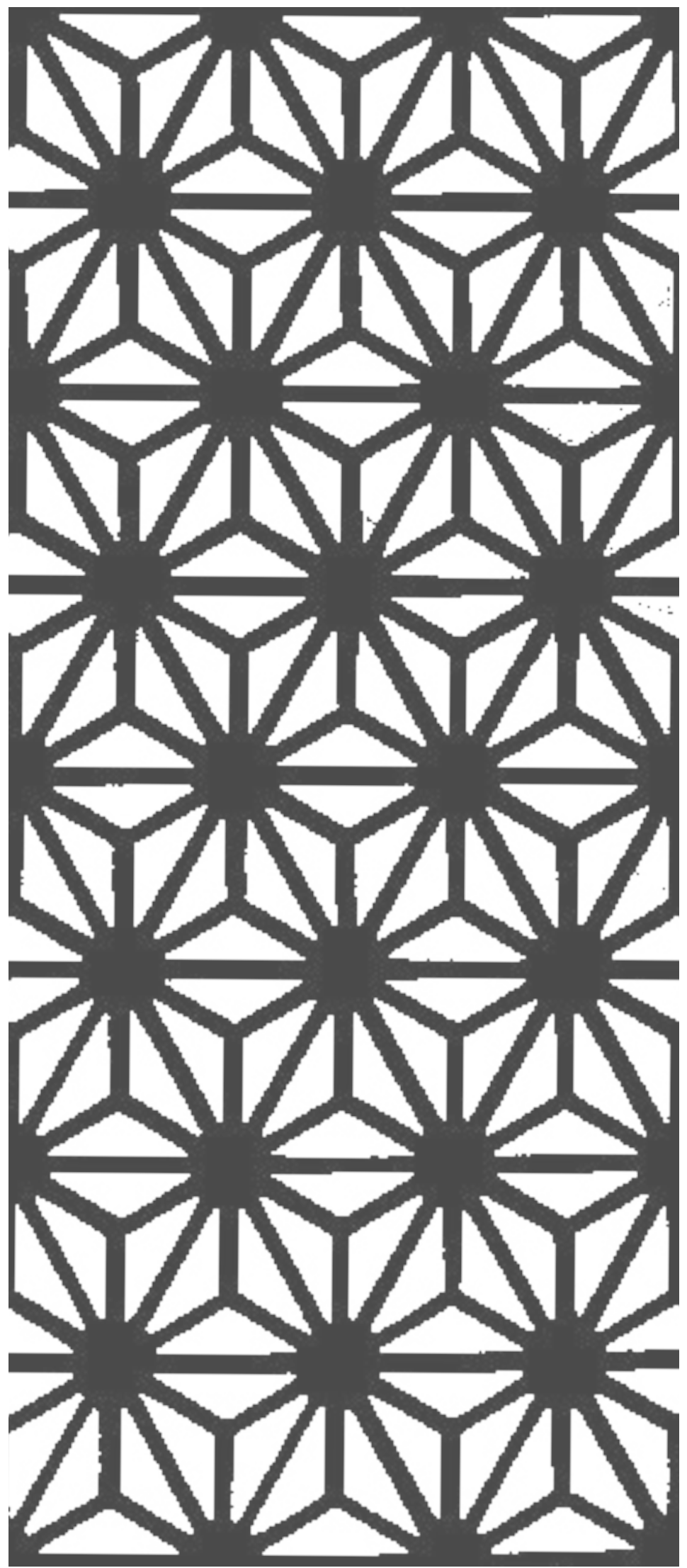

第
吾
章
节
O

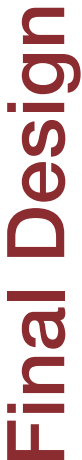



Internal Courtyard Plaza

The design of this space connects people across buildings creating a central

landscaped area connected to both the highly dense pedestrian street and the quiet parkland. The courtyard acts as a transition between these different areas whilst also acting as the main entry into the building complex.

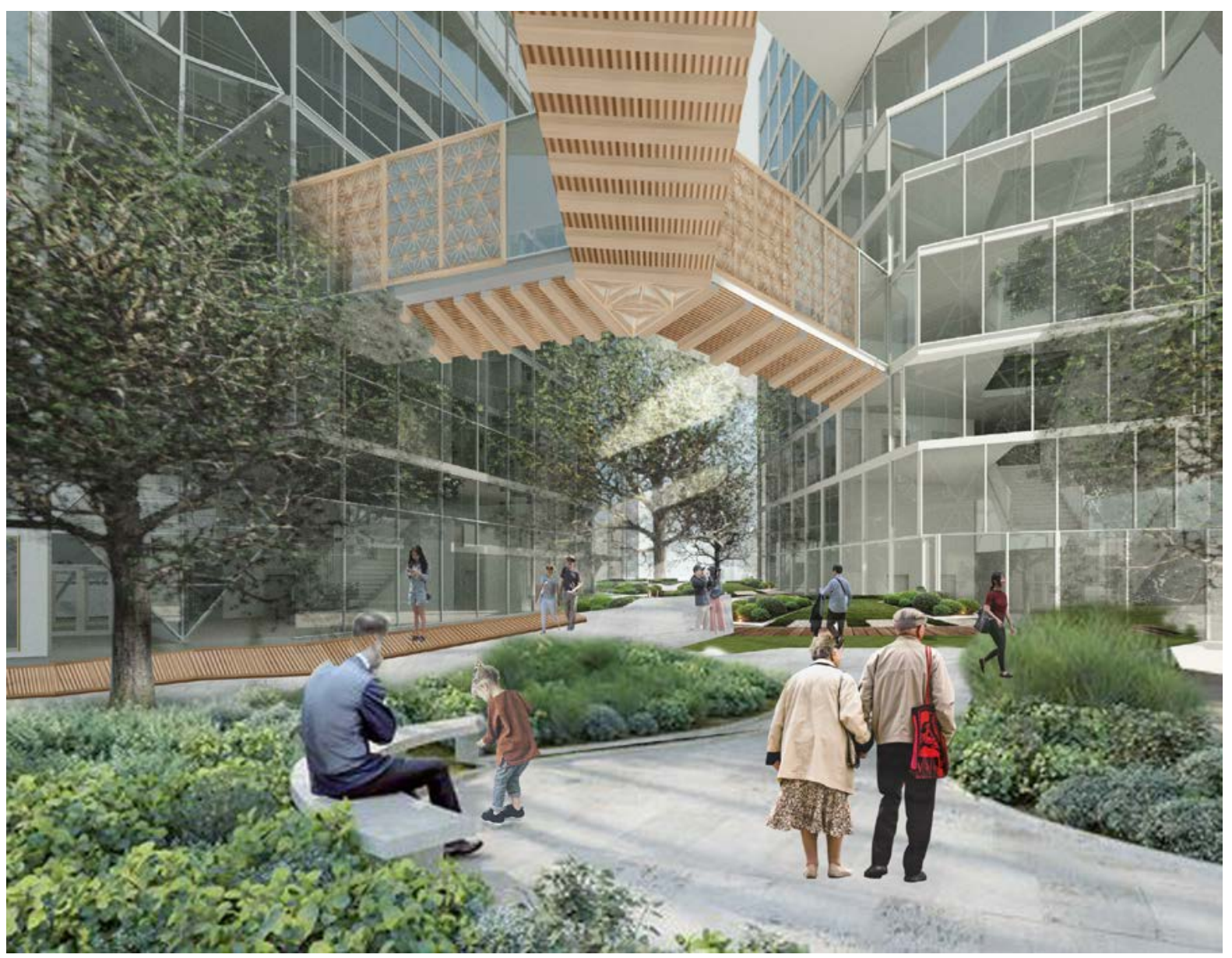




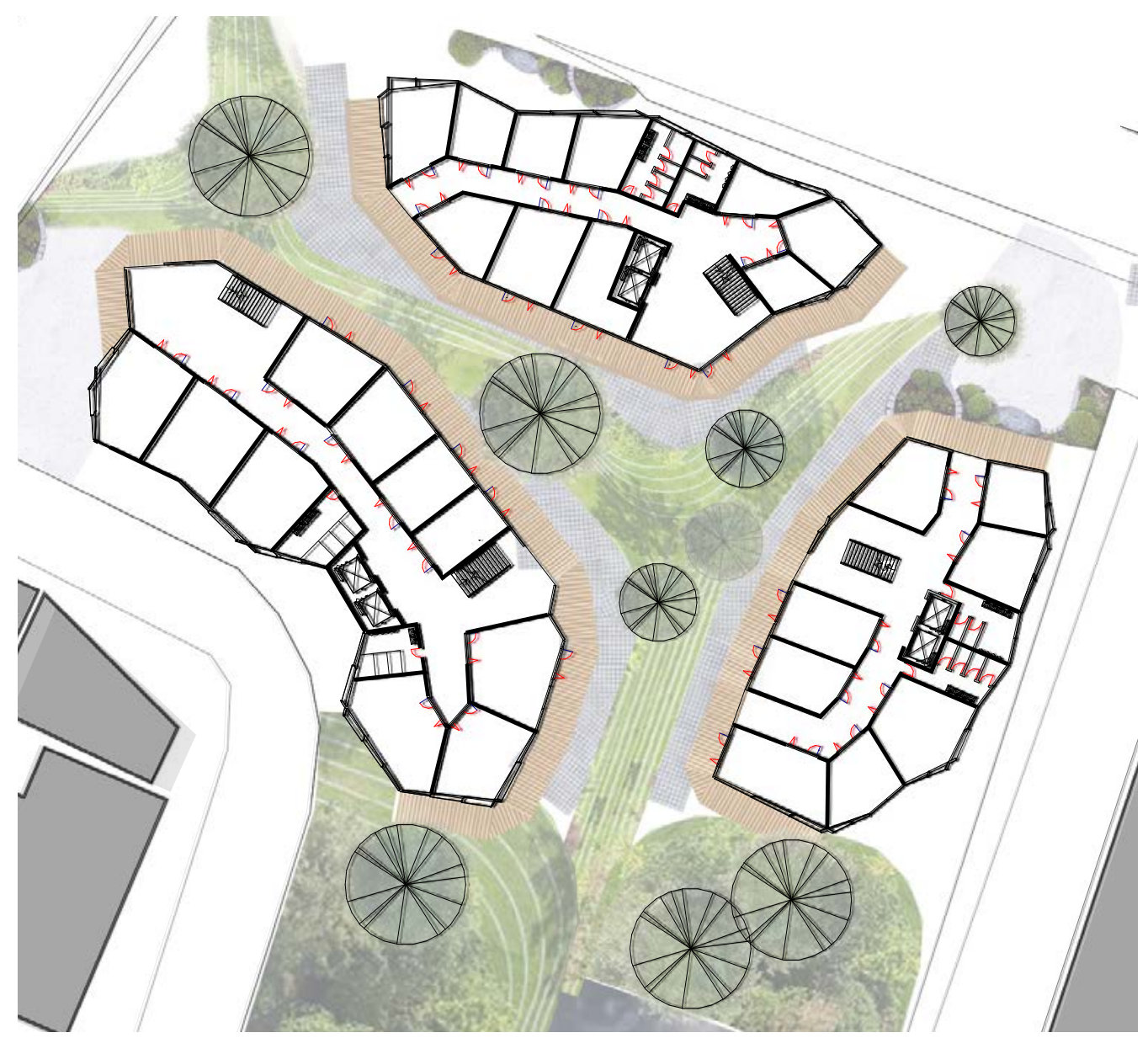

Ground Floor

The ground and second floor across all buildings is dedicated to retail in order to supply amenity lacking in the surrounding community. The ground floor especially is focused on connection between the pedestrain user and the tri of buildings making up the complex. The exterior plaza space aims to connect the park land through to the busy intersection so that green space isnt limited to designated zones and taking on a transitional presence for the community. the programme of the lower floors focuses on the public, not only allowing access to retail but also a plethora of every day health needs. With senior priority the health services are open to the general public and are inclusive of GP's, Physio Therapy, Optomotrist, Audiologist, and Mental Health practitioner just to name a few. The key design diver for the ground floor was to create a space that slows people down, through frequent places to sit, landscaped gardens and winding pathways mirroring the form of the buildings and their relationship to one another this encourages people to meander, observe and take a breath within their day.
Care Delivery Levels

The First care delivery floor are mostly used for staff offices, nurses stations, medical supply rooms and no medical storage. secuirty protected drug rooms are essential for restricted medications and to ensure staff and resident safety. this floor also houses the majoirty of admin staff controling details and up to date care knowledge of local residents. The key component of the circulation within this floor is the interconnecting walkways across the central plaza. This connects the buildings together and ensures that systems can be integrated across the entire design.

The Second Care Delivery floor is focused on staff areas and includes both internal and external staff spaces including roof top garden break space, staff offices, nursing station, meeting rooms and the lower half of laundry space focused on sorting and washing. On this level each building is independent of each other due to not connection across to facilate movement between buildings. The programme of each building is connected to the floor above or below with ample vertical circulation to support this. these areas are used to support staff well being to ensure that they can in turn support the residents. 


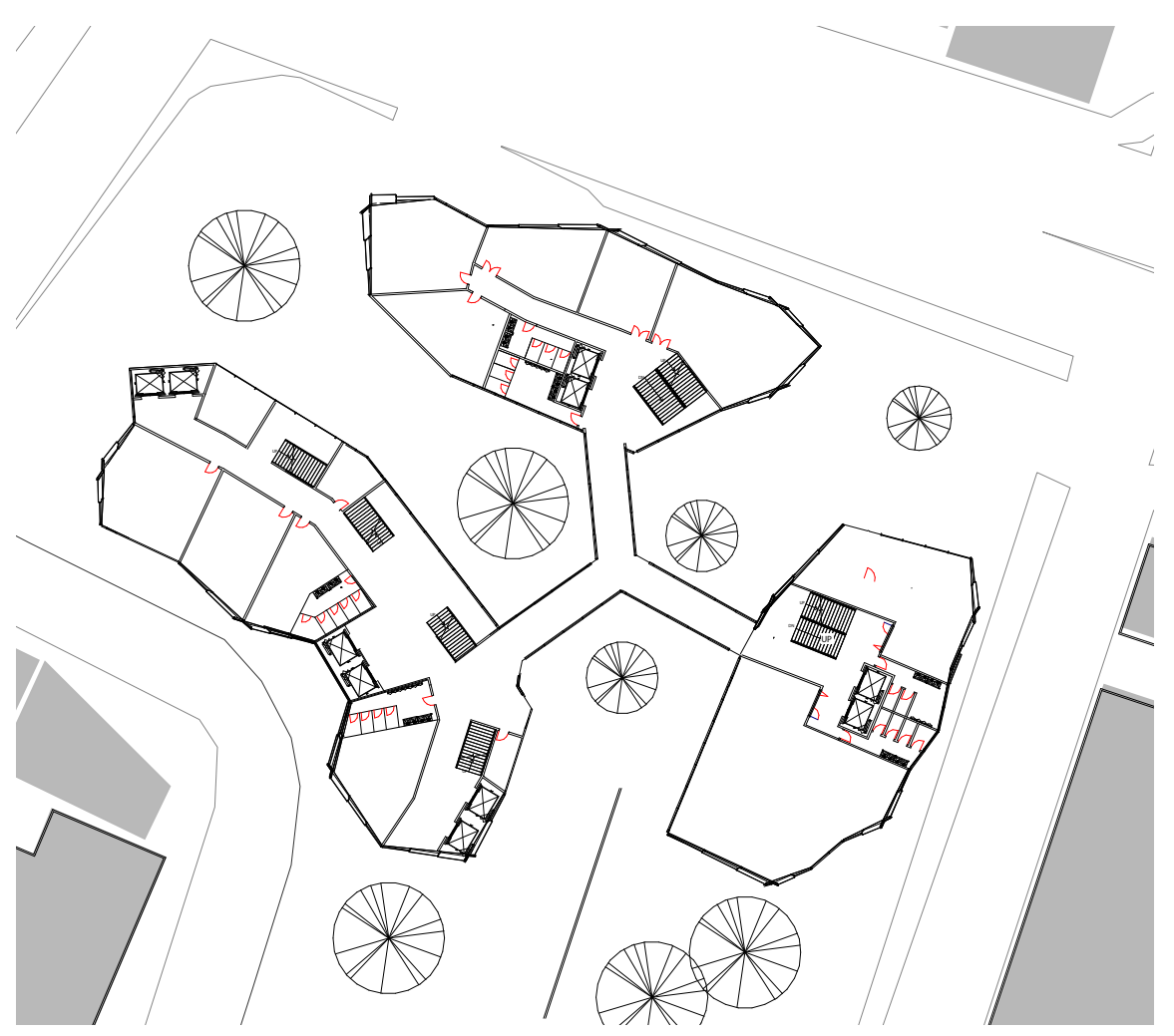

$\frac{}{0}$
$\frac{\Phi}{\sigma}$
है
है

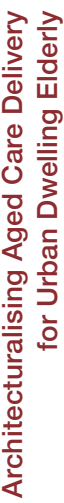

第

五

章

FLOOR 8: FIRST FLOOR CARE DELIVERY

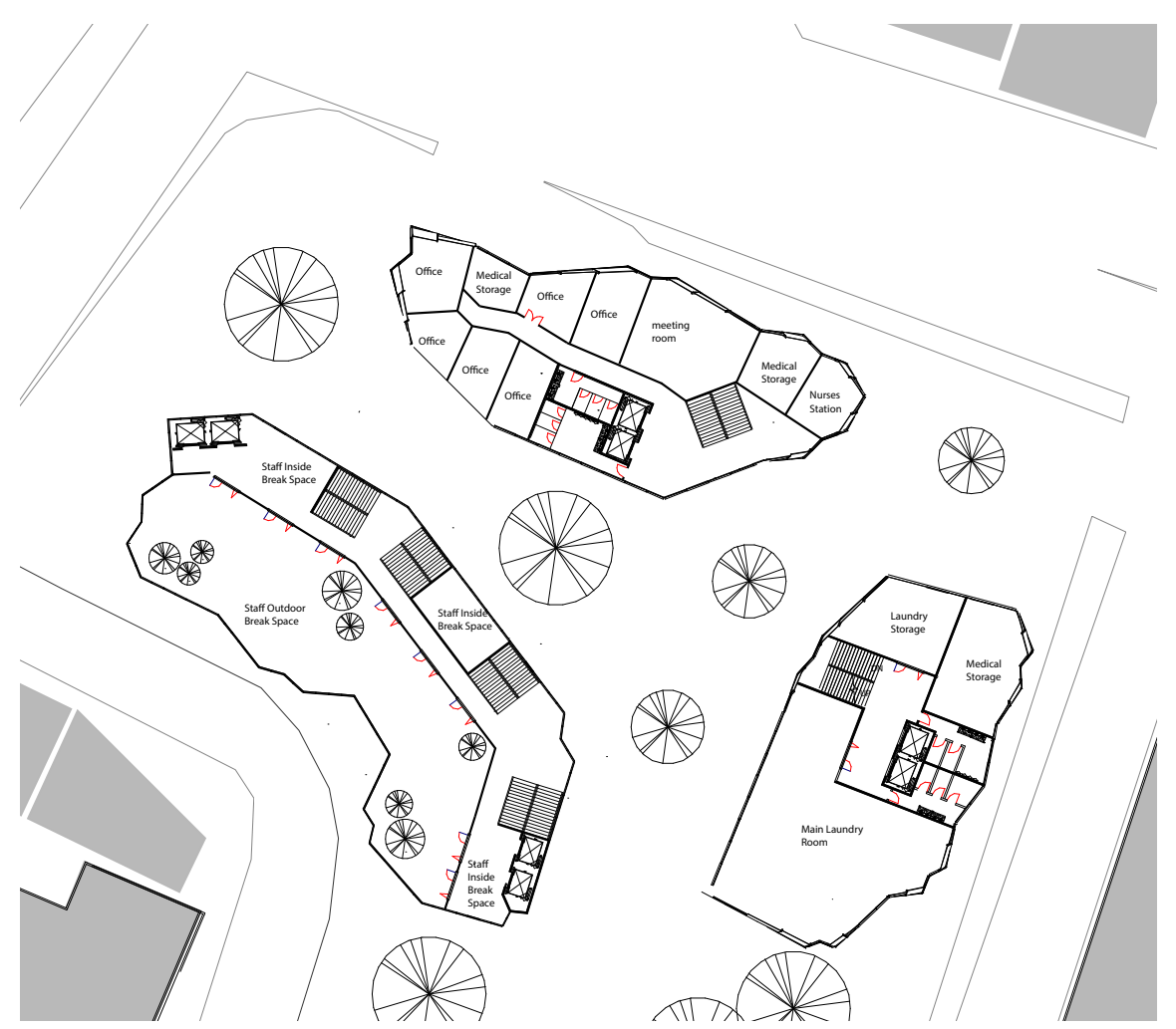

FLOOR 9: SECOND FLOOR CARE DELIVERY 
第
五
章

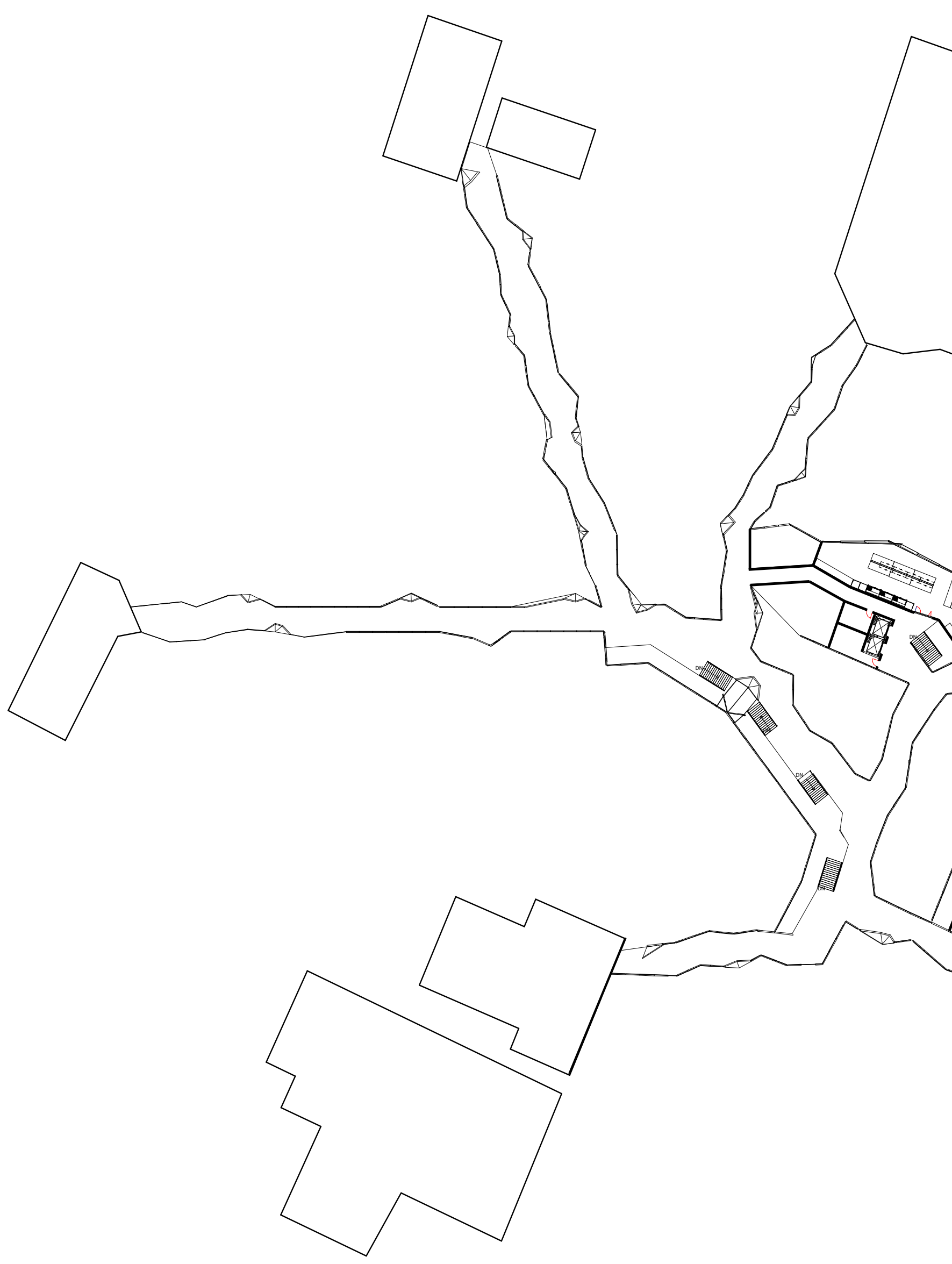


Walkway Bridge Floor: Level 10

The key components to the upper floor plan is delivering meals and laundry services. These programmes are split across the two buildings in a way that separates these two tasks but ensures they are integrated into the walkway system to ensure easy access.

the upper most level also is the access floor for the walkway bridges which allows connection between the three buildings as part of the hub and the exisiting apartment buildings surrounding the site. the way these have been designed integrate into the buildings and their floor plans whilst also creating a path of least resistance, the shortest distances between buildings for efficiency but also structural integrity. the bridges also faciliate movement between buildings within the hub and this was factored into their placement. 

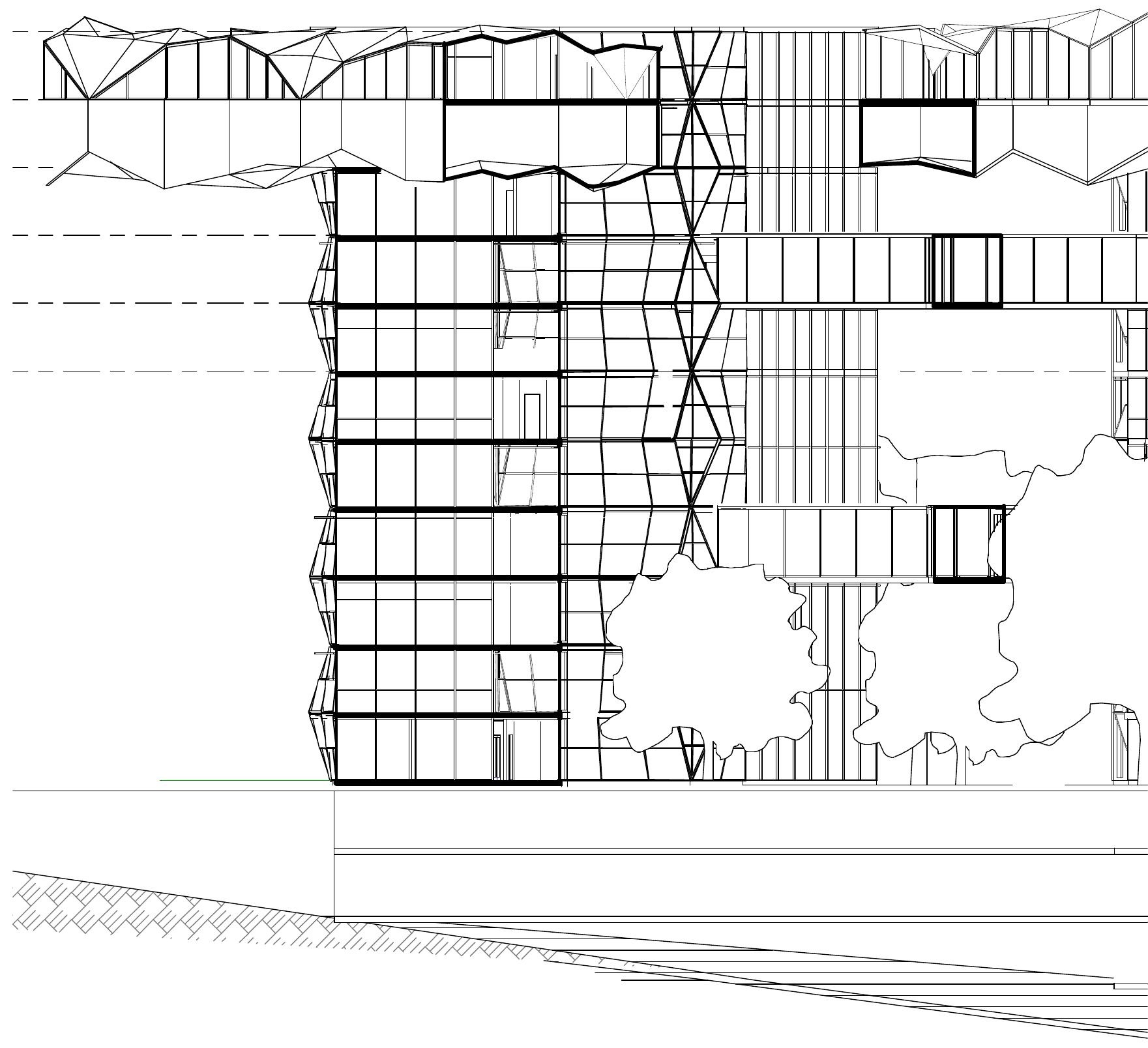

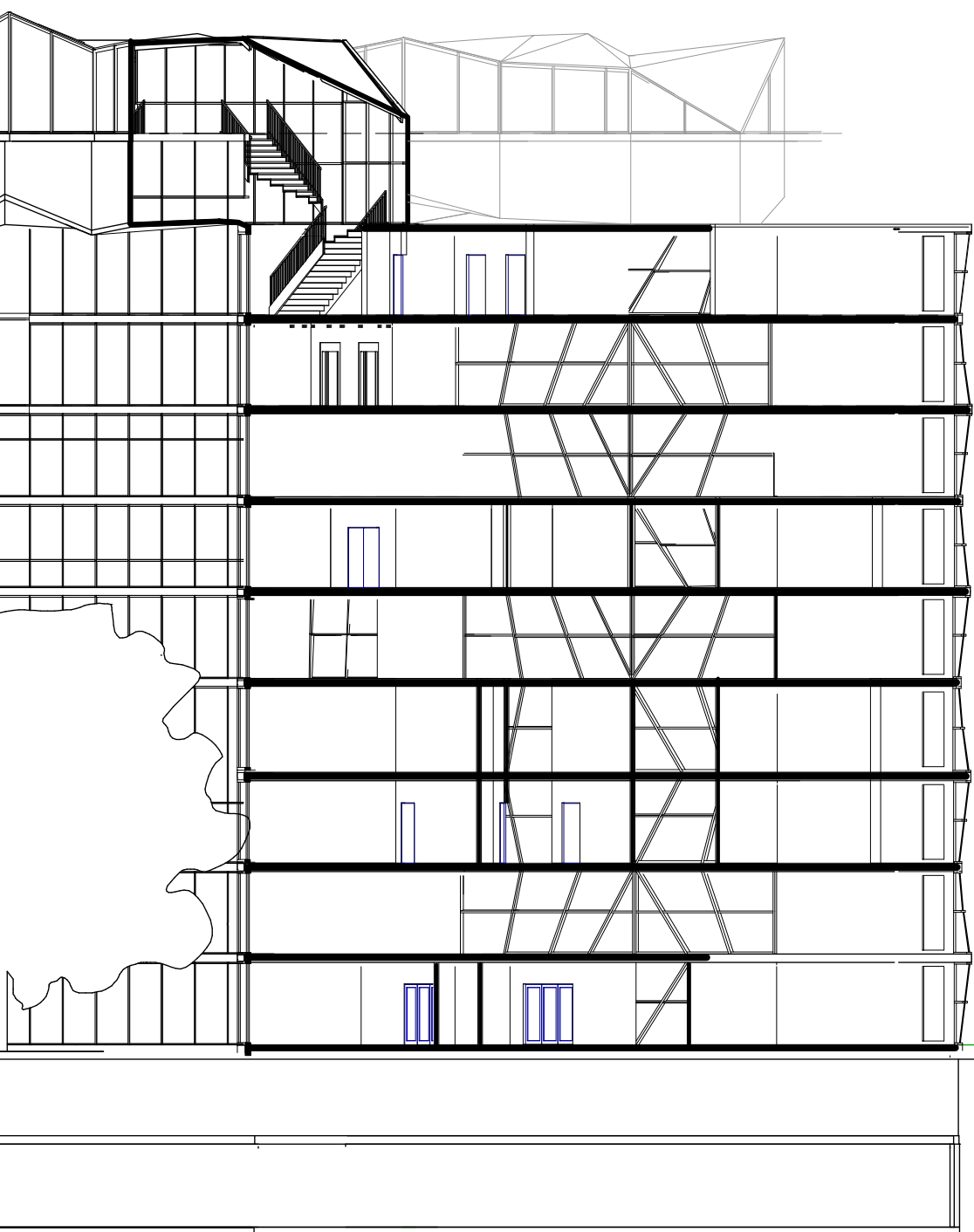

This Section Shows the physical and structural relationship between the upper walkways and the shortest building of the three that sits below the line of the walkways, effectively cantilevering off panels of glazing this section shows the structure that allows this to happen. the reason for this design gesture is to allow more light into the central courtyard and the buildings behind this one which sits on south side of the site therefore blocking the other buildings sunlight for much of the day. 

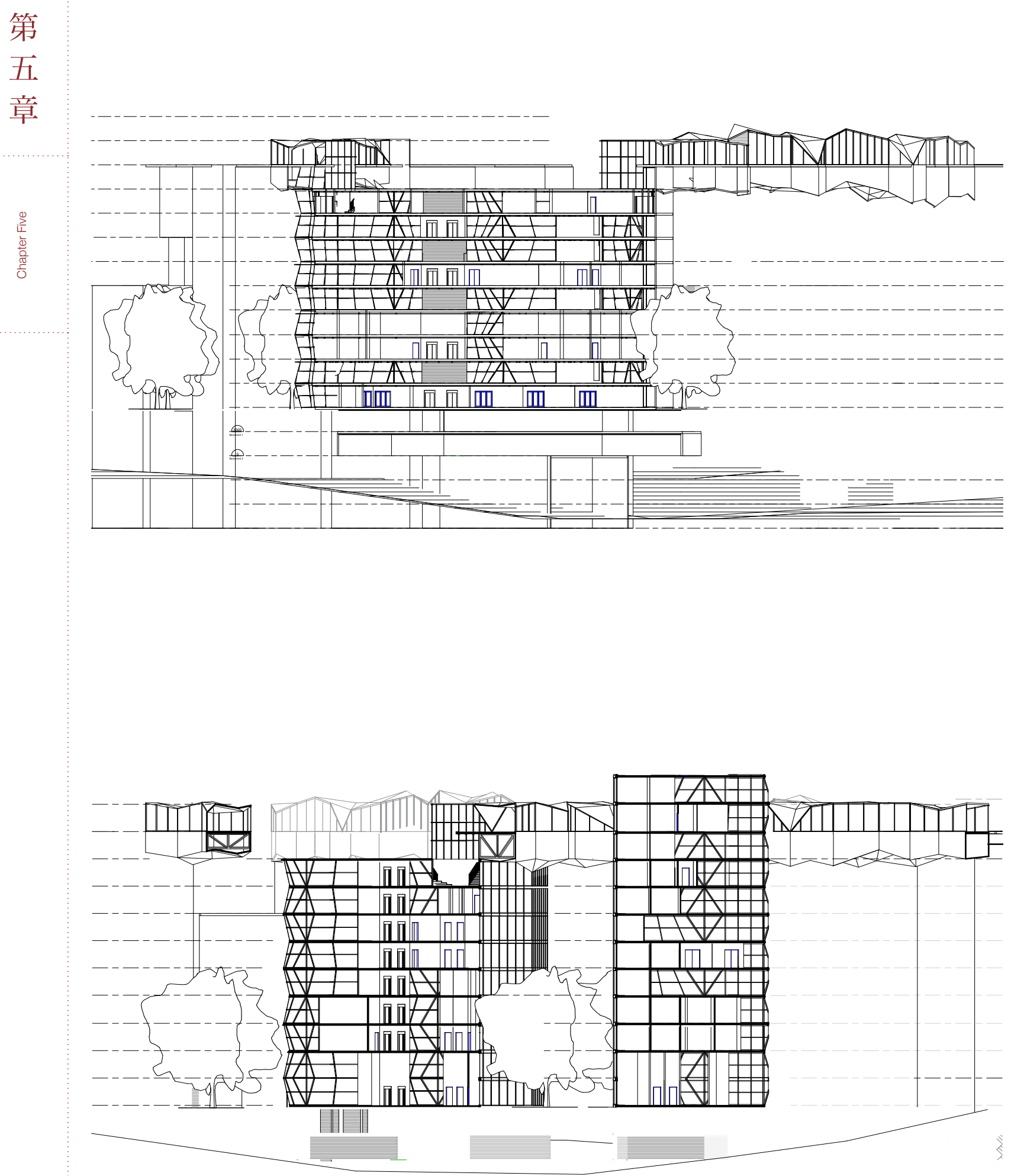
The section drawings help to understand the relationship between the main buildings and the walkway bridges as well as the inernal structure of each building and the slanted glass design gesture. Section 2 shows the connection between lower building and walkway highlighting the cantilever needed and the levels created through reducing the height of the front building on site to create an external staff space. Section 3 is looking left and cutting through two buildings, this shows the distance between them and the ratio between internal and external space. As well as this a greater understanding of the span of the bridges in between buildings across the internal plaza can also be seen in this section drawing as well as further highlighting the connection between bridge and building established in section 2

Looking at the construction of the building further, curtain wall glazing is supported to slant by structural members whilst also connecting straight up and down at some points around the buildings. these areas act as the primary structural columns for the glazing whilst secondary slating columns as well as structural beams top and bottom allow for a visually dramatic angle to be created. these images show in section the connection between a straight wall and the slanted glass, the connection between the slanted glass and the floor and ceiling and the structural supports allowing the glass to tilt.
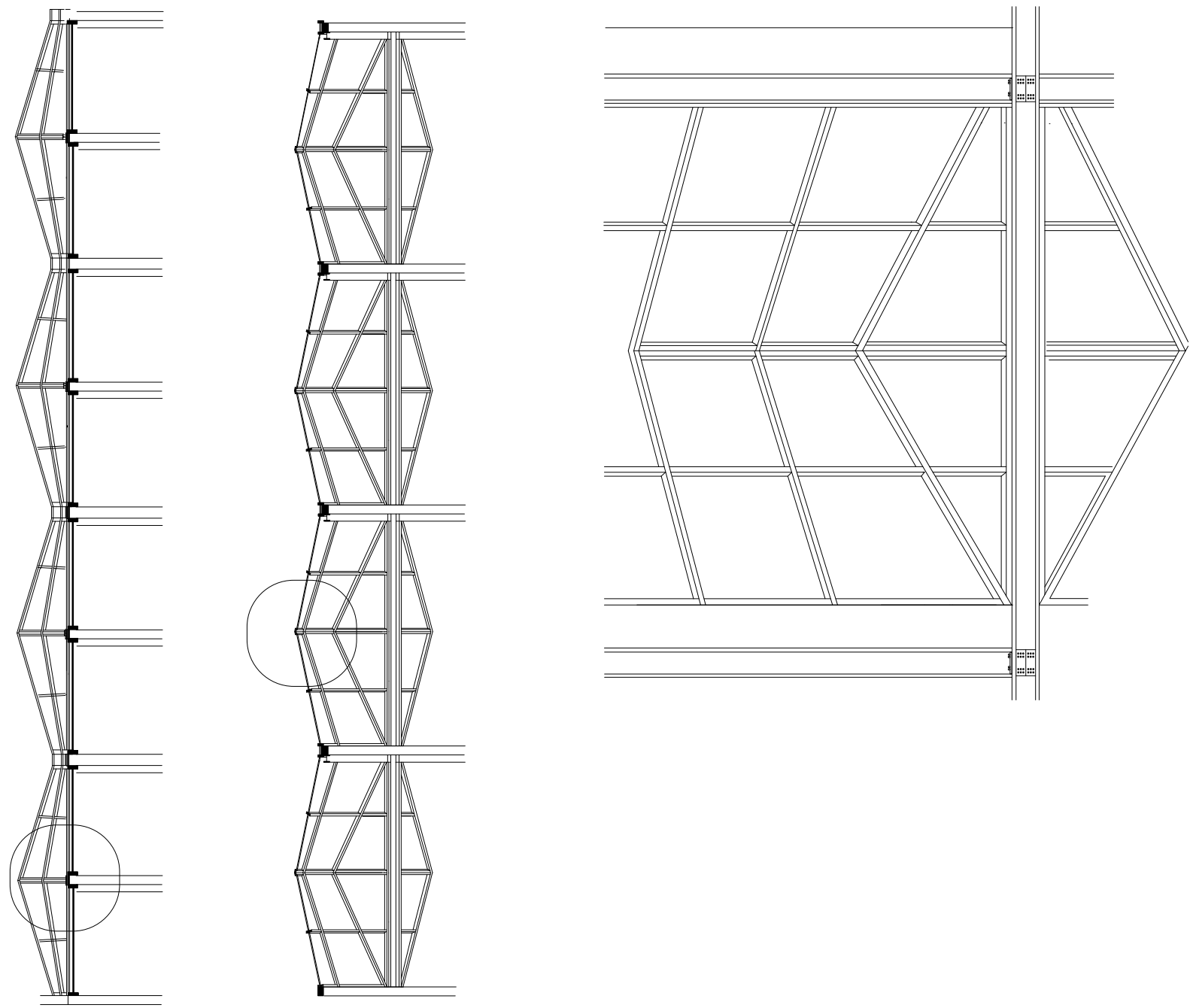


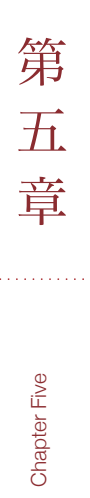

Bridge Structural Frame Design The side members connecting to the lower bridge frame is an idea used as both a stabaliser but also inspires the need to incorporate the floor of the walkway and the window framing into the lower structure which will not only support the roof but will increase the structural integrity of the bridge.

Showcases the ability for bridge design to be created using small members and still maintain structural integrity, also determines the structural shape used for the struture of these bridges

An example of bridge supported but underneath structure, this look is both structurally sound and visually interesting however the span isnt as wide as with the other models and more structural columns are used to support this bridge
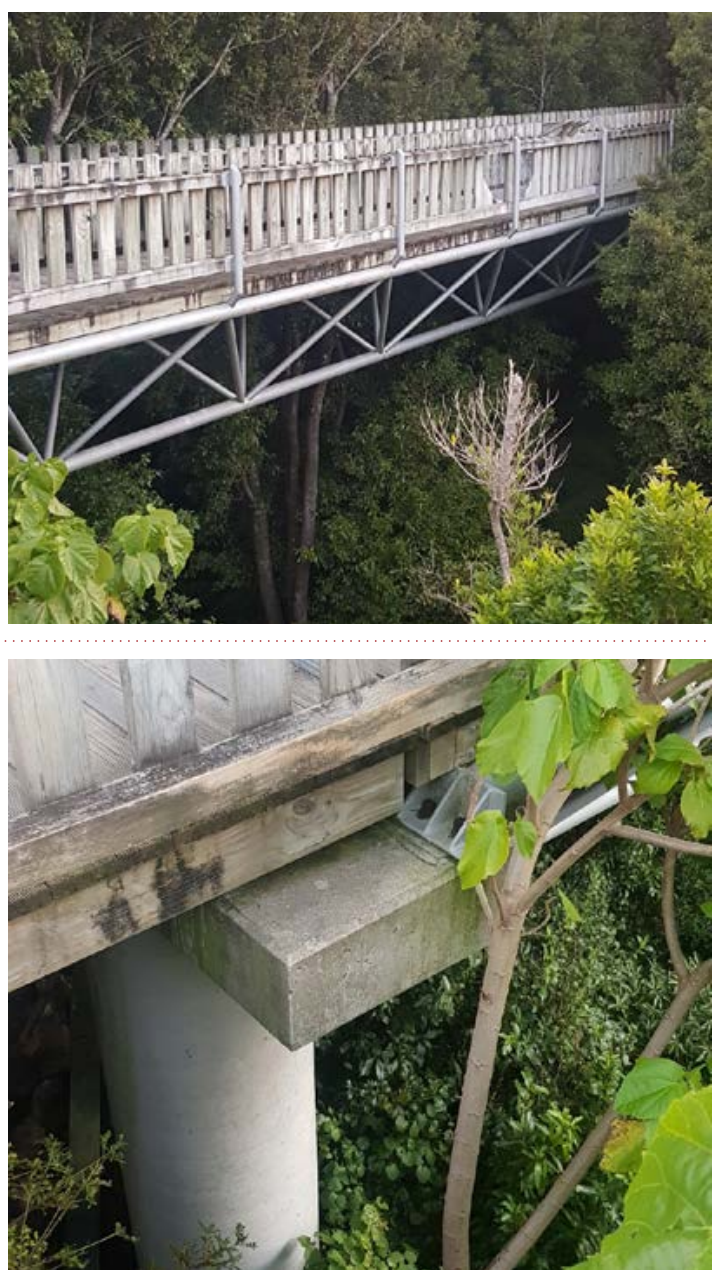

Concrete bridge supports and connection between the steel framing, timber railing and concrete columns. 


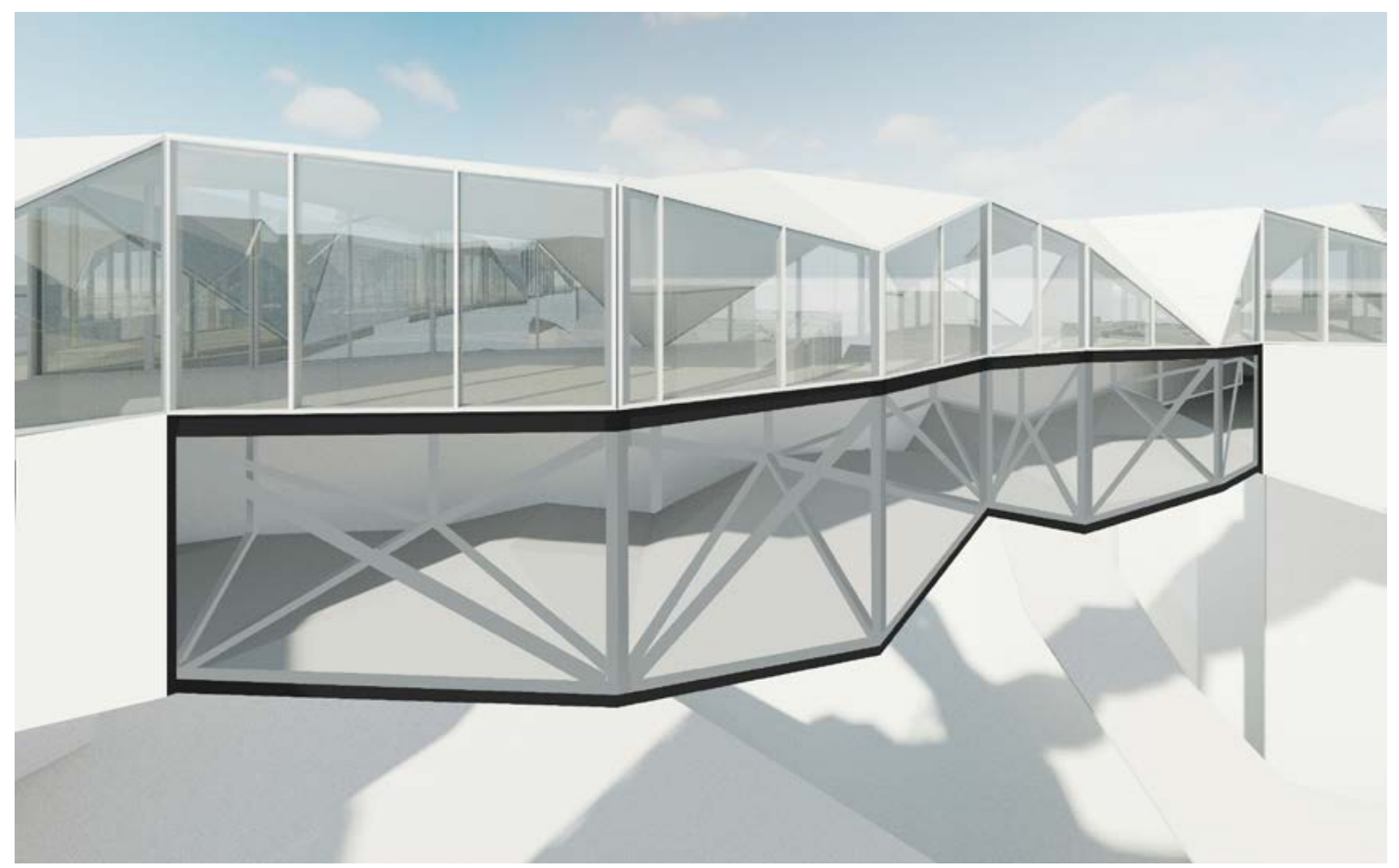

The section drawings help to understand the relationship between the main buildings and the walkway bridges as well as the inernal structure of each building and the slanted glass design gesture. Section 2 shows the connection between lower building and walkway highlighting the cantilever needed and the levels created through reducing the height of the front building on site to create an external staff space. Section 3 is looking left and cutting through two buildings, this shows the distance between them and the ratio between internal and external space. As well as this a greater understanding of the span of the bridges in between buildings across the internal plaza can also be seen in this section drawing as well as further highlighting the connection between bridge and building established in section 2

Looking at the construction of the building further, curtain wall glazing is supported to slant by structural members whilst also connecting straight up and down at some points around the buildings. these areas act as the primary structural columns for the glazing whilst secondary slating columns as well as structural beams top and bottom allow for a visually dramatic angle to be created. these images show in section the connection between a straight wall and the slanted glass, the connection between the slanted glass and the floor and ceiling and the structural supports allowing the glass to tilt. 
第

五

章

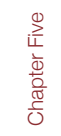

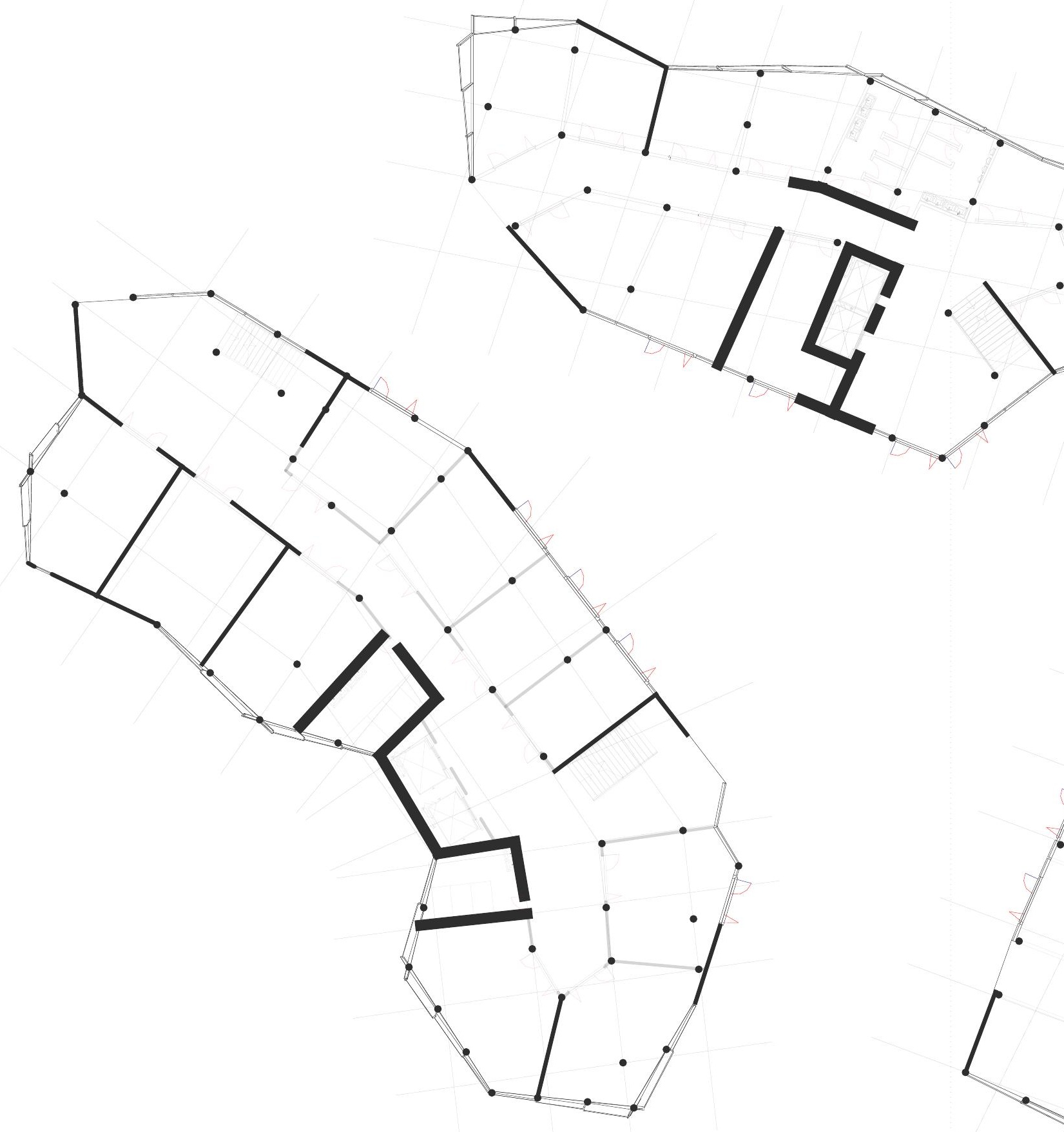




\section{Structural Floor Plan}

Floor plan shows structural column plan, sheer wall layout and central core for each building. sheer walls are mostly internal because of the external curtain wall around the edge of all three buildings. The cores are off center due to lower floor circulation and creating a seemless approach increasing the thickness of the core walls aims to counter the off center cores. The aim of this structural design is to bring the work into a sense of reality and propose how it could be created. because of this the structure used in this plan is similar to a usual building of this size with slightly larger structural members than required. it is hard to know the actual structural capacity needed to hold this bridge system and would definitely require consultation with structural engineers. thinking through the structure gives a sense of reality but by no means does it attempt to structurally resolve the entire building fully. 


\section{第 \\ 五 \\ 章}

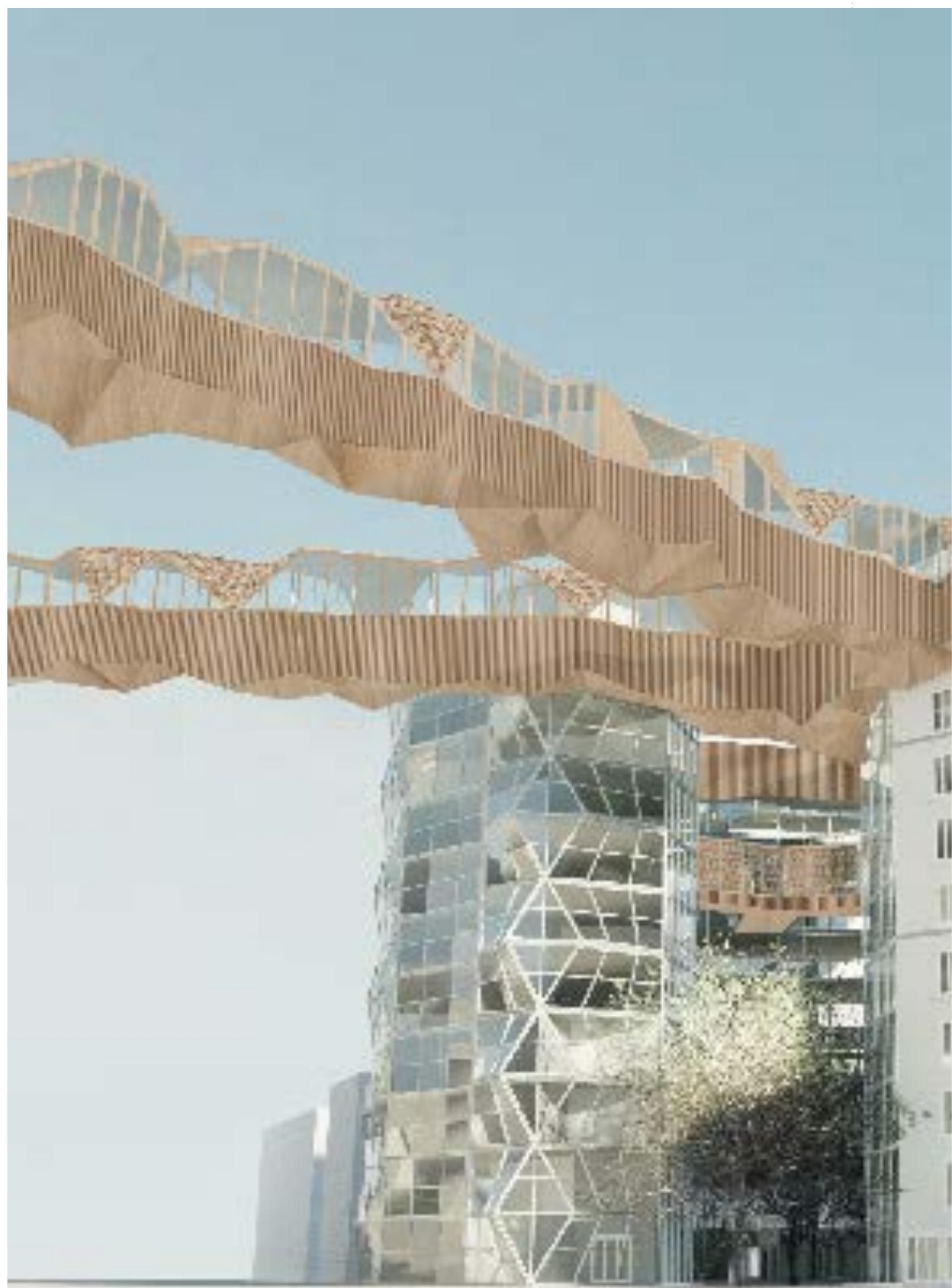




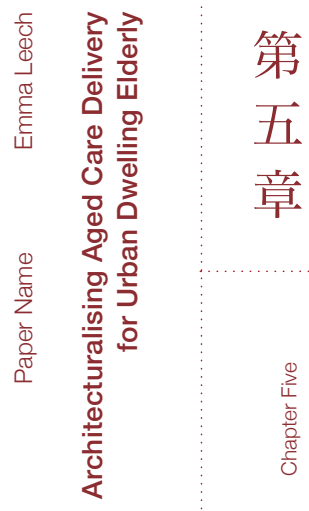




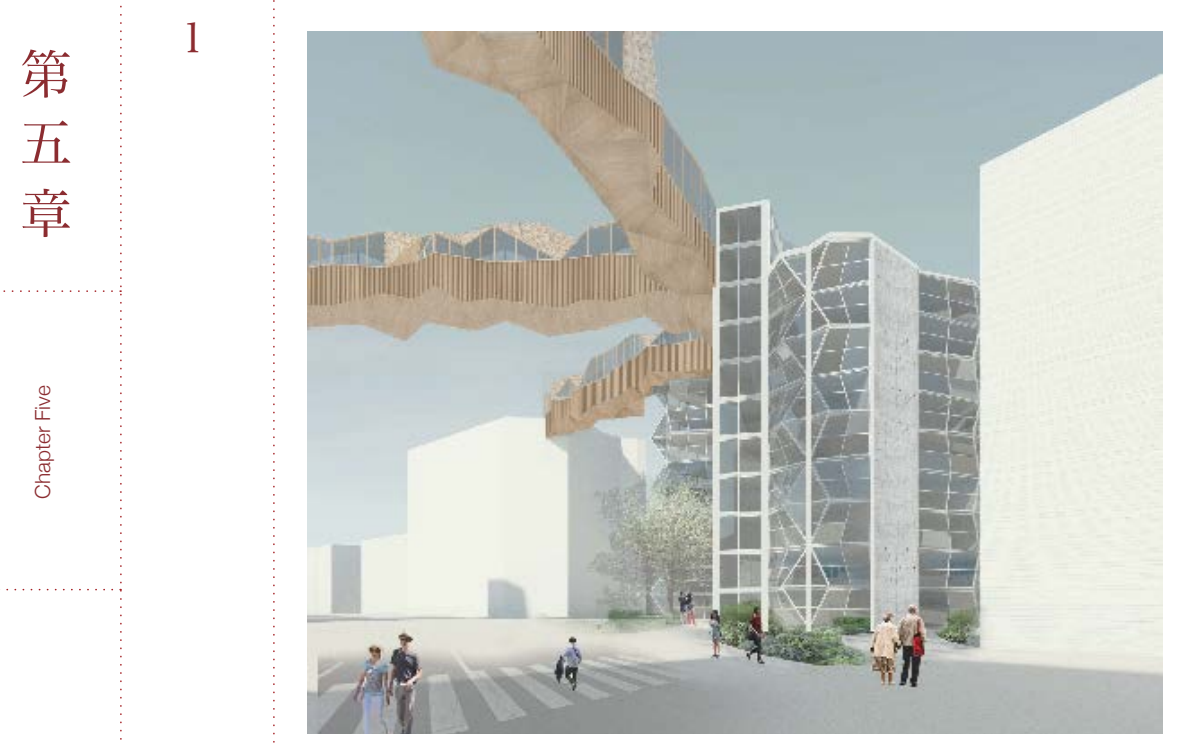

Final Imagery showing view from the street across the large intersection

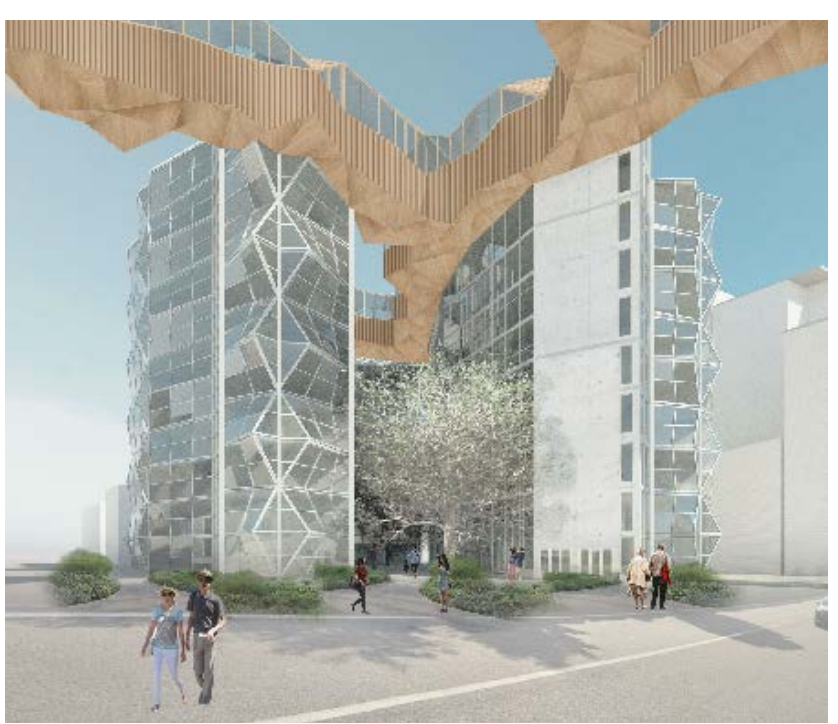

Final Imagery showing integration between bridge walkways and main buildings

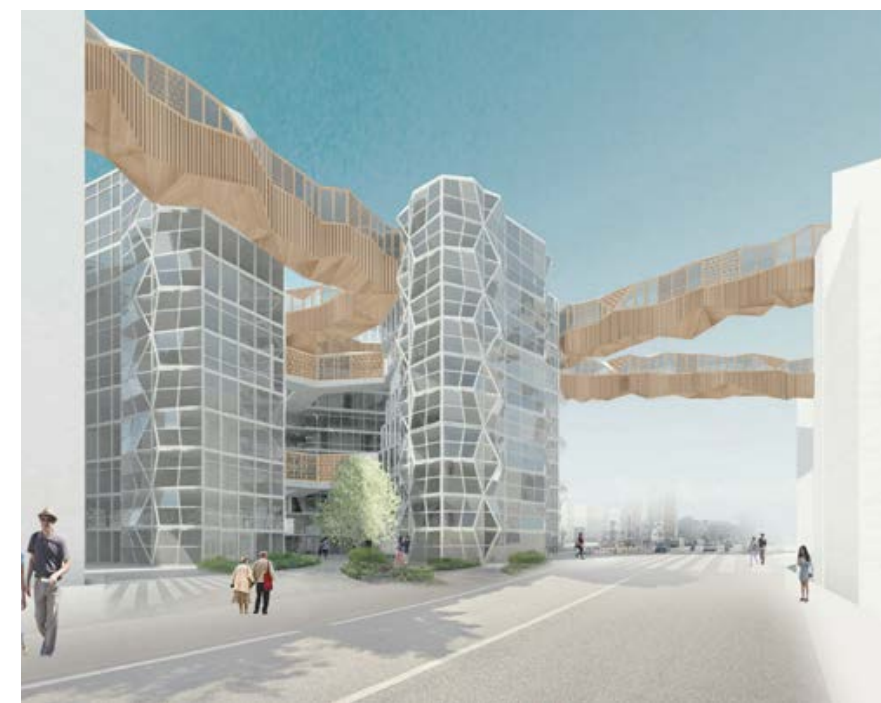

Final Imagrey showing far left hand view from the road. shows connection between the hub bridges and exisiting buildings 


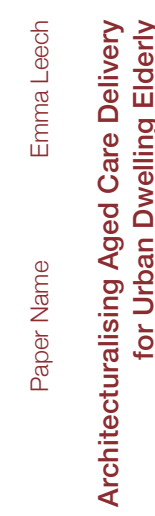

호

을

产

童

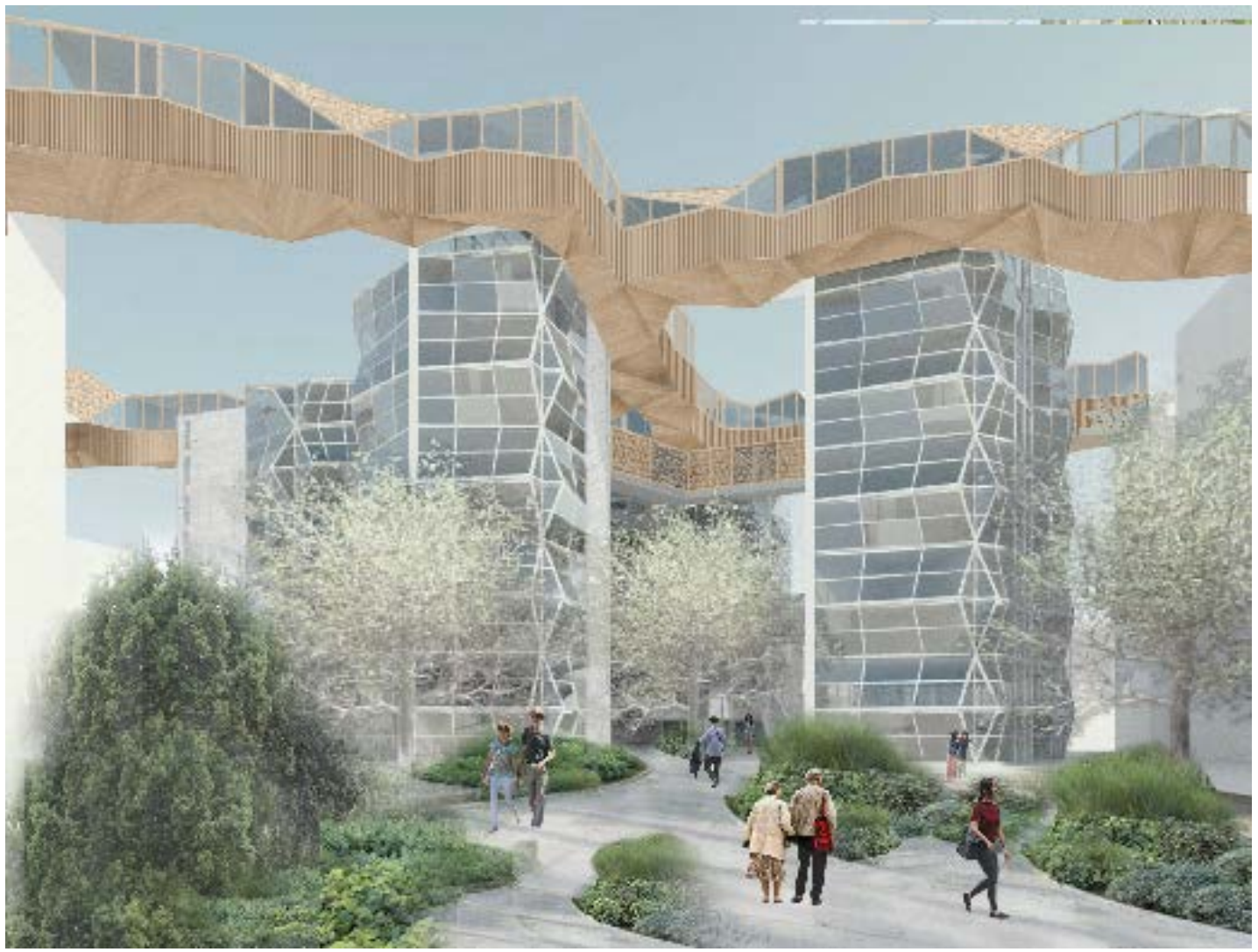





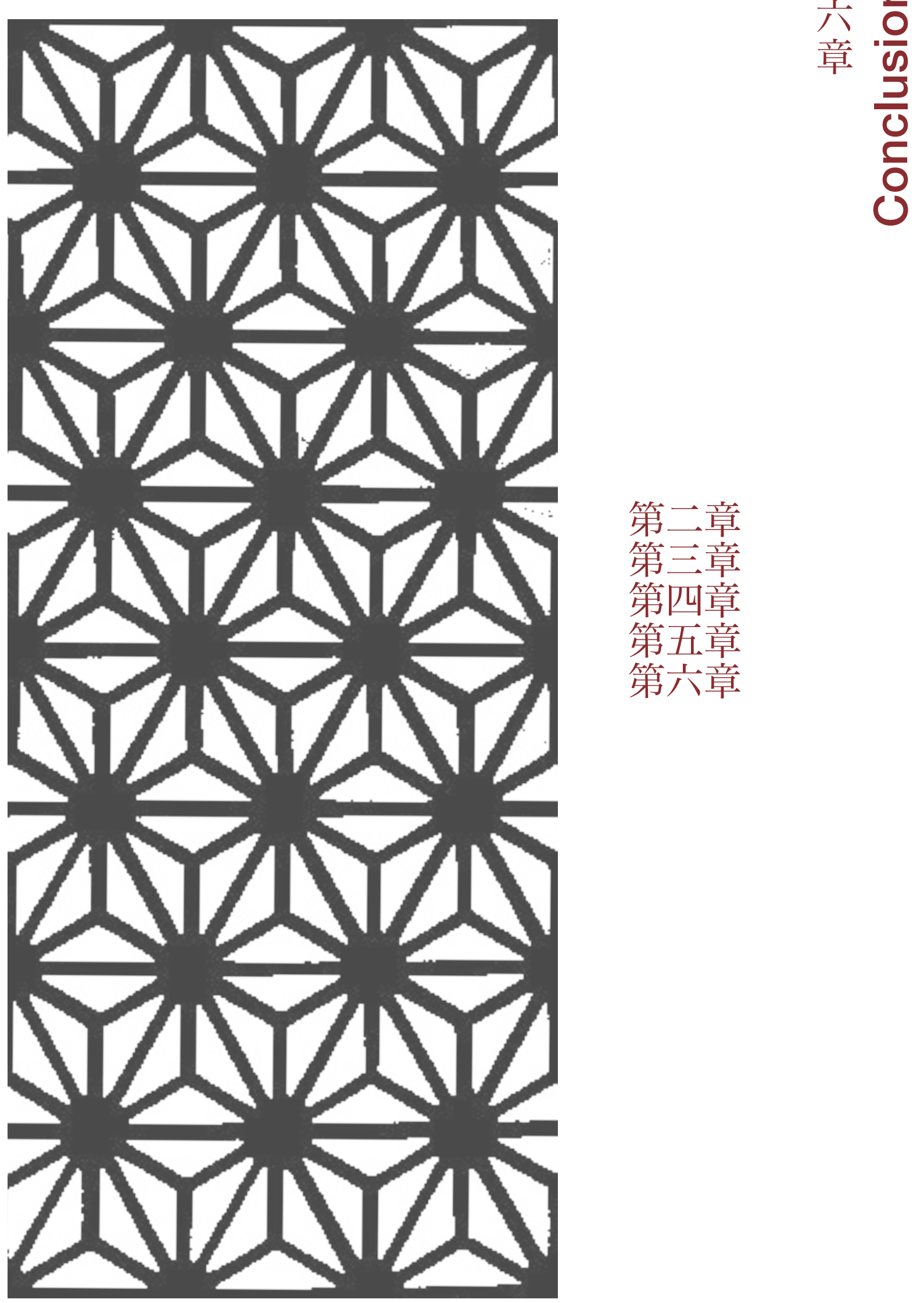

第 0
六
章
$\frac{0}{\mathcal{D}}$
음
O 



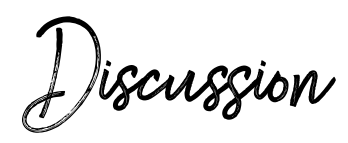

The final design outcome brings together the three key ideas from the original brief whilst also mitigating some problems from throughout the design phases including the structural capacity to create a design that delivers this finished result. The two key elements that have been explored and successfully achieved through the design are the boundaries and relationships between programmes are both highly separated but visually connected and not disjointed in any way. This is imperative as the scheme deals with the opposite ends of the privacy spectrum and those transitions were an element thought through comprehensively throughout the programmatic and planning stages of the design. Visually the design is layered and interesting with key focal points at the diamond corners and openings that bring people into the central plaza, this works effectively to deal with through traffic as well as create what was a non existent connection between the main intersection on the block and the parkland that backs onto the site. From the ground the building doesn't seem top heavy, which was a concern dealing with the scale of structural members needed for the bridge arms but it feels balanced and structurally secure with the large structural members contributing to the overall atmosphere of the design. The contrast between the wood detailing of the bridges and the steel structure and curtain walls makes the bridges stand out as the prominent feature of the design and visually from the ground they create interest with the contrast in textures between the panels and battens and also the fractured form on the under side. The justification for including these bridges at the height that they are is connecting into the surrounding apartment buildings from above and therefore the building needed to be higher that the surrounds. Visually this communicates well and the vertical programme layering splits the different uses in the building in a way that is both legible and economically sustainable with retail and health care on the lower levels closer to the people accessing from below and the care delivery on the upper floors as close to the connection with other buildings as possible.

Relating the final design to the context of the literature and its key findings, this work contributes to the field of research by developing a speculative model providing comprehensive care to elderly ageing in place in an urban environment. This uses the density of elderly in city of Tokyo to the advantage of care provision. This research shows this it is of value to have access to comprehensive care without the need for residential occupation in institutional care, directly addressing concerns in previous research that highlight the challenges of providing in home care in an urban environment. As well as this it demonstrates that that care can be adapted to individual needs and users. The outcome of that this research demonstrates is the importance of infrastructure and architecture in the role of providing aged care in these circumstances.

The findings from literature have been highly involved in design decisionmaking. It has provided the foundational understanding that has lead to design criteria and the analysis to determine the underlying weaknesses of current systems of care delivery including the relationship between architecture and care vision. 
Firstly the major finding from aged care facility research is the underlying segregation effects of this type of care. Not only does segregation affect mental and physical outcomes through social isolation and lack of motivation for physical activities but also affects relationships between elderly and the general public and perpetuates ageist beliefs and thoughts. This has been addressed in this care model through the importance of the home, as the place care would be recieved, which is ideally surrounded by multiple demographic groups. The use of the home in this model is significant for many reasons including the maintenance of autonomy, and independence but a key understanding extrapolated from literature is the relationship to others within a home environment in contrast to an institutional one. The home is highly connected to a sense of ownership as a place of entertainment of friends and family as well as a place of private withdrawal. Ageing in place at home secures this sense of ownership and ensures continued relationships with friends and family regardless of diagnosis. Contrast to this, intuitional environments foster relationships with loved ones focused inherently on health outcome and less on the person or well-being. This setting can also fracture relationships with friends who are uncomfortable in the clinical atmosphere without substantial private breakaway areas suitable for social visits. The use of the home, separate from the main building but indirectly connected through existing apartment circulation retains the individual ownership of space and creates significant boundaries that encourage independence and autonomy without risking the safety of individuals living alone.

Responding to ageing in place literature findings the location of this project is in line with research that suggests that ageing in place within an urban environment is the key to a socially integrated and independent life, essential to ageing positively. The final outcome of this design does not aim to undermine this relationship only support it through delivering care and allowing elderly to experience the urban environment and everything it has to offer without worrying about how they will receive the care that they will need both in the present but also future as their needs increase. Through the retail and lower floor health services this scheme intends to further support the existing urban environment through the inclusion of amenity missing from the general area. This also supports urban ageing research highlighting the importance of close amenity to increase physical activity, an important preventative health measure.

Finally, literature has demonstrated, the place of death within institutional environments is unrepresentative of the wishes of the majority of the world's population. The reason for this is a lack of provision for palliative care within the home environment without excessive burden on family members. The final design outcome is set up to provide a sliding service of care from preventative to palliative as the needs of the individual change. This is achieved through a greater connection to the home than traditional in home care services. The model supports both medical and daily needs, reducing hospital stays with an at home convalescent program for postoperative patients and end of life support for those terminally ill. The idea is that this service would allow palliative care to be recieved at home in comfort with admittance to hospital only for operations or in emergency circumstances aiming to reduce hospital and institutional deaths, valuing and honoring the wishes of majority of elderly.

Relating the final design outcome to the initial set of criteria influenced by the literature review as well as analysis of aged care facility precedents, the design is highly representative of the criteria developed for the project and represents a model of care highly focuses on personal need, privacy and enabling elderly to age in place on their terms. The final design outcome represents the values of the criteria in the following ways. 
1) Preservation of privacy through a separation from the individual space of the home environment

The design connects into the public circulation of the apartment building and not directly into the homes of elderly individuals. This creates a sense of separation between the care delivery service and elderly individual, presenting the space of the home as no different to surrounding apartments occupied by families and young people. This places the position of power into the hands of elderly, optimizing their inclusion in their own care program. This relies on a positive relationship between elderly and the care they are receiving but emphasizes preventative care options on elderly terms.

\section{2) Adaptable Programme allowing} unique adaptions to missing amenity

Limiting the connection to the hub to a 10 minute walking radius supports New Urbanist ideas of community living but it also means that the programme particularly of the lower floors of the building accessible to the public can be personalized to the surrounding area to supply missing amenity but also to not compete with local shops and services and instead work with the surrounding community and enhance the experience of living there. The assumption made here is that the majority of health services would not already be provided to the same extent but this could be problem solved with local practitioners to not provide competing services.

\section{3) Includes other Demographics}

Ground floor retail and local health services open to the community seek to include other demographics in the design and make a space that is elderly friendly but isn't stigmatized as only for elderly consumption. The inclusion of pathways connecting parkland to the busy commuter intersection and public transport metro station is created to increase foot traffic through the buildings internal courtyard plaza and to increase interaction with the retail within the lower floors as well as surrounding landscaped space. The external design of the bridge walkways above the street is related to the visual impact of this design on commuters and pedestrians. The wooden materials and different textures and shapes used to create the design are used to increase their aesthetic quality from below and entice passers by into the retail spaces as well as to provide a visual landmark to those just passing in cars or public transport.

4) Care workers as main user group with easy access provided to delivery care to elderly

The entire structure of the programming and physical form has been conceived around providing easier access for aged care workers to elderly homes to enable ageing in place. This is done through providing provisions for care including medical and medication management, meal services, laundry and cleaning and health care administration in the upper floors of the central building away from the pedestrian street. Bridge walkways that connect to surrounding apartment buildings are connected to these services allowing a direct relationship between services and delivery. Then connecting into apartment circulation provides access to elderly homes indirectly, making servicing multiple elderly people within the same building possible.

5) Care Delivery Separate from the Urban Street in order to preserve its unique existing qualities.

The bridge arms connect elderly care to the home above street level. Through making this only accessible for care workers and not to elderly themselves this maintains the connection to the street environment, the dynamics of which are important to maintaining their independence through doing daily tasks and leisure activities. Introducing additional thoroughfare above the street for care workers reduces the implication of traffic on delivering care as well as providing security for medication and supplies. The lower floor of the building introduces missing amenity 
from the community and contributes to the mixed-use density of the existing urban environment. As previously mentioned it creates a direct relationship to the previously disconnected busy intersection and the surrounding parkland providing more direct pedestrian access to green space.

6) Functions as a health hub space with heath care needs in one place with the aim to increase efficiency and familiarity for frequent elderly visitors.

Currently local care within the community is spread across multiple small practices or centralized at the local hospital. This model aims to include small practitioners into one space not only to synchronize documentation and administration services but also to provide one space for elderly to come and receive their care whether it be an optometrist appointment, physical therapy or a check up with the GP providing all care in one place makes it less likely for elderly to not make appointments or to get lost trying to find various other practitioners. This decision was made based on analysis of medical practices and providers within the local area as a representation of services across Tokyo and the governments reliance on local health care for preventative care through to end of life care within the community. This also is in response to research suggesting urban environment struggles to provide visual cues that support wayfinding. This hub building providing all health services as well as supporting care delivery to the community provides a landmark for care within the urban context. 
The significant outcome that this research has demonstrated is the role of architecture in aged care. Aged care doesn't only affect the singular aged person, or the group of care workers or nurses, but the entire community. For this reason, architecture isn't the only solution but can make a contribution to the field and can inspire collaboration in other sectors. This research represents a vision of care as a speculative test for architecture's contribution. Through the design process, combating segregation of elderly individuals while balancing their privacy needs and independence has been the driver behind design experimentation and creation. What is paramount is the need to deliver choice in order to maintain independence and autonomy. Testing the approach to care, whereby care is brought to individual's home through architectural intervention instead of transferring elderly into facilities to be cared for, identifies the strengths and weaknesses of both approaches. Through the design process, limitations have been found as not only is there no perfect solution for providing aged care but this project is reflective of the context of Japan's unique built environment and social systems of care.

Aged care facilities are becoming more popular and are the place in which elderly in many countries die. The reason for this is the perception that care can be delivered more efficiently and is close at hand. In the pursuit of safety we forget that we are permanently breaking relationships between the old and young. This research begins the conversation
on how to change this perspective and make living at home as safe, or safer than living in institutionalized care. Through initial research it became clear that individuals who need a meal cooked for them, need showering each day and help with their medication but are otherwise coherent individuals who have thoughts and opinions deserve to maintain their autonomy. The support from the environment is not only vital physically but can significantly contribute to wellness. The psychological fragility of this time is not to be underestimated and through our systems of care there seems to be a lack of choice and a lack of humanity, which severely affects mental health. It is not just the physical features of the architecture that create negative experiences. It is the act of segregation through the use of architecture in institutional care models. Ageing in place is not perfect and can also segregate in some circumstances but the urban environment and density of a city bring everything within reach. The alternative solutions we can create when working with an established rich urban environment are inherently more focused on connection and result in an intervention that is connected with its surroundings instead of designed in isolation.

\section{COMBATTING SEGREGATION}

This project starts from the finding that the act of segregation in aged care facilities is the largest barrier to positive mental health for aged care residents. Upon reflecting on the design process and final outcomes, not only has this strengthened this argument but it also shows architecture as the vehicle through which a care vision is reflected. The success of this design is that it strengthens communication and connection between elderly and the care system within an ageing in place model 
The physical use of the built environment improves the jobs of daily carers helping elderly age in place through creating the physical connection between buildings. What has been discovered from this is the necessity of improving the efficiency of ageing in place care without sacrificing the experience of it. An improvement of time and effort taken to travel between patients is one way to ensure that more people can receive quality care. Currently still a walking model, future technology to include care robots and other automated systems would further improve this efficiency. What this project does through design is extrapolating the key programmes from an aged care facility and uses them to connect care into the home instead. Adapting care delivery mechanisms, which can collaborate with Japan's expanding use of robotics in the aged, care sector. The idea tests the space above cities as a blank canvas within which connections can be designed to decongest the street and help get care delivered faster and more effectively. This critiques today's practice of aged care and acts to provide design solutions to allow elderly to age in place with better access to efficient care. Looking to both the future whilst incorporating past community-centered values was key to create the balance between efficiency and humanity that is missing through the act of segregation in aged care facilities. The outcome of this design process strengthens the position that an active fight against systems and architecture that segregates groups of people from one another is needed. Diverse dynamics are so important as sacrificing diversity through segregation is detrimental to our intergenerational relationships.

These ideas reinforce research, which suggest ageing in place in an urban context is the best environment for the longevity of this care plan. As well as this ageing and dying at home aligns with the wishes and preferences of the majority of elderly people. The need for choice in aged care has resulted in the pursuit of community-integrated care visions. This work applies these ideas on a much wider scale to suggest that a true community care vision should be reflective of an ageing in place model. Overall this design is about using architecture to express an ageing in place care vision within which elderly are able to make decisions about their health and changing needs from the preventative stages through to palliative care. Recognizing that one building or complex alone cannot achieve this vision; the intervention is placed within an urban context in order to promote active interaction with the street and the amenity within the surrounding community. This acts to counteract mobility issues with suburban living.

\section{PROVIDING CHOICE}

The most substantial reflection of this project is how far it is from current and past aged care design. Despite significant research in the field of aged care the architectural design of these spaces, particularly in the substance of space, beyond its aesthetic character, has not developed significantly over 20 years of design. Room size, corridors, social spaces, and connection to outside garden space, these features have been upgraded to reflect modern design aesthetic expectations to some extent, but the foundations of the design remain the same.

The speculative design process is helpful for this sector to facilitate ways of looking forward, investigate future challenges without the scope of real world constraints, and allow thoughts without boundaries. "Speculative design serves two distinct purposes: first, to enable us to think about the future; second, to critique current practice." The findings of the design process highlights the faults of the current systems but suggests an approach for the future, which comes full circle back to community care. This research has challenged the expectations of a care space and stretches current technological, physical and functional possibility to explore the idea of connection between frail elderly, their environment, and their health needs. Placing this work into a speculative space enable the thought of what if? 
What does the ideal situation look like for an elderly person to mitigate their daily challenges and how could care be delivered in an individualistic way, consistently changing with need without transitioning through multiple systems or institutions. Systems of care as well as architecture struggle with individualism. Commercial space considers a group as a whole as well as an individual user but that experience cannot be catered to specific lives or people, due to the reinterpretation of each architectural gesture within the minds of each individual. An elderly person experiencing this building for the first time will have an entirely different experience to someone working in the building or someone passing through on their daily commute or a frequent visitor. While care is being delivered individually to each client through the walkway tunnels the central building acts to integrate itself into the urban fabric and represents a collectivistic approach, in order to deal with multiple demographic groups and to not stigmatize the space as only for elderly to use. Through this somewhat incongruousness approach both the needs of elderly are met through the upper floors and the demographics on the street feel as though the space is inclusive of all ages. Although this design intervention is a large imposing figure on the visual landscape of the city, it communicates with surrounding buildings in a different way than the street does, and allows the street to continue to provide connection and richness to the people using the space.

PRIVACY

There is a difference between care offered on ones own terms and care routines in the hands of others, structured and facilitated around schedules, shifts and lunch breaks. The outcome is the same; the individual receives the care that they need but the experience is vastly different. The clear separation between the home and professional environments within this model has been designed as a way to deal with the ever-blurring boundaries of privacy within the lives of elderly people. The separation between these spaces makes the ability to withdraw comfortable and on ones own terms. The assumption with this design decision is that elderly will openly invite care into their homes, and in situations where this is not the case this poses challenges to care workers and heath professionals. The hope is that with early intervention, de-stigmatization of receiving care, consolidating care back into a community environment and improving education and understanding of the importance of preventative and continued care will create a level of trust which will mitigate issues of excluding heath professionals. Literature has concluded the importance of the ownership of individual space and its contribution to autonomy. This boundary between home and professional has been created to uphold this research and support these ideas. The success of this design is in the way it strengthens communication between elderly and the care system through creating a physical connection between them but maintaining the clearly defined boundaries of the home. The opposite approach has been taken when thinking about the relationship between elderly and the street environment. The placement of elderly within urban contexts increases their connection to surroundings due to proximity of amenity and leisure activities. This design successfully creates boundaries between the home and care without obstructing the relationship between elderly and the street. These two elements are key to maintaining autonomy and independence

\section{LIMITATIONS}

The system of distributing care represents a collision of current home care and institutional care available. This approach brings care into the home but through the use of the built environment is able to provide this in a more efficient way connecting carers back into a central hub. The idea around this was to enable privacy and a control over ones home and individual spaces however through the design process issues have been discovered through connecting to traditional Japanese homes that are only accessible from street level. Because 
these buildings do not have communal public core spaces or vertical access they cannot be connected to the bridge arms. Further development is required in order to enable connection to the smaller scale buildings possibly through a greater connection to street level.

For this idea to work really well there needs to be a large amount of elderly reachable through this design. It is hard to know exactly where elderly live without comprehensive census data or other means of evaluation. From the data available to the public, 30000 elderly live within the $8 \mathrm{~km} 2$ area of Chuo City. It is likely that a lot of them live alone but whether they mostly live in smallscale houses or apartments or an even spread of the two is hard information to find. Due to social housing reforms in the 1950's and 60's elderly are more likely than younger people to live in social apartment style housing. And recent research on the importance of the city for elderly independence suggests that elderly that live in the city live in apartments due to the expense of land in central Tokvo and the large amount of poverty within elderly groups. While it is safe to assume that a large amount of elderly live in apartments, this limitation means that not every single elderly person who wants access can be helped by this current scheme. People in the immediate area can still access healthcare easily with care in one place but will not be able to take advantage of the in home help to the same degree. Therefore further investigation of how to expand the ability for greater scope of the bridge arms of connection to buildings further afield would need to be undertaken in order for this model to be a successful means of delivering care to any individual.

What this work does successfully is identify issues with current systems of care around the removal of elderly from their homes and what this means for both individual health and well being as well as the diversity of the community. It highlights the important step we need to take in the future to better deliver home help for those who want to stay in their homes, and emphasizes the importance of open conversations with relatives and friends around the location and circumstances surrounding death, disability through ageing and palliative care. Our inability to confront these issues as a society enable people to fall through the cracks and causes the wide spread mental health issues within elderly individuals as well as the anxiety around what is in store for us when our body or our mind fails us.

Through challenging the design, programme and atmosphere that is created through the built environment and work alongside policy makers to ensure that their care visions are reflected in the environments they provide. As we question the value of aged care facilities in our society and open care environments to their community we can create a future for the industry that balances the ideal scenarios with the reality of life.

The idea of this work is to generate questions and further contribute to the research questioning current systems of care. In order to progress this sector forward a system of care focused on providing the best conditions to age for both physical and mental health needs to be adopted. Moving away from an institutionalized model of care ensures that we don't regress further into a segregated society. Further design research on this idea should develop these ideas both continuing in a speculative space and within real world constraints. The greatest limitation of this intervention is the inability to connect to singular units or terraces only accessible from the street. Further exploration between this connection and also a greater connection to the street would be valuable in supporting the validity of the ideas presented in this thesis. Application of this research to current aged care facility environments could create a first step of developing greater scope of connection between a facility space and community model of care. Exploration within different cultural contexts including less dense urban areas would also provide an understanding of this model to other markets with different needs. Testing at a suburban 
level would also highlight the importance of urban contexts for this concept or could expand the application of the concept into areas of fewer amenities. The design of ages care environments in response to modern research on ageing in place and ways to improve this experience are also significantly important to create and rest to demonstrate the significance of improving access and care standards. This goes beyond architecture. Robotics, automated services, in home technology will all support the ability for care to be provided in the home that promotes better psychological well being. The development of this technology can only enhance the validity of this research, advocating for better-integrated ageing in place care. 



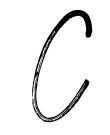

Advanced Care Planning Australia. (2020, 03 17). Greater Respect For Patient Could Have Avoided Trauma in Final Months of Life. Retrieved 02 19, 2020, from HelloCare.

Ageing and Health. (2018, February 5). Retrieved from https://www.who.int/ news-room/fact-sheets/detail/ageing-and-health

Angelopoulou, S. L. (2019, February 08). Intermedia completes JAPANESE nursing home with Triangular wooden canopy. Retrieved March 22, 2020, from https://www.designboom.com/architecture/intermedia-nursing-home/shimabara-japan-02-07-2019

Alvaro, C., Wilkinson, A., Gallant, S., Kostovski, D., \& Gardner, P. (2015). Evaluating Intention and Effect: The Impact of Healthcare Facility Design on Patient and Staff Well-Being. Health Environments Research \& Design Journal , 9 (2), 82-104.

Andersson, J. E. (2011). "Touching Up" Communal Space of a Residential Home Setting a Comparative Study of Tools for Assessing Changes in the Interior Architectural Space . Journal of Housing For the Elderly, 25 (2), 175-216.

Andersson, J. E. (2011). Architecture for the silver generation: Exploring the meaning of appropriate space for ageing in a swedish municipality. Health and Place , 17, 572-587.

Andersson, L. (1998). Loneliness research and interventions: A review of the literature. Aging \& Mental Health , 2 (4), 264-274.

Andersson, M., Rhy, N., \& Malmqvist, I. (2014). Exploring the Function and USe of Common Spaces in Assisted Living for Older Persons. Health Environments Research \& Design Journal , 7 (3), 98-119.

Angus, J., Kontos, P., Dyck, I., Mckeever, P., \& Poland, B. (2005). The Personal significance of home: habitus and the experience of recieving long-term home care. Sociology of Health \& Illness , 27 (2), 161-187.

Annear, M. J., Otani, J., \& Sun, J. (2016). Experiences of Japanese aged care: the pursuit of optimal health and cultural engagement. Age and Ageing , 45, 753-756.

Applegate, M., \& Morse, J. M. (1994). Personal Privacy and Interactional Patterns in a Nursing Home. Journal of Aging Studies , 8 (4), 413-434.

Austin, E., Johnston, Y., \& Morgan, L. (2006). Community Gardening in a Senior Center: A Therapeutic Intervention to Improve the Health of Older Adults. Therapeutic Recreation Journal , 40 (1), 48-56.

Bachmann, I. M. (2014). Aging in Urban Japan- Intergenerational Reading in Tokyo. Working with Older People, 18 (1), 24-29.

Barratt J. (2018, February 12). Humans are living longer than ever. but we aren't necessarily aging well. Retrieved March 19, 2020, from https://www.statnews. /com/2017/02/14/living-longer-living-better-aging 
Barnes, S., \& the Design in Caring Environments Study Group. (2002). The design of care environments and the quality of life of older people. Ageing and Society , 22, 775-789.

Bowling, A. (1998). Measuring Health related quality of life among older people. Aging and Mental Health , 2 (1), 5-6.

Brown, L., Nepal, B., \&amp; Thurecht, L. (2012, September 11). Aged Care In Australia: Past Present and Future. Lecture presented at NATSEM Workshop Series in University of Canberra, Canberra. Retrieved March 19, 2020, from https://natsem.canberra.edu.au/storage/Brown\%20-\%20Aged\%20care\%20 -\%20past\%20present $\% 20$ future.pdf

Brownie, S., \& Nancarrow, S. (2013). Effects of Person-Centered on Residents and Staff in Aged-Care Facilities: A systematic Review. Clinical Interventions in Aging, 8, 1-10. Brownie, S., Horsmanshof, L., \& Garbutt, R. (2014). Factors that impact residents transition and psychological adjustment to long term aged care: A systematic literature review. International Journal of Nursing Studies , 51, 165-1666.

Brownie, S., Horstmanshof, L., \& Garbutt, R. (2014). Factors that impact residents' transition and psychological adjustment to long-term aged care: A systematic Literature Review. International Journal of Nursing Studies , 51, 1654-1666.

Buffel, T., \& Philipson, C. (2016). Can global cities be 'age-friendly cities'? Urban development and ageing populations. Cities , 55, 94-100.

Burton, E. J., Mitchell, L., \& Stride, C. B. (2011). Good Places for Ageing in Place: Development of Objective Built Environment Measures for Investigating Links with Older People Wellbeing. BMC Public Health , 11 (839).

Campbell, J. C., \& Ikegami, N. (2003). Japan's Radical Reform of Long-term Care. Social Policy \& Administration , 37 (1), 21-34.

Campbell, N., \& Kim, D. (2016). Designing an ageless social community: Adapting a New Urbanist Social Core to Suit Baby Boomers. Journal of Housing for the Elderly , 30 (2), 156-174.

Campbell, R. (1984). Nursing Homes and Long Term Care in Japan. Pacific Affairs , 57 (1), 78-89.

Campbell, R. (1984). Nursing Homes and Long-term Care in Japan. Pacific Affairs , 57 (1), 78-89.

Capitanio, M. (2018). The Role of Urban Design In Tokyos Shrinking Peripheral Areas: The Case of Tama New Town. Internal Journal of Architectural Research , 12 (1), 112-133.

Cerina, V., Fornara, F., \& Manca, S. (2017). Architectural Style and Green Spaces Predict Older adults Evaluations of Residential Facilties. European Jounrla of Ageing , 14, 207-217.

Chadwick, N. (2020). Bellmere - independent living facility. Retrieved March 22, 2020, from https://newdirectioncare.com.au/about-bellmere/

Chau, H.-w., Newton, C., Mei Min Woo, C., Ma, N., Wang, J., \& Aye, L. (2018). Design Lessons from Three Australian Dementia Support Facilities. Buildings , 8 (67), 2-14.

Cire, B. (2016, March 28). World's older population grows dramatically. Retrieved from https://www.nih.gov/news-events/news-releases/worldsolder-population-grows-dramatically 
Clarke, P., \& Gallagher, A. (2013). Optimizing Mobility in Later Life: The Role of the Urban Built Environment for Older Adults Aging in Place. Journal of Urban Health , 90 (6), 997-1009.

Commonwealth Parliament, \& Roberts, K. (2019, August 15). International aged care: A quick guide. Retrieved March 19, 2020, from https://www.aph. gov.au/About_Parliament/Parliamentary_Departments/Parliamentary_ Library/pubs/rp/rp1617/Quick_Guides/IntAgedCare

Campbell, J. C. (200). Long-Term Care Insurance Comes to Japan. Health Affairs , 19 (3), 26-39.

Cook Maher, A., Kielb, S., Loyer, E., Connelley, M., Rademaker, A., Mesulam, M., et al. (2017). psychological well-being in elderly adults with extraordinary episodic memory. Plos One , 12 (10).

Creighton, A., Davison, T., \& Kissane, D. (2017). The Prevalence Reporting and Treatment of Anxiety Among Older Adults in Nursing Homes and Other Residential Aged Care Facilities. Journal of Affective Disorders , 227, 416-423.

Davis, S., Byers, S., Nay, R., \& Koch, S. (2009). Guiding design of Dementia Friendly Environments in Residential Care Settings. Dementia , 8 (2), 185203.

Day, K., Carreon, D., \& Stump, C. (2000). The Therapeutic Design of Environments for People with Dementia: A Review of the Empirical Research. The Gerontologist, 40 (4), 397-416. de Veer, A., \& Kerkstra, A. (2001). Feeling at Home in Nursing Homes. Journal of Advanced Nursing , 35 (3), 427-434.

Delle Fave, A., Bassi, M., Boccaletti, E. S., Rocaglione, C., Bernardelli, G., \& Mari, D. (2018). Promoting Well-Being in Old Age: The Psychological Benefits of Two Training Programs of Adapted Physical Activity. Frontiers in Psychology , 9 (828), 1-18.

Devlin, A. S. (2014). Wayfinding in Healthcare Facilities: Contributions from Environmental Psychology. Behavioral Sciences , 4, 423-436.

Farquhar, M. (1995). Elderly Peoples Definitions of Quality of Life. Pergamon, 41 (10), 1439-1446.

Frey, R., Balmer, D., Robinson, J., Gott, M., \& Boyd, M. (2019). The effect of residential aged care size, ownership model, and multichain affiliation on resident comfort and symptom management at the end of life. Journal of Pain and Symptom Management , 57 (3), 545-555.

Frobker, S., \& Grotz, R. (2006). Everyday Mobility of Elderly People in Different Urban Settings: The Example of the City of Bonn Germany. Urban Studies , 43 (1), 99-118.

Fujiwara, Y., Shinkai, S., Kobayashi, E., Minami, U., Suzuki, H., Yoshida, H., et al. (2014). Engagement in paid work as a protective predictor of basic activities of daily living disability in Japanese: urban and rural communitydwelling elderly residents: An 8-year Prospective study. Geriatrics Gerontology , 16, 126-134.

Gall Rule, B., Milke, D. L., \& Dobbs, A. R. (1992). Design of Institutions: Cognitive Functioning and Social Interactions of the Aged Resident. The Journal of Applied Gerontology , 11 (4), 475-488.

Gierveld, J. d., \& Tesch-Romer, C. (2012). Loneliness in old age in eastern and western european societies: theoretical perspectives. European Journal for Ageing , 9, 285-295.

Grewal, I., Nazroo, J., Bajekal, M., Blane, D., \& Lewis, J. (2004). Influences on quality of life: a qualitative investigation of ethnic differences among older people in england. Journal of Ethnic and Migration Studies , 30 (4), 737-761. 
Gu, S., \& Liang, J. (2000). China: Population Aging and Old Age Support. In Aging in East and West: Families, States and the Elderly (pp. 59-137). Springer Publishing.

Hagestad, G. O., \& Uhlenberg, P. (2005). The Social Separation of Old and Young: A Root of Ageism. Journal of Social Issues , 61 (2), 343-360.

Hau Yan Ho, A., Lai Wan Chan, C., Pui Yu Leung, P., Max Chochinov, H., Neimeyer, R., Mei Che Pang, S., et al. (2013) Living and dying with dignity in chinese society: perspectives of older palliative care patients in Hong Kong. Age and Ageing , 42, 455-461.

Hein, L. T., Cumming, R., Cameron, I., Chen, J., Lord, S., March, L., et al. (2005). Atypical Antipsychotic Medications and Risk of Falls in Residents of Age Care Facilities. Jags , 53 (8), 1290-1295.

Hennessy, C. H., \& Hennessy, M. (1990). Community-Based Long-Term Care for the Elderly: Evaluation Practice Reconsidered. Medical Care Review , 47 (2), 221-259.

Higgs, P. (1999). Quality of life and changing parameters of old age . Aging \& Mental Health, 3 (3), 197-198.

Hirayama, Y., Otani, T., \& Matsushima, M. (2016). Japanese citizens' attitude toward end-of-life care and advance directives: A qualitative study for members of medical cooperatives. Journal of gneral and family medicine , $18,378-385$.

Holmen, K., \& Furukawa, H. (2002). Loneliness, health and social network among elderly people- a follow up study. Archives of Gerontology and Geriatrics , 35, 261-274.

Honinx, E., van Dop, N., Smets, T., Deliens, L., Van Den Noortgate, N., Froggatt, K., et al. (2019). Dying in long-term care facilities in Europe: the PACE epidemiological study of deceased residents in six countries. BMC Public Health , 19 (1199).

Hubbard, G., Tester, S., \& Downs, M. (2003). Meaningful social interactions between older people in institutional care settings. Ageing and Society , 23, 99-114.

Hughes, M. (2004). Review: Privacy in Aged Care. Australasian Journal on Ageing , 23 (3), 110-114.

Jacelon, C. (2003). The Dignity of Elders in Acute Care Hospital. Qualitative Health Research, 13 (4), 543-556.

Jacobs, J. (1961). The death and life of great American cities . New York: Vintage Books.

Japan Brandvoice. (2019, March 19). WHY Japan's aging population is an investment opportunity. Retrieved March 22, 2020, from https://www.forbes.com/sites/japan/2018/11/12/why-japans-agingpopulation-is-an-investment-opportunity/\#56023c3c288d

Jonsson, R., Sixt, E., Landahl, S., \& Rosenhall, U. (2004). Prevalence of dizziness and vertigo in an urban elderly population. Journal of Vestibular Research , 14, 47-52.

Kane, R. (2001). Long Term Care and a Good Quality of Life: Bringing Them Closer Together. The Gerontologist , 41 (3), 293-304.

Kane, R., \& Kane, R. (1978). Care of the Aged: Old Problems in Need of New Solutions. Science, 200 (4344), 913-919.

Karmel, R., Gibson, D., Anderson, P., Wells, Y., \& Duckett, S. (2012). Care trajectories through community and residential aged care services: disease effects. Aging \& Society , 32, 1428-1445. 
Kavedzija, I. (2018, May 31). Social care Japanese style-What we can learn from the worlds oldest population. Retrieved February 19, 2020, from The Conversation.

Kavedzija, I. (2016). The Age of Decline? Anxieties about Ageing in Japan. Ethnos Journal of Anthropology , 81 (2), 214-237.

Kendig, H., Browning, C., Pedlow, R., Wells, Y., \& Thomas, S. (2010). Health social and lifestyle factors in entry to residential aged care: an Australian longitudinal analysis. Age and Ageing , 39, 342-349.

Kloseck, M., Crilly, R., \& Gutman, G. (2010). Naturally Occuring Retirement Communities: Untapped Resources to Enable Optimal Aging at Home. Journal of Housing for Elderly , 24 (3), 392-412.

Koujukai. (2019). About Azalee GROUP. Retrieved March 22, 2020, from https://koujukai.azalee.or.jp/english/

Landorf , C., Brewer, G., \& Sheppard, L. (2008). The urban environment and sustainable age critical issues and assessment indicators. Local Environment, 13 (6), 497-514.

Laws, G. (1993). "The Land of Old Age" Society's Changing Attitudes toward Urban Built Environments for Elderly People. Association of American Geographers , 83 (4), 672-693.

Lee, J. H., Ostwald, M. J., \& Lee, H. (2017). Measuring the spatial and social characteristics of the architectural plans of aged care facilities. Frontiers of Architectural Research , 6, 431-441.

Lu, Y., Cai, H., \& Bosch, S. (2017). Key Spatial Factors Influencing the Perceived Privacy in Nursing Units: An Exploration Study With Eight Nursing Units in Hong Kong. Health Environments Research \& Design Journal, 10 (4), 37-48.

Luker, J., Worley, A., Stanley, M., Uy, J., Watt, A., \& Hillier, S. (2019). The evidence for services to avoid or delay residential aged care admission: a systematic review. BMC Geriatrics , 9 (217).

Ma, N., Chau, H.-w., Zhou, J., \& Noguchi, M. (2017). Structuring the environmental experience design research framework through selected aged care facility data analyses in victoria. Sustainability , 9.

Mahal, A., \& McPake, B. (2017). Health Systems of Aging Societies in Asia and the Pacific. Health Systems \& Reform , 3 (3), 149-153.

Marquardt, G., \& Schmieg, P. (2009). Dementia Friendly Architecture: Environments That Facilitate Wayfinding in Nursing Homes. American Journal of Alzheimers disease \& other dementias , 24 (4), 333-340.

Mclaughlan, R., Annear, M., \& Pert, A. (2018). Dementia, ageing and the city: learing from the streets of Melbourne. Arq, 22 (2), 104-114.

Milke, D., Beck, C., Danes, S., \& Leask, J. (2009). Behavioral mapping of residents activity in five residential style care centres for elderly persons diagnosed with dementia: small differences in sites can affect behaviors. Journal of Housing for the Elderly , 23 (4), 335-367.

Minami, U., Nishi, M., Fukaya, T., Hasebe, M., Nonaka, K., Koike, T., et al. (2015). Effects of the change in working status on the health of older people in Japan. PLOS ONE , 10 (12).

Mitchell, L., Burton, E., \& Raman, S. (2004). Dementia-friendly cities: designing intelligible neighbourhoods for life. Journal of Urban Design , 9 (1), 89-101.

Morgan, D. G., Stewart, N. J., D'arcy, K. C., \& Werezak, L. J. (2004). Evaluating rurual nursing home environments: Dementia special care units versus integrated facilities. Aging \& Mental Health , 8 (3), 256-265. 
Murayama, H., Yoshie, S., Sugawara, I., Wakui, T., \& Arami, R. (2012).

Contextual effect of neighborhood environment on homebound elderly in a japanese community. Archives of Gerontology and Geriatrics , 54, 67-71.

Nettleton, S., Buse, C., \& Martin, D. (2018). Envisioning bodies and architectures of care: reflections on competition designs for older people. Journal of Aging Studies , 45, 54-62. NewDirection Care Bellmere. (2018 March 10). NewDirection Care at Bellmere-House Companions [Video File] Retrieved from https://www.youtube.com/watch?v=TvBZOWTGKv8

NewDirection Care Bellmere. (2018 March 10). NewDirection Care at Bellmere-Lifestyle [Video File] Retrieved fromhttps://www.youtube.com/ watch?v=HCPgZYH8CeQ

NewDirection Care Bellmere. (2018 March 10). NewDirection Care at Bellmere-Our Model of Care [Video File] Retrieved from https://www. youtube.com/watch?v=vvYc231e2fE

NewDirection Care Bellmere. (2018 March 10). NewDirection Care at Bellmere-Overview [Video File] Retrieved from https://www.youtube.com/ watch? $\mathrm{v}=2 \mathrm{Mb} 16 \mathrm{f} 8 \mathrm{BttE}$

NewDirection Care Bellmere. (2018 March 10). NewDirection Care at Bellmere-Resident Testimonials [Video File] Retrieved from https://www. youtube.com/watch?v=k2xfOoNCntM

NewDirection Care Bellmere. (2018 March 10). NewDirection Care at Bellmere-Lifestyle [Video File] Retrieved fromhttps://www.youtube.com/ watch?v=HCPgZYH8CeQ

Newton, R., Ormerod, M., Burton, E., Mitchell, L.. \& Ward-Thompson, C. (2010). Increasing Independence for Older People through Good Street Design. Journal of Integrated Care , 18 (3), 24-29.

Nichol, R. (2019, April 16). Why inner-city living isn't always best for elderly people. Retrieved March 19, 2020, from https://www.noted.co.nz/health/ health-health/inner-city-living-elderly-people-isnt-always-best

Nord, C. (2018). Resident-centred care and architecture of two different types of caring residences: a comparative study. International Journal of qualitative studies on health and well-being , 13 (1).

Nummela, O., Sulander, T., Rahkonen, O., Karisto, A., \& Uutela, A. (2008). Social Participation, trust and self rated health: A study among ageing people in urban, semi-urban and rural settings. Health \& Place, 14, 243-253.

O'Neill, M. (1991). Evaluation of a Conceptual Model of Architectural Legibility. Environment and Behavior , 23 (3), 259-284.

Oswald, F., Hieber, A., Wahl, H.-W., \& Mollenkopf, H. (2005). Ageing and person-environment fit in different urban neighbourhoods. European Journal of Ageing , 2, 88-97.

Park, N. S. (2009). The Relationship of Social Engagement to Psychological Well-Being of Older Adults in Assissted Living Facilities. Journal of Applied Gerontology , 28 (4), 461-481.

Parke, B., \& Chappell, N. (2010). Transactions between older people and the hospital environment: A social ecological analysis. Journal of Aging Studies ,24, 115-124.

Parker, D: (2010). Palliative care in residential aged care facilities. Progress in Palliative Care , 18 (6), 352-357.

Parker, D. (2011). Residential Aged Care Facilities. Cultural Studies Review , $17(1), 31-51$. 
Passini, R., Pigot, H., Rainville, C., \& Tetreault, M.-H. (2000). Wayfinding in a Nursing Home for Advanced Dementia of the Alzheimers Type. Environment and Behavior , 32 (5), 684-710.

Pati, D., Harvey, T., Willis, D., \& Pati, S. (2015). identifying elements of the healthcare environment that contribute to wayfinding . health environments research \& design journal, 8 (3), 44-67.

Petersen, M., Wilson, J., Wright, O., Ward, E., \& Capra, S. (2016). The Space of Family Care-Giving in Australian Aged Care Facilities: Implications for Social Work. British Journal of Social Work , 46, 81-97.

Petronio, S., \& Kovach, S. (1997). Managing Privacy Boundaries: Health Providers' Perceptions of Resident Care in Scottish Nursing Homes. Journal of Applied Communication Research , 25 (2), 115-131.

Philipson, C., \& Ray, M. (2016). Ageing in Urban Environments: Challenges and Opportunities for a Critical Social Work Practice. Social Work and the City , 151-171.

Plouffe, L., \& Kalache, A. (2010). Towards global age friendly cities: Determining urban features that promote active aging. Journal of Urban
Health , 87 (5), 733-739.

Pruchno, R., \& Rose, M. (2000). The Effect of Long-Term Care

Environments on Health Outcomes. The Gerontologist , 40 (4), 422-428.

Reynolds, S. G., \& Beamish, J. O. (2003). Residential Satisfaction of Older Adults in Age-Segregated Facilities. Housing and Society , 30 (1), 33-50.

Ribbe, M. W., Ljunggren, G., Steel, K., Topinkova, E., Hawes, C., ikegami, N., et al. (1997). Nursing homes in 10 nations: a comparison between countries and settings. Age and Ageing , 26 (S2), 3-12.

Ritch, A. (2015, November 08). The Elderly and the Workhouse. Retrieved from https://www.bgs.org.uk/resources/the-elderly-and-the-workhouse

Rodin, J. (1986). Aging and Health: Effects of the Sense of Control. Science, 233, 1271-1275.

Rosso, A. L., Taylor, J. A., Tabb, L. P., \& Michael, Y. L. (2013). Mobility, Diability and Social Engagement in Older Adults. Journal of Aging Health , 25 (4), $617-637$.

Seah, E., Tan, J., \& Lien Foundation. (2017, November 9). Comfort, Care and Gourmet Meals. Retrieved March 22, 2020, from http://www.genkikaki. com/episodes/4/1

Schopp , A., Leino-Kilpi, H., Valimaki, M., Dassen, T., Maria , G., Lemonidou, C., et al. (2003). Perceptions of Privacy in The Care of Elderly People in Five European Countries. Nursing Ethics , 10 (1), 39-47.

Shears, A. (2018, May 18). Looking at Innovative Models for Aged Care: Takeaways from the Singapore Ageing Asia Conference. Retrieved 02 19, 2020, from HelloCare Singapore.

Sheehan, B., Burton, E., \& Mitchell, L. (2006). Outdoor Wayfinding in Dementia. Dementia , 5 (2), 271-281.

Sixsmith, A. J., \& Sixsmith, J. A. (1991). Transitions in Home Experience in Later Life. Journal of Architectural and Planning Research , 8 (3), 181-191.

Slaughter, S. E., Estabrooks, C. A., Jones, C. A., \& Wagg, A. S. (2011). Mobility of Vulnerable Elders (MOVE): Study protocol to evaluate the implementation and outcomes of a mobility intervention in long-term care facilities. BMC Geriatrics , 11 (84). 
Strandell, G. (2018, June 07). Japan seen as model For eldercare in Asia. Retrieved March 22, 2020, from https://japan-forward.com/japan-seen-asmodel-for-eldercare-in-asia/

Sugimoto, K., Ogata, Y., \& Kashwagi, M. (2016). Factors promoting resident deaths at aged care facilities in Japan:a Review. Health and Social Care in the Community , 26 (2), 207-224. Taylor, M., \& Buys, L. (2014). Ageing in Suburbia: Designing for Demographic Change in Australia and New Zealand. Architectural Design, 84(2), 54-59.

Tomaka, J., Thompson, S., \& Palacios, R. (2006). The Relation of Social Isolation, Loneliness, and Social Support to Disease Outcomes Among the Elderly. Journal of Aging and Health, 18 (3), 359-384.

Tsutsui, T. (2014). Implementation Process and Challenges for the Community-Based Integrated Care System in Japan. International Journal of Integrated Care , 14, 1-9.

Uesugi, L.-M. C. (2010). Productive Ageing in Japan. China Journal of Social Work , 3 (2), 165-180.

Van Der Wolf, E., Van Hooren, S., Waterink, W., \& Lechner, L. (2017). Wellbeing in elderly long term care residents with chronic mental disorder: a systematic review. Aging \& Mental Health , 23 (3), 287-296.

Van Haitsma, K., Abbott, K., Arbogast, A., Bangerter, L., Heid, A., Behrens, L., et al. (2019). A preferenced-based model of care: an integrative

theoretical model of the role of preferences in person-centered care. The Gerontologist , 1-9.

van Hoof, J., \& Krzysztof Kazak, J. (2018). Urban Ageing . Indoor and Built Environment , 27 (5), 583-586.

van Hoof, J., Kazak, J. K., Perek-Bialas, J. M., \& Peek, S. T. (2018). The Challenges of Urban Ageing: Making Cities Age-Friendly in Europe. International Journal of Environmental Research and Public Health , 15 (2473).

Van Steenwinkel, I., Dierckx de Casterle, B., \& Heylighten, A. (2017). How Architectural Design Affords Experiences of Freedom in Residential Care for Older People. Journal of Aging Studies , 41, 84-92.

Wakui, T., Saito, T., Agree, E. M., \& Kai, I. (2012). Effects of home outside leisure, social and peer activity on psychological health among japanese family caregivers. Aging and Mental Health, 16 (4), 500-506.

Walker, H., \& Paliadelis, P. (2016). Older peoples' experiences of living in a residential aged care facility in Australia. Australasian Journal on Ageing , 35 (3), E6-E10.

Ward-Griffin, C., \& Marshall, V. W. (2003). Reconceptualizing the relationship between Public and Private Eldercare. Journal of Aging Studies , 17, 189-208.

Weissert, W. G., Mathews Cready, C., \& Pawelak, J. E. (1988). The past and future of home-and community-based long-term care. The Milbank Quarterly , 83 (4), 1-71.

Wilker Bezerra Clares, J., de Freitas, M. C., \& Borges, C. L. (2014). Social and Clinical Factors Causing Mobility Limitations in the Elderly. Acts Paul Enferm , 27 (3), 237-242.

Yamamoto Y. (2019, April 20). 9 million senior citizens will be living alone in 2040, study finds. The Asahi Shimbun. Retrieved March 19, 2020, from http://www.asahi.com/ajw/articles/AJ201904200033.html 
Yan, B., Gao, X., \& Lyon, M. (2014). Modeling satisfaction amongst the elderly in different chinese urban neighborhoods. Social Science \& Medicine $, 118,127-134$.

Yen, I. H., Shim, J. K., Martinez, A. D., \& Barker, J. C. (2012). Older People and Social Connectedness: How Place and Activities Keep People Engaged. Journal of Ageing Research . 



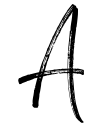

Percentage of population under 15 years old and aged 65 years old and over: 1950 to 2015
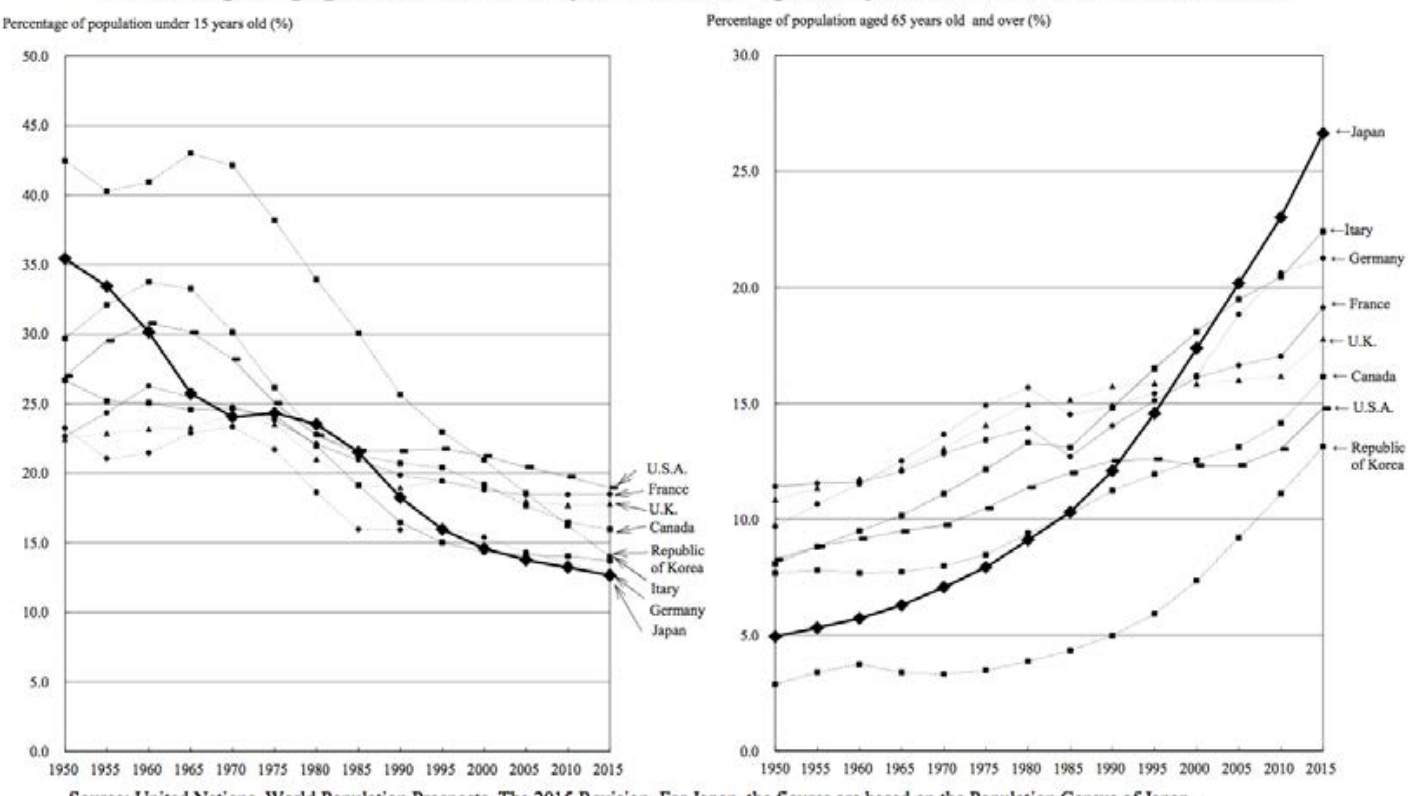
Source: United Nations, World Population Prospects, The 2015 Revision. For Japan, the figures are based on the Population Census of Japan.

Percentage of population composition by age group (among 3 groups)—Japan: 1920 to 2015

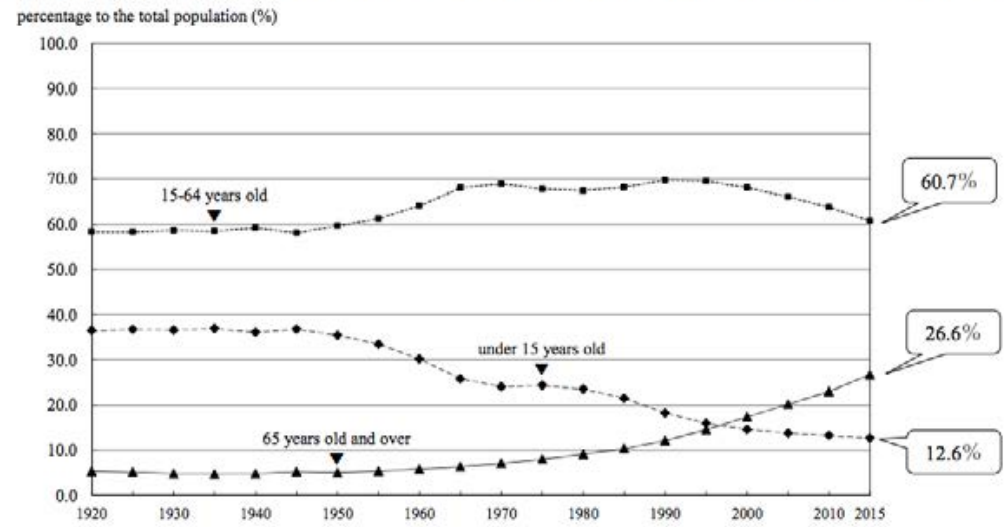


Members per household of private households

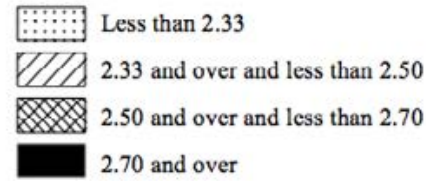

[:-: Less than 2.33

2.50 and over and less than 2.70

2.70 and over
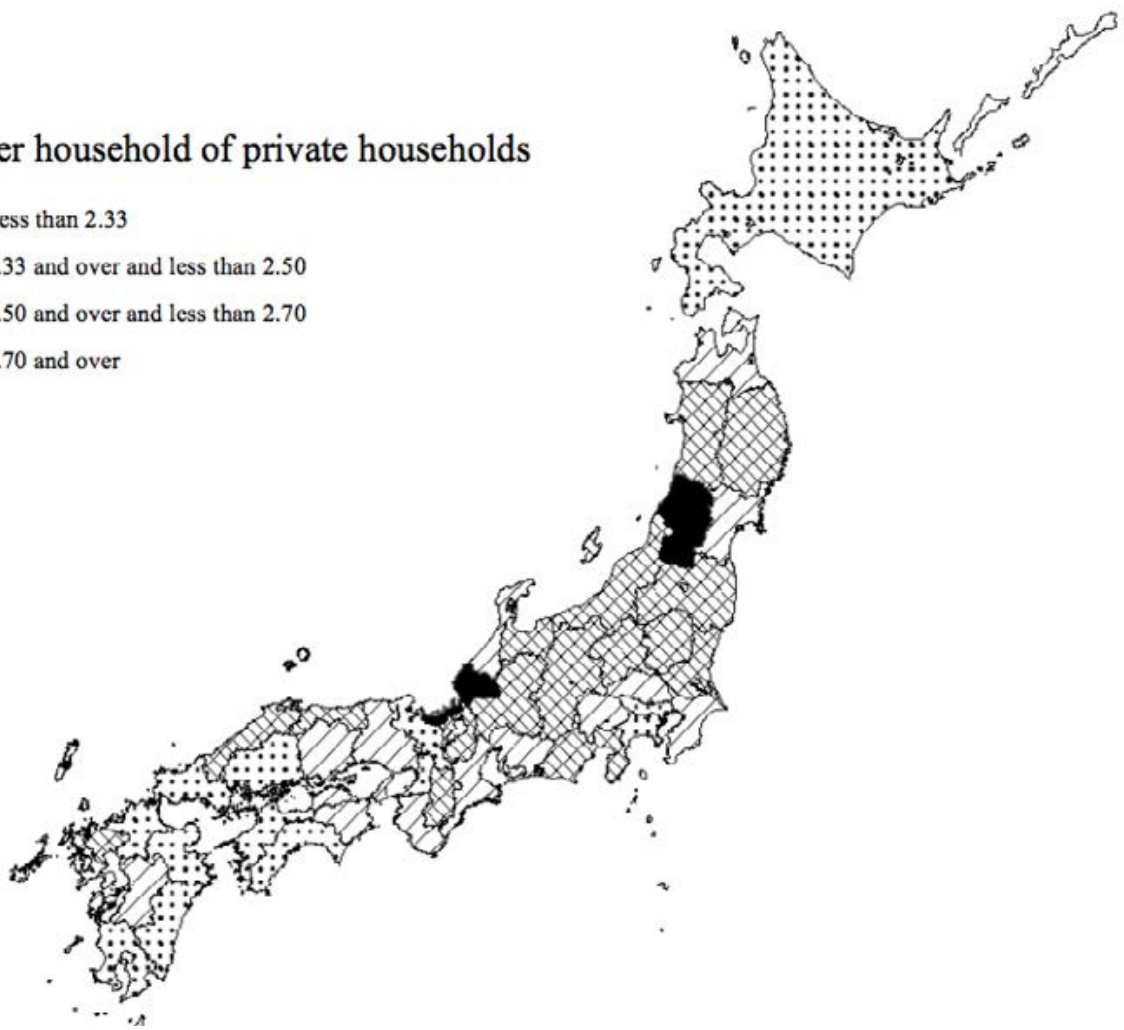


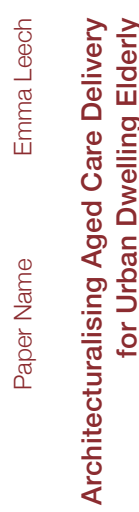

